UNIVERSIDADE DE SÃO PAULO

ESCOLA DE ENGENHARIA DE LORENA

VERÔNICA MARA CORTEZ ALVES DE OLIVEIRA

Estudo dos fenômenos da fluência, corrosão e oxidação isotérmica na liga Ti-6Al-4V submetida aos revestimentos de TiN e TiAIN depositados pela técnica de PVD assistida por plasma. 



\title{
Estudo dos fenômenos da fluência, corrosão e oxidação isotérmica na liga Ti-6Al-4V submetida aos revestimentos de TiN e TiAIN depositados pela técnica de PVD assistida por plasma.
}

\begin{abstract}
Tese apresentada à Escola de Engenharia de Lorena da Universidade de São Paulo como parte das exigências para a obtenção do título de Doutor em Ciências do Programa de Pós-Graduação em Engenharia de Materiais na Área de Materiais Metálicos, Cerâmicos e Poliméricos.
\end{abstract}

Orientador: Prof. Dr. Miguel Justino Ribeiro Barboza.

Co-orientador: Prof. Dr. Alain Laurent Marie Robin

Edição reimpressa e corrigida

Lorena

Agosto, 2014 
Oliveira, Verônica Mara Cortez de

Estudo dos fenômenos da fluência, corrosão e oxidação isotérmica na liga Ti-6Al-4V submetida aos revestimentos de TiN e TiAlN depositados pela técnica de PVD assistida por plasma /Verônica Mara Cortez Alves de Oliveiras.—ed. Reimp., corr.-2014.

150 f.: il.

Tese (Doutor em Ciências - Programa de Pós Graduação em Engenharia de Materiais. Área de Concentração: Materiais Metálicos, Cerâmicos e Poliméricos) - Escola de Engenharia de Lorena - Universidade de São Paulo, 2014.

Orientador: Miguel Justino Ribeiro Barboza; Co-orientador: Alain Laurent Marie Robin

1. Fluência 2.Corrosão 3. Oxidação isotérmica 4. TiN 5. TiAlN/TiAlCrN I. Título. 
Dedico este trabalho ao Amor da minha vida, José Paulo. 



\section{AGRADECIMENTOS}

Ao Prof. Miguel Justino Ribeiro Barboza, que foi tudo aquilo que um mestre deve ser para sua aluna. E a sua esposa, Michele Barboza, pela prontidão, simpatia, bom humor e boa vontade em ajudar.

Ao Prof. Alain Robin, meu co-orientador, sem o qual não teríamos conseguido fazer a parte dedicada à corrosão deste trabalho.

Às alunas de iniciação científica Carla de Aguiar e Amira Muci, que me ajudaram na parte prática deste trabalho com disposição e interesse.

Ao Sr. Geraldo (in memoriam), meu amigo e funcionário da casa, que sempre me ajudou com disposição, bom humor e vontade.

Ao Departamento de Materiais da Escola de Engenharia de Lorena por todo o suporte dado para a conclusão deste trabalho.

Ao Centro Nacional de Pesquisa em Energia e Materiais, CNPEM, e ao Laboratório Nacional de Nanotecnologia, LNNano, que tornaram possível as análises em microscopia de transmissão.

À Faculdade de Engenharia de Guaratinguetá, FEG - UNESP, por colocar a disposição seus laboratórios.

À empresa Bodycote Brasimet Processamento Térmico S.A. que realizou o processo de revestimento por PVD na liga Ti-6Al-4V.

À Fundação de Amparo à Pesquisa do Estado de São Paulo pelo suporte financeiro para a realização deste projeto de pesquisa (Proc. 2011/0511-0). 

"Queridos amigos, viemos bater à porta da casa de Maria. Ela abriu-nos, fez-nos entrar e nos aponta o seu Filho. Agora Ela nos pede: «Fazei o que Ele vos disser» (Jo 2,5). Sim, Mãe, nos comprometemos a fazer o que Jesus nos disser! E o faremos com esperança, confiantes nas surpresas de Deus e cheios de alegria. Assim seja." 



\section{RESUMO}

OLIVEIRA, V. M. C. A. Estudo dos fenômenos da fluência, corrosão e oxidação isotérmica na liga Ti-6Al-4V submetida aos revestimentos de TiN e TiAlN depositados pela técnica de PVD assistida por plasma. 2014. 150 p. Tese (Doutorado em Ciências) - Escola de Engenharia de Lorena, Universidade de São Paulo, Lorena, 2014.

O presente trabalho teve como objetivo principal avaliar o efeito dos recobrimentos TiN e TiAlN depositados por PVD a plasma na liga Ti-6Al-4V sob condições de fluência a $600{ }^{\circ} \mathrm{C}$ e corrosão em meios contendo cloreto a 25,60 e $80{ }^{\circ} \mathrm{C}$. O trabalho foi complementado com análises microestruturais e dos revestimentos superficiais utilizando-se as técnicas de difração de raios X, microscopias óptica, eletrônica de varredura e de transmissão, medidas de microdureza e oxidação isotérmica. Os resultados permitiram concluir que a liga Ti-6Al-4V constituída pela configuração de Widmanstätten apresentou dureza média de 343 HV para a condição como recebida. Após os tratamentos por PVD a plasma observou-se um recobrimento à base de TiN de espessura de 2,2 $\mu \mathrm{m}$ e composição igual a $\mathrm{Ti}_{0,7} \mathrm{~N}$. O recobrimento a base de TiAlN/TiAlCrN apresentou espessura em torno de $6 \mu \mathrm{m}$ e composição igual a $\left(\mathrm{Ti}_{0,38} \mathrm{Al}_{0,62}\right) \mathrm{N} /\left(\mathrm{Ti}_{0,31} \mathrm{Al}_{0,50} \mathrm{Cr}_{0,19}\right) \mathrm{N}$. As medidas do potencial em circuito aberto e polarização mostraram que a liga Ti-6Al-4V apresentou comportamento ativo com transição ativo-passiva em solução $\mathrm{HCl}$ e comportamento passivo em solução $\mathrm{NaCl}$ a 25,60 e 80 ${ }^{\circ} \mathrm{C}$. As amostras recobertas por TiN e TiAlN/TiAlCrN apresentaram comportamento passivo nas duas soluções corrosivas e em todas as temperaturas estudadas. A amostra revestida por TiN depositado por PVD apresentou os menores valores de taxa secundária em fluência para tensões maiores que $222 \mathrm{MPa}$, contudo a amostra nitretada a plasma apresentou maiores valores de vida útil e níveis de ductilidade. A análise conjunta dos expoentes de tensão, energia de ativação e estrutura de discordâncias indicaram que o principal mecanismo de deformação por fluência foi controlado por escalagem de discordâncias. $\mathrm{O}$ cálculo do parâmetro de tolerância ao dano (W) contribuiu para indicar que os revestimentos TiN e TiAlN/TiAlCrN, apesar de protegerem a superfície da oxidação, diminuíram a capacidade de deformação plástica ao longo do estágio terciário e vida útil da liga Ti-6Al-4V, reduzindo a ductilidade. Finalmente, os tratamentos superficiais utilizados neste trabalho foram eficientes por seu efeito de proteção através da deposição de um elemento cerâmico mais estável na superfície e não por transformações causadas na microestrutura.

Palavras-chave: Fluência. Corrosão. Oxidação isotérmica. TiN. TiAlN/TiAlCrN. Nitretação por plasma. Ti-6Al-4V. 


\begin{abstract}
OLIVEIRA, V. M. C. A. Study of the creep, corrosion and isothermal oxidation phenomenon in the Ti-6Al-4V alloy subjected to plasma-assisted PVD TiN and TiAIN coatings. 2014. $150 \mathrm{p}$. Thesis (Doctor of Science) - Escola de Engenharia de Lorena, Universidade de São Paulo, Lorena, 2014.

This study aimed to evaluate the effect of the plasma-assisted PVD TiN and TiAlN/TiAlCrN coatings in the Ti-6Al-4V alloy under creep conditions at $600{ }^{\circ} \mathrm{C}$ and under corrosion conditions in environments containing chloride at 25,60 and $80{ }^{\circ} \mathrm{C}$. The study was complemented by microstructural and surface coatings analysis using XRD, optical, scanning and transmission electron microscopy, microhardness and isothermal oxidation. The results showed that the Ti-6Al$4 \mathrm{~V}$ alloy with Widmanstätten morphology presented an average hardness of $343 \mathrm{HV}$ for as received condition. After treatment by plasma PVD, it was observed a TiN based coating, with 2,2 $\mu \mathrm{m}$ and composition of $\mathrm{Ti}_{0,7} \mathrm{~N}$. The TiAlN/TiAlCrN based coating presented $6 \mu \mathrm{m}$ of thickness and composition of $\left(\mathrm{Ti}_{0,38} \mathrm{Al}_{0,62}\right) \mathrm{N} /\left(\mathrm{Ti}_{0,31} \mathrm{Al}_{0,50} \mathrm{Cr}_{0,19}\right) \mathrm{N}$. Anodic polarization and open circuit potential showed that Ti-6Al-4V alloy had active behavior with active - passive transition in $\mathrm{HCl}$ solution and passive behavior in $\mathrm{NaCl}$ solution at 25,60 and $80{ }^{\circ} \mathrm{C}$. The TiN and TiAlN/TiAlCrN coated samples showed passive behavior in both corrosive solutions and at all studied temperatures. The TiN coated sample showed the lowest values of secondary creep rate for stresses greater than 222 $\mathrm{MPa}$, however, the plasma nitrided sample showed higher levels of service life and ductility. The analysis of stress exponents, activation energy and dislocations structures indicated that the main mechanism of creep was controlled by climbing dislocations. The damage tolerance parameter $(\mathrm{W})$ calculation contributed to indicate that TiN and TiAlN/TiAlCrN coatings, although protect the surface from oxidation, decreased plastic deformation ability throughout tertiary stage and service life of the Ti-6Al-4V alloy, decreasing ductility. Finally, the surface treatments, used in this study, were efficient for their protective effect by depositing a more stable ceramic compound on surface and not by transformations caused on microstructure.
\end{abstract}

Keywords: Creep. Corrosion. Isothermal oxidation. TiN. TiAlN/TiAlCrN. Plasma nitriding. Ti$6 \mathrm{Al}-4 \mathrm{~V}$. 


\section{LISTA DE FIGURAS}

Figura 1. Índice de preços dos fabricantes de produtos de titânio na América (1971-2006) (CHUNXIANG, 2011).

Figura 2. Principais países produtores de titânio entre 2003-2010 (CHUNXIANG, 2011).

Figura 3. Imagem esquemática da microestrutura granular do revestimento: a) PVD; b) CVD e c) PMD (FORTUNA, et al., 2000).

Figura 4. Diagrama de polarização para um metal ativo-passivo (AHMAD, 2006). 37

Figura 5. Curva de fluência para tensão constante apresentando as regiões primária, secundária e terciária (EVANS; WILSHIRE, 1993; LANGDON, 2002; KASSNER; HAYES, 2003).

Figura 6. Diagrama $\mathrm{E}$ versus $\mathrm{pH}$ do titânio, a $25^{\circ} \mathrm{C}$, assumindo passivação por $\mathrm{TiO} 2$ (POURBAIX, 1974).

Figura 7. Ilustração dos corpos de prova de corrosão (a), fluência (b, c) e oxidação isotérmica (d) recobertos com recobrimentos à base de TiN (dourado) e TiAlN (grafite). 54 Figura 8. a) Representação esquemática de um corpo de prova, com seção reta circular, utilizado nos testes de corrosão (dimensão em mm); b) corpo de prova tratado por PVD embutido no suporte de teflon.

Figura 9. Representação esquemática de um corpo de prova, com seção reta circular, utilizado nos testes de fluência (dimensão em mm).

Figura 10. Liga Ti-6Al-4V, como recebida na condição recozida. .59

Figura 11. Liga Ti-6Al-4V, tratada termicamente com morfologia Widmansttäten..... 60

Figura 12. Ti-6Al-4V recoberto por PVD - TiN: a) MEV, $5.0 \mathrm{kx}$; b) MEV, $10.0 \mathrm{kx} . . . . . .61$

Figura 13. Ti-6Al-4V recoberto por PVD - TiAlN: a) MEV, 5.0 kx; b) MEV, 10.0 kx. ..62

Figura 14. Difratograma de raios $X(D R X)$ da amostra sem tratamento superficial. .63

Figura 15. Difratogramas de Raios $X(D R X)$ da liga Ti-6Al-4V com recobrimento. .64

Figura 16. Potencial em circuito aberto vs. tempo para a liga Ti-6Al-4V sem recobrimento e recoberta por TiN e TiAlN/TiAlCrN, em solução $\mathrm{HCl} 2 \mathrm{M}$ a $25^{\circ} \mathrm{C}$.

Figura 17. Potencial em circuito aberto vs. tempo para a liga Ti-6Al-4V sem recobrimento e recoberta por TiN e TiAlN/TiAlCrN, em solução $\mathrm{NaCl} 3,5 \%$ p. a $25^{\circ} \mathrm{C}$

Figura 18. Curva de polarização potenciodinâmica da liga Ti-6Al-4V sem recobrimento e recoberta por TiN e TiAlN/TiAlCrN, em solução $\mathrm{HCl} 2 \mathrm{M}$ a $25^{\circ} \mathrm{C}$. 
Figura 19. Curva de polarização potenciodinâmica da liga Ti-6Al-4V sem recobrimento e recoberta por TiN e TiAlN/TiAlCrN, em solução $\mathrm{NaCl} 3,5 \%$ a $25{ }^{\circ} \mathrm{C}$.

Figura 20. Mapeamento por EDS: presença do elemento cloro nos produtos de corrosão aderidos à superfície da liga Ti-6Al-4V sem revestimento.

Figura 21. Microscopia Eletrônica de Varredura (MEV) das amostras revestidas antes de serem submetidas a um processo corrosivo: a) TiN, b) TiAlN/TiAlCrN. .73

Figura 22. Microscopia eletrônica de varredura (MEV) das superfícies corroídas após 3 horas de imersão + polarização em HCl: a) Ti-6Al-4V, b) TiN, c) TiAlN/TiAlCrN..........76

Figura 23. Microscopia eletrônica de varredura (MEV) das superfícies corroídas após 3 horas de imersão + polarização em NaCl: a) Ti-6Al-4V, b) TiN, c) TiAlN/TiAlCrN ........76

Figura 24. Aspecto da superfície do material após o teste de corrosão: TiAlN em solução de $\mathrm{NaCl}$.

Figura 25. Circuito elétrico equivalente proposto para a condição Ti-6Al-4V em solução HCl 2M (MENDOZA-CANALES; MARÍN-CRUZ, 2008; ROSSI et al., 2003). .78

Figura 26. Circuito elétrico equivalente proposto para a condição Ti-6Al-4V nas soluções $\mathrm{NaCl}$ 3,5 \%p. (ALVES et al., 2009; MANHABOSCO et al., 2011; VASILESCU et al., 2011; WANG et al., 2003). 79

Figura 27. Circuito elétrico equivalente proposto para a condição recoberta (TiN e TiAlN) nas soluções $\mathrm{NaCl}$ 3,5 \%p. e HCl 2M (AHN et al., 2007; GRIPS et al., 2006; LIN; DUH, 2009; LIU et al., 2003).

Figura 28. Ti-6Al-4V sem recobrimento em solução $\mathrm{HCl} 2 \mathrm{M}$ a $25{ }^{\circ} \mathrm{C}$ : a) Diagrama de Nyquist, b) Diagrama de Bode (módulo vs. frequência e fase vs. frequência). 80

Figura 29. Ti-6Al-4V recoberta por TiN em solução $\mathrm{HCl} 2 \mathrm{M}$ a $25{ }^{\circ} \mathrm{C}$ : a) Diagrama de Nyquist, b) Diagrama de Bode (módulo vs. frequência e fase vs. frequência). .81

Figura 30. Ti-6Al-4V recoberta por TiAlN/TiAlCrN em solução $\mathrm{HCl} 2 \mathrm{M}$ a $25{ }^{\circ} \mathrm{C}$ : a) Diagrama de Nyquist, b) Diagrama de Bode (módulo vs. frequência e fase vs. frequência).

Figura 31. Ti-6Al-4V sem recobrimento em solução $\mathrm{NaCl} 3,5 \%$ p. a $25{ }^{\circ} \mathrm{C}$ : a) Diagrama de Nyquist, b) Diagrama de Bode (módulo vs. frequência e fase vs. frequência). .81

Figura 32. Ti-6Al-4V recoberta por TiN em solução $\mathrm{NaCl} 3,5 \%$ p. a $25{ }^{\circ} \mathrm{C}$ : a) Diagrama de Nyquist, b) Diagrama de Bode (módulo vs. frequência e fase vs. frequência). .82

Figura 33. Ti-6Al-4V recoberta por TiAlN/TiAlCrN em solução $\mathrm{NaCl} 3,5$ \%p. a $25{ }^{\circ} \mathrm{C}$ : a) Diagrama de Nyquist, b) Diagrama de Bode (módulo vs. frequência e fase vs. frequência). 
Figura 34. Curva de polarização potenciodinâmica da liga Ti-6Al-4V sem recobrimento e recoberta por TiN e TiAlN/TiAlCrN, em solução $\mathrm{HCl} 2 \mathrm{M}$ : a) $60{ }^{\circ} \mathrm{C}$, b) $80{ }^{\circ} \mathrm{C}$. 88

Figura 35. Curva de polarização potenciodinâmica da liga Ti-6Al-4V sem recobrimento e recoberta por TiN e TiAlN/TiAlCrN, em solução $\mathrm{NaCl} 3,5 \%$ p.: a) $60{ }^{\circ} \mathrm{C}$, b) $80^{\circ} \mathrm{C}$ 88

Figura 36. Influência da temperatura sobre a resistência à corrosão da liga Ti-6Al-4V sem recobrimento e recoberta por TiN e TiAlN/TiAlCrN em solução HCl 2M. 89

Figura 37. Influência da temperatura sobre a resistência à corrosão da liga Ti-6Al-4V sem recobrimento e recoberta por TiN e TiAlN/TiAlCrN em solução $\mathrm{NaCl}$ 3,5 \%p. 90

Figura 38. Variação da impedância $\left(\mathrm{R}_{\mathrm{p}}\right)$ com a temperatura para a liga Ti-6Al-4V sem recobrimento e recoberta por TiN e TiAlN/TiAlCrN em solução HCl 2M.

Figura 39. Variação da impedância $\left(\mathrm{R}_{\mathrm{p}}\right)$ com a temperatura para a liga Ti-6Al-4V sem recobrimento e recoberta por TiN e TiAlN/TiAlCrN em solução $\mathrm{NaCl}$ 3,5 \%p. .92

Figura 40. Cinética da oxidação isotérmica da liga Ti-6Al-4V sem recobrimento e recoberta por TiN e TiAlN/TiAlCrN, testada a $600{ }^{\circ} \mathrm{C}$ ao ar. 94

Figura 41. Difratogramas de raios $X(D R X)$ da liga Ti-6Al-4V sem recobrimento, oxidada a $600{ }^{\circ} \mathrm{C}$ : a) $\left.\mathrm{t}=23 \mathrm{~h}, \mathrm{~b}\right) \mathrm{t}=168 \mathrm{~h}$.

Figura 42. Difratogramas de raios $\mathrm{X}(\mathrm{DRX})$ da liga Ti-6Al-4V recoberta por TiN, oxidada a $600{ }^{\circ} \mathrm{C}$ : a) $\left.\mathrm{t}=23 \mathrm{~h}, \mathrm{~b}\right) \mathrm{t}=168 \mathrm{~h}$.

Figura 43. Difratogramas de raios $\mathrm{X}$ da liga Ti-6Al-4V recoberta por TiAlN/TiAlCrN, oxidada a $600{ }^{\circ} \mathrm{C}$ : a) sobreposição dos difratogramas, b) $\mathrm{t}=23 \mathrm{~h}$, c) $\mathrm{t}=168 \mathrm{~h}$, d) TiAlN/TiAlCrN antes do teste de oxidação isotérmica.

Figura 44. Micrografias das amostras oxidadas isotermicamente a $600{ }^{\circ} \mathrm{C}$ : a) Ti-6Al-4V sem recobrimento, $t=168 \mathrm{~h}, \mathrm{~b}) \mathrm{Ti}-6 \mathrm{Al}-4 \mathrm{~V}$ recoberta por TiN, $\mathrm{t}=23 \mathrm{~h}, \mathrm{c}) \mathrm{Ti}-6 \mathrm{Al}-4 \mathrm{~V}$ recoberta por TiN, $\mathrm{t}=168 \mathrm{~h}, \mathrm{~d}) \mathrm{Ti}-6 \mathrm{Al}-4 \mathrm{~V}$ recoberta por TiAlN/TiAlCrN, $\mathrm{t}=168 \mathrm{~h}$. .... 101

Figura 45. Aspecto geral da superfície de fratura a $600^{\circ} \mathrm{C}$ : a) Ti-6Al-4V sem recobrimento a 300 MPA, b) Ti-6Al-4V nitretado a plasma a 350 MPa (OLIVEIRA,2010). 104

Figura 46. Curva deformação $\mathrm{x}$ tempo para a liga nas condições recoberta por TiN e TiAlN/TiAlCrN a $600{ }^{\circ} \mathrm{C}$ e $190 \mathrm{MPa}$.

Figura 47. Curva deformação x tempo para a liga nas condições CR (OLIVEIRA, 2010), nitretada por plasma (OLIVEIRA, 2010) e recoberta por TiN e TiAlN/TiAlCrN a $600{ }^{\circ} \mathrm{C}$ e $222 \mathrm{MPa}$. 106

Figura 48. Curva deformação $x$ tempo para a liga nas condições $C R$, nitretada por plasma (OLIVEIRA, 2010) e recoberta por TiN e TiAlN/TiAlCrN a $600{ }^{\circ} \mathrm{C}$ e $250 \mathrm{MPa}$. 106 
Figura 49. Curva deformação $x$ tempo para a liga nas condições $C R$, nitretada por plasma (OLIVEIRA, 2010) e recoberta por TiN e TiAlN/TiAlCrN a $600{ }^{\circ} \mathrm{C}$ e $278 \mathrm{MPa}$. 107

Figura 50. Curva deformação x tempo para a liga nas condições CR (OLIVEIRA, 2010), nitretada por plasma (OLIVEIRA, 2010) e recoberta por TiN e TiAlN/TiAlCrN a $600{ }^{\circ} \mathrm{C}$ e $300 \mathrm{MPa}$.

Figura 51. Dependência da taxa estacionária com a tensão a $600^{\circ} \mathrm{C}$ para a liga nas condições CR, nitretada por plasma, recoberta por TiN e por TiAlN/TiAlCrN

Figura 52. Ln (tensão) vs. ln (taxa secundária) a $600^{\circ} \mathrm{C}$ para a liga nas condições $\mathrm{CR}$, nitretada por plasma, recoberta por TiN e por TiAlN/TiAlCrN.

Figura 53. Dependência do tempo de fratura com a tensão a $600^{\circ} \mathrm{C}$ para a liga nas condições CR, nitretada por plasma, recoberta por TiN e por TiAlN/TiAlCrN

Figura 54. Ln (tensão) vs. ln (tempo de fratura) a $600^{\circ} \mathrm{C}$ para a liga nas condições $\mathrm{CR}$, nitretada por plasma, recoberta por TiN e por TiAlN/TiAlCrN

Figura 55. Dependência da deformação final com a tensão a $600^{\circ} \mathrm{C}$ para a liga nas condições CR, nitretada por plasma, recoberta por TiN e por TiAlN/TiAlCrN

Figura 56. Aspecto geral da superfície de fratura a $600^{\circ} \mathrm{C}$ e $190 \mathrm{MPa}$ na condição recoberta por TiN. 116

Figura 57. Aspecto geral da superfície de fratura a $600^{\circ} \mathrm{C}$ e $300 \mathrm{MPa}$ na condição recoberta por TiN.

Figura 58. Aspecto geral da superfície de fratura a $600^{\circ} \mathrm{C}$ e $190 \mathrm{MPa}$ na condição recoberta por TiAlN/TiAlCrN.

Figura 59. Aspecto geral da superfície de fratura a $600^{\circ} \mathrm{C}$ e $300 \mathrm{MPa}$ na condição recoberta por TiAlN/TiAlCrN. 118

Figura 60. Imagem obtida por MET na liga Ti-6Al-4V na condição CR após fluência a $600^{\circ} \mathrm{C}$ e $222 \mathrm{MPa}$.

Figura 61. Imagem obtida por MET na liga nitretada por plasma após fluência a $600^{\circ} \mathrm{C}$ e $222 \mathrm{MPa}$.

Figura 62. Relação entre as taxas de deformação e os tempos de ruptura a $600^{\circ} \mathrm{C}(\mathrm{MG})$.

Figura 63. Relação entre as taxas de deformação e os tempos de ruptura a $600^{\circ} \mathrm{C}$ (MGM).

Figura 64. Seção transversal das amostras recobertas por PVD: a) TiN, b) TiAlN/TiAlCrN. 
Figura 65. a) Perfil de nanodureza e b) Módulo Elástico (E) da amostra nitretada por plasma. 128

Figura 66. Diagrama de fases do sistema Ti-Al (ASM HANDBOOK, 1992). ................129

Figura 67. Microscopia Eletrônica por Transmissão (MET) da liga Ti-6Al-4V de morfologia Widmanstätten antes do processo de fluência. 130

Figura 68. Microscopia Eletrônica por Transmissão (MET) da liga Ti-6Al-4V nitretada por plasma após o processo de fluência. 


\section{LISTA DE TABELAS}

Tabela 1 - Propriedades do titânio CP (LEYENS; PETERS, 2003; METALS HANDBOOK, 1990; ZHECHEVA et al., 2005).

Tabela 2 - Propriedades da liga Ti-6Al-4V (LEYENS; PETERS, 2003; METALS HANDBOOK, 1990).

Tabela 3 - Valores de n, p e D associados aos diferentes mecanismos de fluência (LANGDON, 2000; WILSHIRE; WHITTAKER, 2009).

Tabela 4 - Parâmetros de corrosão obtidos de vários autores para diversas ligas e metais com e sem revestimento: potencial de corrosão $\left(E_{\text {corr }}\right)$, densidade de corrente de corrosão $\left(i_{\text {corr }}\right)$ e resistência à transferência de carga $\left(\mathrm{R}_{\mathrm{p}}\right)$. .46

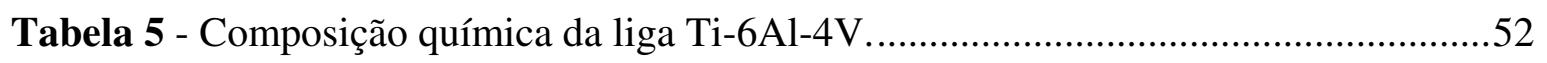

Tabela 6. Condições de deposição dos revestimentos TiN e TiAlN ..................................54

Tabela 7. Parâmetros eletroquímicos da liga Ti-6Al-4V sem recobrimento e recoberta por TiN e TiAlN/TiAlCrN, a $25^{\circ} \mathrm{C}$ em meio $\mathrm{HCl} 2 \mathrm{M}$. .68

Tabela 8. Parâmetros eletroquímicos da liga Ti-6Al-4V sem recobrimento e recoberta por TiN e TiAlN/TiAlCrN, a $25{ }^{\circ} \mathrm{C}$ em meio $\mathrm{NaCl} 3,5 \%$. .68

Tabela 9 - Valores de densidade de corrente de corrosão (icorr) eletroquímica para testes conduzidos com ligas metálicas recobertas com TiN e TiAlN. 75

Tabela 10. Parâmetros obtidos através do ajuste do modelo de circuito elétrico equivalente com duas constantes de tempo para a liga Ti-6Al-4V com e sem recobrimento, em solução $\mathrm{HCl} 2 \mathrm{M}$ a $25^{\circ} \mathrm{C}$. 83

Tabela 11. Parâmetros obtidos através do ajuste do modelo de circuito elétrico equivalente com duas constantes de tempo para a liga Ti-6Al-4V com e sem recobrimento, em solução $\mathrm{NaCl} 3,5 \%$ p. a $25^{\circ} \mathrm{C}$

Tabela 12 - Valores de resistência a transferência de carga $\left(\mathrm{R}_{\mathrm{p}}\right)$ para testes conduzidos com ligas metálicas em meios ácidos e neutros, tratadas ou não superficialmente. .84

Tabela 13. Valores de densidade de corrente de corrosão ( $i_{\text {corr }}$ ) da liga Ti-6Al-4V sem recobrimento e recoberta por TiN e TiAlN/TiAlCrN em $\mathrm{HCl} 2 \mathrm{M}$ a 25, 60 e $80^{\circ} \mathrm{C}$.

Tabela 14. Valores de densidade de corrente de corrosão ( $i_{\text {corr }}$ ) da liga Ti-6Al-4V sem recobrimento e recoberta por TiN e TiAlN/TiAlCrN em $\mathrm{NaCl} 3,5$ \%p. a 25,60 e $80^{\circ} \mathrm{C}$....89 Tabela 15. Porcentagem de proteção superficial $\left(\mathrm{P}_{\mathrm{i}} \%\right)$ dos recobrimentos TiN e TiAlN/TiAlCrN em solução HCl 2M. 
Tabela 16. Porcentagem de proteção superficial (Pi \%) dos recobrimentos TiN e TiAlN/TiAlCrN em solução $\mathrm{NaCl}$ 3,5 \%p

Tabela 17. Parâmetros experimentais de fluência a $600{ }^{\circ} \mathrm{C}$ para a liga na condição CR. 104 Tabela 18. Parâmetros experimentais de fluência a $600{ }^{\circ} \mathrm{C}$ para a liga na condição nitretada por plasma (OLIVEIRA, 2010). 104

Tabela 19. Parâmetros experimentais de fluência a $600{ }^{\circ} \mathrm{C}$ para a liga na condição recoberta por TiN. 108

Tabela 20. Parâmetros experimentais de fluência a $600{ }^{\circ} \mathrm{C}$ para a liga na condição recoberta por TiAlN/TiAlCrN. 108

Tabela 21. Constantes de MG e MGM para a liga Ti-6Al-4V. 123

Tabela 22. Parâmetros de tolerância ao dano (W). 124

Tabela 23. Analise estatística da alteração da quantidade de fase (\%) e do tamanho de grão (mm) com os tratamentos térmicos. 


\section{LISTA DE SÍMBOLOS E ABREVIATURAS}

PVD - deposição física a vapor (physical vapor deposition)

$\mathrm{T}_{\beta}$ - temperatura de transformação da fase $\alpha \mathrm{em} \beta$

$\mathrm{HC}$ - hexagonal compacto

CCC - cúbico de corpo centrado

${ }^{\circ} \mathrm{C}$ - graus Celsius

CVD - deposição química a vapor (chemical vapor deposition)

PMD - deposição por pulverização catódica via plasma (plasma-enhanced magnetron sputtered deposition)

DC - corrente de descarga (discharge current)

$\mathrm{N}-$ Newton

$\mathrm{i}_{\text {crít }}-$ corrente crítica

$\mathrm{E}_{\mathrm{p}}$ - potencial de passivação

$\mathrm{i}_{\text {pass }}-$ corrente de passivação

$\mathrm{E}_{\text {transpassivo }}$ - potencial transpassivo

E - voltagem oscilante

$\mathrm{E}_{0}$ - amplitude da voltagem oscilante

I - corrente oscilante

$\mathrm{I}_{0}$ - amplitude da corrente oscilante

$\omega$ - freqüência angular

$\phi$ - ângulo de fase

IE - interface eletroquímica

Z - impedância

$\mathrm{CPE}$ - elemento em fase constante

$\mathrm{T}_{\mathrm{m}}$ - temperatura de fusão

$\sigma-$ tensão

$\varepsilon_{0}-$ deformação instantânea inicial

d $\varepsilon / \mathrm{dt}$ - taxa de deformação

$\mathrm{t}_{\mathrm{p}}$ - tempo correspondente ao início da região secundária

$\mathrm{Q}_{\mathrm{p}}$ - energia de ativação para a região primária

$\dot{\varepsilon}_{S}$ - taxa de fluência secundária ou taxa estácionária de fluência

$\mathrm{Q}_{\mathrm{s}}$ - energia de ativação da região secundária

$\mathrm{n}$ - expoente de tensão 
$\mathrm{D}_{1}$ - coeficiente de autodifusão na rede

$\mathrm{D}_{\mathrm{gb}}$ - coeficiente de difusão nos contornos de grão

$\mathrm{E}_{\mathrm{F}}^{\circ}$ - potencial de Flade

$\mathrm{K}_{\mathrm{p}}$ - taxa de crescimento do óxido

$\mathrm{i}_{\text {corr }}$ - densidade de corrente de corrosão

$\mathrm{R}_{\mathrm{p}}$ - resistência à transferência de carga

$\mathrm{E}_{\text {corr }}$ - potencial de corrosão

ECS - eletrodo de calomelano saturado

ENH - eletrodo normal (padrão) de hidrogênio

OCP - potencial em circuito aberto (open-circuit potential)

EDS - Espectroscopia por dispersão de energia (Energy dispersive spectroscopy)

$\mathrm{R}_{\mathrm{s}}$ - resistência da solução

$\mathrm{C}_{\mathrm{dc}}$ - capacitância da dupla camada

$\mathrm{R}_{\mathrm{fpor}}$ - resistência da camada porosa mais externa

$\mathrm{C}_{\mathrm{fpor}}$ - capacitância da camada porosa mais externa

$\mathrm{R}_{\mathrm{fpass}}$ - resistência da camada óxida passiva mais interna

$\mathrm{C}_{\text {fpass }}$ - capacitância da camada óxida passiva mais interna

$\mathrm{R}_{\mathrm{rev}}$ - resistência do revestimento defeituoso

$\mathrm{C}_{\mathrm{rev}}$ - capacitância do revestimento defeituoso

$P_{i}-$ proteção superficial

$\Delta \mathrm{m} / \mathrm{A}$ - variação da massa em miligramas por centímetro quadrado

$\mathrm{k}_{\mathrm{ox}}$ - taxa de oxidação

cps - contagem por segundo

$\mathrm{t}_{\mathrm{f}}-$ tempo de fratura

$\varepsilon_{\mathrm{f}}-$ deformação correspondente à fratura

$\mathrm{CR}$ - como recebida

MET - microscopia eletrônica de transmissão

$\mathrm{T}$ - temperatura absoluta

$\mathrm{R}$ - constantes dos gases

$\dot{\varepsilon}_{\text {min }}$ - taxa mínima de fluência

D - coeficiente de difusão

$\mathrm{G}$ - módulo de cisalhamento

d - tamanho médio de grão

$\mathrm{p}$ - expoente de tamanho médio de grão 
P. A. - para análise

C - capacitância na interface

$\mathrm{n}$ - coeficiente relacionado ao desvio entre capacitância real e capacitância pura

$|Z|$ - valor absoluto da impedância

$\theta$ - ângulo de fase

$f$ - frequência

$\varepsilon-$ deformação por fluência

MEV - microscopia eletrônica de varredura

$\lambda$ - comprimento de onda

W - tolerância ao dano

$\mathrm{t}$ - tempo 


\section{SUMÁRIO}

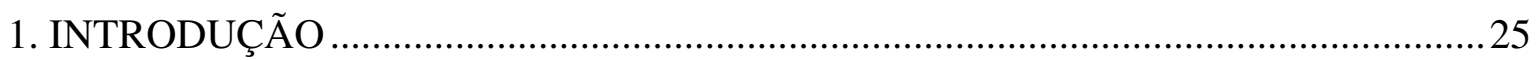

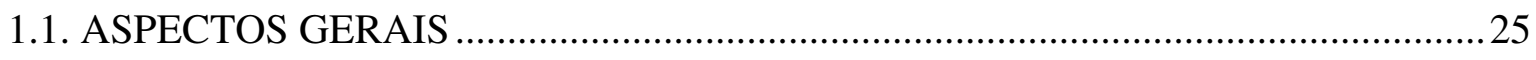

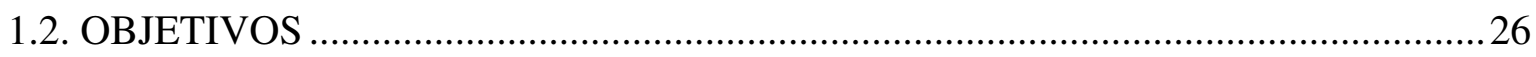

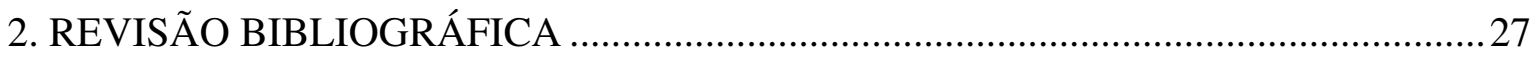

2.1. TITÂNIO E SUAS LIGAS - DESENVOLVIMENTOS DE MERCADO, PROPRIEDADES E APLICAÇÕES........................................................................... 27

2.2. MODIFICAÇÃO NO COMPORTAMENTO MECÂNICO DO TITÂNIO E DE SUAS LIGAS SUBMETIDOS A DIVERSOS TRATAMENTOS SUPERFICIAIS ..........31

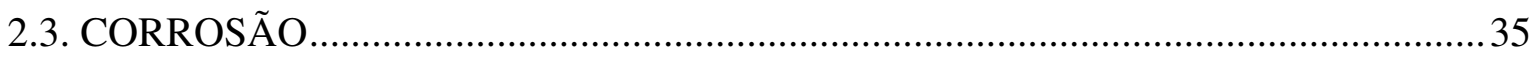

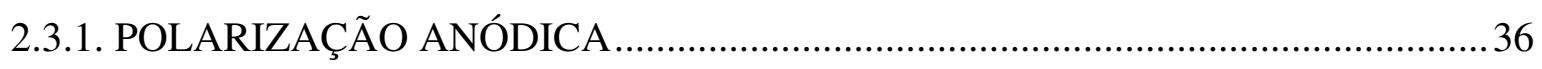

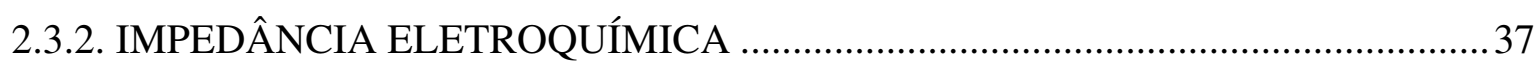

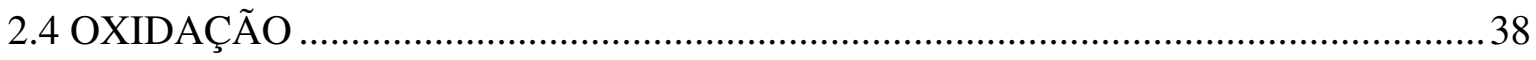

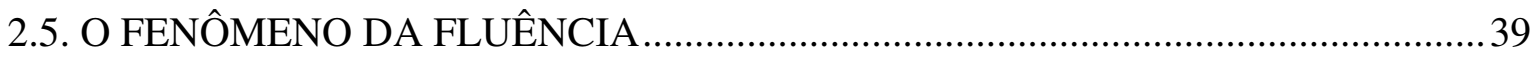

2.6. COMPORTAMENTO DO TITÂNIO E SUAS LIGAS COM E SEM APLICAÇÃO DE REVESTIMENTOS SUBMETIDOS À CORROSÃO ELETROQUIMICA E

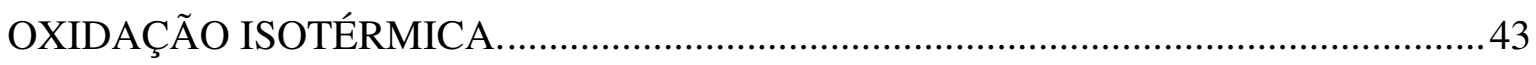

2.7. DESEMPENHO DAS LIGAS DE TITÂNIO SUBMETIDAS À FLUÊNCIA ............48

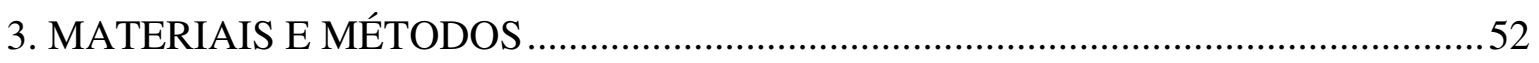

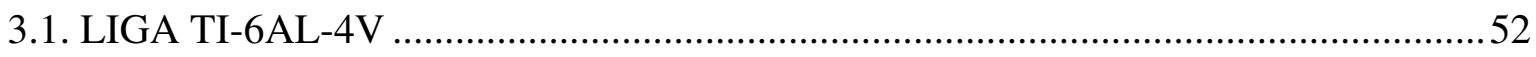

3.2. CARACTERIZAÇÃO METALOGRÁFICA …......................................................52

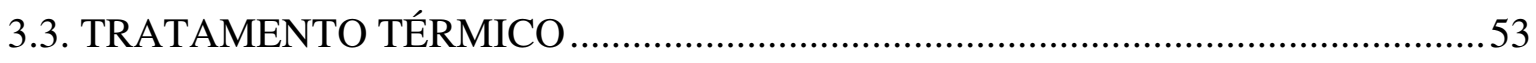

3.4. DEPOSIÇÃO FÍSICA A VAPOR ASSISTIDA POR PLASMA .................................53

3.5. CARACTERIZAÇÃO POR MICROSCOPIA ELETRÔNICA DE VARREDURA E

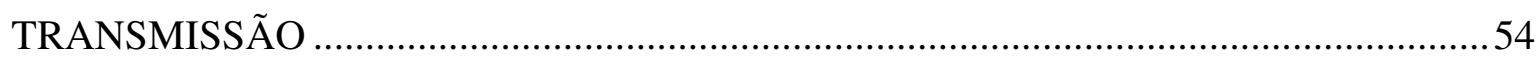

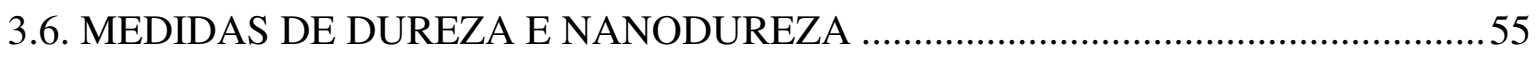

3.7. CARACTERIZAÇÃO POR DIFRATOMETRIA DE RAIOS X ................................55

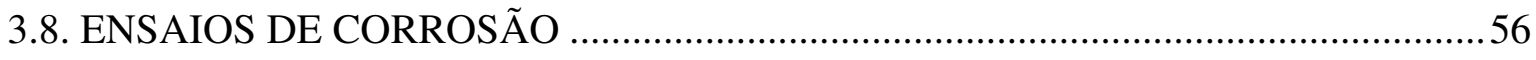

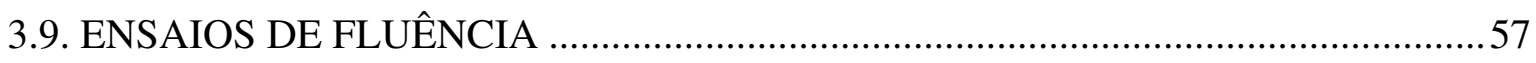

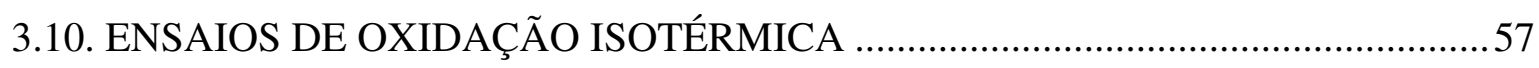

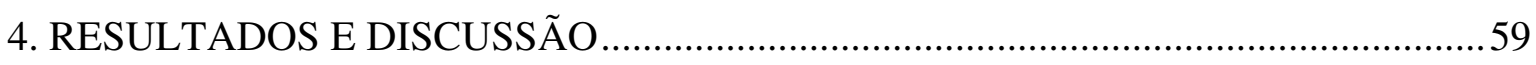

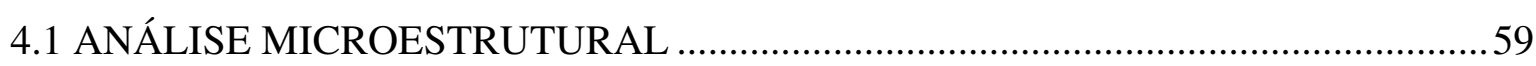


4.2. DIFRATOMETRIA DE RAIOS X. .63

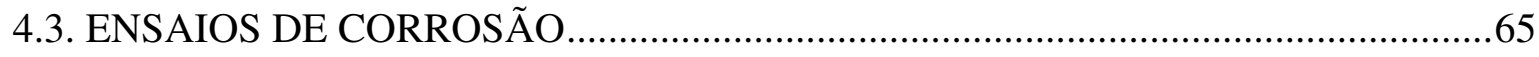

4.3.1. MEDIDAS DO POTENCIAL EM CIRCUITO ABERTO E POLARIZAÇÃO

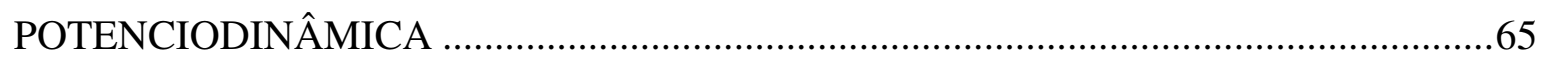

4.3.2. ESPECTROSCOPIA DE IMPEDÂNCIA ELETROQUÍMICA …………………......77

4.3.2.1. MODELAGEM DOS CIRCUITOS ELÉTRICOS …….............................................77

4.3.2.2. MEDIDAS DE IMPEDÂNCIA ELETROQUÍMICA ………………………..........8

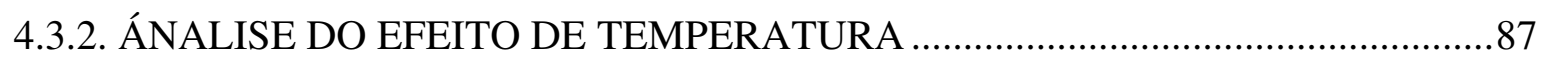

4.4. ENSAIOS DE OXIDAÇÃO ISOTÉRMICA...........................................................93

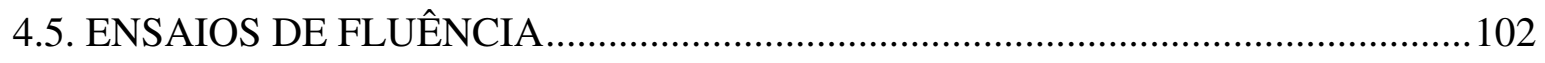

4.5.1. LIGA TI-6AL-4V NA CONDIÇÃO SEM RECOBRIMENTO E NITRETADA POR

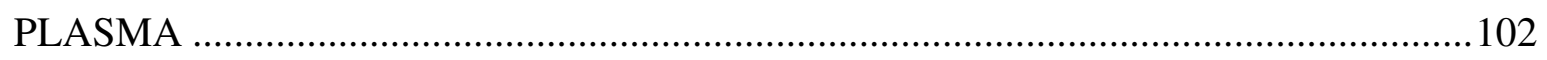

4.5.2. LIGA TI-6AL-4V NA CONDIÇÃO RECOBERTA POR TIN E TiAIN/TiAlCrN 105

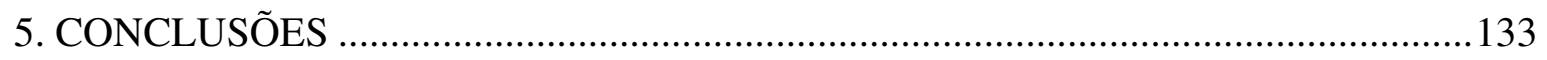

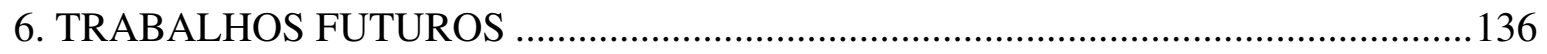

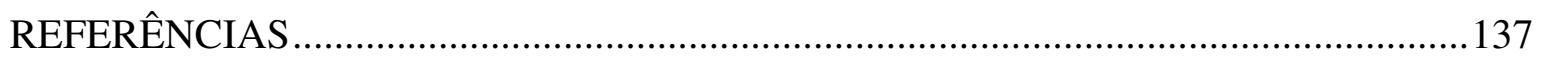




\section{INTRODUÇÃO}

\subsection{ASPECTOS GERAIS}

Titânio e suas ligas são amplamente utilizados em diversos ramos industriais como aeronáutico, biomédico, militar, automotivo, químico, entre outros. Esta variada gama de campos de aplicação é devido a suas excelentes propriedades como alta resistência específica, bicompatibilidade, resistência à corrosão e resistência mecânica (LIU et al., 2004; POLMEAR, 2005).

Sendo um material estrutural, o titânio e suas ligas estão sujeitos a solicitações que envolvem condições extremas como altas temperaturas, ambientes altamente corrosivos e altas tensões. Cerca de $80 \%$ da produção de titânio mundial é destinada à fabricação de peças do setor aeroespacial como turbinas a gás, asas e outros componentes de sustentação de cargas. Parte deste material também é destinada a aplicações em ambientes corrosivos como na produção de pinos, stents e válvulas cardíacas artificiais que são submetidos ao fluido corpóreo (CHUNXIANG et al., 2011; GURRAPPA, 2003; LIU et al., 2004).

A necessidade de sistemas de produção mais eficientes levou a demanda de materiais que apresentem maior tempo de vida e que resistam a condições severas com pouco ou nenhum risco de falha. Nesse sentido, pesquisas com diversos materiais, já existentes e novos, têm sido feitas. Boa parte delas destinada às ligas convencionais de titânio devido a suas qualidades já mencionadas e ao fato deste material ser bem conhecido na área industrial devido a sua utilização como componente estrutural desde meados do século 20 (CHUNXIANG et al., 2011; ES-SOUNI, 2001).

Contudo, o titânio apresenta limitações no comportamento tribológico caracterizado por baixa dureza, alto coeficiente de fricção, baixa resistência ao desgaste e à abrasão. O titânio também é um metal muito reativo e reage instantaneamente com oxigênio, originando uma camada óxida superficial resistente a corrosão e/ou oxidação em temperatura ambiente, mas perde sua resistência em altas temperaturas expondo o material às intempéries do meio e tornando-o inadequado para qualquer aplicação em temperaturas maiores que $500{ }^{\circ} \mathrm{C}$ (CESCHINI et al., 2008; GURRAPPA, 2003; POLMEAR, 2005). 
Neste contexto, as técnicas de modificação superficial são utilizadas como uma alternativa para melhorar o desempenho das ligas de titânio, protegendo a superfície com compostos duros sem alterar significativamente as propriedades do metal base (CESCHINI et al., 2008; LIU et al., 2004).

\subsection{OBJETIVOS}

A aplicação de revestimentos cerâmicos ou mesmo de tratamentos termoquímicos já apresentou bons resultados em testes de fadiga, desgaste e fluência (BARAGETTI, 2007; COSTA et al., 2011; MAURER, SCHULZ, 2013; OLIVEIRA, 2010). Porém, nenhum estudo foi feito sobre o comportamento da liga Ti-6Al-4V recoberta por PVD a plasma sob condições de fluência.

Desta forma, os principais objetivos deste trabalho estão focados nos estudos dos fenômenos de fluência, corrosão e oxidação isotérmica na liga Ti-6Al-4V submetida aos revestimentos de TiN e TiAlN/TiAlCrN depositados pela técnica de PVD assistida por plasma.

Os objetivos específicos deste trabalho envolvem os seguintes itens:

a) Avaliar as principais características dos revestimentos depositados por PVD a plasma;

b) Medir a resistência à corrosão da liga Ti-6Al-4V sem e com os revestimentos através de diferentes técnicas eletroquímicas e correlacionar os resultados gerados em cada técnica;

c) Observar a influência do meio corrosivo utilizando uma solução neutra que simula a concentração de $\mathrm{NaCl}$ na água do mar $(\mathrm{NaCl} 3,5 \%$ p.) e uma solução ácida que simula ambientes industriais ou processos biológicos inflamatórios ( $\mathrm{HCl} 2 \mathrm{M})$;

d) Estudar o efeito do aumento da temperatura na resistência à corrosão da liga Ti6Al-4V sem e com os revestimentos;

e) Medir a resistência à oxidação da liga Ti-6Al-4V sem e com os revestimentos a $600{ }^{\circ} \mathrm{C}$ e caracterizar os óxidos que se formam em sua superfície;

f) Estudar o comportamento da liga Ti-6Al-4V sem e com os revestimentos em fluência e compará-lo com os resultados obtidos em um estudo prévio da liga Ti-6Al-4V nitretada por plasma (OLIVEIRA, 2010); 
g) Analisar os principais aspectos de fratura por fluência bem como os mecânismos responsáveis por tal deformação;

h) Avaliar possíveis alterações microestruturais que os tratamentos superfícias, PVD por plasma e nitretação a plasma (OLIVEIRA, 2010), possam ter gerado na microestrutura da liga Ti-6Al-4V.

Todas as análises serão úteis para diversas aplicações, em especial para o setor aeronáutico e biomédico.

\section{REVISÃO BIBLIOGRÁFICA}

2.1. TITÂNIO E SUAS LIGAS - DESENVOLVIMENTOS DE MERCADO, PROPRIEDADES E APLICAÇÕES.

Ti-6Al-4V foi a primeira liga desenvolvida com sucesso nos EUA no ano de 1954. Atualmente, esta liga consome cerca de $80 \%$ da produção mundial de titânio quando comparada às outras famílias de ligas de titânio. Os principais produtores de titânio são EUA, Rússia, Japão, China, Inglaterra, França, Alemanha e Itália (CHUNXIANG, 2011).

Os países exploradores de titânio vêm aumentando suas capacidades anuais nos últimos tempos. Por exemplo, a China passou de 9500 t/ano em 2005 para 45200 t/ano em 2007, um crescimento de 373\%, no ano de 1995 esta capacidade de produção não passava de 3650 t. O Japão expandiu de 37000 t/ano em 2005 para 52000 t/ano em 2009, crescimento de $40 \%$. Na Rússia a produção anual de 2011 atingiu a marca de 44000 t; nos EUA o aumento foi de 20200 t/ano em 2007 para 41970 t/ano em 2010. No ano de 2011 a programação mundial de produção de titânio foi de superar em duas vezes a produção de 2005, ou seja, atingir a marca de 113500 t/ano (CHUNXIANG, 2011; LIAN; GUOZHEN, 1998).

As Figuras 1 e 2 mostram o aumento nos preços do titânio laminado ao longo dos anos e o aumento da produção da matéria prima (esponja de titânio) nos principais países que detém sua exploração (CHUNXIANG, 2011). 


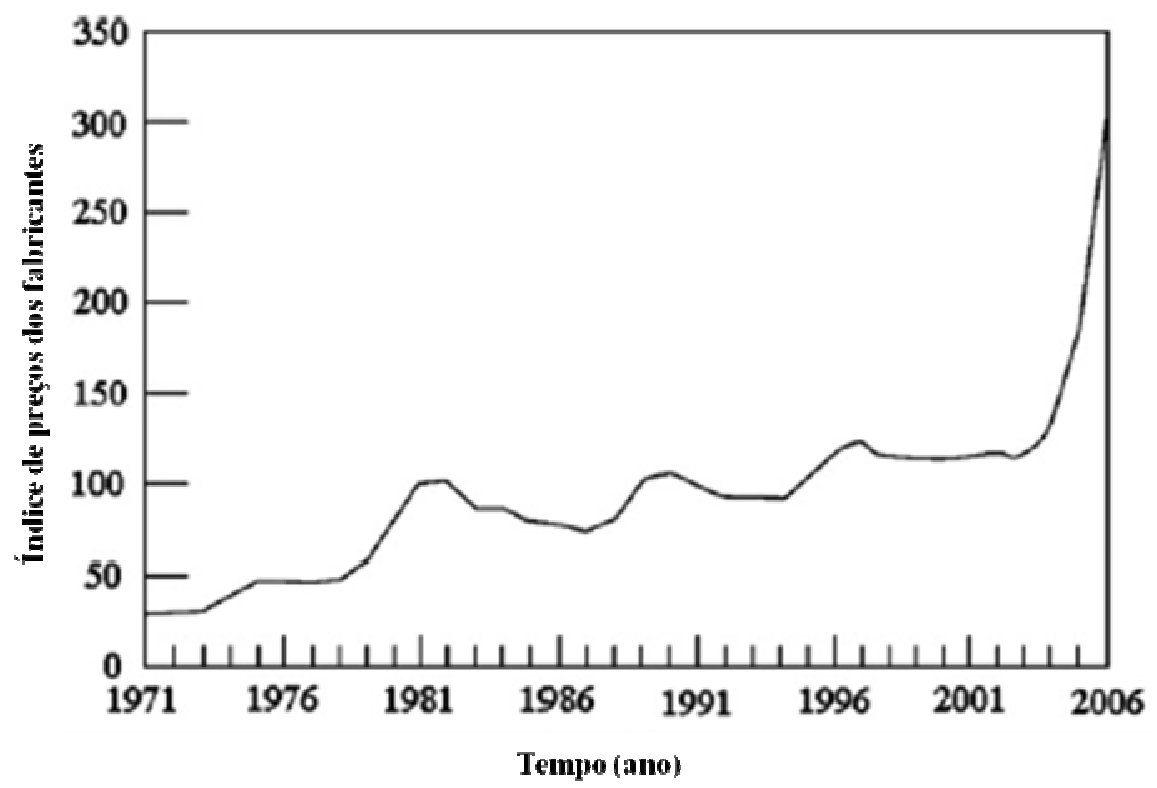

Figura 1. Índice de preços dos fabricantes de produtos de titânio na América (1971-2006) (CHUNXIANG, 2011).

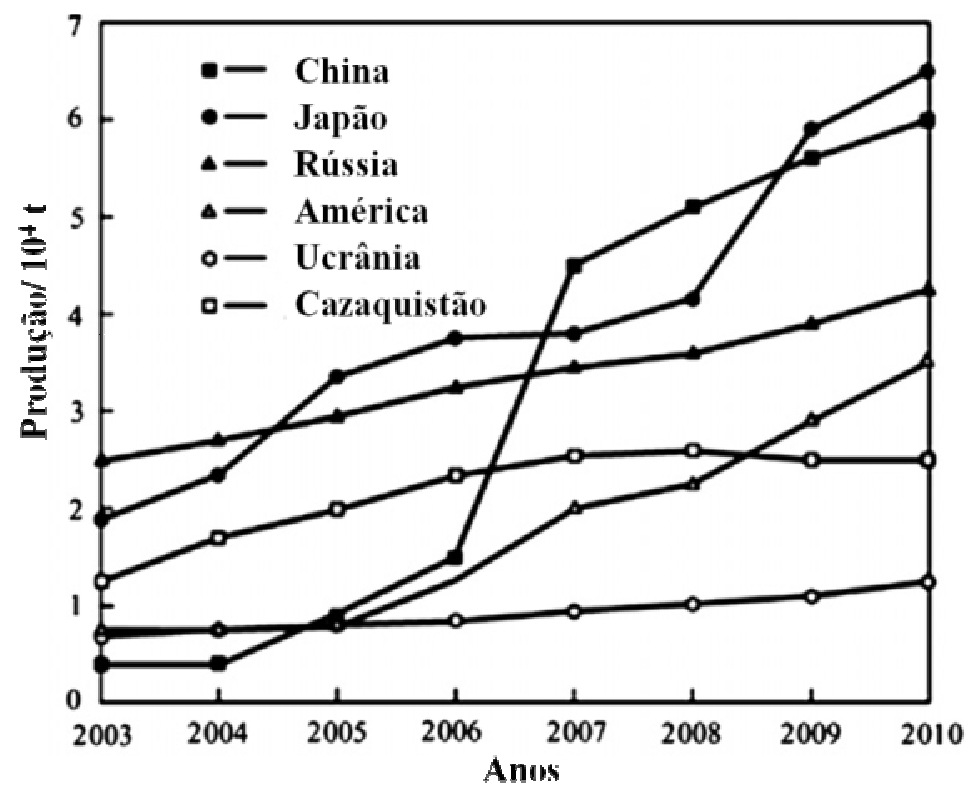

Figura 2. Principais países produtores de titânio entre 2003-2010 (CHUNXIANG, 2011).

De fato, a demanda por titânio tende só a aumentar, pois este material vem sendo aplicado nos mais variados setores industriais. O Japão é um caso, onde a demanda por titânio se concentra mais em setores automobilísticos e de materiais de consumo (esportes e eletrodomésticos). Contudo o setor aeroespacial concentra ainda a maior demanda (CHUNXIANG, 2011; YAMADA, 1996).

As principais propriedades do titânio CP (comercialmente puro) e da liga Ti-6Al4V estão listadas nas Tabelas 1 e 2. 
Tabela 1 - Propriedades do titânio CP (LEYENS; PETERS, 2003; METALS HANDBOOK, 1990; ZHECHEVA et al., 2005).

\begin{tabular}{ll}
\hline \multicolumn{1}{c}{ Propriedades } & \\
\hline Número atômico & 22 \\
Peso atômico & 47,9 u.a. \\
Densidade & $4,51 \mathrm{~g} / \mathrm{cm}^{3}(60 \%$ menor do que o ferro $)$ \\
Ponto de fusão & $1668^{\circ} \mathrm{C}$ \\
Ponto de ebulição & $3260^{\circ} \mathrm{C}$ \\
Configuração eletrônica & $1 \mathrm{~s}^{2} 2 \mathrm{~s}^{2} 2 \mathrm{p}^{6} 3 \mathrm{~s}^{2} 3 \mathrm{p}^{6} 4 \mathrm{~s}^{2} 3 \mathrm{~d}^{2}$ \\
Módulo elástico & Compressão $-110 \mathrm{GPa}$ \\
& Tração $-105 \mathrm{GPa}$ \\
Ductilidade & Alongamento - 20 a $40 \%$ \\
Resistência à tração & Redução de área -45 a $65 \%$ \\
Tensão de escoamento & 315 a $660 \mathrm{MPa}$ \\
Dureza & 215 a $530 \mathrm{MPa}$ \\
\hline
\end{tabular}

Tabela 2 - Propriedades da liga Ti-6Al-4V (LEYENS; PETERS, 2003; METALS HANDBOOK, 1990).

\begin{tabular}{ll}
\hline \multicolumn{2}{c}{ Propriedades } \\
\hline Densidade & $4,43 \mathrm{~g} / \mathrm{cm}^{3}$ \\
$\mathrm{~T}_{\beta}(\beta$ transus $)$ & $995^{\circ} \mathrm{C}$ \\
Módulo elástico & 110 a $140 \mathrm{GPa}$ \\
& Alongamento -13 a $16 \%$ \\
Ductilidade & Redução de área -20 a $30 \%$ \\
Resistência à tração & $\sim 900 \mathrm{MPa}$ \\
Tensão de escoamento & 830 a $924 \mathrm{MPa}$ \\
Dureza & 300 a $400 \mathrm{HV}$ \\
\hline
\end{tabular}

O titânio possui grande afinidade pelos elementos hidrogênio, carbono, nitrogênio e oxigênio, todos formadores de soluções sólidas intersticiais (LONG; RACK, 1998).

A diversidade microestrutural do titânio é resultado de um fenômeno alotrópico. $\mathrm{O}$ titânio passa por transformação alotrópica a $882^{\circ} \mathrm{C}$. Abaixo desta temperatura, ele exibe estrutura cristalina hexagonal compacta $(\mathrm{HC})$, conhecida como fase $\alpha$, enquanto que a temperaturas maiores que $882^{\circ} \mathrm{C}$ sua estrutura é cúbica de corpo centrado (CCC), denominada de fase $\beta$ (BALAZIC et al., 2007). Através desta variação cristalográfica obtidas principalmente pela adição de elementos ligantes e processamentos térmicos, podese produzir uma gama de ligas que atendem a diversas aplicações (ZHECHEVA et al., 2005).

As alterações na composição e os diferentes processamentos termomecânicos são as técnicas que mais afetam o comportamento mecânico das ligas de titânio. A adição de elementos ligantes resulta em reforço por formação de solução sólida, ou até formação de uma segunda fase, aumentando assim, a resistência mecânica do titânio (BALAZIC et al., 2007). Para que as fases $\alpha$ e $\beta$ possam coexistir no campo do diagrama de fases devem ser adicionados elementos estabilizadores das fases $\alpha$ e $\beta$. A manipulação microestrutural das 
ligas de titânio através de tratamentos térmicos baseia-se na nucleação e crescimento da fase $\alpha$ a partir de $\beta$, ao se resfriar o material (NASTAC et al., 2006; REIS, 2005).

O titânio e suas ligas não estão entre os materiais mais baratos do mercado. Por exemplo, o processamento de cerca de $30 \mathrm{~m}^{3}$ de titânio custa 5 vezes mais do que o processamento do alumínio e sua transformação em produtos acabados cerca de 10 vezes mais. Contudo, suas características mecânicas e físico-químicas justificam sua utilização ao invés de outros materiais menos onerosos, pois se espera que estas propriedades garantam à estrutura maior tempo de vida (CHUNXIANG et al., 2011; LEYENS; PETERS, 2003; POLMEAR, 2005).

Como já mencionado, o setor aeroespacial é o que requer maior quantidade de titânio, tanto para a fabricação de aviões comerciais como para a fabricação de aviões de guerra. No EUA, em alguns aviões de combate, a quantidade de titânio em seu peso total chega a 10\%. E, ainda, o desenvolvimento de alguns aviões comerciais como Boeing 777, 787 e Airbus 380 vão, sozinhos, necessitar de pelo menos 50\% da demanda total de titânio para todos os outros tipos de aviões comerciais. Titânio e suas ligas são muito utilizados também na fabricação de peças de turbinas, compressores, ventiladores de motor, além de fuselagem e cozinha dos aviões. A liga Ti-6Al-4V forjada é utilizada, principalmente na sustentação de motor, ripas das asas e em componentes do trem de pouso. O objetivo da aplicação destas ligas é diminuir o peso dos equipamentos, melhorar a resistência à corrosão e evitar propagação de trincas (CHUNXIANG et al., 2011; POLMEAR, 2005).

No setor biomédico titânio e suas ligas são utilizados devido ao seu baixo módulo, alta biocompatibilidade e resistência à corrosão superior quando comparados às ligas convencionais de cobalto e aço inoxidável. Sua aplicação mais comum é na produção de articulações artificiais do quadril e joelho além de próteses dentárias. Com o objetivo de se proporcionar melhor osteointegração, estas peças geralmente são tratadas superficialmente com algum material bioinerte, o mais comum deles é a hidroxiapatita. Outras aplicações do titânio neste setor são na produção de válvulas cardíacas, marcapassos, aparelhos de circulação, além de pinos, placas e implantes maxilofacial (LIU et al., 2004).

$\mathrm{Na}$ indústria automobilística o titânio é usado em peças onde as vantagens tecnológicas são excepcionais. Por exemplo, em bielas, válvulas, molas e rotores no motor; e em sistemas de exaustão e suspensão na carcaça. O melhor desempenho do motor e à redução de peso da carcaça permitem menor consumo de combustível e menos emissão de gás carbônico e outros poluentes. A Toyota no Japão utilizou Ti-6Al-4V para as válvulas de entrada e IMI 834 (Ti-5,8Al-4,0Sn-3,5Zr-0,7Nb-0,5Mo-0,35Si-0,06C) para as de 
exaustão, 40 e $16 \%$ mais leves que suas correspondentes de aço, respectivamente. $\mathrm{O}$ resultado gerou um motor que trabalha em regimes de temperaturas maiores, capaz de gerar 700 rpm com redução de ruído em 30\% (POLMEAR, 2005).

Titânio também é muito atrativo em aplicações em ambientes marítimos como plataformas de petróleo e gás. A Rússia é um líder em desenvolvimento de ligas de titânio para tais aplicações e desenvolveu ligas do tipo $\alpha$ e near- $\alpha$ para esta aplicação particular. $\mathrm{O}$ titânio é aplicado na produção de peças como trocadores de calor, brocas de perfuração, oleodutos, válvulas de fundição e fixadores (POLMEAR, 2005). Em 1992, no Japão, Ti6Al-4V foi aplicado em válvulas de pressão de um veículo não tripulado denominado “KAIKO" devido a sua boa resistência a corrosão, atingindo $10.000 \mathrm{~m}$ de profundidade (YAMADA, 1996).

A boa resistência do titânio na presença de cloretos faz desta liga uma alternativa para o setor industrial químico. Com um desempenho melhor do que dos aços inoxidáveis e das ligas de cobre, ligas de titânio são aplicadas em peças como tubulação, válvulas, carcaças de bombas, trocadores de calor e condensadores a vapor, tudo para aplicação em ambientes de salmoura quente, agentes clareadores e clorados (POLMEAR, 2005).

Ao mesmo tempo titânio e suas ligas encontram dificuldades em campos da engenharia mecânica que exigem boas propriedades tribológicas como, resistência à abrasão, ao desgaste e baixo coeficiente de fricção (ZHECHEVA et al., 2005). Outro problema é a reatividade química do titânio que é dependente da temperatura. A ação do metal com outras substâncias ocorre mais prontamente em temperaturas elevadas. Este comportamento pode ser melhorado por aplicação de revestimentos e tratamentos termoquímicos superficiais (REIS, 2005; ZHECHEVA et al., 2005).

2.2. MODIFICAÇÃO NO COMPORTAMENTO MECÂNICO DO TITÂNIO E DE SUAS LIGAS SUBMETIDOS A DIVERSOS TRATAMENTOS SUPERFICIAIS

A aplicação de revestimentos em titânio e em ligas de titânio já é uma alternativa bastante estudada e desenvolvida. De fato, existem vários estudos sobre a influência da aplicação de revestimentos nas propriedades mecânicas de diversos materiais. Estes estudos observam o comportamento dos diversos metais e ligas em condições de fadiga, desgaste, fluência, corrosão, entre outros. A grande maioria dos trabalhos tem como 
objetivo encontrar a condição ótima de tratamento superficial (espessura, porosidade, rugosidade, tempo de tratamento, natureza do revestimento, entre outros) a fim de se obter uma sobrevida maior possível. A seguir estão comentados alguns destes trabalhos.

Os diversos tipos de deposição podem modificar as características microestruturais de um mesmo revestimento. Este foi o estudo feito por Fortuna e colaboradores (2000) que fizeram a deposição de TiN via PVD, CVD e por pulverização catódica a plasma (uma variação do PVD conhecida como PMD). Foi observado que a morfologia dos grãos, bem como seu tamanho e tensão interna residual, são diferentes para cada uma das técnicas avaliadas. A técnica PMD demonstrou-se superior no que diz respeito à maior compactação e nenhuma delaminação. Os revestimentos formados por CVD apresentaram menor tensão residual interna. A Figura 3 propõe um esquema microestrutural dos revestimentos depositados por estas diferentes técnicas (FORTUNA et al., 2000).

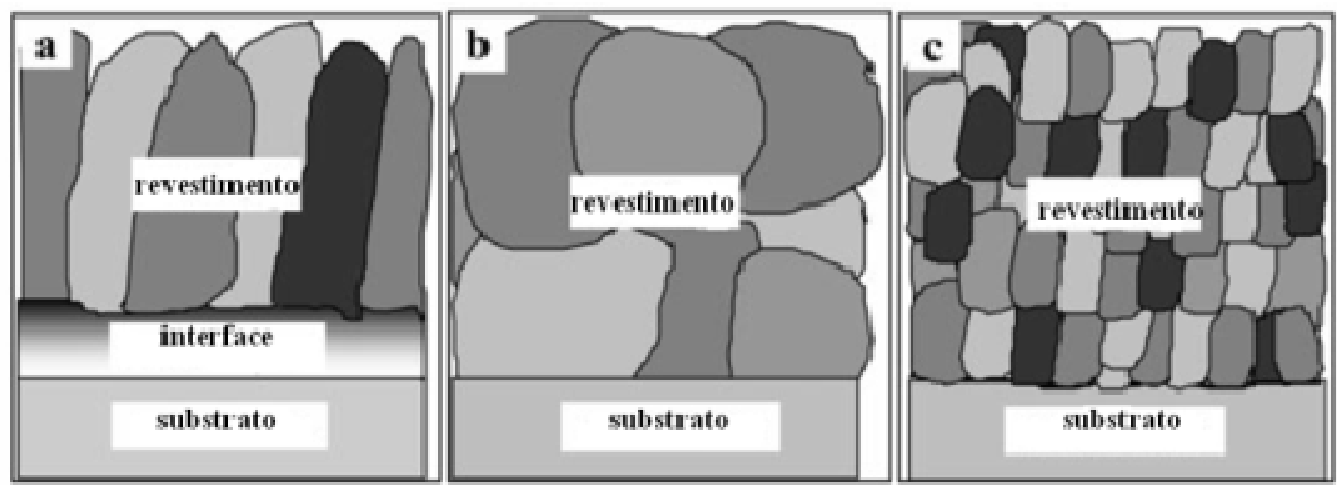

Figura 3. Imagem esquemática da microestrutura granular do revestimento: a) PVD; b) CVD e c) PMD (FORTUNA, et al., 2000).

Outro aspecto que pode influenciar na formação de recobrimentos é o ângulo de incidência do fluxo de íons sobre o substrato. Shetty e colaboradores (2011) estudaram as diferenças na microestrutura de revestimentos formados via pulverização catódica com descarga elétrica pulsada, nos ângulos normal $\left(\alpha=0^{\circ}\right)$ e oblíquo $\left(\alpha=45^{\circ}\right)$. Observaram que a microestrutura do revestimento depositado com ângulos oblíquos apresentava buracos em sua extensão. Consequentemente, a dureza e o módulo de Young para este revestimento diminuíram devido à presença das microcavidades e do efeito de sombreamento. Contudo, na medida em que a temperatura aumentava a inclinação das colunas da microestrutura diminuía, mostrando que em temperaturas mais altas o ângulo de incidência não é determinante para a microestrutura (SHETTY et al., 2011).

Os autores Mo e Zhu (2009) fizeram um estudo das propriedades tribológicas de alguns revestimentos cerâmicos: $\mathrm{CrN}, \mathrm{AlCrN}$ e $\mathrm{AlTiN}$, formados pela técnica de deposição 
iônica multiarco e aplicados como revestimentos de ferramentas e máquinas. Através de testes de desgaste (ball-on-disc) e estudos triboquímicos, os autores investigaram o comportamento da oxidação tribológica e sua influência nas propriedades de desgaste. Concluíram que, com relação às propriedades de desgaste, a dureza do revestimento não tem tanta influência sobre o comportamento de oxidação tribológica. De fato, o revestimento que apresentou maior dureza, $\mathrm{AlCrN}$, demonstrou pior resistência ao desgaste quando comparado ao revestimento à base de CrN (MO; ZHU; 2009). Devia et al. (2011) também fizeram um estudo que, dentre outras propriedades, observaram o comportamento tribológico dos revestimentos TiN, TiC e do compósito TiN/TiC. Concluíram que, devido à sinergia observada entre $\mathrm{TiN}$ e $\mathrm{TiC}$, o compósito demonstrou melhor aderência ao substrato e maior resistência ao desgaste (DEVIA et al., 2011).

Costa e colaboradores (2011) fizeram um estudo do comportamento de fadiga da liga Ti6Al4V recoberta pelos revestimentos $\mathrm{TiN}, \mathrm{CrN}$, depositados por arco catódico e DLC (WC:H), depositado por pulverização. Os autores concluíram que, neste caso, os revestimentos tendem a piorar o comportamento da liga Ti6Al4V em fadiga. $\mathrm{O}$ revestimento DLC, foi o que apresentou menor volume de defeitos, devido ao método de deposição, e por isso apresentou o melhor comportamento sob carregamento cíclico (COSTA et al., 2011).

Man et al. (2004) analisaram a resistência à oxidação e a penetração de hidrogênio em revestimentos à base de TiN e TiAlN, e concluíram que a presença do alumínio aumenta a resistência desses revestimentos à oxidação e à penetração de hidrogênio, principalmente em altas temperaturas (> $600{ }^{\circ} \mathrm{C}$ ) (MAN et al., 2004). Miau Du e colaboradores (2011), em um estudo parecido, observaram que o aumento da quantidade de alumínio na composição de filmes à base TiAlN diminui a rugosidade superficial e aumenta a estabilidade térmica do revestimento (MIAU DU et al., 2011). A durabilidade de qualquer revestimento depende de sua composição e forma de aplicação. Os revestimentos que apresentam alumínio em sua composição apresentam uma capacidade de restaurar a camada protetora que eventualmente lasca por ser muito espessa em altas temperaturas. A aplicação de revestimentos protetores sobre as ligas de titânio é essencial para melhorar seu tempo de vida (GURRAPPA, 2003). Contudo, estudos feitos por Aihua e colaboradores (2012) indicaram que revestimentos com grandes quantidades de $\mathrm{Al}$, como AlTiN e CrAlN, não apresentam propriedades de fricção e desgaste melhores, pois a alta quantidade de alumínio torna o revestimento reativo causando desgaste por adesão do resíduo (AIHUA et al., 2012). 
Ceschini e colaboradores (2008) estudaram as propriedades de desgaste e fricção de revestimentos depositados por oxidação eletrolítica a plasma sobre Ti-6Al-4V e os compararam com revestimentos à base de $\mathrm{TiN},(\mathrm{Ti}, \mathrm{Al}) \mathrm{N}$ e $\mathrm{CrN} / \mathrm{NbN}$ também depositados sobre Ti-6Al-4V. Os autores encontraram que o revestimento à base de TiN depositado por PVD apresentou o melhor desempenho tribológico até cargas de $20 \mathrm{~N}$ no tribômetro (CESCHINI et al., 2008). Adicionalmente, Yoon et al. (2002) testaram revestimentos à base de TiN e TiAlN depositados por galvanização iônica a arco em condições de impacto (ball-on-plate) e desgaste em câmara de umidade controlada (ball-on-disc). Os resultados mostraram que o revestimento à base de TiAlN demonstrou maior resistência ao impacto e falhou por fratura frágil. O revestimento à base de TiN apresentou maior resistência ao desgaste abrasivo e menor coeficiente de fricção. O coeficiente de fricção do TiAlN aumentou durante o desgaste devido a reações triboquímicas, resultantes da umidade relativa da câmara. TiN falhou por deformação plástica devido a processos de oxidação durante o teste de impacto (YOON et al., 2002).

Serro e colaboradores (2009) também estudaram as propriedades de alguns revestimentos, para aplicação no campo biomédico. Os revestimentos estudados foram TiN, TiNbN e TiCN, depositados pela técnica de evaporação a arco. Os estudos analisaram principalmente as propriedades superficiais e a citotoxicidade dos revestimentos. Como resultados encontraram que os três revestimentos demonstraram topografia (rugosidade) e molhabilidade similares. Apesar de TiN ser mais hidrofílico, as propriedades de fricção e desgaste dos três revestimentos se mostraram dependentes do tipo de lubrificante utilizado (solução de proteínas). Os três revestimentos foram capazes de adsorver albumina, mas a captação em massa para TiN foi um pouco maior. Todos os revestimentos não apresentaram citotoxicidade e podem ser usados como biomateriais (SERRO et al., 2009).

Como pode se observar através dos trabalhos mencionados, existem muitos estudos que utilizam os revestimentos TiN e TiAlN, mas nenhum trabalho ainda que analise suas propriedades de fluência, corrosão e oxidação isotérmica quando aplicados à liga Ti6Al4V. Neste sentido, este trabalho visa contribuir com os resultados já existentes em outras áreas a fim de que se tenha um entendimento completo do comportamento da liga Ti6Al4V e se possa aperfeiçoar o seu desempenho o máximo possível. 


\subsection{CORROSÃO}

Entende-se por corrosão a deterioração de um material, geralmente metálico, por meio de ação química ou eletroquímica do meio ambiente. As transformações resultantes do processo de corrosão são indesejáveis, pois causam alteração estrutural e química, além de interferir na durabilidade e desempenho dos materiais metálicos (GENTIL 2003).

Para que a corrosão aconteça é essencial a formação de uma célula de corrosão onde a energia química é convertida em energia elétrica. Essa tendência à corrosão é medida através da variação de energia livre de Gibbs $(\Delta \mathrm{G})$ e, geralmente, quanto mais negativa, maior a possibilidade da reação (corrosão) acontecer (REVIE; UHLIG, 2008).

Um processo eletroquímico corrosivo se estabelece quando um metal (condutor eletrônico) está em contato com um eletrólito (condutor iônico). O processo corrosivo ocorre devido à diferença de potenciais eletroquímicos entre o sistema metálico e o sistema oxidante relacionado com a solução. Ocorre uma pilha anodo/catodo onde o anodo está relacionado com o processo de oxidação e o catodo com o processo de redução. Há transferência de elétrons na interface metal/solução entre o metal e o oxidante da solução (AHMAD, 2006; GENTIL, 2003; REVIE; UHLIG, 2008).

De forma geral, a corrosão acontece na área anódica, o eletrodo perde massa devido à liberação de íons metálicos para solução, hidratação ou por formação de íons complexos, e a solução em torno dele atinge um estado de valência mais elevado. Os elétrons desprendidos pela reação anódica são consumidos no catodo pelas espécies oxidantes (AHMAD, 2006; GENTIL, 2003).

O estudo do fenômeno da corrosão em metais é complexo, pois envolve muitos ramos da ciência pura e aplicada (física, química, metalurgia física, biotecnologia, etc.). Qualquer observação feita em casos de corrosão deve envolver as interações entre características estruturais do metal (composição, estrutura atômica, heterogeneidades, etc.), natureza do ambiente (natureza química, concentração das espécies reagentes, pressão, velocidade, temperatura, etc.) e reações que ocorrem na interface metal/meio corrosivo (cinética de oxidação e dissolução metálica, cinética de redução das espécies em solução, etc.) (SHREIR; JARMAN; BURSTEIN, 1994). 


\subsubsection{POLARIZAÇÃO ANÓDICA}

Observações experimentais mostraram que muitos metais não sofrem corrosão em um determinado meio, resistindo à corrosão ou corroendo a taxas muito baixas, mesmo quando apresentam $\Delta \mathrm{G}<0$. É o caso do ferro em $\mathrm{HNO}_{3}$, quando colocado em $\mathrm{HNO}_{3}$ diluído sofre processo de corrosão, mas quando colocado em $\mathrm{HNO}_{3}$ concentrado não é atacado, diz-se nesse caso que o metal está em seu estado passivo. A passividade é uma característica fundamental para o controle de corrosão de muitos metais estruturais como, alumínio, níquel e aço inoxidável e pode ser explicada por algumas teorias. A primeira delas diz que a passivação é o resultado de polarização anódica em altas densidades de corrente. Outra considerada é que um metal é considerado passivo quando resiste à corrosão em um dado meio mesmo tendo uma tendência termodinamicamente forte a reagir (GENTIL, 2003; REVIE; UHLIG, 2008).

A passivação aumenta a resistência à corrosão formando uma película fina sobre a superfície. Essa película pode ser facilmente destruída, mas, em alguns casos, pode ser formada novamente mesmo se fraturada. Portanto, as curvas de polarização anódica (Figura 4) são muito importantes para o melhor entendimento do comportamento de passivação dos metais. Os parâmetros mais importantes são (AHMAD, 2006; GENTIL, 2003):

- Corrente crítica $\left(\mathrm{i}_{\text {crít }}\right)$ - corrente que precisa ser atingida durante a polarização para passivar o metal, ou corrente na qual a maior taxa de corrosão é atingida, quanto menor, mais fácil do metal tornar-se passivo;

- Potencial de passivação $\left(\mathrm{E}_{\mathrm{p}}\right)$ - potencial correspondente à corrente crítica, representa $\mathrm{o}$ potencial de transição do metal de um estado ativo para um estado passivo. Com o inicio da passivação, a densidade de corrente começa a cair por causa da formação de um filme óxido na superfície do metal;

- Corrente de passivação $\left(\mathrm{i}_{\text {pass }}\right.$ ) - corrente mínima necessária para manter o metal em seu estado passivo, neste ponto há dissolução metálica a uma taxa constante e o filme óxido torna-se mais espesso;

- Potencial transpassivo ( $\mathrm{E}_{\text {transpassivo }}$ - potencial no qual se observa aumento brusco da corrente que pode ser devido à oxidação da água, à dissolução anódica do filme passivador 
ou à quebra do filme passivo, resultando em aumento da taxa de corrosão e corrosão localizada (por pite) (GENTIL, 2003; REVIE; UHLIG, 2008).

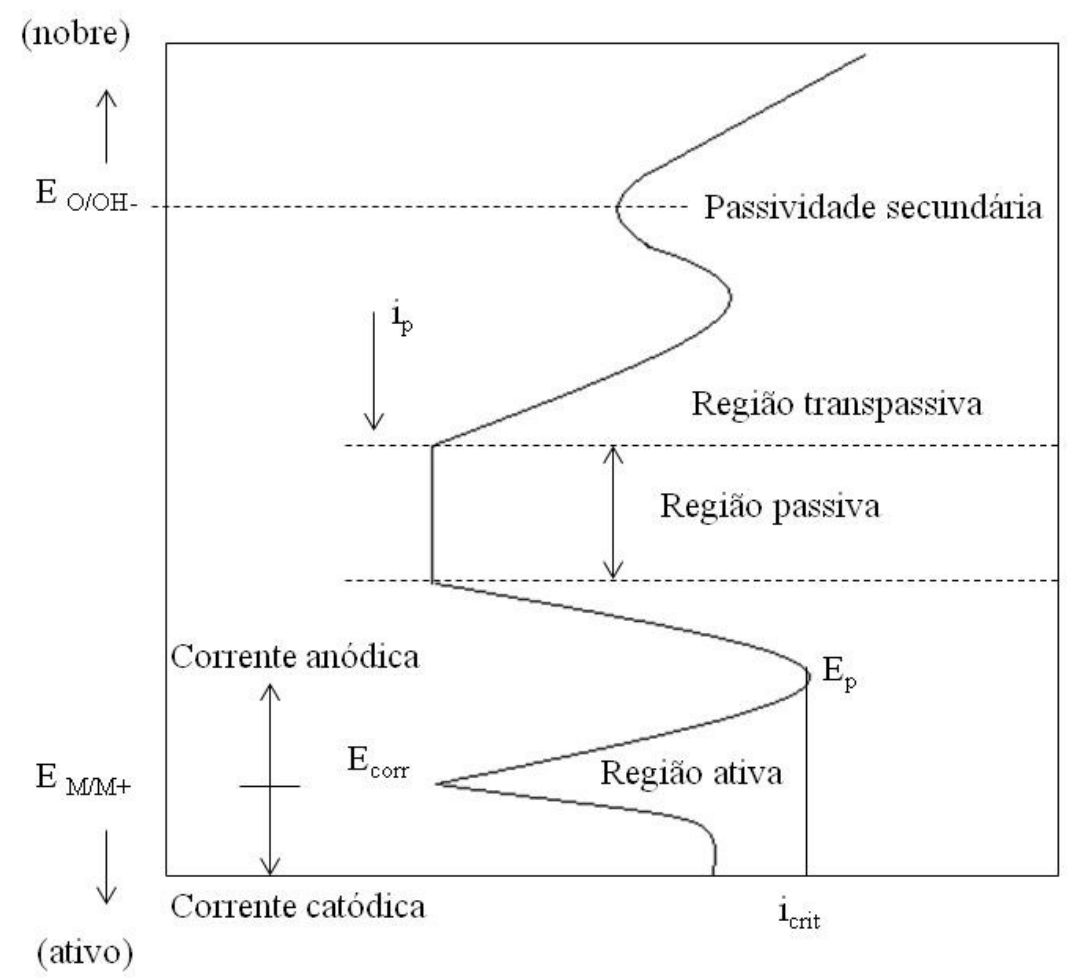

Figura 4. Diagrama de polarização para um metal ativo-passivo (AHMAD, 2006).

\subsubsection{IMPEDÂNCIA ELETROQUÍMICA}

Em espectroscopia de impedância química mede-se o impedimento de um fluxo de íons através da solução e do eletrodo de trabalho. Essa medida é feita através de uma perturbação senoidal no potencial e é lida em termos de corrente defasada em um ângulo de fase característico $\phi$. As equações que correspondem à perturbação no potencial e à resposta em corrente estão representadas nas Equações 1 e 2, respectivamente (LIU et al., 2003; MOISEL et al., 2008).

$E=E_{0} \sin \omega t$

$I=I_{0} \sin \omega t+\phi$ 
onde $\mathrm{E}$ é a voltagem oscilante, $\mathrm{E}_{0}$ a amplitude da voltagem oscilante, I a corrente oscilante, $\mathrm{I}_{0}$ a amplitude da corrente oscilante, $\omega$ a frequência angular da perturbação e $\phi$ o ângulo de fase (MOISEL et al., 2008).

O espectro de impedância pode refletir o comportamento dielétrico, as reações de oxidação-redução e a transferência de massa na interface eletroquímica (IE). As propriedades elétricas e químicas da solução corrosiva e do material do eletrodo estão relacionadas com o comportamento de uma IE específica. O ajuste das medidas de impedância é feito através de circuitos elétricos equivalentes que descrevem uma IE. Sendo assim, a impedância teórica de um circuito elétrico proposto pode ser derivada como uma função de multivariáveis. Em uma IE, a resposta capacitiva costuma ser a de um capacitor não ideal. Este comportamento é considerado nos cálculos de um circuito elétrico pela substituição da capacitância pura por um elemento em fase constante (CPE), segundo a Equação 3 (LIU et al., 2003; MOISEL et al., 2008, RUDENJA et al., 1999).

$Z_{C P E}=\left[Y_{0}(j \omega)^{n}\right]^{-1}$

onde $\mathrm{Z}$ é a impedância e $\mathrm{Y}_{0}\left[\mathrm{~F} \cdot \mathrm{cm}^{-2}\right]$ e $\mathrm{n}(\mathrm{n} \leq 1)$ são parâmetros ajustáveis. Se a superfície agir como um capacitor ideal, $n$ será igual a um $(n=1)$ e $Y_{0}$ será idêntico à capacitância $C$ (RUDENJA et al., 1999). Y 0 é dado em Faraday, pois representa um valor de capacitância (não ideal) (GRIPS et al., 2006; LIU et al., 1995; TRIBOLLET; ORAZEM, 2008).

\subsection{OXIDAÇÃO}

Quando um metal é exposto a uma atmosfera contendo oxigênio, enxofre, halogênios, vapor d'água, ele pode sofrer corrosão mesmo na ausência de um líquido eletrólito. Este processo é conhecido como oxidação e leva, principalmente, à formação de uma camada óxida fina ou espessa sobre o substrato metálico (GENTIL, 2003; REVIE; UHLIG, 2008).

O crescimento da película óxida está vinculado com a capacidade de transporte através da mesma, quanto mais rápido for o processo de transporte de íons e elétrons, maior será a espessura da camada óxida. As três principais equações que expressam a relação entre a espessura da camada óxida formada sobre o metal e o tempo são do tipo 
linear, parabólica e logarítmica. Estes comportamentos estão descritos nas Equações 4, 5, e 6 para os crescimentos do tipo linear, parabólico e logarítmico, respectivamente (GENTIL, 2003; REVIE; UHLIG, 2008).

$y=k_{o x} t+$ const

$y^{2}=2 k_{o x} t+$ const

$y=k_{o x} \ln \left(\frac{t}{\text { const }}+1\right)$

Para a equação linear (observada em filmes descontínuos devido a porosidades ou trincas), a taxa de oxidação é constante. Pode ser observado em alguns metais e em determinadas temperaturas, por exemplo, W acima de $1000{ }^{\circ} \mathrm{C}, \mathrm{Fe}$ acima de $900{ }^{\circ} \mathrm{C}$ e $\mathrm{Ti}$ entre 650-950 ${ }^{\circ} \mathrm{C}$. No caso da equação parabólica (regra geral para metais a altas temperaturas que desenvolvem filmes compactos e espessos) a velocidade de oxidação é inversamente proporcional à espessura do recobrimento. Exemplos de metais que seguem esse comportamento em temperaturas elevadas: $\mathrm{Fe}, \mathrm{Cu}, \mathrm{Ni}, \mathrm{Cr}$ e $\mathrm{Co}$. Quando o produto de corrosão metálica é um filme fino protetor e a corrosão ocorre em temperatura baixa (ambiente), diz-se que o metal sofreu oxidação comandada por um comportamento logarítmico. A formação deste filme fino segundo o comportamento logarítmico ocorre na oxidação inicial de metais como $\mathrm{Cu}, \mathrm{Fe}, \mathrm{Zn}, \mathrm{Ni}$, Al e Ti (GENTIL, 2003; REVIE; UHLIG, 2008).

\subsection{O FENÔMENO DA FLUÊNCIA}

A fluência dos materiais é classicamente associada com a plasticidade dependente do tempo, sob uma carga ou tensão fixada em uma dada temperatura. O fenômeno sob estas condições é descrito na Figura 5 para a condição de tensão constante (KASSNER; HAYES, 2003). 


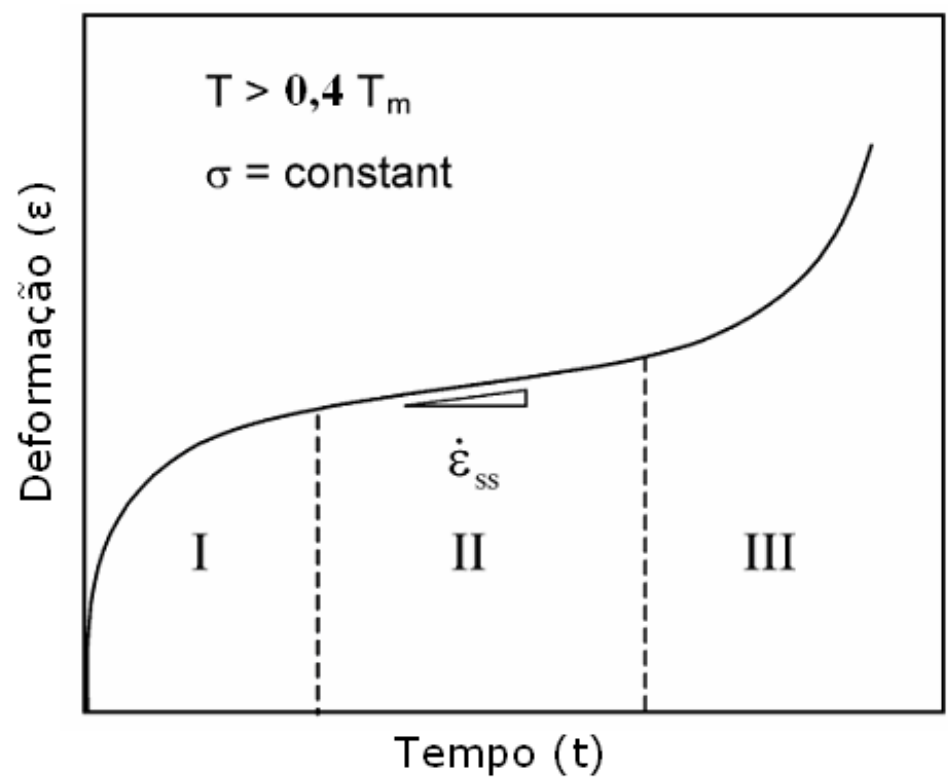

Figura 5. Curva de fluência para tensão constante apresentando as regiões primária, secundária e terciária (EVANS; WILSHIRE, 1993; LANGDON, 2002; KASSNER; HAYES, 2003).

Sob carga trativa uniaxial, a deformação em uma barra aumenta com o tempo até a falha finalmente ocorrer. Baseada numa resposta parecida de muitos materiais, como descrito na Figura 5, a curva de fluência é dividida em três regiões. Depois de uma deformação instantânea inicial, denominada $\varepsilon_{0}$, o material geralmente sofre um período de resposta transiente. A taxa de deformação, de/d t diminui com o tempo até um valor estacionário que persiste por uma porção significativa da vida do material. Essas duas regiões são denominadas de estágio primário ou transiente e estágio secundário ou fluência estacionária. A falha final que ocorre com a ruptura do material ocorre logo depois que a taxa de fluência começa a aumentar no estágio terciário da fluência (FU, 1980).

O estágio I pode ser considerado como um regime de fluência onde dois fenômenos acontecem: encruamento e recuperação. O encruamento, predominante neste estágio, é resultado do movimento e interação de discordâncias. A restrição ao movimento das discordâncias faz com que as tensões internas do material aumentem e com que a taxa de deformação por fluência diminua (ES-SOUNI, 2000; 2001). Esse estágio é, portanto, caracterizado por processos de geração e redistribuição de discordâncias no cristal. Com o aumento da densidade de discordâncias, a estrutura começa a se organizar em subgrãos e a fração livre de discordâncias neste volume diminui por aniquilação (recuperação) (ORLOVÁ; CADEK, 1986). 
$\mathrm{O}$ estágio primário pode ser associado ao parâmetro $\mathrm{t}_{\mathrm{p}}$, o qual é definido como o tempo correspondente ao início da região secundária. Este parâmetro, fundamental na caracterização da fluência primária, pode ser descrito como função da tensão aplicada $(\sigma)$ e da temperatura absoluta (T) pela Equação 7 (HAYES, 1996).

$$
t_{p}=A \sigma^{-m} \exp \left(\frac{Q_{p}}{R T}\right)
$$

onde $\mathrm{R}$ é a constante dos gases, $\mathrm{Q}_{\mathrm{p}}$ corresponde à energia de ativação para a região primária e A e m são constantes que dependem da microestrutura, temperatura e da tensão inicialmente aplicada.

No estágio II, a taxa de deformação é constante porque dois processos concorrentes, encruamento e recuperação, atingem um equilíbrio. Esta taxa permanece constante independente do tempo ou da deformação por fluência. Fatores como densidade de discordâncias e a formação de células contribuem para manter a taxa constante. Este estágio, em termos de fluência, é controlado por difusão de lacunas, escalagem de discordâncias em cunha e dispersão de elementos ligantes no caso de ligas e soluções sólidas (BLUM; EINSENLOHR; BREUTINGER, 2002; CALLISTER, 2008; ES-SOUNI, 2001; EVANS; WILSHIRE, 1993; ORLOVÁ; CADEK, 1986; VALANIS; LEE, 1981; WEERTMAN, 1955).

Dentre as várias relações propostas na literatura, a de maior aplicabilidade prática relaciona a dependência da taxa de fluência estacionária com a tensão e a temperatura absoluta, sendo representada pela Equação 8 (EVANS; WILSHIRE, 1993).

$$
\dot{\mathcal{E}}_{s}=B \sigma^{n} \exp \left(-\frac{Q_{s}}{R T}\right)
$$

onde $\mathrm{Q}_{\mathrm{s}}$ corresponde à energia de ativação da região secundária e $\mathrm{B}$ e $\mathrm{n}$ são constantes que dependem da microestrutura, temperatura e da tensão inicialmente aplicada.

Ao atingir o estágio III, a taxa de deformação é acelerada de uma forma que o resultado é a ruptura do material. Os mecanismos responsáveis por esse comportamento são deslizamento dos contornos de grão, gerando a nucleação de vazios e cavidades nos contornos de grão e grande atividade de discordâncias. Para os corpos de prova ensaiados 
sob carga trativa surge, neste estágio, a estricção em algum ponto da região sob deformação. O número de cavidades e pequenas trincas é significativamente maior neste ponto, o que leva à diminuição da área transversal efetiva e ao aumento da taxa de deformação. Os tipos de fraturas, causados pela ruptura por fluência neste estágio, vão depender da temperatura, da tensão e da velocidade de fluência (CALLISTER, 2008; LAPIN; NAZMY, 2004; SOUZA, 1982; WILSHIRE; BATTENBOUGH, 2007).

Existe, hoje, um bom entendimento no que diz respeito ao comportamento de metais puros e ligas sob ação de fluência. Em uma ampla faixa de tensões, a taxa estacionária de fluência, $\dot{\varepsilon}_{s}$, varia com a tensão aplicada, $\sigma$, e pode ser relacionada com uma potência conhecida como expoente de tensão, $n$. O expoente de tensão normalmente está na faixa de 3-6. Esta relação perde seu valor em altas tensões onde $n$ aumenta continuamente com o aumento da tensão e, em baixas tensões, existe uma transição para uma região onde $n \approx 1$ (EVANS; WILSHIRE, 1993; LANGDON, 2000).

Vale lembrar que os diversos mecanismos de deformação por fluência dependem da temperatura e da tensão aplicada (MEYERS; CHAWLA, 1982). Em uma região de baixa tensão, $\sigma / \mathrm{G} \leq 10^{-4}$, três tipos de mecanismos de fluência podem ocorrer. Estes mecanismos são chamados de fluência por difusão e pode ser subdividida em Nabarro-Herring, Coble, fluência Harper-Dorn e fluência por escorregamento de contornos de grão. Em faixas de tensões mais altas, $\sigma / \mathrm{G}>10^{-2}$, a fluência ocorre por deslizamento e escalagem de discordâncias (LANGDON, 2000; MEYERS; CHAWLA, 1982).

Na Tabela 3 estão listados os valores experimentais dos parâmetros $n$, $p$ (parâmetro relacionado com o tamanho de grão) e $D$ (coeficiente de difusão) associados aos mecanismos de fluência (LANGDON, 2000; REED-HILL, 1964).

Tabela 3 - Valores de n, p e D associados aos diferentes mecanismos de fluência (LANGDON, 2000; WILSHIRE; WHITTAKER, 2009).

\begin{tabular}{lccc}
\hline \multicolumn{1}{c}{ Mecanismo } & $\boldsymbol{n}$ & $\boldsymbol{p}$ & $\mathbf{D}$ \\
\hline Fluência por difusão Nabarro-Herring & 1 & 2 & $\mathrm{D}_{1}$ (coef. de autodifusão na rede) \\
Fluência por difusão Coble & 1 & 3 & $\mathrm{D}_{\mathrm{gb}}$ (coef. de difusão nos contornos de grão) \\
Fluência por Harper-Dorn & 1 & 0 & $\mathrm{D}_{1}$ \\
Deslizamento do contorno de grão & 3 & 1 & $\mathrm{D}_{1}$ \\
& 2 & 2 & $\mathrm{D}_{\mathrm{gb}}$ \\
Escalagem e deslizamento de discordâncias & $n$ & 0 & $\mathrm{D}_{1}$ \\
\hline
\end{tabular}


2.6. COMPORTAMENTO DO TITÂNIO E SUAS LIGAS COM E SEM APLICAÇÃO DE REVESTIMENTOS SUBMETIDOS À CORROSÃO
ELETROQUIMICA E OXIDAÇÃO ISOTÉRMICA.

O titânio é 1,2 V mais ativo que o ferro, pode se oxidar liberando íons $\mathrm{Ti}^{+3}$, é capaz de se passivar em soluções aquosas aeradas alcalinas e ácidas. O filme protetor que se forma sobre sua superfície, à base de $\mathrm{TiO}_{2}$, apresenta características semicondutoras tipo- $\mathrm{n}$ relacionadas a lacunas do ânion oxigênio $\mathrm{O}^{2-}$ e intersticiais de $\mathrm{Ti}^{+3}$. $\mathrm{O}$ potencial de Flade é relativamente ativo $\left(\mathrm{E}_{\mathrm{F}}^{\circ}=-0,05 \mathrm{~V} / \mathrm{ENH}\right)$ o que faz do titânio estável quando passivado. A Figura 6 mostra o comportamento do potencial do titânio com a variação do pH (Diagrama de Pourbaix) (POURBAIX, 1974).

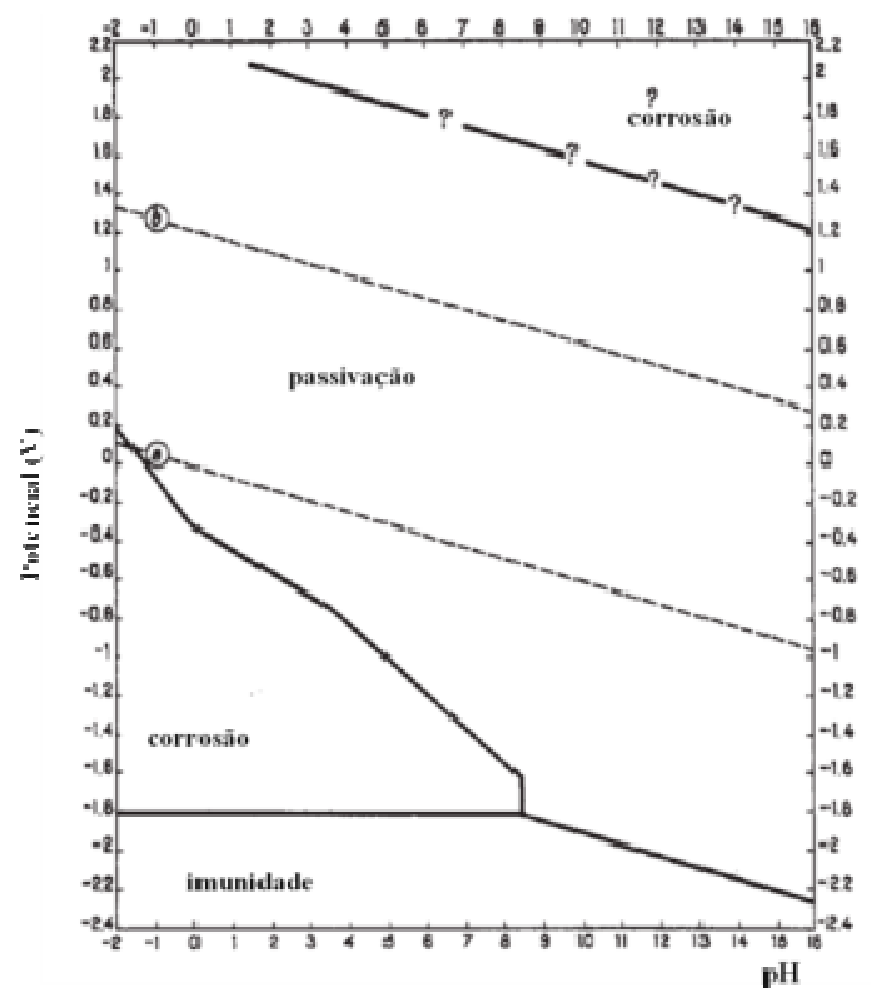

Figura 6. Diagrama E versus pH do titânio, a $25^{\circ} \mathrm{C}$, assumindo passivação por TiO2 (POURBAIX, 1974).

A utilização de revestimentos em ligas de titânio atrai uma atenção considerável por agirem como barreiras para a difusão de elementos metálicos. A liberação de produtos de corrosão de ligas metálicas em um ambiente biológico, por exemplo, pode causar toxicidade, alergia e mutagenicidade (SUBRAMANIAN; ANANTHAKUMAR; JAYACHANDRAN, 2010). A maioria dos metais de transição forma nitretos binários ou ternários com boas propriedades mecânicas, tribológicas, anticorrosivas e 
biocompatibilidade. Nos últimos anos nitretos metálicos como TiN, ZrN, TiAlN, NbN, TaN e VN foram usados como camadas protetoras contra desgaste e corrosão com a finalidade de aumentar o tempo de vida de próteses e implantes (SUBRAMANIAN et al., 2011). Os revestimentos à base de $\mathrm{TiN}$ e $(\mathrm{Ti}, \mathrm{Al}) \mathrm{N}$ podem também ser utilizados em lâminas de motor de compressor aeronáutico submetidas a temperaturas entre 300 e 500 ${ }^{\circ} \mathrm{C}$. Essas lâminas que trabalham ou permanecem em ambiente marinho podem sofrer com problemas de corrosão induzida por cloretos. Os cloretos podem induzir ou à aceleração da corrosão em altas temperaturas quando são depositados na superfície de materiais metálicos ou à corrosão aquosa a temperatura ambiente quando um filme fino aquoso contendo cloreto se forma sobre a superfície. Nesses casos, a resistência à corrosão eletroquímica dos revestimentos é um fator muito importante (LI; QU; WANG, 2003).

Com relação aos estudos de corrosão, Souza e Robin (2007) testaram titânio em uma solução de $\mathrm{H}_{2} \mathrm{SO}_{4}$, preparada nas concentrações 20, 40, 60 e $80 \%$ p $\mathrm{H}_{2} \mathrm{SO}_{4}$ e mantidas nas temperaturas 25,50 e $75{ }^{\circ} \mathrm{C}$. Concluíram que para todas as temperaturas, a menor resistência à corrosão foi observada na solução $80 \%$ de $\mathrm{H}_{2} \mathrm{SO}_{4}$, e a resistência geralmente tendeu a aumentar com a diminuição da concentração de $\mathrm{H}_{2} \mathrm{SO}_{4}$. Já a maior resistência à corrosão foi observada em $25{ }^{\circ} \mathrm{C}$ que diminuiu com o aumento da temperatura (SOUZA; ROBIN, 2007).

$\mathrm{Lu}$ (2009) estudou o comportamento do titânio puro exposto ao $\mathrm{H}_{3} \mathrm{PO}_{4}$, nas concentrações de $0,1 \mathrm{~mol} / 1$ e $1 \mathrm{~mol} / 1$, a $250{ }^{\circ} \mathrm{C}$, por $24 \mathrm{~h}$, observou que a $0,1 \mathrm{~mol} / 1$ houve corrosão moderada, $0,01 \mathrm{mg} / \mathrm{cm}^{2} . h$, enquanto que a $1 \mathrm{~mol} / 1$ a corrosão foi muito severa, 0,1 $\mathrm{mg} / \mathrm{cm}^{2} . \mathrm{h}$ (LU, 2009).

Atapour e coautores (2011) avaliaram o comportamento à corrosão das ligas Ti6Al-4V e Ti-8Al-1Mo-1V, nas soluções $\mathrm{NaCl} 3,5 \%$ e $\mathrm{HCl} 5 \%$. Ambas as ligas apresentaram passividade espontânea na solução de $\mathrm{NaCl}$ e transição ativo-passiva na solução de HCl. Segundo os testes de perda de massa, a liga Ti-6Al-4V apresentou maior resistência à corrosão quando comparada a liga Ti-8Al-1Mo-1V. Para as duas ligas a perda de massa variou linearmente com o tempo, indicando uma taxa de corrosão constante. A taxa de corrosão da liga Ti-8Al-1Mo-1V foi cerca de duas vezes maior do que da liga Ti6Al-4V depois de 10 dias de teste. Sabe-se que a presença do molibdênio aumenta a resistência do titânio à corrosão, mas pequenas quantidades só servem para aumentar a área superficial do grão aumentando a suscetibilidade da liga à corrosão. No mais as interfaces $\alpha / \beta$ podem atuar como um par galvânico, devido à diferença de composição das duas fases. A maior quantidade de $\mathrm{Al}$ na fase $\alpha$ e a presença de dois elementos estabilizadores de fase 
$\beta$ (Mo e V) aumentaram a interação galvânica entre as duas fases tornando a liga Ti-8Al$1 \mathrm{Mo}-1 \mathrm{~V}$ menos resistente à corrosão nas interfaces $\alpha / \beta$ (ATAPOUR et al., 2011a).

Martin e colaboradores (2010) estudaram o efeito da microestrutura e orientação cristalográfica no comportamento à corrosão, tribocorrosão e desgaste do Ti-6Al-4V em uma solução de $\mathrm{NaCl}(1 \%)$. A liga Ti-6Al-4V foi utilizada nas formas de grãos grosseiros, lamelar e bimodal. A microestrutura que apresentou melhor resistência à corrosão foi a bimodal. A resistência à corrosão diminuiu quando os planos basais foram preferencialmente alinhados paralelos à superfície onde ocorreu corrosão, porque o óxido formado sobre o plano prismático tem maior resistência à transferência de carga do que o formado sobre os planos basais (MARTIN et al., 2010).

Krishnan e colaboradores desenvolveram dois revestimentos à base de TiAlN e WC/C, ambos produzidos pela técnica de PVD. O substrato utilizado foi uma liga $\beta$ titânio para aplicação em fios ortodônticos, submetida à corrosão por fluoretos. O revestimento à base de TiAlN demonstrou-se mais estável e resistente à corrosão em meio fluoreto (KRISHNAN et al., 2011). Subramanian e coautores (2011) também fizeram um teste comparativo entre os revestimentos à base de TiN, TiAlN e TiON, preparados via pulverização catódica reativa (DC magnetron sputtering) sobre titânio puro. Concluíram que o revestimento TiAlN apresentou resistência à corrosão superior quando comparado a TiN e TiON e ao substrato que não recebeu nenhum tratamento (SUBRAMANIAN et al., 2011). Segundo Chung et al. (2004), os bons resultados divulgados acima para o uso de revestimentos à base de nitretos metálicos são devido a mecanismos de redução da corrente anódica na região passiva e aumento positivo do potencial de corrosão (CHUNG et al., 2004).

Na Tabela 4 segue os principais parâmetros de corrosão obtidos por autores que trabalharam com diversas ligas e metais com e sem revestimentos protetores contra corrosão. 
Tabela 4 - Parâmetros de corrosão obtidos de vários autores para diversas ligas e metais com e sem revestimento: potencial de corrosão $\left(\mathrm{E}_{\text {corr }}\right)$, densidade de corrente de corrosão $\left(\mathrm{i}_{\text {corr }}\right)$ e resistência à transferência de carga $\left(\mathrm{R}_{\mathrm{p}}\right)$.

\begin{tabular}{|c|c|c|c|c|c|}
\hline Material & $\begin{array}{l}\text { Meio de } \\
\text { corrosão }\end{array}$ & $\begin{array}{c}\mathbf{E}_{\text {corr }} \\
(\mathrm{V} / \mathrm{ESC})\end{array}$ & $\begin{array}{c}\mathbf{i}_{\text {corr }} \\
\left(\mathbf{m A} / \mathbf{c m}^{2}\right)\end{array}$ & $\begin{array}{c}\mathbf{R}_{\mathbf{p}} \\
\left(\Omega . \mathbf{c m}^{2}\right)\end{array}$ & Referências \\
\hline Ti6Al4V & Ringer & -0.433 & $6.7 \times 10^{-4}$ & 10200 & KUMAR et al., 2010 \\
\hline Ti cp & Fusayama & -0.205 & $8.13 \times 10^{-4}$ & 1114 & SUBRAMANIAN et al., 2011 \\
\hline Ti6Al4V & $3.5 \% \mathrm{NaCl}$ & -0.403 & $0.05 \times 10^{-12}$ & - & ATAPOUR et al., 2011a \\
\hline $\mathrm{TiN}^{*}$ & Fusayama & -0.198 & $1.34 \times 10^{-4}$ & 2722 & SUBRAMANIAN et al., 2011 \\
\hline $\mathrm{TiN}^{* *}$ & $\mathrm{H}_{2} \mathrm{SO}_{4}+\mathrm{NaCl}$ & -0.280 & $4.9 \times 10^{-9}$ & 7680 & YILBAS et al., 1995 \\
\hline TiAlN* & Fusayama & -0.128 & $0.28 \times 10^{-4}$ & 20244 & SUBRAMANIAN et al., 2011 \\
\hline$\gamma$-TiAl & $3.5 \% \mathrm{NaCl}$ & $-0.428 \times 10^{-3}$ & $1.94 \times 10^{-9}$ & $2.47 \times 10^{6}$ & $\begin{array}{l}\text { DELGADO-ALVARADO; } \\
\text { SUNDARAM, } 2007\end{array}$ \\
\hline
\end{tabular}

* utilizado como revestimento de titânio puro

** utilizado como revestimento da Ti-6Al-4V

*** utilizado como revestimento de uma liga base níquel

Pode-se observar nos resultados reportados na Tabela 4 que a utilização de revestimentos melhora a resistência à corrosão diminuindo a velocidade de corrosão $\left(i_{\text {corr }}\right)$, aumentando a estabilidade do material no meio corrosivo $\left(\mathrm{E}_{\mathrm{corr}}\right)$ e a resistência à transferência de carga (impedância $-\mathrm{R}_{\mathrm{p}}$ )

A liga Ti-6Al-4V é muito indicada para fabricação de peças estruturais, porém apresenta baixa resistência à oxidação, principalmente em altas temperaturas. Por causa da difusão do oxigênio na superfície, que também é um $\alpha$ estabilizador, fragiliza-se e falha quando em serviço. A espessura da camada óxida que se forma na superfície aumenta com o tempo de exposição em altas temperaturas e a formação do rutilo $\mathrm{TiO}_{2}$, que não é resistente a altas temperaturas, ocorre com maior facilidade do que a formação da alumina $\mathrm{Al}_{2} \mathrm{O}_{3}$. Por esse motivo $\mathrm{Yu}$ e colaboradores (2007) fizeram testes de oxidação ao ar, nas temperaturas de 700 e $800{ }^{\circ} \mathrm{C}$ e mediram o ganho de massa em intervalos regulares de tempo. Encontraram que a camada óxida formada sobre a liga começou a lascar a $700{ }^{\circ} \mathrm{C}$ depois de 20 h. Com a sua descamação o substrato ficou em contato direto com o ar e a taxa de corrosão aumentou a partir desse momento. A camada óxida formada a $800{ }^{\circ} \mathrm{C}$ esfarelou durante os resfriamentos, o ganho de massa nesse caso foi considerado enorme $\left(12 \mathrm{mg} / \mathrm{cm}^{2} \mathrm{em} 20 \mathrm{~h}\right)$. A camada de rutilo não foi considerada protetora nessas condições (YU et al., 2007a).

Gurrappa (2003) buscou compreender as características de oxidação da liga Ti5,8Al-4,06Sn-3,61Zr-0,7Nb-0,54Mo através de testes de oxidação isotérmica, conduzidos ao ar nas temperaturas de 600,700 e $800{ }^{\circ} \mathrm{C}$ por um período de $100 \mathrm{~h}$. O autor notou que o 
ganho de massa das amostras testadas (associada à taxa de crescimento dos óxidos formados sobre a superfície) aumentou com o aumento da temperatura de teste, sendo medidas constantes de crescimento parabólico de $\mathrm{K}_{\mathrm{p}}=3,2 \times 10^{-2}\left[\mathrm{mg} / \mathrm{cm}^{2} \mathrm{~h}\right]$ para $800{ }^{\circ} \mathrm{C}$ e $\mathrm{K}_{\mathrm{p}}=3,1 \times 10^{-4}\left[\mathrm{mg} / \mathrm{cm}^{2} . \mathrm{h}\right]$ para $600{ }^{\circ} \mathrm{C}$. Sobre todas as amostras foi detectado formação de $\mathrm{TiO}_{2}$ seguido de $\mathrm{Al}_{2} \mathrm{O}_{3}$. Em altas temperaturas a formação de $\mathrm{Al}_{2} \mathrm{O}_{3}$ não é uniforme enquanto que o composto $\mathrm{TiO}_{2}$ perde suas características protetoras contra a oxidação. Depois de atingir uma determinada espessura a camada óxida começou a lascar na temperatura de $800^{\circ} \mathrm{C}$. O autor concluiu que o maior ganho de massa na temperatura de $800{ }^{\circ} \mathrm{C}$ não está apenas relacionado com a formação da camada óxida, mas também com a quantidade de oxigênio dissolvido e com o fácil desprendimento da camada óxida que se forma sobre a superfície. Desta forma, a superfície metálica é constantemente exposta ao agente oxidante $\left(\mathrm{O}_{2}\right)$, permitindo que a formação de fase $\alpha$ atinja profundidades ainda maiores e que as propriedades mecânicas das ligas de titânio sejam modificadas (GURRAPPA, 2003).

A necessidade do barateamento de voos pelas companhias aéreas, que cada vez mais sofrem concorrência e a exigência de meios de transporte menos poluentes e barulhentos, exigiram um melhoramento de equipamentos aeroespaciais no que diz respeito ao bom funcionamento, maior eficiência e segurança. De todas as ligas leves presentes no mercado, as ligas de titânio são as mais adequadas para o setor aeroespacial sendo, portanto, muito utilizada na fabricação de rotores e lâminas de disco de estatores que trabalham em altas temperaturas. Portanto, Leyens e colaboradores (1997) estudaram a influência da oxidação nas propriedades mecânicas da liga TIMETAL 1100 (Ti-6Al-2.5Sn4Zr-0.4Mo-0.45Si) submetida a um processo de revestimento com um filme fino à base de Ti-Al. Os autores concluíram que a liga foi protegida contra oxidação devido aos revestimentos utilizados. Como a penetração do oxigênio foi prevenida a fragilização da superfície via transformação $\beta \rightarrow \alpha$ foi evitada e a ductilidade do substrato medida a temperatura ambiente foi mantida mesmo quando exposto a uma temperatura de $600{ }^{\circ} \mathrm{C}$ (LEYENS; PETERS; KAYSSER, 1997).

Huang e Duh (1996) estudaram o comportamento dos revestimentos TiN e TiAlN submetidos à oxidação, a $600{ }^{\circ} \mathrm{C}$, em atmosfera $20 \% \mathrm{O}_{2}-80 \% \mathrm{~N}_{2}$, por $6 \mathrm{~h}$. O revestimento TiN foi oxidado a $600{ }^{\circ} \mathrm{C}$ e rompeu durante o aquecimento. De fato, este composto tende a oxidar em temperaturas acima de $500{ }^{\circ} \mathrm{C}$ resultando na formação de uma camada frágil e pouco aderente de $\mathrm{TiO}_{2}$. A transformação de $\mathrm{TiN}$ em $\mathrm{TiO}_{2}$ está associada a uma expansão térmica muito grande e por isso o revestimento descama da superfície. Para os 
revestimentos TiAlN, não houve observação de descamação ou trincas, apenas pequenas quantidades de óxidos de titânio, como $\mathrm{TiO}_{2}$ e $\mathrm{Ti}_{2} \mathrm{O}_{3}$, sobre a superfície. A maior resistência à corrosão com relação a TiN foi atribuída à presença do $\mathrm{Al}$, e na medida em que a quantidade de $\mathrm{Al}$ aumenta na composição do filme menos se observa a presença de óxidos na superfície (HUANG; DUH, 1996). Posteriormente, Man e colaboradores (2004) estudaram as propriedades do ternário TiAlN e as compararam com o nitreto TiN, ambos depositados sobre aço inox pela técnica de pulverização (sputtering). Os autores observaram desprendimento da camada TiN devido à formação de $\mathrm{TiO}_{2}$ acima de $500{ }^{\circ} \mathrm{C} \mathrm{e}$ o melhor desempenho do revestimento à base de TiAlN que não apresentou nenhuma evidência de $\mathrm{TiO}_{2}$ (detectável por DRX) apenas $\mathrm{Al}_{2} \mathrm{O}_{3}$ (MAN et al., 2004).

\subsection{DESEMPENHO DAS LIGAS DE TITÂNIO SUBMETIDAS À FLUÊNCIA}

O titânio e suas ligas são muito aplicados nos setores aeronáuticos e automobilísticos, entretanto sua alta reatividade química superficial pode resultar em perda de propriedades mecânicas e diminuição de vida útil (PARK et al., 2006). A sensibilidade à deformação e à oxidação das ligas de titânio quando expostas a altas temperaturas é um fenômeno bem conhecido. O oxigênio, por exemplo, é estabilizador da fase $\alpha$. A formação desta fase pura na superfície é caracterizada por alta resistência e baixa ductilidade. Em pequenas quantidades este elemento contribui com o desempenho das ligas de titânio submetidas a altas temperaturas, mas a longa exposição destas ligas ao oxigênio aumenta a dureza e a fragilidade. Os mecanismos principais de fragilização por oxigênio são redução da quantidade relativa de fase $\beta$ e formação de solução sólida intersticial de oxigênio com a fase $\alpha$. O titânio também possui afinidade com o hidrogênio, sendo capaz de absorvê-lo nos interstícios de sua rede cristalina e/ou formar o hidreto TiH. O hidrogênio pode ser absorvido do vapor d'água, ácidos, óleos e hidrocarbonetos, basicamente em altas temperaturas e em concentrações que pode variar de 20 a 750 ppm, dependendo da liga. Acima de 20 ppm $(0.1 \%$ at. H), o hidrogênio fragiliza as ligas de titânio, reduzindo a resistência ao impacto e causando fratura sem deformação plástica (DONACHIE, 1988).

Reis (2005) estudou as propriedades em fluência da liga Ti-6Al-4V em ar e em atmosfera de nitrogênio com e sem recobrimento. As condições de tensão e temperatura foram $500{ }^{\circ} \mathrm{C}$ de 312 a $520 \mathrm{MPa} ; 600{ }^{\circ} \mathrm{C}$ de 125 a $319 \mathrm{MPa}$ e $700{ }^{\circ} \mathrm{C}$ de 14 a $56 \mathrm{MPa}$. Foi 
verificado que a resistência à fluência do Ti-6Al-4V aumenta quando o teste é conduzido em atmosferas de nitrogênio, devido à formação de nitretos na superfície. As análises fractográficas revelaram que o mecanismo de fratura foi por formação e coalescência de microcavidades. O expoente de tensão, $n$, variou de 2,23 a 11,73 e ao ser relacionado com os valores da energia de ativação permitiu concluir que o mecanismo de deformação por fluência é controlado por escalagem de discordâncias (REIS, 2005). Similarmente, Barboza et. al. (2006), investigou o comportamento de fluência para a liga Ti-6Al-4V com a morfologia de Widmanstätten. Os valores encontrados para o expoente de tensão foram 4,4 a $500{ }^{\circ} \mathrm{C}$ e 4,1 a $600{ }^{\circ} \mathrm{C}$ e o mecanismo de deformação por fluência foi controlado por escalagem de discordâncias. Foi observado, também, que a taxa de deformação por fluência desta liga é menor quando comparada com as taxas de compósitos à base de titânio. Este comportamento foi atribuído à interface $\alpha / \beta$ que age como obstáculo ao movimento das discordâncias e ao tamanho do grão que reduz o escorregamento dos contornos de grão, as fontes de discordâncias e a difusão de oxigênio ao longo dos grãos (BARBOZA et al., 2006).

Boehlert e Chen (2009) avaliaram os mecanismos de deformação para uma liga Ti6Al-4V modificada pela adição de boro. Os experimentos foram conduzidos ao ar, sob tensão constante e as ligas utilizadas foram Ti-6Al-4V, Ti-6Al-4V-0.1B e Ti-6Al-4V-1B. Para a liga Ti-6Al-4V-1B, o valor do expoente de tensão foi de 8,7 e a energia de ativação foi de $275 \mathrm{~kJ} / \mathrm{mol}$ nas condições de $450 \mathrm{MPa}$ a $400{ }^{\circ} \mathrm{C}$. A liga Ti-6Al-4V-0.1B apresentou expoente de tensão igual a 14,5 e energia de ativação de $377 \mathrm{~kJ} / \mathrm{mol}$ para as mesmas condições de tensão e temperatura. O mecanismo de fratura foi associado à formação e coalescência de microcavidades e à formação de trincas na interface das fases $\alpha / \beta$ e no interior das mesmas. O composto formado pela adição do boro, TiB (whisker), apresentou trincas perpendiculares à direção da carga aplicada e pouca ou nenhuma deformação plástica. O mecanismo de fluência dominante para todas as condições e ligas examinadas foi a escalagem de discordâncias ativado pela autodifusão na rede cristalina (BOEHLERT; CHEN, 2009).

Gollapudi e colaboradores (2008) analisaram o comportamento de fluência para a liga Ti-3Al-2,5V, na faixa de temperatura de 450 a $600{ }^{\circ} \mathrm{C}$, em um equipamento ligado a um sistema fechado de pressurização interna. Identificaram a presença de três regimes. Os valores dos expoentes de tensão para cada um dos regimes foram 1, 2 e 5 respectivamente. Os valores da energia de ativação foram $\mathrm{Q}_{\mathrm{I}}=\mathrm{Q}_{\mathrm{II}}=232 \mathrm{~kJ} / \mathrm{mol}$ e $\mathrm{Q}_{\mathrm{III}}=325 \mathrm{~kJ} / \mathrm{mol}$. Os mecanismos de deformação por fluência em cada região foram escalagem de discordâncias 
ao longo das bandas de escorregamento para o regime I, sob baixas tensões. Para o regime II, escorregamento de contornos de grãos sob tensões intermediárias. Por fim, o regime III apresentou dois comportamentos distintos: escalagem de discordâncias com posterior formação de subgrãos sob altas tensões e, movimento de jogs através de discordâncias em hélice em regime de baixa tensão (GOLLAPUDI et al., 2008).

Es-souni (2001) submeteu três ligas near $\alpha$ à fluência nas condições de tensão variando entre $100-550 \mathrm{MPa}$. E temperatura variando na faixa de 500 a $600{ }^{\circ} \mathrm{C}$. O expoente de tensão ficou na faixa entre 4,5 a 5,2. A energia de ativação encontrada foi maior do que a energia de ativação para autodifusão em ligas $\alpha$, variando de 345 a 304 kJ/mol. Estes valores são devido à presença de elementos de liga que impedem a autodifusão do Ti e, portanto, aumenta os valores de energia de ativação. O mecanismo de deformação por fluência foi controlado por escalagem de discordâncias (ES-SOUNI, 2001).

Boehlert e Miracle (1999) estudaram as ligas Ti-Al-Nb. Os testes de fluência foram conduzidos ao ar, entre 650 e $760{ }^{\circ} \mathrm{C}$ na faixa de 15 a $450 \mathrm{MPa}$. Características da fluência de Coble, incluindo expoente de tensão próximo de 1 e baixa energia de ativação, foram observadas sob os menores níveis de tensão. Em níveis de tensões intermediárias observou-se escorregamento de contornos de grão e acomodação por formação de cavidades nos contornos. Deslizamento de discordâncias, incluindo expoentes de tensão maior ou igual a 3,5, energia de ativação relativamente alta e elevada densidade de discordâncias caracterizaram o regime conduzido sob altas tensões (BOEHLERT; MIRACLE, 1999).

Lapin nos anos de 2004 e 2006 estudou as ligas Ti-45,2Al-2W-0,6Si-0,7B (at. \%) e Ti-46Al-2W-0,5Si (at.\%) respectivamente. Os testes de fluência foram conduzidos nas temperaturas 700,750 e $800{ }^{\circ} \mathrm{C}$, sob uma tensão variando de 200 a $390 \mathrm{MPa}$. No primeiro caso (2004), o expoente de tensão ficou próximo de 5 e a energia de ativação calculada foi $355 \mathrm{~kJ} / \mathrm{mol}$. O mecanismo de deformação por fluência foi controlado por escalagem de discordâncias. No segundo caso (2006) o expoente de tensão foi 7,3 e a energia de ativação determinada foi de $405 \mathrm{~kJ} / \mathrm{mol}$. O mecanismo de deformação por fluência foi controlado por escorregamento não-conservativo de jogs ao longo do comprimento das discordâncias em hélice (LAPIN, 2004, 2006).

Li e colaboradores (2011) estudaram o comportamento da liga Ti6Al4V, laminada a quente e, tratada a 940,980 e $1000{ }^{\circ} \mathrm{C}$, as condições de fluência escolhidas foram $575 \mathrm{MPa}$ a 400 e $420{ }^{\circ} \mathrm{C}$. A taxa de fluência estacionária e o tempo de vida em fluência medidos, para cada liga, nos testes conduzidos a $420{ }^{\circ} \mathrm{C}$ foram de $2.3 \times 10^{-7} / \mathrm{s}$ e $81 \mathrm{~h}$ para a liga tratada 
a $940{ }^{\circ} \mathrm{C} ; 1.33 \times 10^{-7} / \mathrm{s}$ e $151,5 \mathrm{~h}$ para liga tratada a $980{ }^{\circ} \mathrm{C}$ e $8.89 \times 10^{-8} / \mathrm{s}$ e $180 \mathrm{~h}$ para a liga tratada a $1000{ }^{\circ} \mathrm{C}$. Na condição de $400{ }^{\circ} \mathrm{C}$, a taxa de fluência estacionária diminuiu e o tempo de vida aumentou, indicando uma sensibilidade da liga a temperatura quando submetida à fluência. Foi calculada também a energia de ativação para as condições de tratamento $940{ }^{\circ} \mathrm{C}$ e $1000{ }^{\circ} \mathrm{C}$, os valores obtidos foram $185 \mathrm{~kJ} / \mathrm{mol}$ e $249,8 \mathrm{~kJ} / \mathrm{mol}$, respectivamente (LI, et al., 2011). 


\section{MATERIAIS E MÉTODOS}

\subsection{LIGA TI-6AL-4V}

Para a realização deste trabalho foi utilizada a liga Ti-6Al-4V na condição recozida, adquirida com recursos FAPESP (proc. 2011/00511-0) junto a Empresa Realum Indústria e Comércio de Metais Puros e Ligas Ltda. na forma de barras com 12,7 mm de diâmetro e 1 m de comprimento.

A composição química (\% peso) fornecida pelo Certificado de Qualidade da Realum Indústria e Comércio de Metais Puros e Ligas Ltda é apresentada na Tabela 5.

Tabela 5 - Composição química da liga Ti-6Al-4V.

\begin{tabular}{cc}
\hline Elemento químico & Teor \% \\
\hline $\mathrm{Al}$ & 5,980 \\
$\mathrm{C}$ & 0,005 \\
$\mathrm{Fe}$ & 0,200 \\
$\mathrm{H}$ & 0,001 \\
$\mathrm{~N}$ & 0,005 \\
$\mathrm{O}_{2}$ & 0,100 \\
$\mathrm{~V}$ & 4,070 \\
$\mathrm{Ti}$ & Balanço \\
\hline
\end{tabular}

\subsection{CARACTERIZAÇÃO METALOGRÁFICA}

A preparação de todas as amostras seguiram os padrões usuais de metalografia, envolvendo embutimento a quente, seguido de lixamento manual com lixas à base de SiC, na sequência de granas 200, 600, 800 e 1200 \#. O polimento foi feito com uma suspensão de sílica coloidal (OP-S). $\mathrm{O}$ ataque foi realizado à base de $\mathrm{HF}, 1 \%, \mathrm{HNO}_{3}, 4 \%$, e água (ataque Kroll).

O conjunto de amostras destinado às análises via microscópio eletrônico de transmissão foi cortado na Isomet-1000 Buehler entre 1-2 mm de espessura e lixado com lixas à base de $\mathrm{SiC}$ na sequência de 350 a 600 \#. Posteriormente, o conjunto de amostras foi cortado por estampagem em um diâmetro de $3 \mathrm{~mm}$, polido com uma suspensão de $\mathrm{Al}_{2} \mathrm{O}_{3}$ e levado ao dimpler para obtenção de uma calota centralizada. Por último, polido 
ionicamente através do PIPS (Precision Ion Polish System). A preparação das amostras para análises por transmissão foi feita no Laboratório de Microscopia Eletrônica do LNLS, Campinas.

\subsection{TRATAMENTO TÉRMICO}

O material como recebido foi tratado termicamente para fins de obtenção da estrutura Widmansttäten. As etapas do tratamento térmico foram as seguintes: as amostras foram encapsuladas em argônio para aquecimento até $1050{ }^{\circ} \mathrm{C}$ por 30 minutos, resfriamento com rampa de descida de $6{ }^{\circ} \mathrm{C} / \mathrm{min}$. até $700{ }^{\circ} \mathrm{C}$; estas amostras foram mantidas a $700{ }^{\circ} \mathrm{C}$ por 1 hora seguido de resfriamento ao ar. $\mathrm{O}$ forno utilizado foi da marca Lindberg/Blue M, com temperatura máxima na faixa de $1700{ }^{\circ} \mathrm{C}$.

A fim de se determinar a influência da temperatura de trabalho dos tratamentos superficiais na microestrutura da liga Ti-6Al-4V, o material de estrutura Widmansttäten foi tratado em duas rotas diferentes: no primeiro tratamento a amostra foi aquecida a $500{ }^{\circ} \mathrm{C}$ por 1 hora, resfriada ao ar, aquecida a $725^{\circ} \mathrm{C}$ por 6 horas e resfriada ao ar novamente (simulação do tratamento de nitretação a plasma); no segundo tratamento a amostra foi aquecida a $500{ }^{\circ} \mathrm{C}$ por 6 horas e resfriada ao ar (simulação do tratamento de PVD por plasma).

\subsection{DEPOSIÇÃO FÍSICA A VAPOR ASSISTIDA POR PLASMA}

Foram depositados revestimentos à base de TiN e TiAlN/TiAlCrN sobre um total de 24 corpos de prova submetidos à fluência, 36 corpos de prova submetidos à corrosão e 20 corpos de prova submetidos à oxidação. Os revestimentos foram depositados pela técnica de deposição física a vapor (PVD) por arco catódico assistida por plasma em um equipamento Vacotec (grupo Eifeler) na empresa Bodycote Brasimet Processamento Térmico S. A., situada em Jundiaí - SP. Na Tabela 6, as condições de tratamento estão resumidas. 
Tabela 6. Condições de deposição dos revestimentos TiN e TiAlN

\begin{tabular}{cc}
\hline Condições de Deposição & Valores \\
\hline Tensão de trabalho & $80-220 \mathrm{~V}$ \\
Pressão inicial na câmara & $5 \times 10^{-5} \mathrm{mbar}$ \\
Pressão de trabalho & $0,008-0,02 \mathrm{mbar}$ \\
Temperatura de trabalho & $450-480^{\circ} \mathrm{C}$ \\
Temperatura do alvo & $50{ }^{\circ} \mathrm{C}$ \\
Tempo de processo & $\sim 6 \mathrm{~h}$ \\
Composição dos alvos & $\mathrm{TiN}-\mathrm{Ti}(99,99 \%)$ \\
Atmosfera de trabalho & TiAlN $-\mathrm{AlTi}(67 / 33 \%$ em peso $), \mathrm{Cr}(99,8 \%)$ \\
\hline
\end{tabular}

A Figura 7 mostra os corpos de prova de corrosão, fluência e oxidação isotérmica depois do tratamento por PVD.

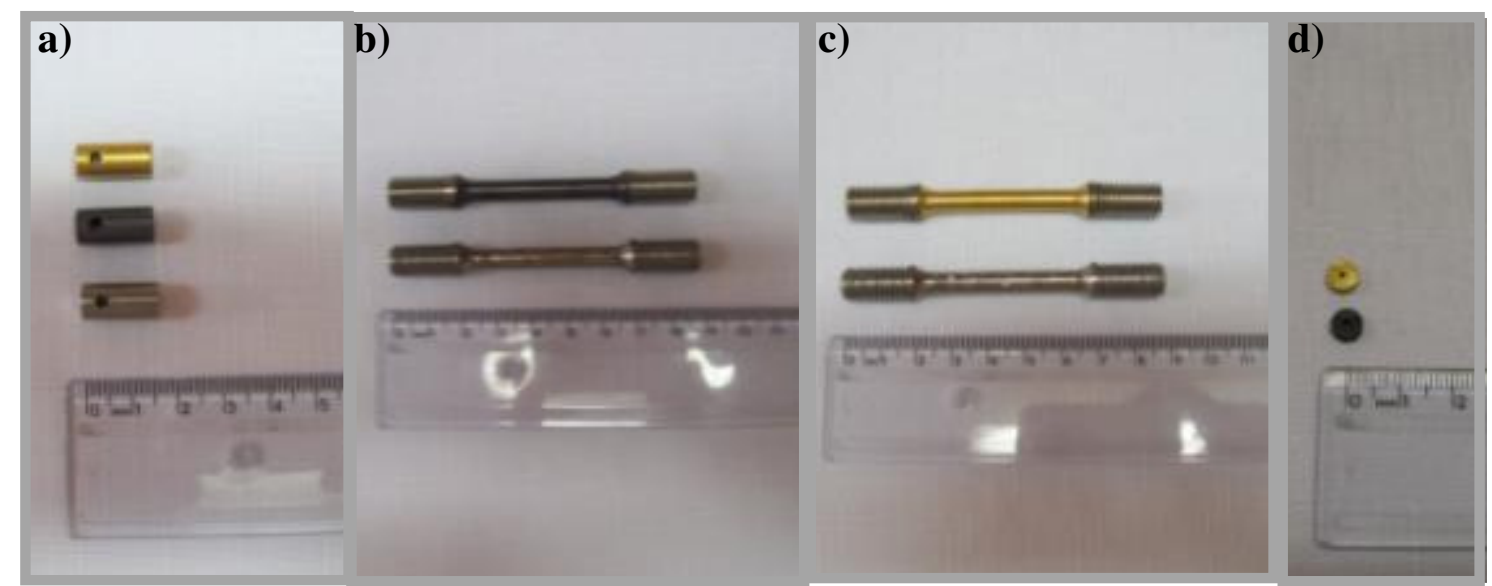

Figura 7. Ilustração dos corpos de prova de corrosão (a), fluência (b, c) e oxidação isotérmica (d) recobertos com recobrimentos à base de TiN (dourado) e TiAlN (grafite).

\subsection{CARACTERIZAÇÃO POR MICROSCOPIA ELETRÔNICA DE} VARREDURA E TRANSMISSÃO

Para a aquisição e captura das imagens foram utilizados um microscópio eletrônico de varredura, de bancada, da marca Hifachi, modelo TM 3000 (imagens das amostras e das camadas depositadas e EDS); e um da marca LEO, modelo 1450-VP (imagens de fratura), ambos instalados na Escola de Engenharia de Lorena - USP. As análises de transmissão foram feitas em duas etapas: na primeira parte do trabalho foi utilizado o microscópio eletrônico de transmissão da marca Jeol 100CX disponibilizado pela Universidade Federal de São Carlos (UFSCar); na segunda parte foi utilizado o microscópio eletrônico de 
transmissão da marca JEOL JEM 2100 LaB6 TEM em parceria com Laboratório Nacional de Nanotecnologia (LNNano - CNPEM).

\subsection{MEDIDAS DE DUREZA E NANODUREZA}

As medidas de microdureza Vickers foram realizadas ao longo da seção transversal como parte da caracterização mecânica da liga Ti-6Al-4V sem recobrimento. Para tanto, foi utilizado um microdurômetro de marca HMV microhardness tester de marca Shimadzu pertencente ao Departamento de Materiais da FEG/UNESP. A carga utilizada foi de 100 gf, por $30 \mathrm{~s}$.

As medidas de nanodureza e módulo elástico foram realizadas com a colaboração da Universitat Autonoma de Barcelona-Departament de Física. Para tanto, foi utilizado um Equipamento UMIS da Fischer-Cripps Laboratories equipado com ponta de diamante piramidal do tipo Berkovich. A carga utilizada para as medidas foi de $5 \mathrm{mN}$ por $30 \mathrm{~s}$.

\subsection{CARACTERIZAÇÃO POR DIFRATOMETRIA DE RAIOS X}

A liga Ti-6Al-4V sem revestimento e revestidas por PVD foram caracterizadas pela técnica de difratometria de raios $\mathrm{X}$ para a identificação das fases presentes na liga. Os experimentos foram realizados em um equipamento da marca Panalytical, modelo Empyrean, instalado na Escola de Engenharia de Lorena - USP. As condições de teste foram as seguintes: radiação Cuka com filtro de níquel, tensão $40 \mathrm{kV}$, corrente de $30 \mathrm{~mA}$,

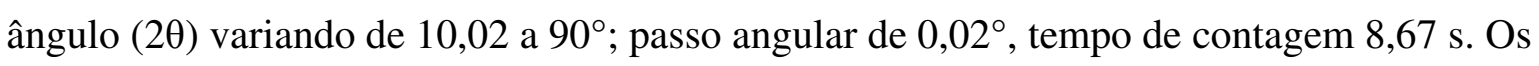
compostos formados foram identificados com o uso dos dados contidos nos registros JCPDS-ICDD (JCPDS - ICDD, 1988) e Villars-Calvert (VILLARS; CALVERT, 1991). As fases presentes nas amostras foram identificadas com o auxílio do programa PowderCell for Windows. 


\subsection{ENSAIOS DE CORROSÃO}

Amostras cilíndricas da liga Ti-6Al-4V de $8 \mathrm{~mm}$ de diâmetro e $17 \mathrm{~mm}$ de comprimento (Figura 8a) sem revestimento e revestidas por PVD foram embutidas a quente em um suporte de PTFE (teflon) deixando uma área exposta de aproximadamente $0,5 \mathrm{~cm}^{2}$ (Figura 8b). O contato elétrico foi feito através de uma haste de tântalo recoberta com cobre, posicionada verticalmente, passada através de um furo no suporte e rosqueada na amostra cilíndrica.

Os corpos de prova da liga sem revestimento foram lixados mecanicamente com lixas à base de SiC até \#1200. Depois de lixadas, as amostras foram lavadas com água destilada, secas e transferidas rapidamente para a solução corrosiva. Os corpos de prova da liga com revestimento foram usados como embutido.

a)

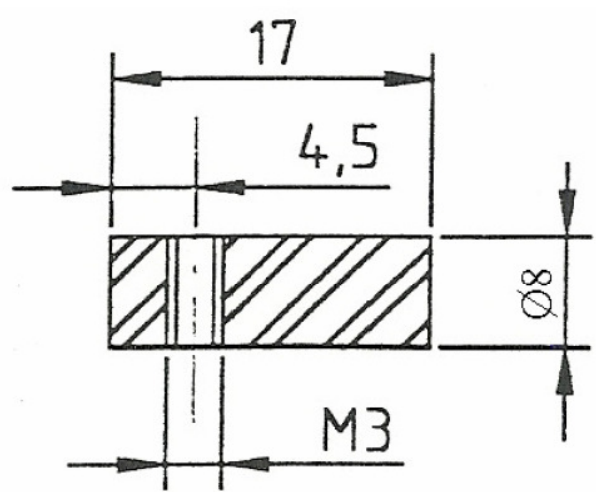

b)

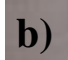

Figura 8. a) Representação esquemática de um corpo de prova, com seção reta circular, utilizado nos testes de corrosão (dimensão em mm); b) corpo de prova tratado por PVD embutido no suporte de teflon.

As soluções investigadas foram $\mathrm{NaCl} 3,5 \%$ p. e $\mathrm{HCl} 2 \mathrm{M}$; todas preparadas com reagentes P. A. e água destilada. As temperaturas das soluções foram mantidas a $25{ }^{\circ} \mathrm{C}, 60$ ${ }^{\circ} \mathrm{C}$, e $80{ }^{\circ} \mathrm{C}$, estas duas últimas fazendo uso de banho Maria com temperatura controlada (FISATOM mod. 550). Uma folha de platina (Pt), recortada na forma de um quadrado, de área igual a $18 \mathrm{~cm}^{2}$, serviu como o contra-eletrodo. Um eletrodo de calomelano saturado (ECS), $\mathrm{E}_{\mathrm{ECS}}=+0,242 \mathrm{~V} / \mathrm{ENH}$, foi usado como referência.

O estudo do comportamento eletroquímico, para todas as condições experimentais, foi feito pelas seguintes técnicas: medição do potencial em circuito aberto versus tempo; polarização potenciodinâmica com baixa velocidade de varredura do potencial $(1 \mathrm{mV} / \mathrm{s}) \mathrm{e}$ impedância eletroquímica no potencial de corrosão com amplitude do sinal de $10 \mathrm{mV}$ e freqüências de $0,1 \mathrm{~Hz}$ a $100 \mathrm{kHz}$. Os aparelhos utilizados foram a Interface Eletroquímica 
SOLARTRON mod. 1287 A e o Analisador de Resposta em Frequência SOLARTRON mod. 1260 A, controlados pelo programa Ecorr/Zplot SOLARTRON mod. 125587S. A aquisição e tratamento dos dados foram feitos pelo mesmo programa. Os dados eletroquímicos obtidos foram analisados em função do tratamento por PVD, da solução utilizada e da temperatura de trabalho.

\subsection{ENSAIOS DE FLUÊNCIA}

Os ensaios de fluência foram conduzidos sob condições de carga constante na faixa de tensões de 190 a $300 \mathrm{MPa}$ a $600^{\circ} \mathrm{C}$ para as condições recobertas por TiN e TiAlN/TiAlCrN. Os testes de fluência foram feitos no equipamento Instron Model M3 Creep and Stress Rupture Tester com capacidade de $30 \mathrm{kN}$ adquirido com recursos FAPESP (Projeto 07/54987-0).

Os corpos de prova para os testes de fluência, cuja configuração está apresentada na Figura 9, foram confeccionados na EEL-USP com base nas especificações da norma ASTM 139/95.
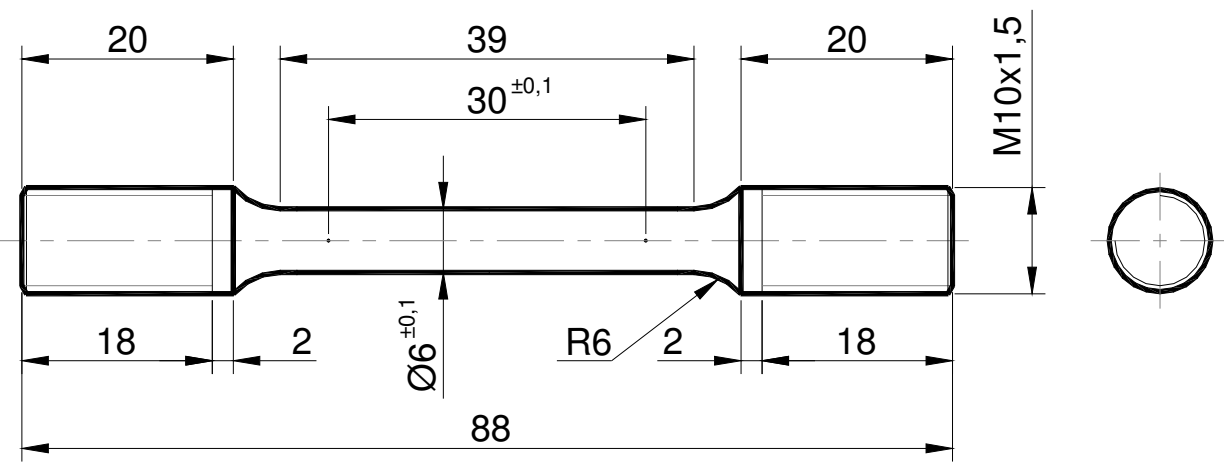

Figura 9. Representação esquemática de um corpo de prova, com seção reta circular, utilizado nos testes de fluência (dimensão em mm).

\subsection{ENSAIOS DE OXIDAÇÃO ISOTÉRMICA}

Um conjunto de amostras cilíndricas $(\mathrm{d}=6 \mathrm{~mm}, 1=2 \mathrm{~mm})$ da liga Ti-6Al-4V na condição sem revestimento e revestidas por PVD foram submetidas a testes de oxidação 
isotérmica ao ar na temperatura de $600{ }^{\circ} \mathrm{C}$ envolvendo períodos de tempo de 20 a $180 \mathrm{~h}$ de exposição. As amostras foram pesadas em uma balança eletrônica antes e após o processo de oxidação. Os óxidos formados sobre a superfície foram identificados por difratometria de raios $X$. 


\section{RESULTADOS E DISCUSSÃO}

\subsection{ANÁLISE MICROESTRUTURAL}

A Figura 10 mostra a microestrutura da liga Ti-6Al-4V como recebida, na condição recozida. Já a Figura 11 apresenta a microestrutura da amostra tratada termicamente com uma microestrutura do tipo Widmanstätten, cuja configuração é estável em altas temperaturas, situação esta essencial para este trabalho.
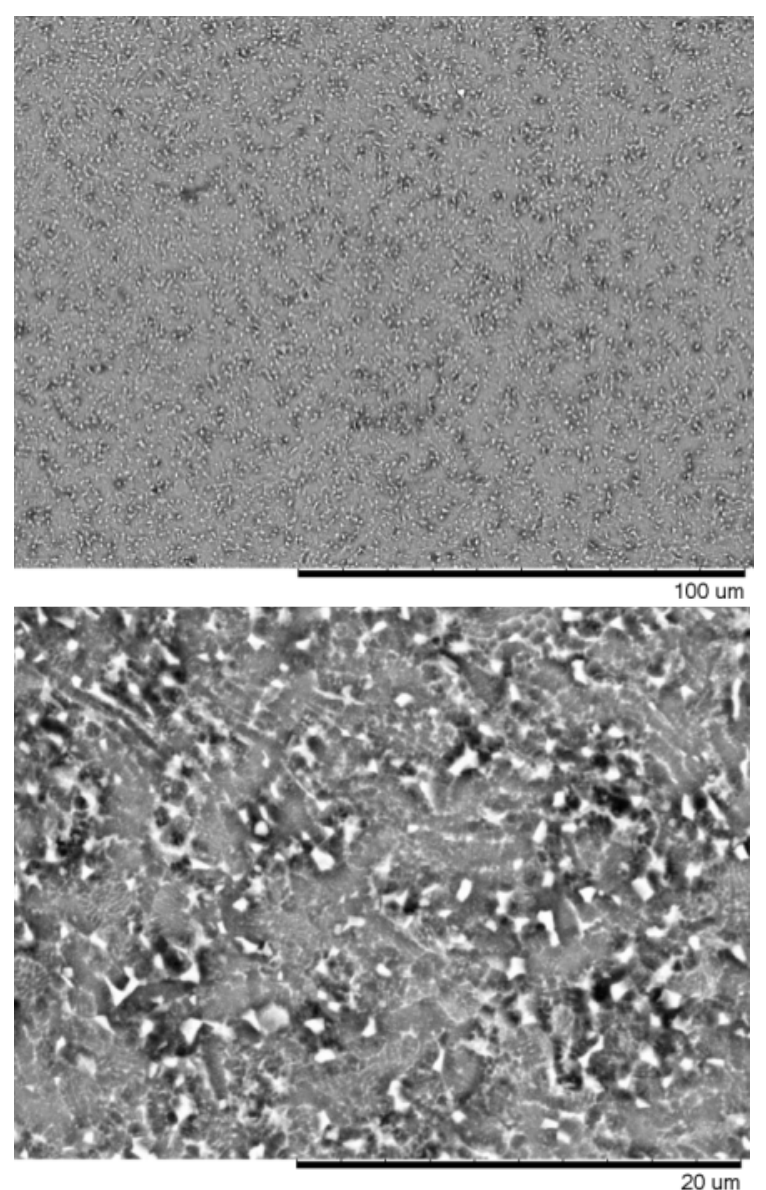

Figura 10. Liga Ti-6Al-4V, como recebida na condição recozida.
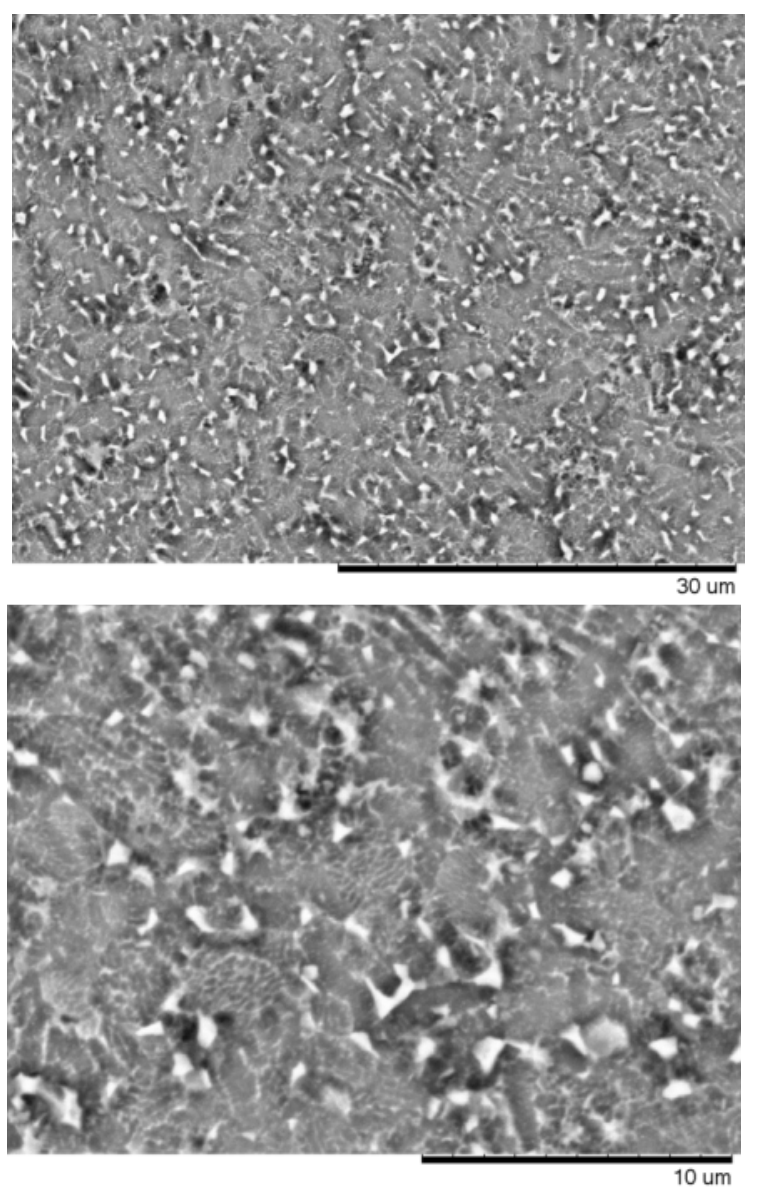

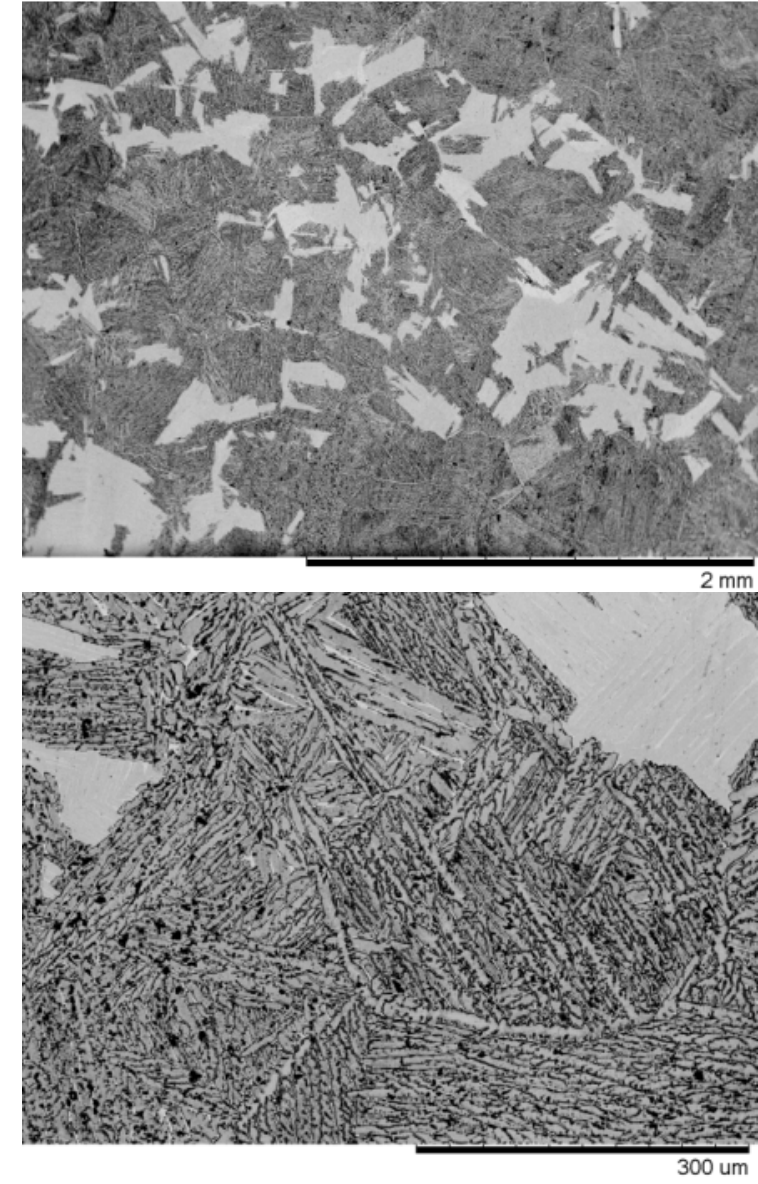

Figura 11. Liga Ti-6Al-4V, tratada termicamente com morfologia Widmansttäten.
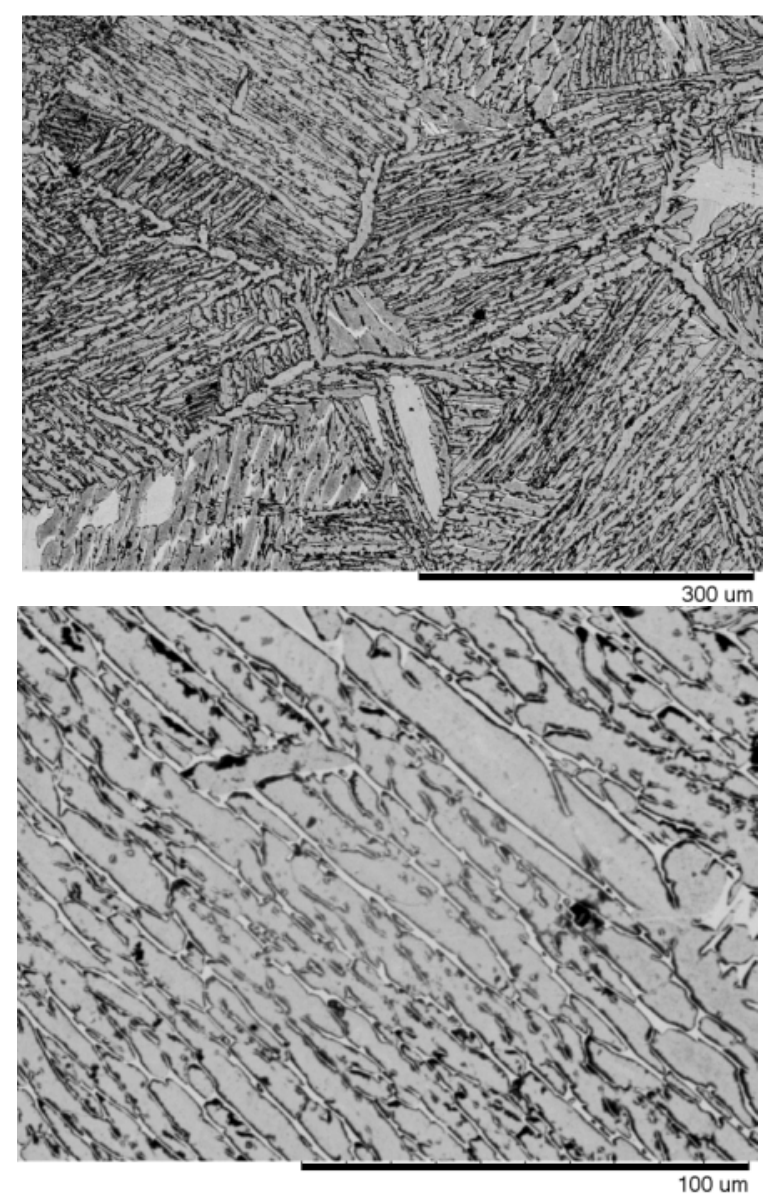

00 um

Após a realização do tratamento térmico a partir do campo $\beta$, observa-se a manutenção da microestrutura típica de Widmanstätten com grãos grosseiros. Observa-se, também, a presença da fase $\alpha$ secundária em regiões vizinhas e ao longo dos contornos de grão. Este resultado está de acordo com os que foram encontrados por Gil e colaboradores (2001). Segundo o autor, o aquecimento da liga Ti-6Al-4V em temperaturas acima da linha $\beta$ transus leva a formação de uma microestrutura lamelar e, quando resfriada a taxas muito baixas, forma-se fase $\alpha$ secundária devido à lentidão do processo que permite aos átomos que se difundam com facilidade (GIL et al., 2001). A formação de colônias $\alpha$ na morfologia Widmanstätten é importante, pois impede a movimentação de discordâncias, as quais precisam mudar de orientação para continuar se movimentando de uma colônia para a outra. $\mathrm{O}$ tamanho destas colônias depende do tamanho que os grãos da fase $\beta$ atingem durante o tratamento térmico acima da linha $\beta$ transus (SEARLES et al., 2005). Filip e colaboradores (FILIP et al., 2003) observaram que as várias orientações das colônias $\alpha$ impedem o crescimento de trincas. Ao se cruzar um limite de uma colônia para outra, a trinca muda de direção, o que causa a criação de ramificações ou trincas secundárias. Este processo requer energia adicional e resulta em aumento da tenacidade a fratura do material. 
Para a liga Ti-6Al-4V estuda no presente trabalho, a estimativa grosseira do tamanho médio de grão corresponde a aproximadamente $1250 \mu \mathrm{m}$. A espessura das lamelas e a largura das colônias correspondem aos valores médios de $11 \mu \mathrm{m}$ e $342 \mu \mathrm{m}$, respectivamente.

A microdureza encontrada para a liga foi de $343 \pm 20 \mathrm{HV}$, sabe-se que este valor está diretamente relacionado à espessura das lamelas $\alpha$ e a quantidade de fase $\alpha$ secundária presentes na liga (GIL et al., 2001). O valor encontrado está na mesma faixa do encontrado por Balla e colaboradores (BALLA et al., 2012).

A Figura 12 mostra um corte transversal do revestimento à base de TiN formado sobre a liga Ti-6Al-4V.
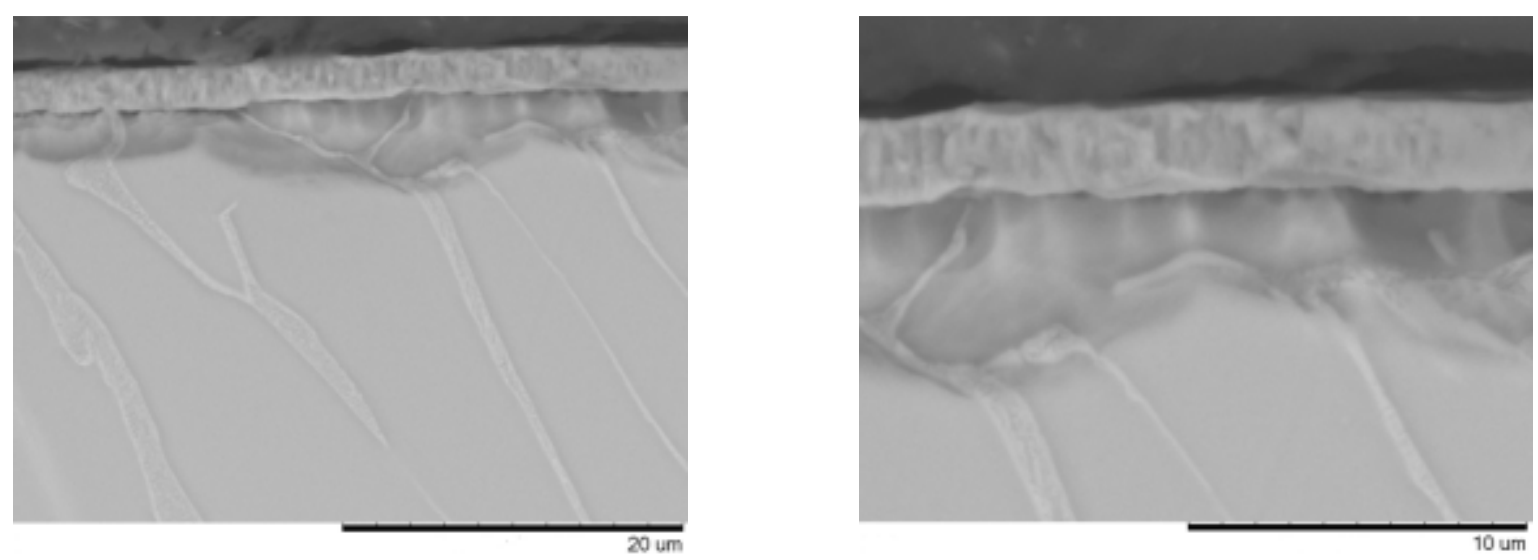

Figura 12. Ti-6Al-4V recoberto por PVD - TiN: a) MEV, $5.0 \mathrm{kx}$; b) MEV, $10.0 \mathrm{kx}$.

A espessura estimada da camada de TiN foi de $2,2 \mu \mathrm{m}$. A composição da camada obtida por análises de EDS na superfície dos corpos de prova foi igual a 57,7\% at. de nitrogênio e $42,3 \%$ at. de titânio. Com esses valores pode-se estimar que a fórmula do composto formado sobre a superfície é igual a $\mathrm{Ti}_{0,7} \mathrm{~N}$.

A Figura 13 ilustra o corte transversal de uma típica multilayer ou revestimento multicamada formado por camadas à base de TiAlCrN (mais claro) e TiAlN (mais escuro). 

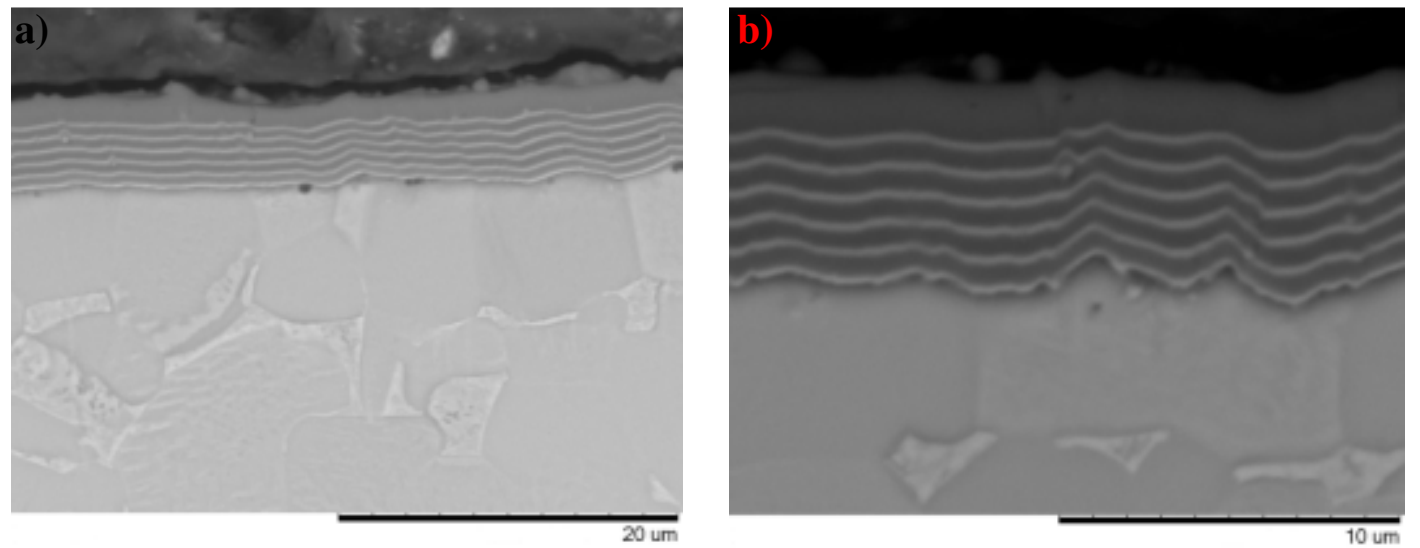

Figura 13. Ti-6Al-4V recoberto por PVD - TiAlN: a) MEV, $5.0 \mathrm{kx}$; b) MEV, $10.0 \mathrm{kx}$.

Esse tipo de deposição tem o objetivo de garantir maior proteção ao substrato contra intempéries. A presença do alumínio e do cromo e a sobreposição de camadas aumentam a resistência à oxidação e corrosão, melhora as propriedades mecânicas, diminui os defeitos da camada como um todo e torna a microestrutura mais densa e compacta (CAIRNEY et al., 2004; LIU et al., 2007; MAN et al., 2004; MIAU DU et al., 2011; YOON et al., 2002). A espessura total da multicamada foi estimada em torno de $6 \mu \mathrm{m}$, a camada superficial de TiAlN (última camada depositada) ficou em torno de $2 \mu \mathrm{m}$, as intercamadas de TiAlCrN apresentaram espessura aproximada de $217 \mathrm{~nm}$ e as de TiAlN $540 \mathrm{~nm}$. O número de interfaces $\mathrm{N}$ foi igual a 11. A composição da camada obtida por análises de EDS na superfície dos corpos de prova foi igual a 67,3\% at. de nitrogênio, 20,1 $\%$ at. de alumínio e 12,6 \% at. de titânio, o que nos dá um composto de fórmula $\left(\operatorname{Ti}_{0,38} \mathrm{Al}_{0,62}\right) \mathrm{N}$. Para as intercamadas que possuem cromo na composição as quantidades atômicas identificadas por EDS na seção transversal das amostras foram $61,1 \%$ at. de nitrogênio, 19,3\% at. de alumínio, $12,0 \%$ at. de titânio e 7,6 \% at. de cromo. $\left(\mathrm{Ti}_{0,31} \mathrm{Al}_{0,50} \mathrm{Cr}_{0,19}\right) \mathrm{N}$ é a fórmula desta camada.

Os valores de microdureza dos revestimentos foram informados pela fabricante e correspondem a $2500 \mathrm{HV}$ para a condição recoberta por TiN e a $3300 \mathrm{HV}$ para a condição recoberta por TiAlN/TiAlCrN. Estes valores encontram-se dentro da faixa de durezas Vickers reportada na literatura para diversos nitretos. Variando de 1083 HV (compostos binários) a 3331 HV (compostos ternários) (AIHUA et al., 2012; MO; ZHU, 2009; YILDIZ et al., 2008; ZHAO et al., 2010). 


\subsection{DIFRATOMETRIA DE RAIOS X}

A Figura 14 mostra a análise feita para a liga Ti-6Al-4V com morfologia Widmanstätten e na condição sem tratamento superficial.

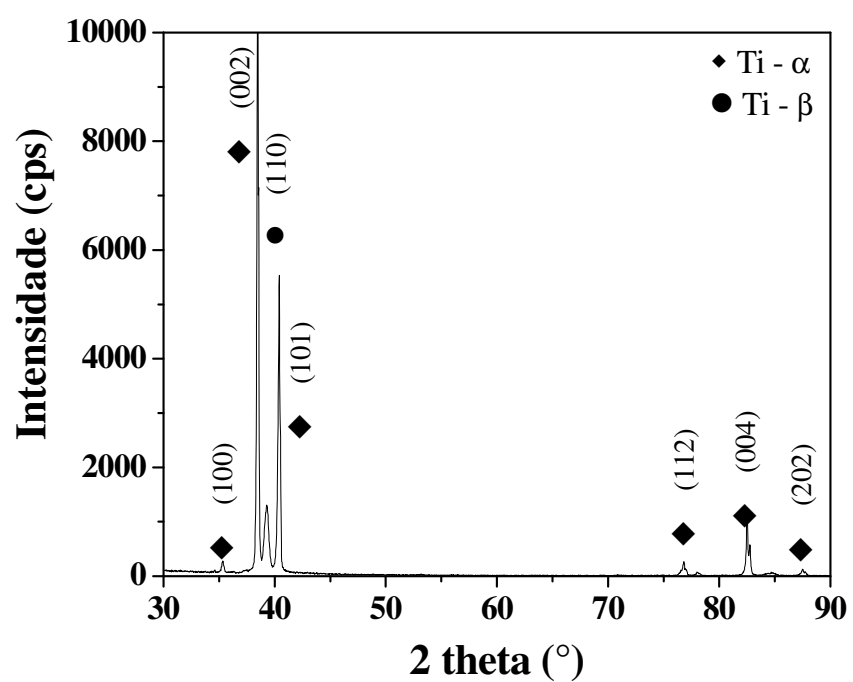

Figura 14. Difratograma de raios $X(D R X)$ da amostra sem tratamento superficial.

Observa-se na Figura 14 a presença de picos de maior intensidade relacionados com a fase $\alpha$, encontrados nas posições $2 \theta=35,37^{\circ}, 2 \theta=38,33^{\circ}, 2 \theta=40,41^{\circ}, 2 \theta=76,85^{\circ}, 2 \theta=$ $82,47^{\circ}$ e $2 \theta=87,81^{\circ}$. Observa-se também uma pequena quantidade de fase $\beta$, caracterizada pelo pico referente ao plano (110), plano característico da presença de fase $\beta$, encontrado em $2 \theta=39,22^{\circ}$. Os resultados estão de acordo com vários outros trabalhos que utilizaram a liga Ti-6Al-4V (ELMER; PALMER; WONG, 2003; SILVA et al., 1999; ZHAO et al., 2008).

A Figura 15 mostra a análise de DRX feita para a liga Ti-6Al-4V recoberta por TiN e TiAlN/TiAlCrN. 


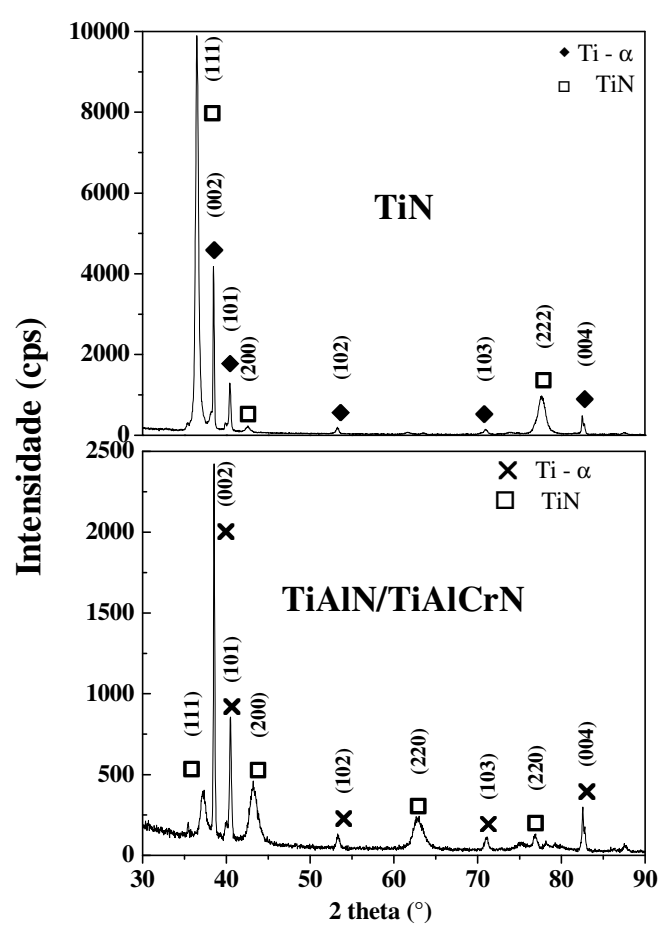

Figura 15. Difratogramas de Raios $X(D R X)$ da liga Ti-6Al-4V com recobrimento.

Para a liga recoberta com TiN pode-se constatar que esta fase tem uma forte orientação preferencial no plano (111) em $2 \theta=36,38^{\circ}$ e está de acordo com o que foi encontrado pelos autores Liu et al. (2001), Yoon et al. (2002) e Yang et al. (2005) (LIU et al., 2001; YANG et al., 2005; YOON et al., 2002). Segundo Yoon e colaboradores (2002), o aparecimento da orientação preferencial para o plano (111) é típico da deposição do TiN pela técnica de PVD (YOON et al., 2002). Adicionalmente observou-se a presença de picos relacionados com os planos (200) em $2 \theta=42,65^{\circ}$ e $(222)$ em $2 \theta=77,68^{\circ}$ o que está de acordo com o trabalho de Yoo e colaboradores (YOO et al., 2008). Para o caso do recobrimento multicamada à base de TiAlN/TiAlCrN observou-se que a incorporação do alumínio e cromo fez com que aparecessem outras orientações cristalográficas (111), (200), (220) ligados à presença do nitreto TiN e (102) e (103) pertencentes à fase $\alpha$ Ti, adicionalmente, a intensidade do plano (200) aumentou. A forte tendência de diminuição da intensidade e alargamento do pico (111) para TiN pode estar relacionada com a redução da cristalização pelo aparecimento de defeitos induzidos pela incorporação do alumínio e do cromo. Yoo e colaboradores (2008) atribuíram essa modificação do pico (111) à diminuição do tamanho do grão e da tensão residual devido ao alumínio (YOO et al., 2008). TiAlN e TiAlCrN são formados por solução sólida substitucional onde átomos do soluto $\mathrm{Al}$ ou Cr são incorporados pela matriz de TiN, substituindo alguns átomos de titânio 
na matriz cúbica. Por este motivo o parâmetro de rede tende a diminuir já que o raio covalente do alumínio e do cromo $(1,18 \AA$ A) é menor do que o raio covalente do titânio $(1,32 \AA$ A $)$. Este fenômeno pode ser observado na Figura 15 onde o pico referente ao plano (111) do composto TiN desloca-se para a direita quando relacionado a TiAlN. A estrutura cristalina do composto $\mathrm{Ti}_{1-\mathrm{x}} \mathrm{Al}_{\mathrm{X}} \mathrm{N}$ depende da quantidade de alumínio: para $\mathrm{x}<0,6 \mathrm{TiAlN}$ apresenta uma estrutura cúbica típica de $\mathrm{NaCl}$, entre $0,6 \leq \mathrm{x}<0,7$ duas fases coexistem uma do tipo $\mathrm{NaCl}$ e outra hexagonal relacionada com a presença do composto AlN, para $\mathrm{x}$ $>$ 0,7 apenas AlN se forma (MIAU DU et al., 2011; PANJAN et al., 2007; YANG et al., 2005; YOO et al., 2008). A análise de DRX do revestimento multicamada TiAlN/TiAlCrN está de acordo com os estudos conduzidos por Miau Du e colaboradores (MIAU DU et al., 2011).

\subsection{ENSAIOS DE CORROSÃO}

4.3.1. MEDIDAS DO POTENCIAL EM CIRCUITO ABERTO E POLARIZAÇÃO POTENCIODINÂMICA

As Figuras 16 e 17 mostram a evolução do potencial em circuito aberto (OCP) em função do tempo de exposição em $\mathrm{HCl} 2 \mathrm{M}$ a $25{ }^{\circ} \mathrm{C}$ e em $\mathrm{NaCl} 3,5 \%$ a $25{ }^{\circ} \mathrm{C}$, respectivamente. 


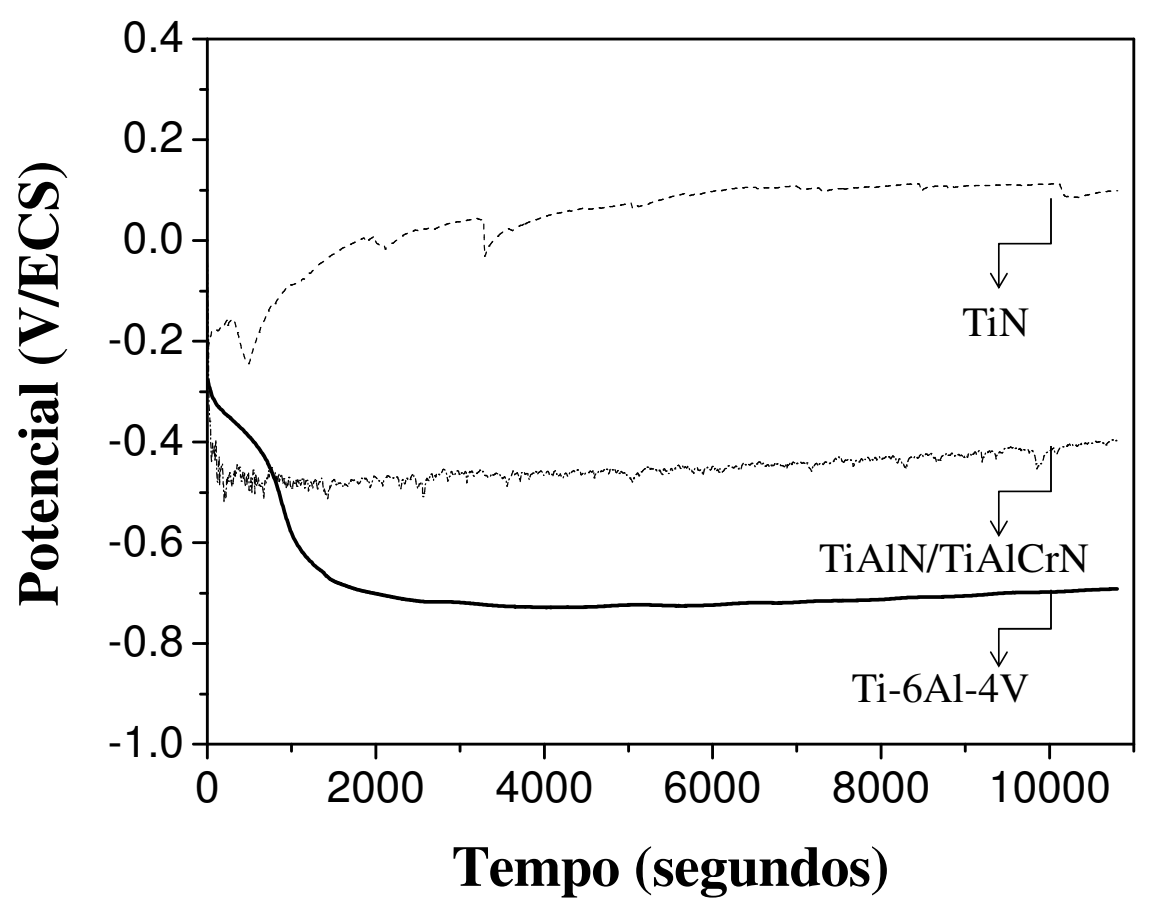

Figura 16. Potencial em circuito aberto vs. tempo para a liga Ti-6Al-4V sem recobrimento e recoberta por TiN e TiAlN/TiAlCrN, em solução $\mathrm{HCl} 2 \mathrm{M}$ a $25^{\circ} \mathrm{C}$.

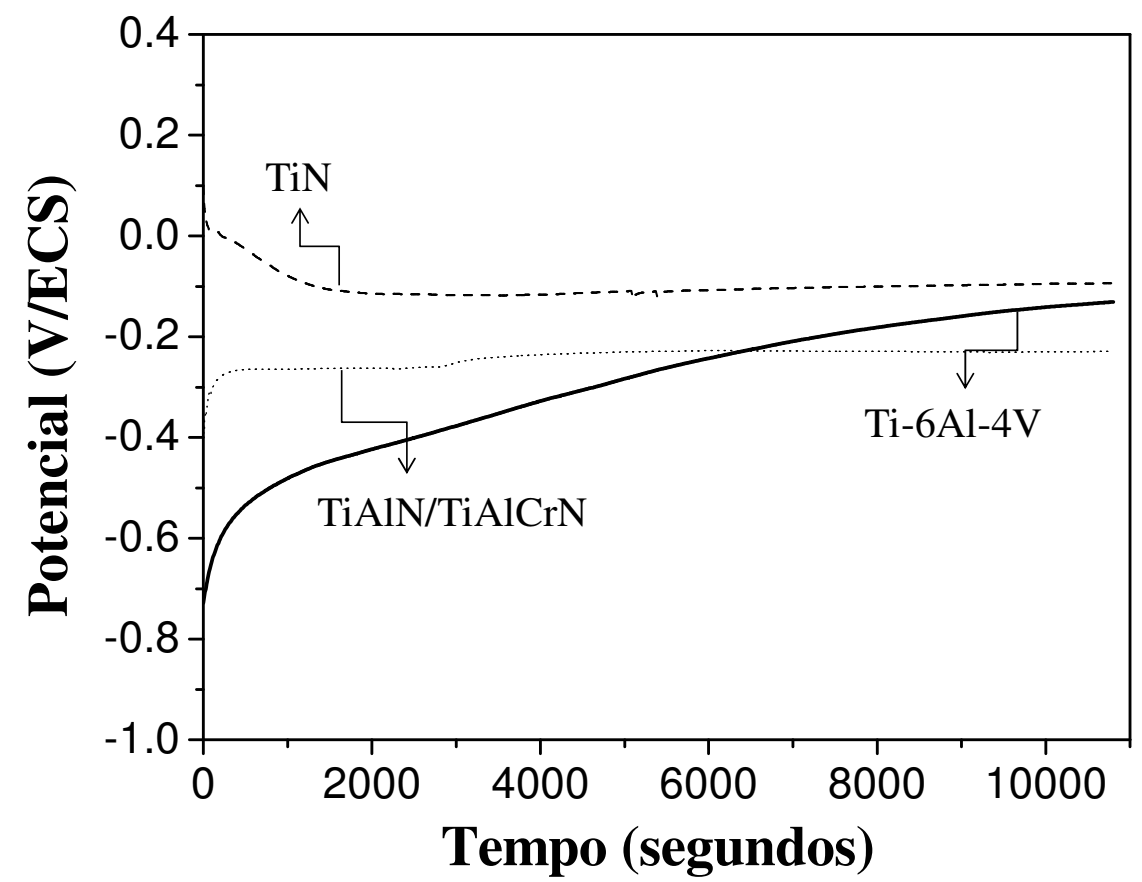

Figura 17. Potencial em circuito aberto vs. tempo para a liga Ti-6Al-4V sem recobrimento e recoberta por TiN e TiAlN/TiAlCrN, em solução $\mathrm{NaCl} 3,5 \%$ p. a $25^{\circ} \mathrm{C}$

As Figuras 18 e 19 mostram os gráficos gerados do teste de polarização da liga Ti6Al-4V com e sem recobrimento nas soluções $\mathrm{HCl} 2 \mathrm{M}$ a $25{ }^{\circ} \mathrm{C}$ e $\mathrm{NaCl} 3,5 \%$ a $25{ }^{\circ} \mathrm{C}$, respectivamente. 


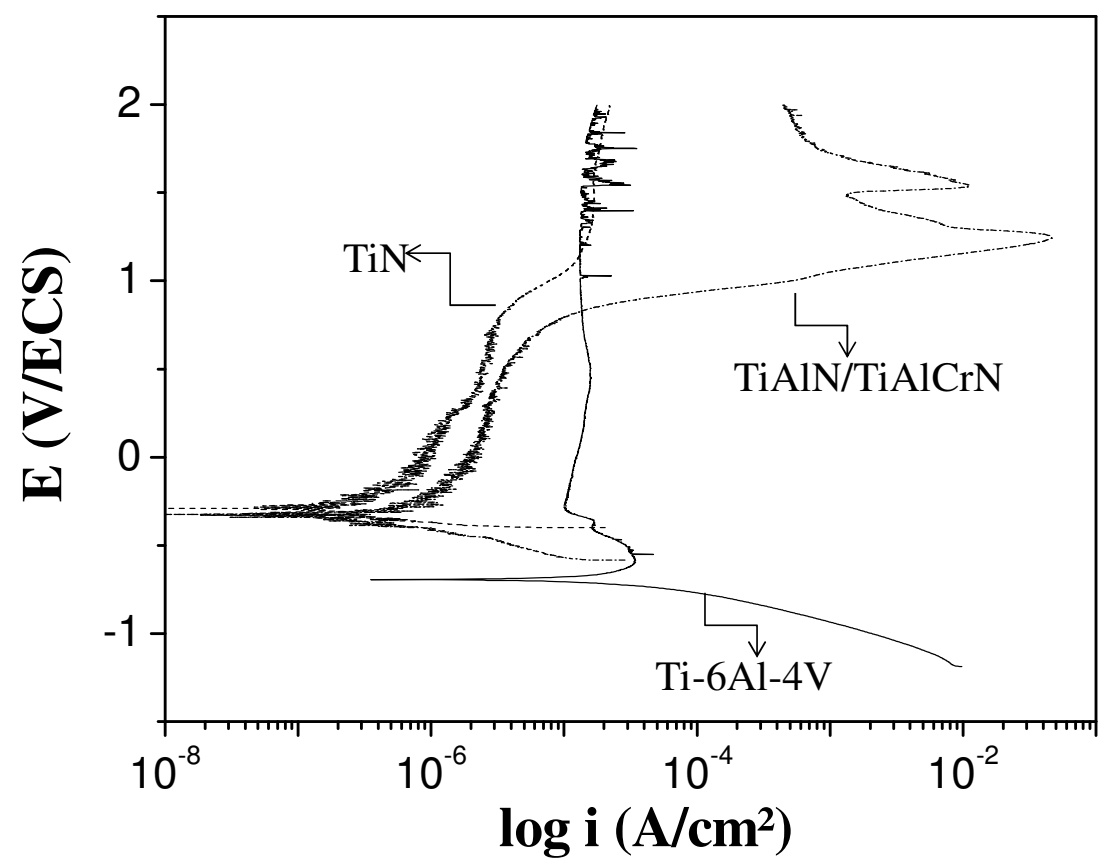

Figura 18. Curva de polarização potenciodinâmica da liga Ti-6Al-4V sem recobrimento e recoberta por TiN e TiAlN/TiAlCrN, em solução $\mathrm{HCl} 2 \mathrm{M}$ a $25^{\circ} \mathrm{C}$.

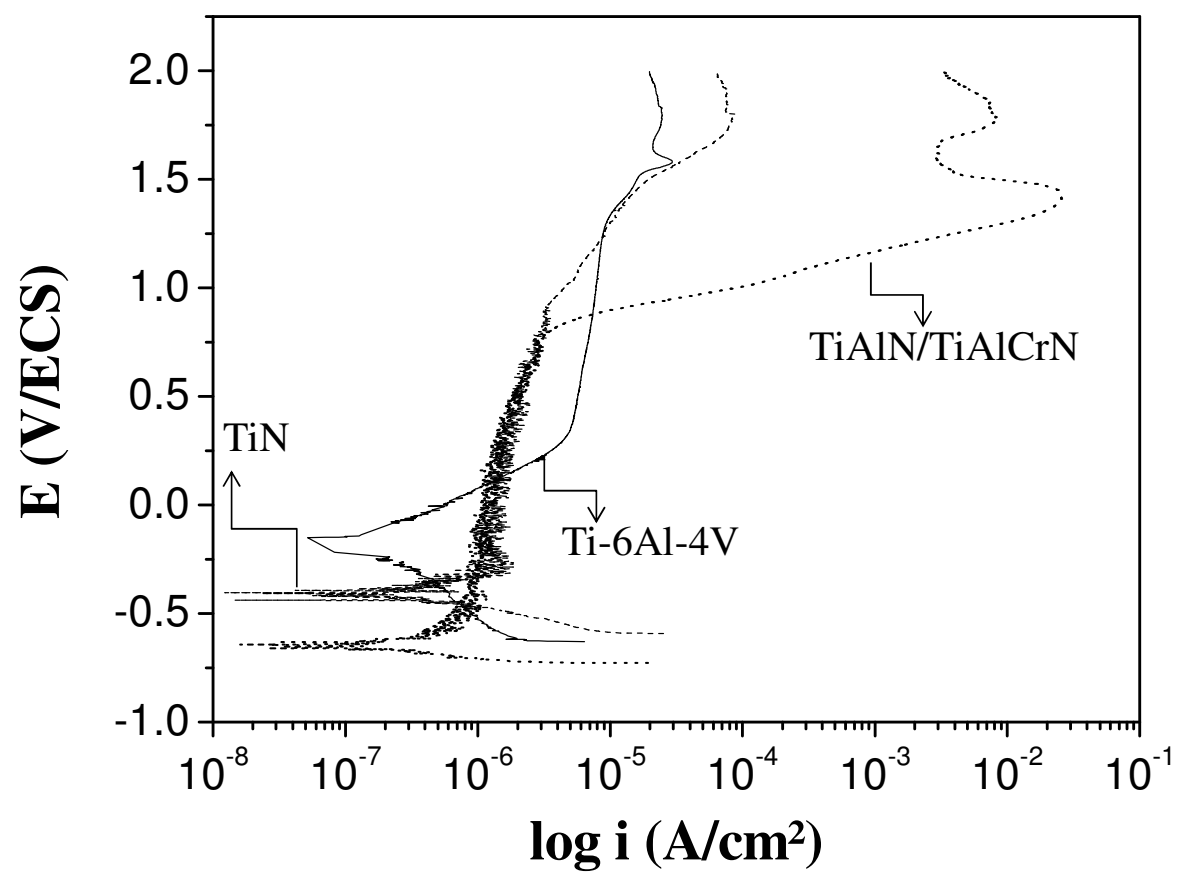

Figura 19. Curva de polarização potenciodinâmica da liga Ti-6Al-4V sem recobrimento e recoberta por TiN e TiAlN/TiAlCrN, em solução $\mathrm{NaCl} 3,5 \%$ a $25{ }^{\circ} \mathrm{C}$.

As Tabelas 7 e 8 mostram os valores de $\mathrm{E}_{\text {corr }}$, medidos em circuito aberto após 3 horas de exposição, e os parâmetros de polarização eletroquímica, tais como a densidade 
da corrente de corrosão ( $\left.\mathrm{i}_{\text {corr }}\right)$, a densidade de corrente critica $\left(\mathrm{i}_{\text {crit }}\right)$ e a densidade de corrente passiva (i $\left.i_{\text {Pass }}\right)$.

Tabela 7. Parâmetros eletroquímicos da liga Ti-6Al-4V sem recobrimento e recoberta por TiN e TiAlN/TiAlCrN, a 25 ${ }^{\circ} \mathrm{C}$ em meio $\mathrm{HCl} 2 \mathrm{M}$

\begin{tabular}{ccccc}
\hline \multirow{2}{*}{ Amostra } & \multicolumn{4}{c}{ Parâmetros } \\
& $\mathbf{E}_{\text {corr }}(\mathbf{V})$ & $\mathbf{i}_{\text {corr }}\left(\mathbf{A} / \mathbf{c m}^{2}\right)$ & $\mathbf{i}_{\text {crít }}\left(\mathbf{A} / \mathbf{c m}^{2}\right)$ & $\mathbf{i}_{\text {pass }}\left(\mathbf{A} / \mathbf{c m}^{2}\right)$ \\
\hline Ti-6Al-4V & $-0,7$ & $2,0 \times 10^{-5}$ & $3,4 \times 10^{-5}$ & $1,5 \times 10^{-5} *$ \\
TiN & $-0,3$ & $4,9 \times 10^{-7}$ & & $3,0 \times 10^{-6 *}$ \\
TiAIN/TiAICrN & $-0,4$ & $7,2 \times 10^{-7}$ & & $3,7 \times 10^{-6 *}$ \\
\hline
\end{tabular}

$*$ medidos em $\mathrm{E}=0,5 \mathrm{~V} / \mathrm{ECS}$

Tabela 8. Parâmetros eletroquímicos da liga Ti-6Al-4V sem recobrimento e recoberta por TiN e TiAlN/TiAlCrN, a 25 ${ }^{\circ} \mathrm{C}$ em meio $\mathrm{NaCl} 3,5 \%$.

\begin{tabular}{|c|c|c|c|c|}
\hline \multirow{2}{*}{ Amostra } & \multicolumn{4}{|c|}{ Parâmetros } \\
\hline & $\mathbf{E}_{\text {corr }}(\mathrm{V})$ & $\mathbf{i}_{\text {corr }}\left(\mathrm{A} / \mathrm{cm}^{2}\right)$ & $\mathbf{i}_{\text {crít }}\left(\mathrm{A} / \mathrm{cm}^{2}\right)$ & $\mathbf{i}_{\text {pass }}\left(\mathrm{A} / \mathbf{c m}^{2}\right)$ \\
\hline Ti-6Al-4V & $-0,1$ & $3,7 \times 10^{-7}$ & & $5,7 \times 10^{-6} *$ \\
\hline TiN & $-0,09$ & $6,3 \times 10^{-7}$ & & $2,1 \times 10^{-6 *}$ \\
\hline TiAlN/TiAlCrN & $-0,2$ & $3,8 \times 10^{-7}$ & & $2,1 \times 10^{-6} *$ \\
\hline
\end{tabular}

$*$ medidos em $\mathrm{E}=0,5 \mathrm{~V} / \mathrm{ECS}$

A Figura 16 mostra que o potencial em circuito aberto da liga não revestida em $\mathrm{HCl}$ diminui com o tempo e estabiliza após cerca de $2000 \mathrm{~s}$ para potenciais muito negativos, indicando um comportamento ativo. A camada de óxido formada naturalmente no Ti-6Al$4 \mathrm{~V}$ (à base principalmente de $\mathrm{TiO}_{2}$ ) é progressivamente dissolvida, o que explica a variação da OCP com o tempo de potenciais mais nobres para potenciais menos nobres. As possíveis reações são (FEKRY, 2009):

$H^{+}+1 e^{-} \rightarrow \frac{1}{2} H_{2}$

$\mathrm{H}_{2} \mathrm{O}+\mathrm{TiO}_{2}+\mathrm{H}^{+} \rightarrow \mathrm{Ti}(\mathrm{OH})_{3}^{+}$

Após a dissolução total da camada passiva, a liga de Ti-6Al-4V sofre dissolução ativa formando íons de $\mathrm{Ti}^{3+}$ como mostra a reação a seguir: $\mathrm{Ti} \rightarrow T i^{3+}+3 e^{-}$(SOUZA; ROBIN, 2007; ARMSTRONG; HARRISON, 1970). Segundo Armstrong et al. (1970),

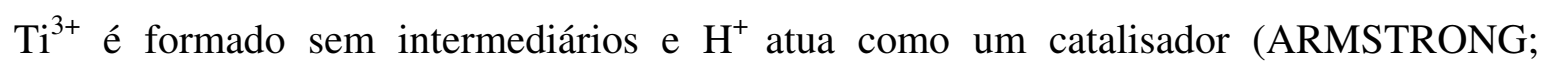
HARRISON, 1970).

Atapour e colaboradores (2011) observaram que a liga Ti-6Al-4V comporta-se ativamente em solução $\mathrm{HCl}$, e sugeriram que este comportamento se deve às altas taxas de corrosão na fase $\beta$ enriquecida com vanádio. A presença do vanádio contribui com a formação de óxidos de vanádio solúveis em soluções ácidas e, portanto contribui com a corrosão na liga Ti-6Al-4V. No entanto, este mesmo elemento é essencial para a manutenção da fase $\beta$. Adicionalmente, a presença de elementos de liga nas diferentes fases (Al na fase $\alpha$ e $\mathrm{V}$ na fase $\beta$ ) permite a formação de um par galvânico entre as duas 
fases, tornando a liga menos resistente à corrosão nas interfaces $\alpha / \beta$ (ATAPOUR et al., 2011a). Neste presente trabalho, foi observado que a liga Ti-6Al-4V sofreu corrosão nas interfaces $\alpha / \beta$. A Figura 20 mostra um mapeamento por EDS (em relação ao cloro) da liga Ti-6Al-4V sem revestimento depois do teste de polarização em solução de $\mathrm{HCl}$.

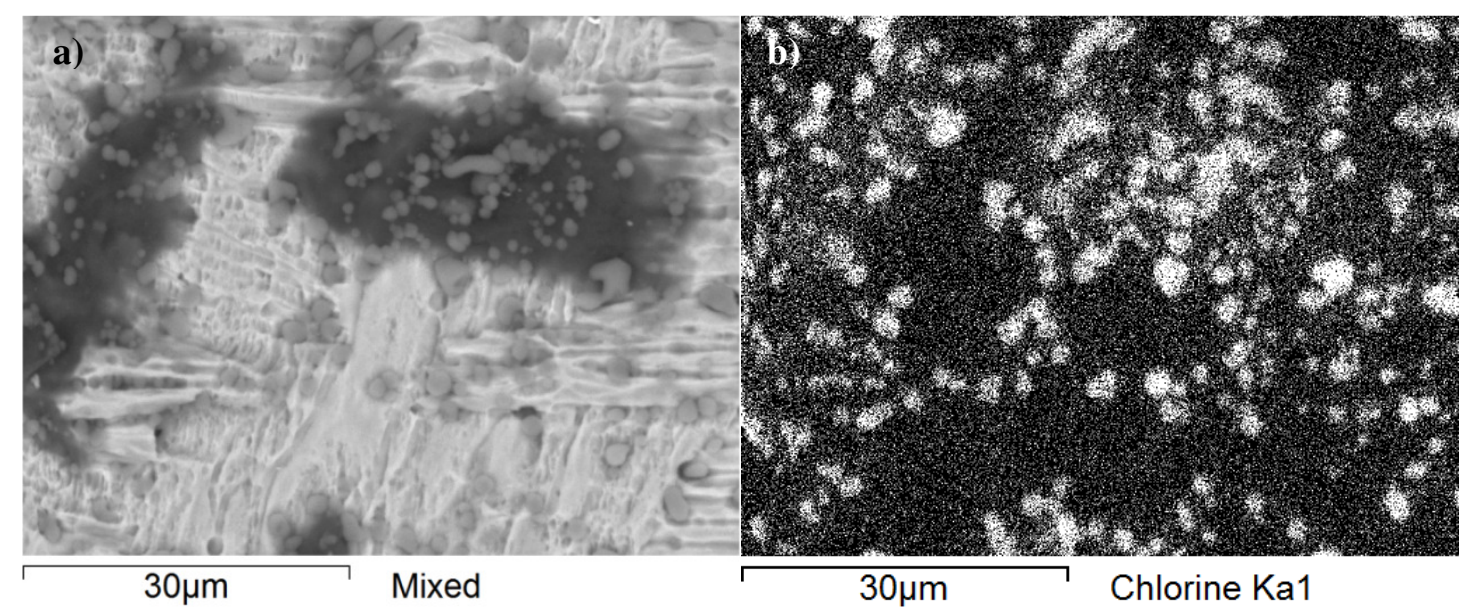

Figura 20. Mapeamento por EDS: presença do elemento cloro nos produtos de corrosão aderidos à superfície da liga Ti6Al-4V sem revestimento.

Com base na Figura 20, observa-se a presença do elemento cloro (região branca na Figura 20b) nos produtos de corrosão que aderiram à superfície da liga Ti-6Al-4V sem revestimento. Segundo Fekry (2009), íons $\mathrm{Cl}^{-}$são capazes de reagir com o titânio formando produtos de corrosão solúveis e consumindo o filme passivo à base de $\mathrm{TiO}_{2}$ (FEKRY, 2009).

Como mostrado na Figura 18, a liga Ti-6Al-4V sem revestimento apresenta comportamento ativo sob condições de corrente nula, mas sofre uma transição ativopassiva durante a polarização. $O$ valor de $i_{\text {crit }}$ foi igual a $3,4 \times 10^{-5} \mathrm{~A} / \mathrm{cm}^{2}$ e a densidade de corrente passiva, medida a $0,5 \mathrm{~V} / \mathrm{ECS}$, foi igual a $1,5 \times 10^{-5} \mathrm{~A} / \mathrm{cm}^{2}$. Atapour e colaboradores (2011) observaram também uma transição ativo-passiva no comportamento em corrosão da liga Ti-6Al-4V em solução 5\% HCl (ATAPOUR et al., 2011a). Souza e Robin (2003) que estudaram o comportamento do titânio e de ligas $\mathrm{Ti}$ - Ta à temperatura ambiente em solução $80 \%$ p. $\mathrm{H}_{2} \mathrm{SO}_{4}$ encontraram, para o titânio puro, $\mathrm{i}_{\text {crít }}$ e $\mathrm{i}_{\text {pass }}$ aproximadamente igual a $2,2 \times 10^{-3}$ e $6,25 \times 10^{-4} \mathrm{~A} / \mathrm{cm}^{2}$, respectivamente (SOUZA; ROBIN, 2003). Fekry e colaboradores (2009) encontraram $i_{\text {crit }}$ igual a $1,02 \times 10^{-5} \mathrm{~A} / \mathrm{cm}^{2}$ e $i_{\text {pass }}$ igual a $5,14 \times 10^{-6}$ $\mathrm{A} / \mathrm{cm}^{2}$ em análises do comportamento de corrosão da liga Ti-6Al-4V em solução $1 \mathrm{M}$ de ácido oxálico a $25{ }^{\circ} \mathrm{C}$ (FEKRY, 2009). Estes resultados demonstram que a liga Ti-6Al-4V é ativa em soluções ácidas redutoras e apresenta região de transição ativo-passiva como o encontrado no presente trabalho. 
Já as análises da Figura 17 demonstram que o potencial da liga Ti-6Al-4V em NaCl se torna mais positivo com o tempo e tende a se estabilizar. Este comportamento sugere a formação e crescimento de um filme passivador (também à base de $\mathrm{TiO}_{2}$ ). Um material que se comporta desta maneira é chamado de espontaneamente passivo. As reações que estão envolvidas neste processo corrosivo podem ser descritas da seguinte forma (MCCAFFERTY, 2005; PJESCIC; MENTUS; BLAGOJEVIC, 2002):

$\mathrm{O}_{2}+2 \mathrm{H}_{2} \mathrm{O}+4 \mathrm{e}^{-}=4 \mathrm{OH}^{-}$

$\mathrm{Ti}+4 \mathrm{OH}^{-}-4 \mathrm{e}^{-}=\mathrm{TiO}_{2}+2 \mathrm{H}_{2} \mathrm{O}$

Este comportamento à corrosão do titânio em soluções $\mathrm{NaCl}$ foi observado por diversos autores. Amaya-Vazquez e coautores (2012) e Savonov e colaboradores (2011) estudaram o comportamento da liga Ti-6Al-4V modificados por tratamentos por plasma, em solução $3,5 \% \mathrm{NaCl}$ à temperatura ambiente e obtiveram $\mathrm{E}_{\text {corr }}$ igual a $-0,383 \mathrm{~V}_{\mathrm{ECS}} \mathrm{e}$ 0,211 $\mathrm{V}_{\mathrm{ECS}}$, respectivamente (AMAYA-VAZQUEZ et al., 2012; SAVONOV et al., 2011). Atapour e colaboradores (2011) estudaram as características eletroquímicas da liga Ti-6Al$4 \mathrm{~V}$ em solução $0,9 \% \mathrm{NaCl}$, a $37{ }^{\circ} \mathrm{C}$ (condições que simulam a composição e o $\mathrm{pH}$ do fluido corpóreo) e encontraram $\mathrm{E}_{\mathrm{corr}}=-0,380 \mathrm{~V}_{\mathrm{ECS}}$ para Ti-6Al-4V (ATAPOUR et al., 2011b). Balamurugan e colaboradores (2009) analisaram o comportamento eletroquímico de biocompósitos depositados sobre a liga Ti-6Al-4V em uma solução de fluido corpóreo sintético a $37{ }^{\circ} \mathrm{C}(\sim 0,9 \% \mathrm{NaCl})$ e encontraram $\mathrm{E}_{\text {corr }}$ igual a $-0,95 \mathrm{~V}_{\mathrm{ECS}}$ para a liga sem recobrimento (BALAMURUGAN et al., 2009). Robin e colaboradores (2008) avaliaram o comportamento do titânio puro, da liga Ti-6Al-4V e de ligas base Ti-Nb-Zr em solução de Ringer (fluido corpóreo sintético) a $37^{\circ} \mathrm{C}$. Através da observação do gráfico Potencial em circuito aberto vs. Tempo, observa-se que o $\mathrm{E}_{\text {corr }}$ encontrado pelos autores para a liga Ti6Al-4V encontra-se em torno de $-0,08 \mathrm{~V}_{\mathrm{ECS}}\left(\mathrm{ROBIN}\right.$ et al., 2008). O valor de $\mathrm{E}_{\text {corr }}$ encontrado no presente trabalho para a liga Ti-6Al-4V, $-0,10 \mathrm{~V}_{\mathrm{ECS}}$ a $25^{\circ} \mathrm{C}$ está de acordo com os resultados de Robin et al. (2008). Contudo, é muito difícil comparar resultados de potencial em circuito aberto com outros autores visto que, este valor é função da preparação superficial e dos tratamentos térmicos aos quais as ligas foram submetidas (ROBIN et al., 2008).

$\mathrm{Na}$ solução de $\mathrm{NaCl}$ o valor de $\mathrm{i}_{\text {pass }}$ para Ti-6Al-4V foi igual a $5,7 \times 10^{-6} \mathrm{~A} / \mathrm{cm}^{2}$. O menor valor de $\mathrm{i}_{\text {pass }}$ da liga sem recobrimento relacionado à solução de $\mathrm{NaCl}$ quando comparado ao meio $\mathrm{HCl}$ indica que, ao ser submetido a este meio corrosivo, o filme óxido formado sobre a superfície da liga de titânio possui melhor propriedade de isolação do metal base. Impedindo, portanto, a passagem de corrente e, consequentemente, as reações 
entre solução e metal (KUMAR et al., 2010). Martin e colaboradores (2010) que estudaram a influência da microestrutura e da textura no comportamento em corrosão da liga Ti-6Al$4 \mathrm{~V}$ em solução $1 \% \mathrm{NaCl}$ encontraram $\mathrm{i}_{\text {pass }}$ variando na faixa de $4,51 \times 10^{-6}$ a $5,90 \times 10^{-6}$ $\mathrm{A} / \mathrm{cm}^{2}$, de acordo com as diferentes microestruturas e com o alinhamento preferencial dos planos cristalográficos. Segundo o autor a resistência à corrosão da liga Ti-6Al-4V pode aumentar ou diminuir de acordo com a modificação na microestrutura ou no alinhamento dos planos cristalográficos (MARTIN et al., 2010).

As análises das Figuras 16 e 17 mostram que a aplicação de revestimentos superficiais tornaram a liga Ti-6Al-4V mais nobre em solução de $\mathrm{HCl}$, ou seja, valores de $\mathrm{E}_{\text {corr }}$ mais positivos. Em solução de $\mathrm{NaCl}$, as três condições apresentaram valores de $\mathrm{E}_{\text {corr }}$ semelhantes, ou seja, níveis de nobreza próximos. Para o revestimento à base de TiN em $\mathrm{HCl}$, o potencial medido em circuito aberto desloca-se, com o decorrer do tempo, em uma direção de potenciais mais nobres e se estabiliza em torno de $0,3 \mathrm{~V} / \mathrm{ECS}$. O potencial em circuito aberto do revestimento TiAlN/TiAlCrN em $\mathrm{HCl}$ quase não muda com o tempo. As curvas de polarização de ambos os revestimentos em $\mathrm{HCl}$ são características de materiais passivos (Figura 18). Não obstante os seus comportamentos anódicos são bastante diferentes. A camada à base de TiN apresenta um comportamento passivo secundário por volta de $1 \mathrm{~V} / \mathrm{ECS}$, enquanto que a camada à base de TiAlN/TiAlCrN sofre corrosão localizada em 0,83 V/ECS. As análises das curvas de polarização em NaCl (Figura 19) demonstram que os recobrimentos apresentaram comportamento passivo nesta solução. Assim como em $\mathrm{HCl}$, a camada de TiN apresenta um comportamento passivo secundário por volta de 1,9 V/ECS e a camada de TiAlN/TiAlCrN sofre corrosão localizada em torno de $0,8 \mathrm{~V} / \mathrm{ECS}$.

Segundo Rossi et al. (2003) a estabilidade do TiN em meios corrosivos é devido a sua inércia química que garante bom desempenho em corrosão mesmo em meios mais agressivos, como por exemplo, contendo cloreto (ROSSI et al., 2003). Manhabosco e colaboradores (2011) estudaram o comportamento da liga Ti-6Al-4V, sem recobrimento e nitretada, em uma solução sintética de fluido corpóreo (composta principalmente por $\mathrm{NaCl}$ ). Os autores informaram que o tratamento de nitretação aumentou o potencial de corrosão da liga sem nenhuma proteção superficial de $-83 \mathrm{mV}_{\mathrm{ECS}}$ para $-41 \mathrm{mV}_{\mathrm{ECS}}$ a $37{ }^{\circ} \mathrm{C}$ (MANHABOSCO et al., 2011).

A adição de elementos ligantes nos nitretos binários de metais de transição, tais como $\mathrm{Al}$ e $\mathrm{Cr}$, controla o tamanho e a densidade dos microporos, melhora a dureza e a tenacidade à fratura e resulta em maior resistência à corrosão e ao desgaste quando 
comparado com os nitretos simples (GRIPS et al., 2006). Um revestimento multicamada pode melhorar o comportamento em corrosão quando comparado com um revestimento simples devido ao aumento da espessura do revestimento, que leva a uma diminuição estatística da possibilidade de defeitos (poros), ao aparecimento de contornos cristalinos descontínuos na estrutura colunar, que diminui a possibilidade de formação de poros e à formação de camadas alternadas de composições diferentes, que podem redirecionar o fluxo de corrente entre revestimento e substrato. Portanto, revestimentos multicamadas podem melhorar a resistência à corrosão de metais revestidos por PVD se as fases e as estruturas forem apropriadas (LIU et al., 2001). O que se observou no presente trabalho foi que a resistência à corrosão da amostra revestida por TiAlN/TiAlCrN foi menor em $\mathrm{HCl}$ ou semelhante em $\mathrm{NaCl}$ à resistência à corrosão da amostra revestida por TiN. Sabe-se que a fórmula do revestimento à base de TiAlN estudado aqui apresenta concentração atômica do alumínio maior que a concentração do titânio na multicamada. Segundo Grips e colaboradores (2006) o aumento da concentração de Al nos nitretos TiAlN leva a um aumento da resistência à corrosão. Porém, o aumento da concentração de $\mathrm{Al}$ para valores maiores que 50 at. \% diminui a aderência e a dureza do revestimento (GRIPS et al., 2006). Kovalev e colaboradores (2010) estudaram o impacto da adição de elementos ligantes a revestimentos do tipo TiN sobre suas propriedades mecânicas e concluíram que não só a quantidade de alumínio, mas também a quantidade de defeitos e lacunas na microestrutura influenciam a estabilidade da fase TiAlN (KOVALEV et al., 2010). As analises de DRX para TiAlN (Figura 15) permitiram concluir, através da formação de picos mais largos, que a adição de alumínio e cromo resultou no aparecimento de defeitos e/ou lacunas na microestrutura. Portanto, a instabilidade no comportamento de corrosão e a pouca efetividade do revestimento TiAlN quando comparado a TiN estão relacionadas com a grande quantidade de alumínio na composição e com os defeitos que a introdução de $\mathrm{Al}$ e Cr gerou.

A variação no potencial de corrosão durante as medidas de potencial em circuito aberto vs. tempo dos revestimentos TiN e TiAlN em $\mathrm{HCl}$ é diferente da encontrada para a liga Ti-6Al-4V sem nenhum recobrimento. A rápida diminuição do potencial da liga não revestida indica um comportamento ativo. Pode-se observar que com o passar do tempo o potencial dos revestimentos, em $\mathrm{HCl}$, apresenta flutuações e então volta a ser estável. Quando o potencial da amostra revestida diminui rapidamente indica que a solução corrosiva passa através do revestimento atingindo o substrato. A estabilização do potencial com o passar do tempo indica uma situação de corrosão estacionária (ZHAO et al., 2011). 
Os valores de $\mathrm{E}_{\text {corr }}$ para os revestimentos $\mathrm{TiN}$ e TiAlN/TiAlCrN encontrados neste presente trabalho demonstraram-se menos nobres em solução $\mathrm{HCl}$ quando comparados com os valores de $\mathrm{E}_{\text {corr }}$ em solução $\mathrm{NaCl}$. Isto indica que em soluções mais agressivas como $\mathrm{HCl}$ o revestimento protetor torna-se mais instável.

Revestimentos cerâmicos duros como TiN e TiAlN são quimicamente inertes e termicamente estáveis em, praticamente, qualquer meio corrosivo. Portanto, o ataque deste meio acontece através de defeitos do revestimento (microtrincas, poros, cavidades, contornos de grão). Estes defeitos criam um caminho direto entre eletrólito e substrato metálico, afetando o comportamento à corrosão destes revestimentos. Portanto, a corrosão em soluções aquosas de revestimentos depositados por PVD acontece, principalmente, de forma localizada devido à diferença de potencial que se estabelece entre revestimento e substrato (menos nobre) (GRIPS et al., 2006; LIU et al., 2001). A Figura 21 mostra o aspecto superficial dos revestimentos antes da imersão e polarização em solução corrosiva.
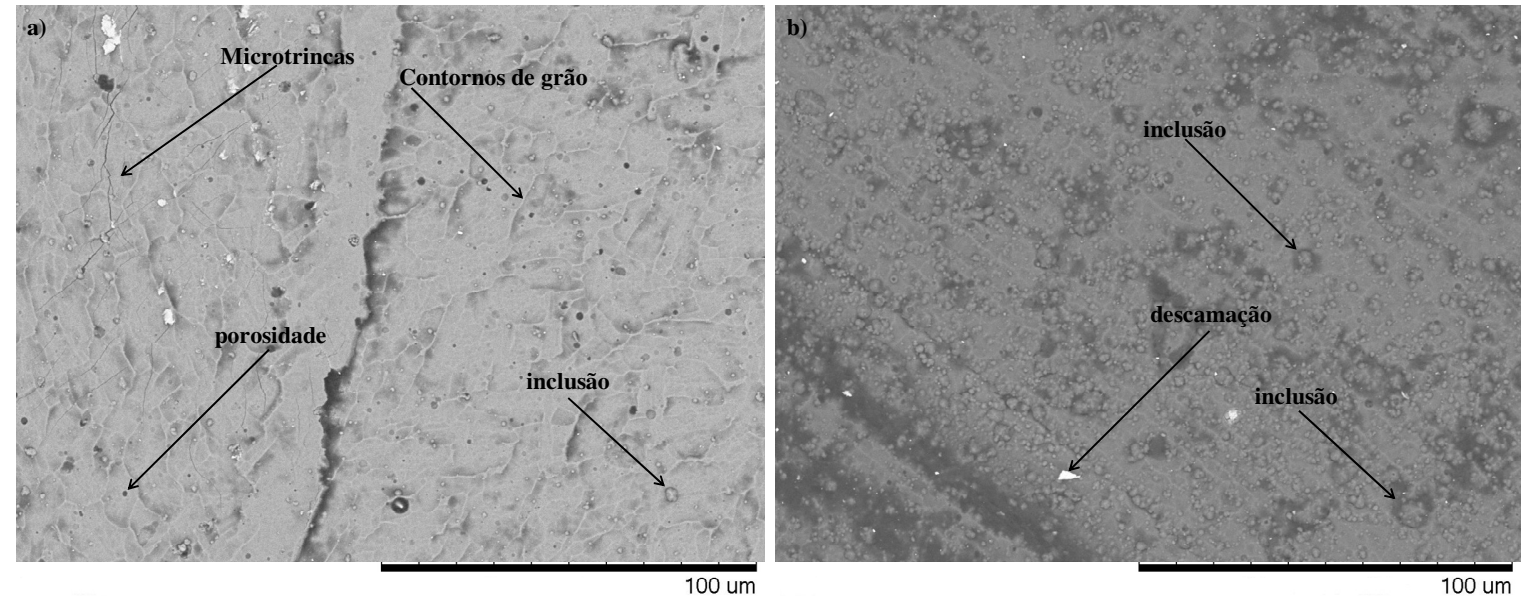

Figura 21. Microscopia Eletrônica de Varredura (MEV) das amostras revestidas antes de serem submetidas a um processo corrosivo: a) TiN, b) TiAlN/TiAlCrN.

TiN apresenta estrutura colunar o que permite à solução corrosiva chegar até o substrato através dos contornos intergranulares (LIU et al., 2001; GRIPS et al., 2006). Segundo Yilbas e colaboradores (1995) o principal mecanismo de corrosão de revestimentos base TiN depositados por PVD é, quase que sem exceção, por ataque da solução corrosiva via microporos e microtrincas. Ainda assim, os autores observaram que o revestimento melhora a resistência à corrosão da liga Ti-6Al-4V (YILBAS et al., 1995).

Segundo Kovalev e colaboradores (2010) as microestruturas dos revestimentos base $\left(\mathrm{Al}_{0,67} \mathrm{Ti}_{0,33}\right) \mathrm{N}$ apresentam-se de forma densa e do tipo colunar (KOVALEV et al., 2010). Entretanto, a formação das multicamadas impede que se forme um caminho direto entre a 
solução corrosiva e o substrato, pois uma intercamada serve como bloqueio para os defeitos (microporos) da anterior (GRIPS et al., 2006). No presente trabalho, o efeito de bloqueio não foi expressivo o bastante para impedir que a solução corrosiva entrasse em contato com o substrato. As possíveis justificativas, além do aumento do número de defeitos pela incorporação do alumínio ao nitreto, é a grande espessura da multicamada e das intercamadas ( $6 \mu \mathrm{m}, 217 \mathrm{~nm} \mathrm{CrN}, 540 \mathrm{~nm}$ TiAlN, respectivamente) e o pequeno número de interfaces $(\mathrm{N}=11)$. Trabalhos reportados por Grips et al. (2006), Liu et al. (2007) e Ananthakumar et al. (2012) mostram ótimos resultados de resistência à corrosão para revestimentos multicamadas com espessura total de até $2 \mu \mathrm{m}$, espessura da intercamada em torno de 20-30 nm e número de interfaces variando de $45<\mathrm{N}<430$ (ANANTHAKUMAR et al., 2012; GRIPS et al., 2006; LIU et al., 2007). O estudo de Aperador e colaboradores (2013) sobre o comportamento em corrosão de um aço carbono revestido em solução $\mathrm{NaCl}$ mostrou que a resistência à corrosão aumenta com o aumento do número de intercamadas em um revestimento multicamada do tipo TiN/CrN (APERADOR et al., 2013). De acordo com Nordin et al. (1999) e Barshilia et al. (2004), a resistência à corrosão diminui com o aumento da espessura das intercamadas (BARSHILIA et al., 2004; NORDIN et al., 1999). De fato, existem poucos estudos sobre a influência da microestrutura no desempenho em corrosão de revestimentos multicamadas e, por isso, mais resultados são necessários para se concluir eficientemente sobre o desempenho do revestimento TiAlN/TiAlCrN no presente trabalho.

Pohrelyuk e colaboradores (2013) estudaram o comportamento da liga Ti-6Al-4V com e sem revestimentos à base de nitretos em solução de Ringer. Segundo os autores, a nitretação melhorou a resistência à corrosão da liga Ti6Al4V. O potencial de corrosão tornou-se mais positivo e a densidade de corrente na dissolução anódica diminuiu. Os autores atribuíram esta melhora à alta resistência das ligações químicas do nitreto de titânio. Os autores ainda explicaram que o comportamento passivo da liga na solução de Ringer é comandado por duas reações principais: a primeira trata-se da oxidação de TiN em um oxinitreto que acontece segundo a seguinte reação (POHRELYUK et al., 2013):

$2 \mathrm{TiN}+2 \mathrm{yH}_{2} \mathrm{O} \rightarrow 2 \mathrm{TiN}_{x} \mathrm{O}_{y}+(1-x) \mathrm{N}_{2}+4 y \mathrm{H}^{+}+4 y e^{-}$

A segunda etapa está relacionada com a oxidação dos oxinitretos para óxidos de titânio não estequiométricos como ilustra as reações a seguir (POHRELYUK et al., 2013):

$2 \mathrm{TiN}_{x} \mathrm{O}_{y}+2 \mathrm{H}_{2} \mathrm{O} \rightarrow 2 \mathrm{Ti}^{3+}+(\mathrm{y}+1) \mathrm{O}_{2}+x \mathrm{~N}_{2}+4 \mathrm{H}^{+}+10 e^{-}$ $\mathrm{Ti}^{3+}+x \mathrm{H}_{2} \mathrm{O} \rightarrow \mathrm{TiO}_{x}+2 x \mathrm{H}^{+}+(2 x-3) e^{-}$. 
Neste trabalho considerou-se que as duas etapas descritas acima comandaram o comportamento passivo da liga recoberta por TiN e TiAlN em todas as condições experimentais. Adicionalmente, a adição de alumínio e cromo ao nitreto TiN pode levar a formação dos óxidos $\mathrm{Al}_{2} \mathrm{O}_{3}$ e $\mathrm{Cr}_{2} \mathrm{O}_{3}$ durante o processo corrosivo segundo as seguintes reações (FENG et al., 2006; BARSHILIA et al., 2009; CHEN et al., 2013; WEFERS; MISRA, 1987; GAO et al., 2013):

$2 \mathrm{Al}+3 \mathrm{H}_{2} \mathrm{O} \rightarrow \mathrm{Al}_{2} \mathrm{O}_{3}+3 \mathrm{H}_{2}$

$4 \mathrm{Cr}+3 \mathrm{O}_{2} \rightarrow 2 \mathrm{Cr}_{2} \mathrm{O}_{3}$.

A Tabela 9 apresenta os valores de densidade de corrente de corrosão ( $i_{\text {corr }}$ ) obtidos por vários autores.

Tabela 9 - Valores de densidade de corrente de corrosão (icorr) eletroquímica para testes conduzidos com ligas metálicas recobertas com TiN e TiAlN.

\begin{tabular}{|c|c|c|c|}
\hline Revestimento & Referências & Condições de corrosão* & $i_{\text {corr }}\left(\mathrm{A} / \mathrm{cm}^{2}\right)$ \\
\hline \multirow{13}{*}{$\mathrm{TiN}$} & GRIPS et al., 2006 & $3,5 \% \mathrm{NaCl}$ & $7,69 \times 10^{-6}$ \\
\hline & YOO et al., 2008 & $3,5 \% \mathrm{NaCl}$ & $4,39 \times 10^{-6}$ \\
\hline & AHN et al., 2007 & $3,5 \% \mathrm{NaCl}$ & $8,45 \times 10^{-6}$ \\
\hline & \multirow{2}{*}{ POHRELYUK et al., 2013} & Solução de Ringer $36{ }^{\circ} \mathrm{C}$ & $5,5 \times 10^{-6}$ \\
\hline & & Solução de Ringer $40^{\circ} \mathrm{C}$ & $5 \times 10^{-6}$ \\
\hline & LI et al., 2003 & $0,5 \mathrm{~mol} / \mathrm{l} \mathrm{NaCl}$ & $3,35 \times 10^{-7}$ \\
\hline & YILBAS et al., 1995 & $\begin{array}{c}0,1 \mathrm{~N} \mathrm{H}_{2} \mathrm{SO}_{4}+0.05 \mathrm{M} \\
\mathrm{NaCl}\end{array}$ & $4,9 \times 10^{-6}$ \\
\hline & \multirow{2}{*}{ CUNHA et al., 1998} & $9 \% \mathrm{NaCl}$ & $3,6 \times 10^{-8}$ \\
\hline & & $3,4 \% \mathrm{HCl}$ & $3,3 \times 10^{-7}$ \\
\hline & MATTHES et al., 1991 & $0,5 \mathrm{M} \mathrm{H}_{2} \mathrm{SO}_{4}$ & $1 \times 10^{-5}$ \\
\hline & WANG et al., 2007 & $0,5 \mathrm{M} \mathrm{H}_{2} \mathrm{SO}_{4}$ & $1,75 \times 10^{-6}$ \\
\hline & HSU et al., 2013 & $3,5 \% \mathrm{NaCl}$ & $1,12 \times 10^{-6}$ \\
\hline & SOUTO et al., 2000 & $0,5 \mathrm{M} \mathrm{NaCl}$ & $6,6 \times 10^{-8}$ \\
\hline \multirow{8}{*}{ TiAlN } & GRIPS et al., 2006 & $3,5 \% \mathrm{NaCl}$ & $4,26 \times 10^{-6}$ \\
\hline & YOO et al., 2008 & $3,5 \% \mathrm{NaCl}$ & $2,23 \times 10^{-6}$ \\
\hline & LI et al., 2003 & $0,5 \mathrm{~mol} / \mathrm{l} \mathrm{NaCl}$ & $1,71 \times 10^{-7}$ \\
\hline & $\begin{array}{l}\text { SUBRAMANIAN et al., } \\
2011\end{array}$ & solução corpórea sintética & $2,8 \times 10^{-6}$ \\
\hline & CHUNG et al., 2004 & Solução de Ringer & $3,68 \times 10^{-7}$ \\
\hline & CUNHA et al., 1998 & $3,4 \% \mathrm{HCl}$ & $3,9 \times 10^{-7}$ \\
\hline & CHAN et al., 2013 & $3,5 \% \mathrm{NaCl}$ & $1,65 \times 10^{-6}$ \\
\hline & SOUTO et al., 2000 & $0,5 \mathrm{M} \mathrm{NaCl}$ & $6,3 \times 10^{-8}$ \\
\hline
\end{tabular}

$*$ as temperaturas foram informadas quando diferentes de $25^{\circ} \mathrm{C}$. 
Os valores de $i_{\text {corr }}$ reportados no presente trabalho para as condições revestidas por TiN e TiAlN/TiAlCrN foram da ordem de $10^{-7} \mathrm{~A} / \mathrm{cm}^{2}$ nas duas soluções corrosivas. Este resultado demonstra que estes compostos são realmente inertes e que não apresentam variação significativa no comportamento à corrosão com a mudança de meios corrosivos. Os valores de $\mathrm{i}_{\text {corr }}$ reportados por Li (2003), Cunha (1998) e Chung (2004) encontram-se na mesma ordem de grandeza dos valores de $i_{\text {corr }}$ encontrados no presente trabalho (CHUNG et al., 2004; CUNHA et al., 1998; LI et al., 2003). Sabe-se que variáveis como microestrutura, técnica de deposição, espessura, entre outras, influenciam consideravelmente nos resultados obtidos (AHN et al., 2007; CUNHA et al., 1998, FORTUNA et al., 2000; GRIPS et al., 2006; ZHAO et al., 2011) e, portanto, uma comparação de valores torna-se complicada. Adicionalmente, deposições conduzidas por plasma permitem melhor controle da estrutura da camada e maior adesão (AVELARBATISTA et al., 2005). A multicamada de TiAlN/TiAlCrN não teve o desempenho esperado, ou seja, não apresentou uma resistência à corrosão muito melhor em relação à camada à base de TiN. As Figuras 22 e 23 mostram o aspecto da superfície corroída da liga Ti-6Al-4V com e sem revestimento nas soluções corrosivas $\mathrm{HCl}$ e $\mathrm{NaCl}$, respectivamente.
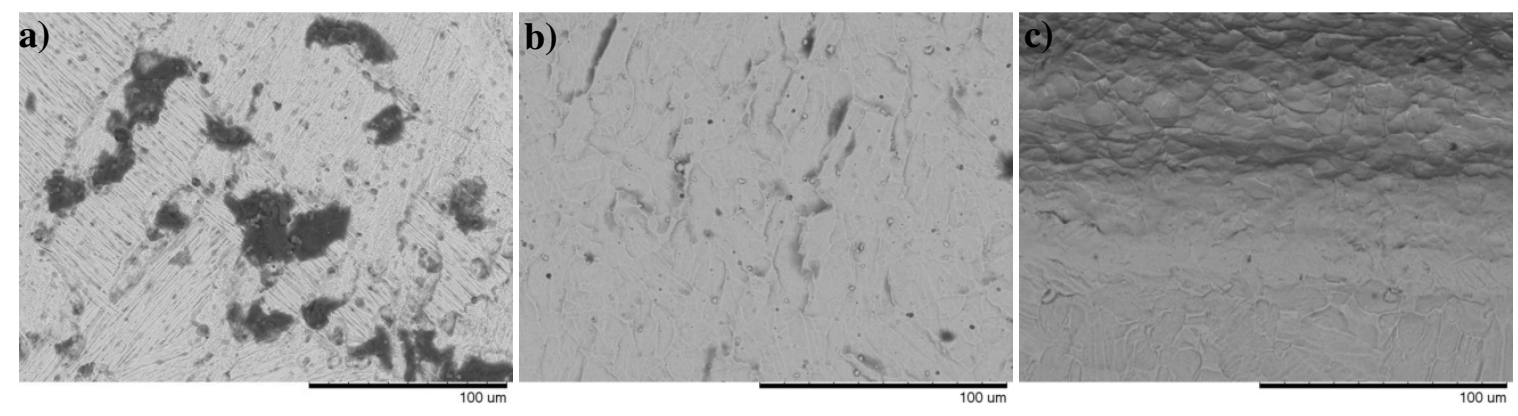

Figura 22. Microscopia eletrônica de varredura (MEV) das superfícies corroídas após 3 horas de imersão + polarização em HCl: a) Ti-6Al-4V, b) TiN, c) TiAlN/TiAlCrN.

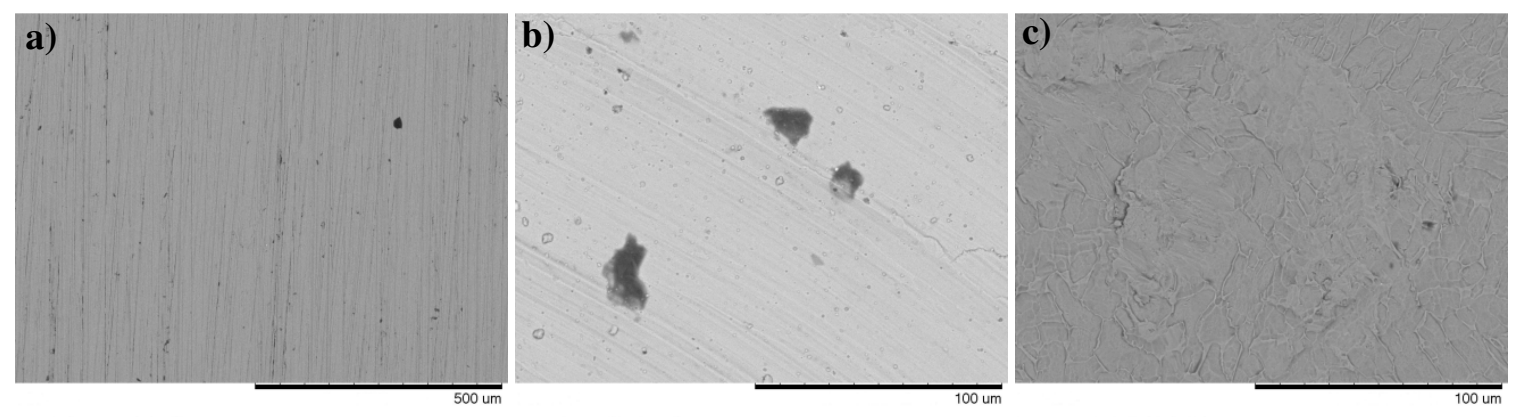

Figura 23. Microscopia eletrônica de varredura (MEV) das superfícies corroídas após 3 horas de imersão + polarização em NaCl: a) Ti-6Al-4V, b) TiN, c) TiAlN/TiAlCrN.

Com base nas observações das Figuras 22 e 23 pode-se notar que a liga Ti-6Al-4V sem recobrimento em $\mathrm{HCl}$ foi atacada nas interfaces $\alpha / \beta$ e nos contornos de grão e, em 
solução $\mathrm{NaCl}$, não apresentou nenhuma modificação na superfície mostrando-se com aspecto lixado como antes da corrosão. O revestimento à base de TiN manteve sua integridade microestrutural após o teste de corrosão nas duas soluções corrosivas, embora a sua espessura depois dos testes corrosivos tenha decrescido de 2,2 $\mu \mathrm{m}$ para 1,8 $\mu \mathrm{m}$ (esta variação da espessura foi parecida para as duas soluções). O revestimento à base de TiAlN/TiAlCrN desprendeu-se completamente da superfície após polarização tanto em $\mathrm{HCl}$ como em NaCl. A Figura 24 ilustra o aspecto da superfície depois de sofrer descamação com o revestimento depositado no fundo do béquer.

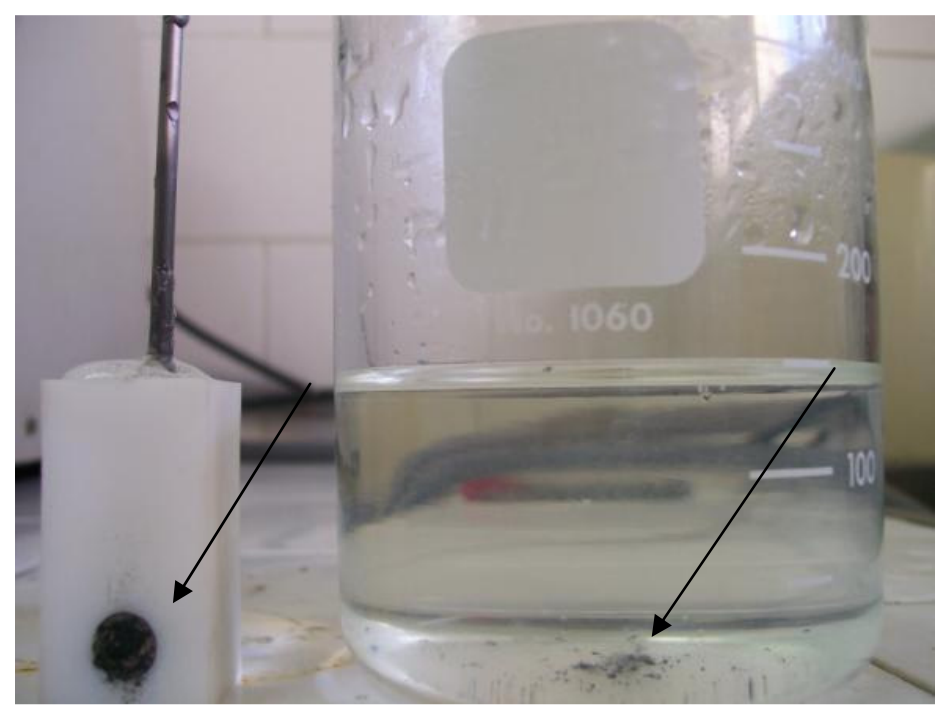

Figura 24. Aspecto da superfície do material após o teste de corrosão: TiAlN em solução de $\mathrm{NaCl}$.

\subsubsection{ESPECTROSCOPIA DE IMPEDÂNCIA ELETROQUÍMICA}

\subsubsection{MODELAGEM DOS CIRCUITOS ELÉTRICOS}

A escolha de um modelo de circuito elétrico capaz de descrever uma IE é feita baseando-se nas curvas geradas pelo teste de impedância eletroquímica. Segue abaixo os modelos de circuito elétrico propostos para cada uma das condições estudadas.

a) Ti-6Al-4V sem recobrimento em solução $\mathrm{HCl}$ :

A liga comportou-se ativamente nesta solução expondo a superfície metálica à corrosão com a posterior formação de produtos de corrosão que aderiram à superfície. $\mathrm{O}$ circuito equivalente proposto foi de duas constantes de tempo. A primeira relacionada com 
a resistência à polarização da superfície metálica e a segunda relacionada com a resistência à polarização dos produtos de corrosão aderidos à superfície. Os elementos que constituiram este circuito equivalente foram os seguintes: $R_{S}$ que corresponde à resistência da solução corrosiva, $\mathrm{R}_{1}$ e $\mathrm{C}_{1}$ estão relacionados, respectivamente, com a resistência e com a pseudo-capacitância (CPE) dos produtos de corrosão e $R_{p}$ e $C_{d c}$ que correspondem, respectivamente, à resistência à transferência de carga e à pseudo-capacitância da dupla camada elétrica formada na interface solução/superfície metálica (MENDOZACANALES; MARÍN-CRUZ, 2008; ROSSI et al., 2003). A Figura 25 ilustra o modelo com os elementos descritos acima.

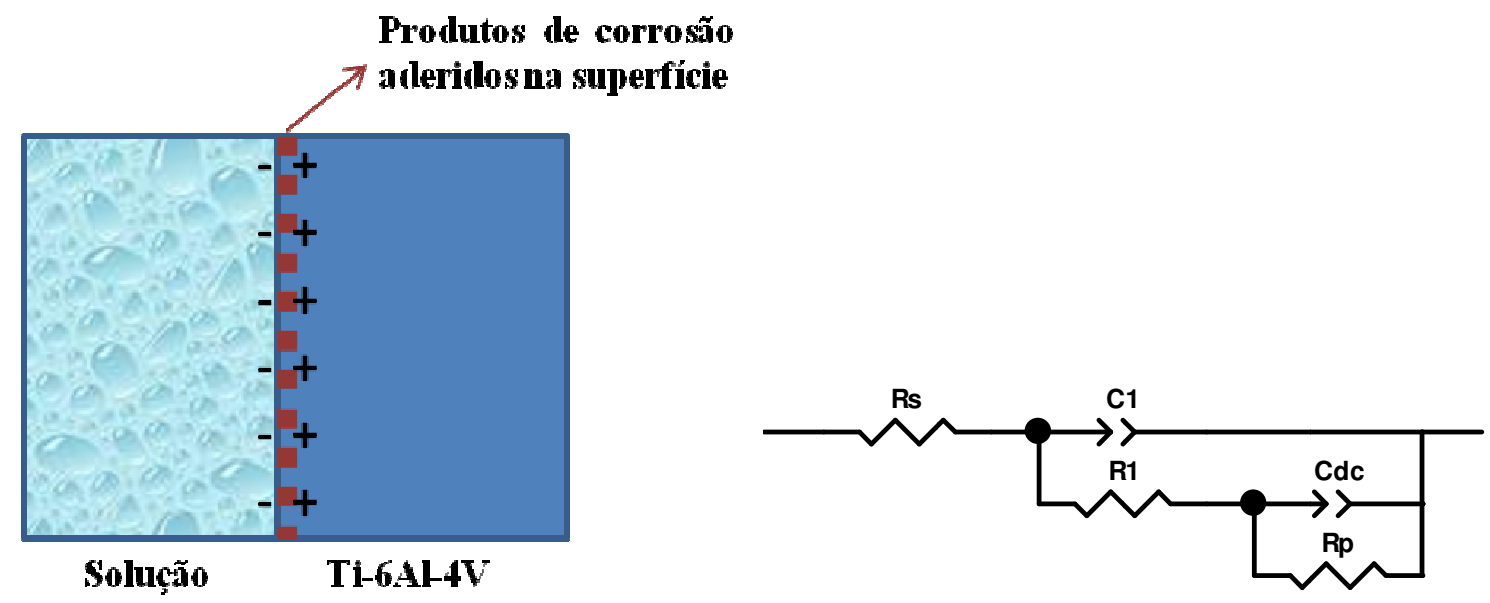

Figura 25. Circuito elétrico equivalente proposto para a condição Ti-6Al-4V em solução HCl 2M (MENDOZACANALES; MARÍN-CRUZ, 2008; ROSSI et al., 2003).

Os autores Mendoza-Canales (2008) e Rossi et al. (2003) estudaram o comportamento de ligas de titânio em soluções ácidas, os primeiros utilizaram titânio grau 2 em $\mathrm{HCl}+\mathrm{H}_{2} \mathrm{~S}$, os últimos trabalharam com Ti-6Al-4V em $\mathrm{HCl}$. Ambos os autores observaram comportamento ativo de suas respectivas ligas nas soluções ácidas, fizeram analises de impedância eletroquímica e ajustaram seus resultados segundo um modelo de circuito equivalente de duas constantes de tempo. Os autores explicam que este comportamento é resultado da formação de produtos de corrosão que aderem à superfície e possuem natureza eletroquímica diferente da base metálica e, portanto, criam uma sobreposição no tempo em que o processo de transferência de carga está acontecendo. Contudo, os autores não especificam quais são as reações e os possíveis produtos de corrosão que estão envolvidos neste processo especificamente (MENDOZA-CANALES; MARÍN-CRUZ, 2008; ROSSI et al., 2003). Além disso, Kahled (2004) estudou o comportamento do ferro em $\mathrm{HCl}$ através da impedância eletroquímica. Segundo o autor, metais que sofrem corrosão ativa apresentam resultados de impedância que se ajustam 
segundo um modelo de duas constantes de tempo quando forma-se sobre a superfície uma camada óxida incompleta, ou seja, não se estende por toda a superfície (KAHLED, 2004). Por isso, pode-se considerar que as constantes $\mathrm{R}_{1}$ e $\mathrm{C}_{1}$ estão relacionadas com a resistência e capacitância dos produtos de corrosão, respectivamente e, $R_{p}$ e $C_{d c}$ estão relacionados com a resistência à polarização (ou à transferência de carga) e capacitância da interface eletrodo/eletrólito, respectivamente (MENDOZA-CANALES; MARÍN-CRUZ, 2008).

b) Ti-6Al-4V sem recobrimento em solução $\mathrm{NaCl}$ :

A liga comportou-se passivamente em $\mathrm{NaCl}$ o que indica que a camada passiva óxida à base de $\mathrm{TiO}_{2}$, formada ao ar, estabilizou-se nos meios corrosivos à base de $\mathrm{NaCl}$. $\mathrm{O}$ filme protetor à base de $\mathrm{TiO}_{2}$ tende a formar sobre si, quando em solução eletrolítica, uma camada mais porosa também à base de $\mathrm{TiO}_{2}$. Portanto, o circuito equivalente proposto foi de duas constantes de tempo. A primeira relacionada com a resistência à polarização da camada porosa mais externa e a segunda relacionada com a resistência à polarização da camada compacta mais interna. Os elementos que constituem este circuito equivalente são os seguintes: $R_{s}$ que corresponde à resistência da solução corrosiva, $R_{f p o r}$ e $C_{\text {fpor }}$ estão relacionados, respectivamente, com a resistência e com a pseudo-capacitância (CPE) da camada porosa mais externa e $\mathrm{R}_{\text {fpass }}$ e $\mathrm{C}_{\text {fpass }}$ que estão relacionados com a resistência e com a pseudo-capacitância (CPE) da camada óxida compacta mais interna (ALVES et al., 2009; MANHABOSCO et al., 2011; VASILESCU et al., 2011; WANG et al., 2003). A Figura 26 ilustra o modelo com os elementos descritos acima.
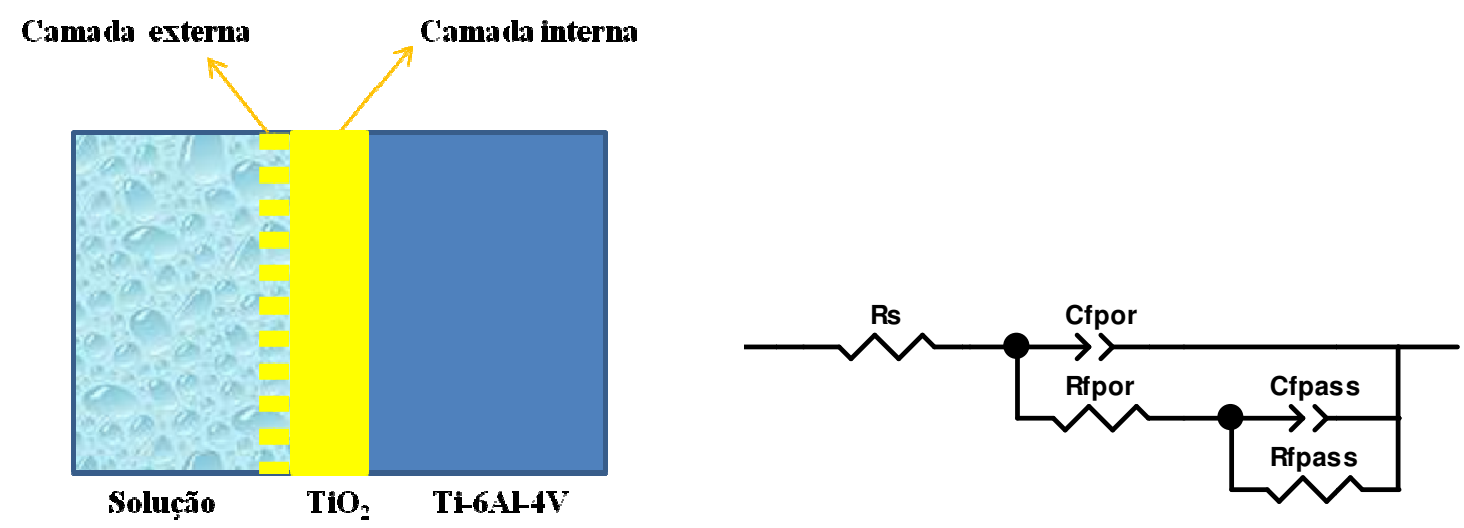

Figura 26. Circuito elétrico equivalente proposto para a condição Ti-6Al-4V nas soluções NaCl 3,5 \%p. (ALVES et al., 2009; MANHABOSCO et al., 2011; VASILESCU et al., 2011; WANG et al., 2003).

c) Ti-6Al-4V recoberto com TiN e TiAlN nas soluções $\mathrm{NaCl}$ e $\mathrm{HCl}$ :

Os dois recobrimentos comportaram-se passivamente nas duas soluções corrosivas. Como mencionado anteriormente, recobrimentos à base de nitretos são inertes em praticamente qualquer meio corrosivo. O problema está no método de aplicação (PVD) que 
leva a formação de um recobrimento com defeitos (poros, trincas, contornos de grão) (GRIPS et al., 2006; LIU et al., 2003). Nas duas soluções a liga comportou-se segundo o modelo de circuito elétrico equivalente de duas constantes de tempo com os seguintes elementos: $R_{s}$ que corresponde à resistência da solução corrosiva, $R_{\text {rev }}$ representa a resistência do revestimento defeituoso (poros, trincas, contornos de grão) à transferência iônica; $R_{p}$ representa a resistência à transferência de carga na interface revestimento/substrato. $\mathrm{C}_{\mathrm{rev}}$ e $\mathrm{C}_{\mathrm{dc}}$ representam as pseudo-capacitâncias nas interfaces solução/revestimento e revestimento/substrato, respectivamente (AHN et al., 2007; GRIPS et al., 2006; LIN; DUH, 2009; LIU et al., 2003). A Figura 27 ilustra o modelo com os elementos descritos acima.

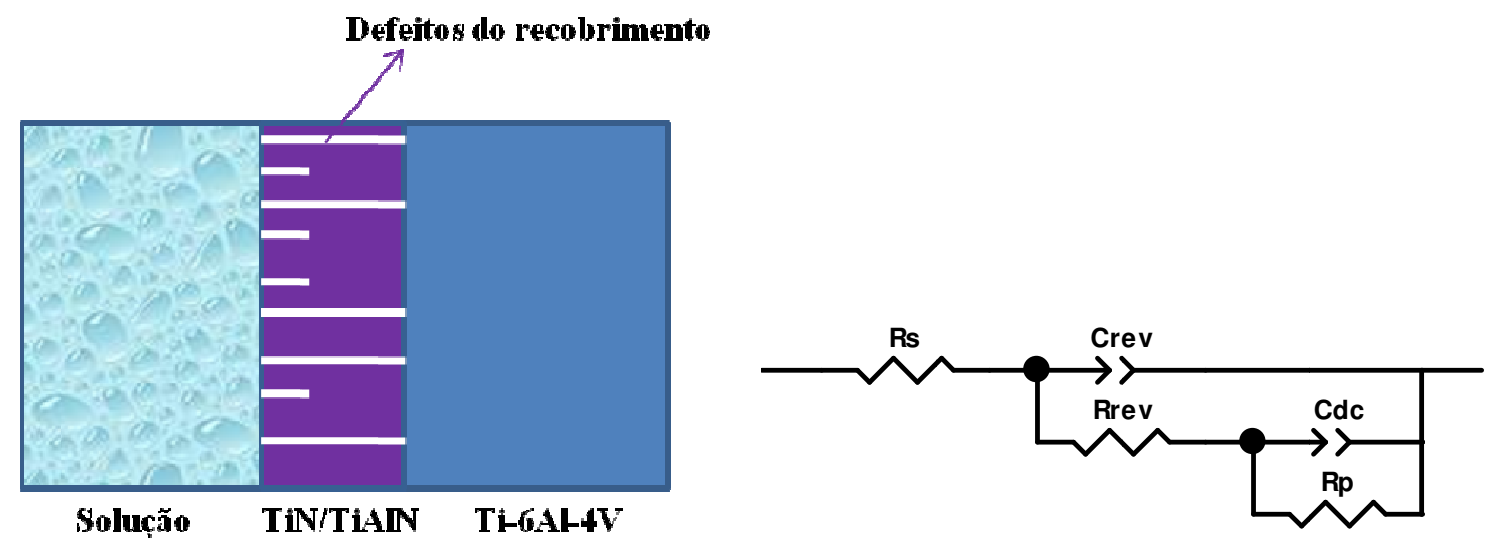

Figura 27. Circuito elétrico equivalente proposto para a condição recoberta (TiN e TiAlN) nas soluções $\mathrm{NaCl} 3,5 \%$ p. e HCl 2M (AHN et al., 2007; GRIPS et al., 2006; LIN; DUH, 2009; LIU et al., 2003).

\subsubsection{MEDIDAS DE IMPEDÂNCIA ELETROQUÍMICA}

As Figuras 28 a 30 mostram os diagramas de Nyquist e Bode para a liga Ti-6Al-4V sem e com recobrimento em solução $\mathrm{HCl}$.
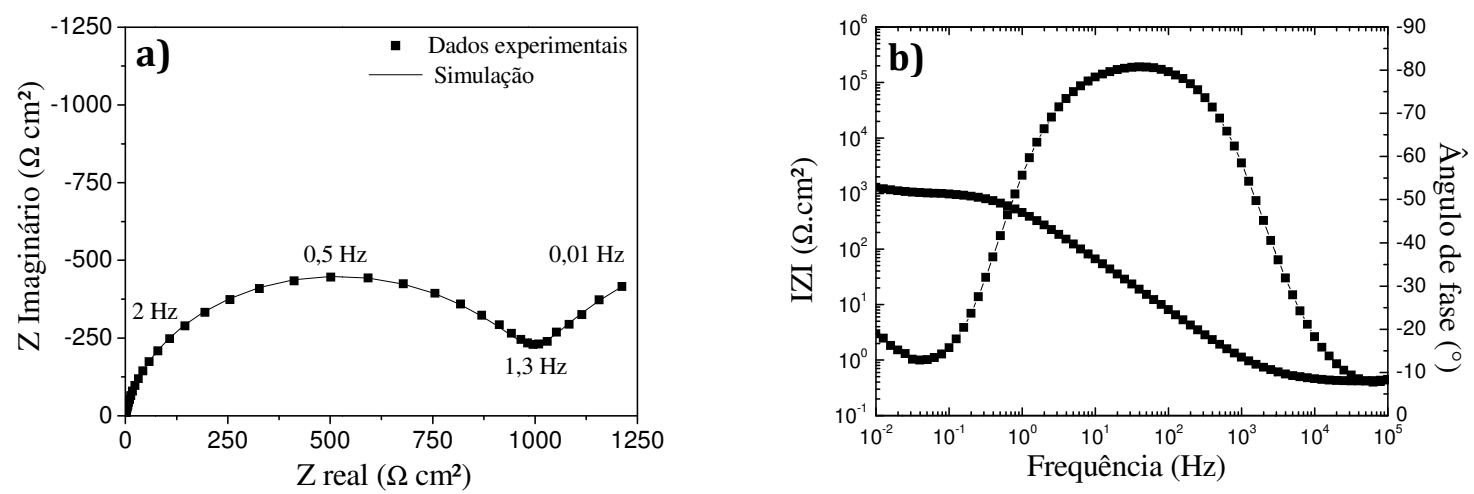

Figura 28. Ti-6Al-4V sem recobrimento em solução $\mathrm{HCl} 2 \mathrm{M}$ a $25{ }^{\circ} \mathrm{C}$ : a) Diagrama de Nyquist, b) Diagrama de Bode (módulo vs. frequência e fase vs. frequência). 

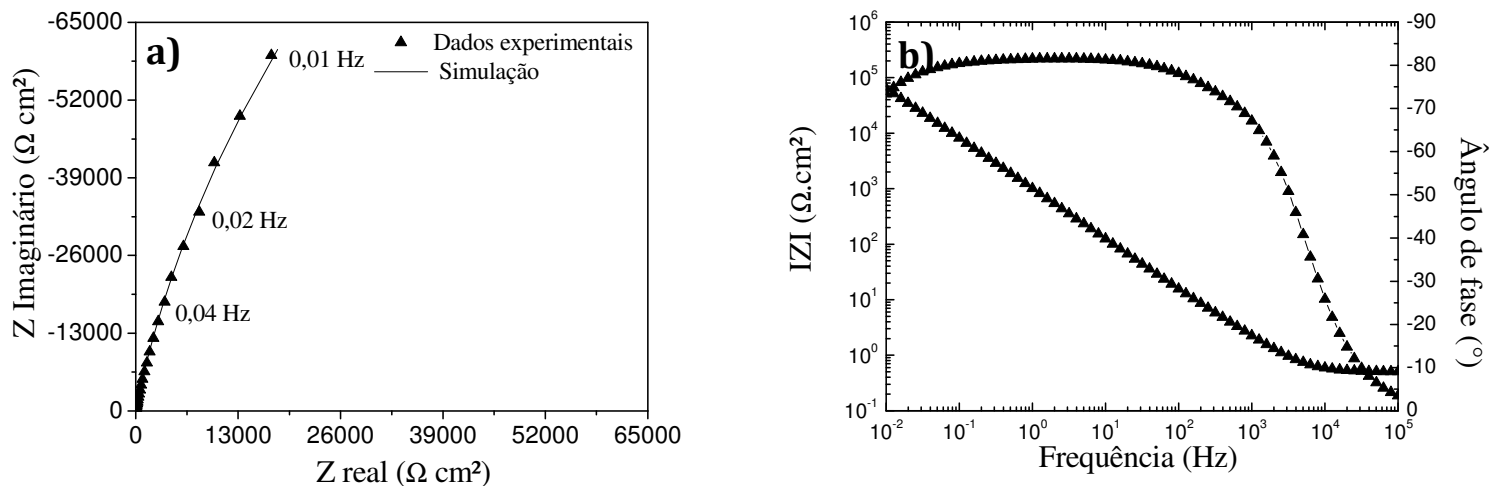

Figura 29. Ti-6Al-4V recoberta por TiN em solução $\mathrm{HCl} 2 \mathrm{M}$ a $25^{\circ} \mathrm{C}$ : a) Diagrama de Nyquist, b) Diagrama de Bode (módulo vs. frequência e fase vs. frequência).
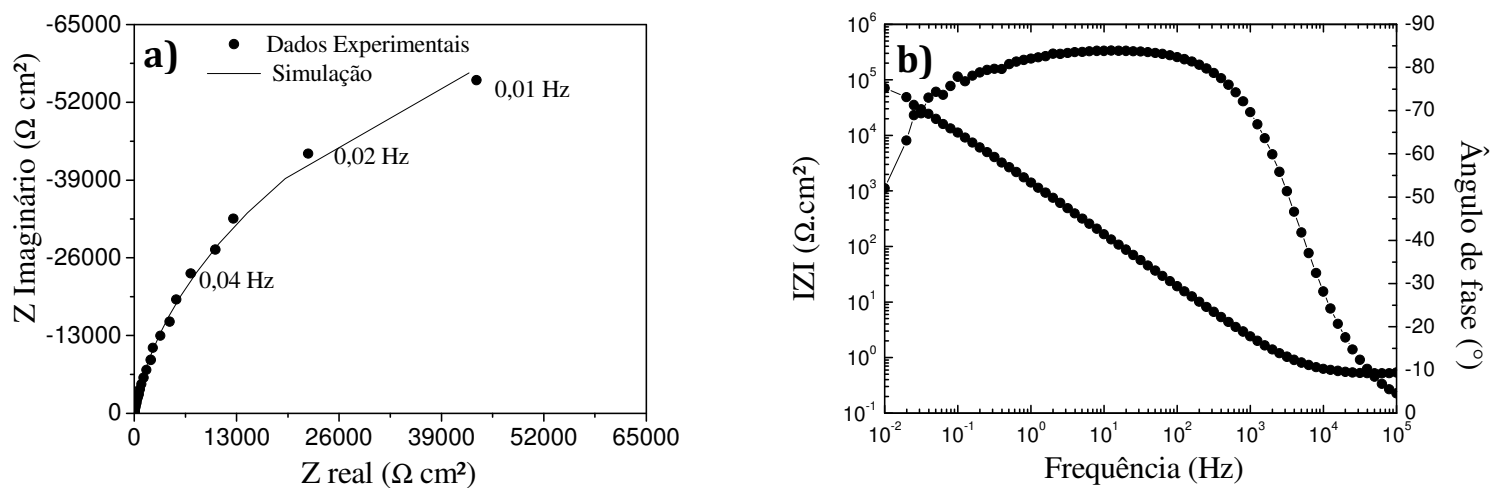

Figura 30. Ti-6Al-4V recoberta por TiAlN/TiAlCrN em solução $\mathrm{HCl} 2 \mathrm{M}$ a $25{ }^{\circ} \mathrm{C}$ : a) Diagrama de Nyquist, b) Diagrama de Bode (módulo vs. frequência e fase vs. frequência).

As Figuras 31 a 33 mostram os diagramas de Nyquist e Bode para a liga Ti-6Al-4V sem e com recobrimento em solução $\mathrm{NaCl}$.
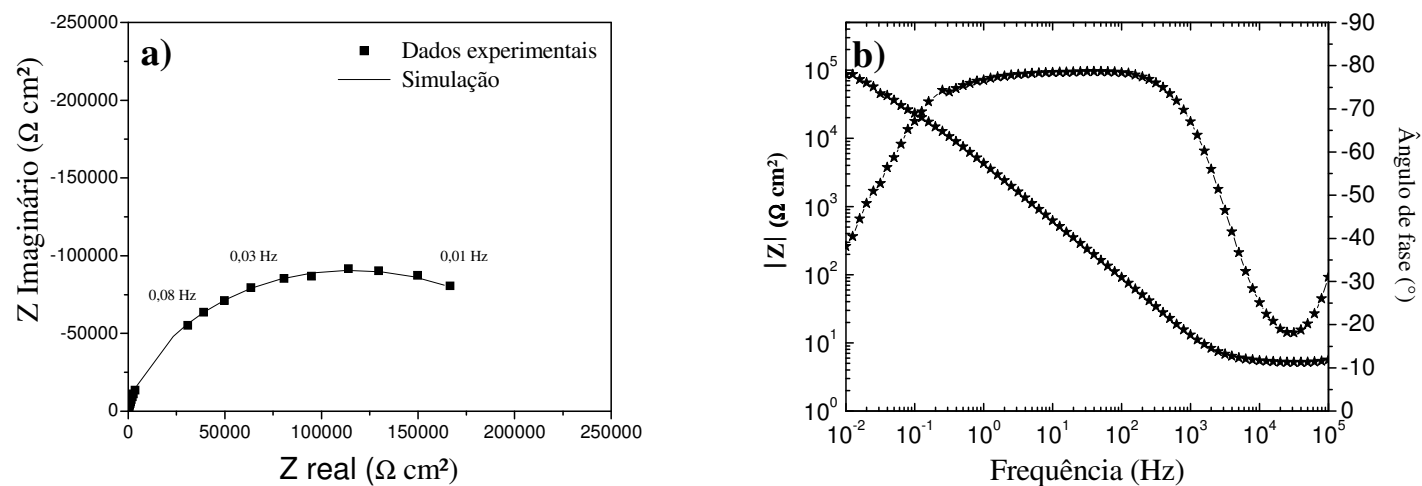

Figura 31. Ti-6Al-4V sem recobrimento em solução $\mathrm{NaCl} 3,5 \%$ p. a $25{ }^{\circ} \mathrm{C}$ : a) Diagrama de Nyquist, b) Diagrama de Bode (módulo vs. frequência e fase vs. frequência). 

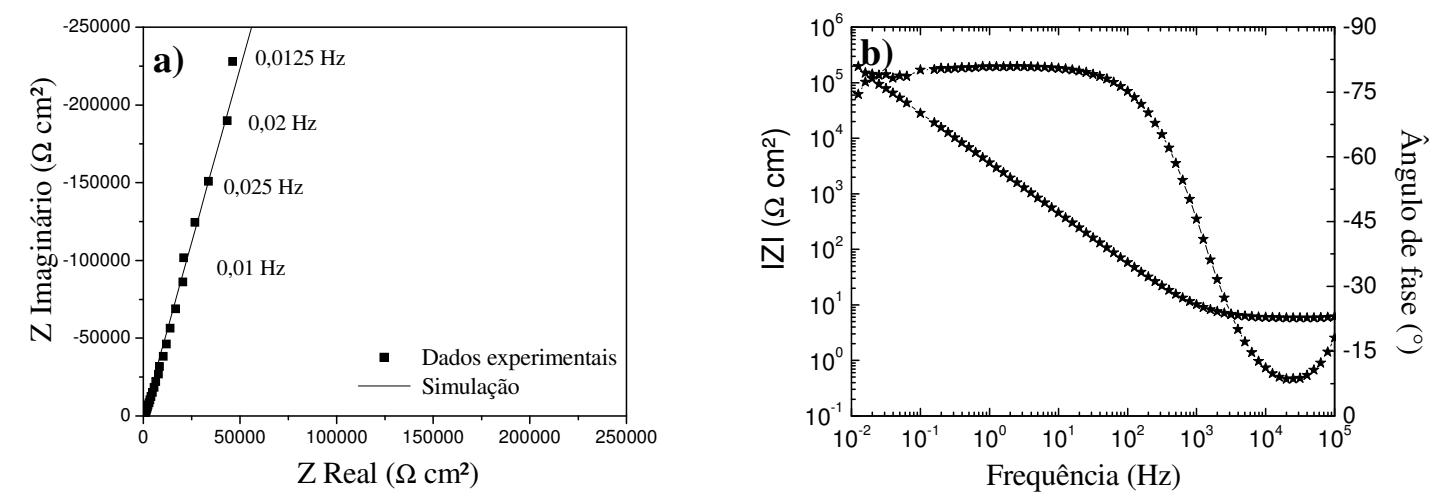

Figura 32. Ti-6Al-4V recoberta por TiN em solução $\mathrm{NaCl} 3,5 \%$ p. a $25{ }^{\circ} \mathrm{C}$ : a) Diagrama de Nyquist, b) Diagrama de Bode (módulo vs. frequência e fase vs. frequência).
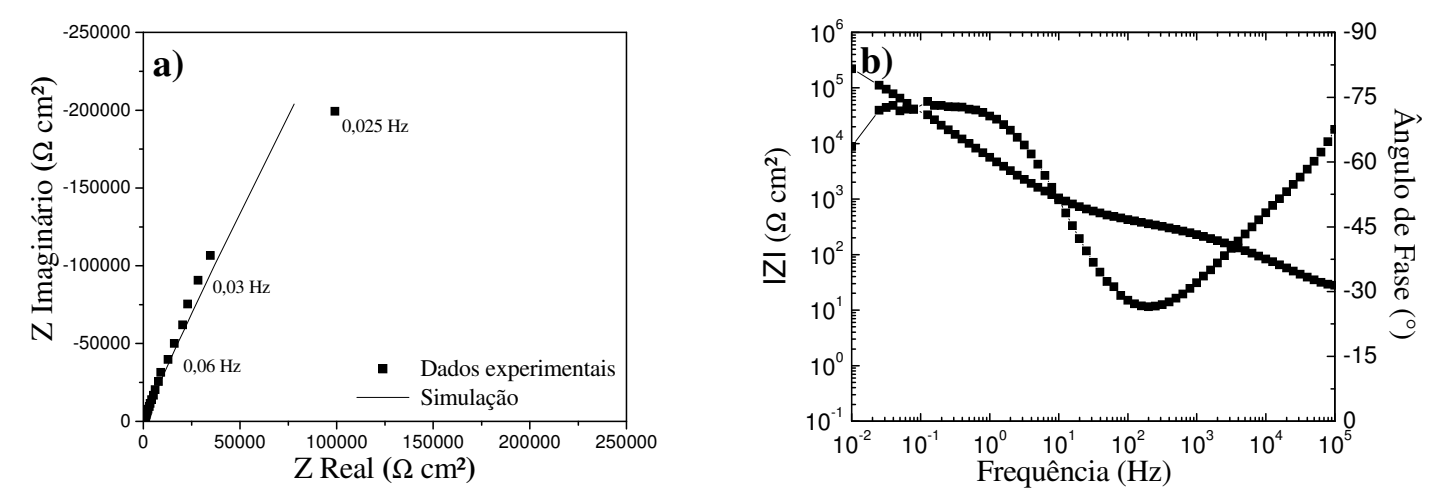

Figura 33. Ti-6Al-4V recoberta por TiAlN/TiAlCrN em solução $\mathrm{NaCl} 3,5 \%$ p. a $25{ }^{\circ} \mathrm{C}$ : a) Diagrama de Nyquist, b) Diagrama de Bode (módulo vs. frequência e fase vs. frequência).

As medidas de impedância são feitas de acordo com os diâmetros do semicírculo do diagrama de Nyquist: quanto maior o diâmetro do semicírculo maior a resistência do material na solução corrosiva. Nos diagramas de Bode, o módulo de $\mathrm{Z}$ e o ângulo de fase ( $\theta)$ são representados em função do logaritmo da frequência. Se $\theta$ é igual a $-90^{\circ}$, então o eletrodo se comporta como um capacitor ideal; se $\theta$ é igual a $0^{\circ}$, o eletrodo se comporta como uma resistência. De forma geral, em regiões de baixas e altas frequências $(f<10 \mathrm{~Hz}$ ou $f>100 \mathrm{kHz})$, o ângulo de fase tende a $0^{\circ}$. Já para frequências intermediárias $(0,1<f<$ $100 \mathrm{kHz}$ ) o ângulo de fase mantém-se próximo a $-90^{\circ}$. Quanto maior está faixa de frequências intermediárias próxima a $-90^{\circ}$, mais estável é o filme óxido passivante (MOISEL; MELE; MÜLLER, 2008; VASILESCU et al., 2011). Para a liga revestida as análises do diagrama de Bode mostram que a impedância em alta frequência representa a resposta do revestimento (informação do material cerâmico), enquanto que em baixas frequências a informação é sobre o processo relacionado com a reação na interface solução/substrato através dos defeitos do revestimento (YANG et al., 2005). 
As Tabelas 10 e 11 apresentam os parâmetros calculados segundo os ajustes feitos por cada modelo de circuito elétrico equivalente de duas constantes de tempo, descritos no item 4.3.2.1.

Tabela 10. Parâmetros obtidos através do ajuste do modelo de circuito elétrico equivalente com duas constantes de tempo para a liga Ti-6Al-4V com e sem recobrimento, em solução $\mathrm{HCl} 2 \mathrm{M}$ a $25^{\circ} \mathrm{C}$.

\begin{tabular}{|c|c|c|c|c|c|c|c|}
\hline \multirow[b]{2}{*}{ Amostras } & \multicolumn{7}{|c|}{ Parâmetros } \\
\hline & $\begin{array}{c}\mathrm{CPE}_{1} \\
\left(\mathbf{F} . \mathrm{cm}^{-2}\right)\end{array}$ & $\mathbf{n}_{1}$ & $\begin{array}{c}\mathrm{CPE}_{\mathrm{dc}} \\
\left(\mathbf{F} . \mathrm{cm}^{-2}\right)\end{array}$ & $\mathbf{n}_{\mathrm{dc}}$ & $\begin{array}{c}\mathbf{R}_{\mathbf{s}} \\
\left(\mathbf{\Omega . c m ^ { 2 }}\right)\end{array}$ & $\begin{array}{c}\mathbf{R}_{1} \\
\left(\mathbf{\Omega . c m}{ }^{2}\right)\end{array}$ & $\begin{array}{c}\mathbf{R}_{\mathbf{p}} \\
\left(\mathbf{\Omega . c m ^ { 2 } )}\right.\end{array}$ \\
\hline Ti-6Al-4V & $4,2 \times 10^{-4}$ & 0,91 & 0,01 & 0,84 & 0,43 & 1066 & $1,4 \times 10^{3}$ \\
\hline & $\begin{array}{c}\mathbf{C P E}_{\mathrm{rev}} \\
\left(\mathrm{F} \cdot \mathrm{cm}^{-2}\right)\end{array}$ & $\mathbf{n}_{\text {rev }}$ & $\underset{\left(\mathrm{F}^{-\mathrm{cm}^{-2}}\right)}{\mathrm{CPE}_{\mathrm{dc}}}$ & $\mathbf{n}_{\mathrm{dc}}$ & $\begin{array}{c}\mathbf{R}_{\mathrm{s}} \\
\left(\mathbf{\Omega . c m ^ { 2 }}\right)\end{array}$ & $\begin{array}{c}\mathbf{R}_{\text {rev }} \\
\left.(\mathbf{\Omega . c m})^{2}\right)\end{array}$ & $\begin{array}{c}\mathbf{R}_{\mathbf{p}} \\
(\mathbf{\Omega . c m})^{2}\end{array}$ \\
\hline TiN & $1,3 \times 10^{-4}$ & 0,93 & $5,4 \times 10^{-5}$ & 0,85 & 0,52 & 21 & $4,7 \times 10^{5}$ \\
\hline TiAlN/TiAlCrN & $3,8 \times 10^{-4}$ & 0,86 & $1,8 \times 10^{-4}$ & 0,99 & 0,52 & 4242 & $1,2 \times 10^{5}$ \\
\hline
\end{tabular}

Tabela 11. Parâmetros obtidos através do ajuste do modelo de circuito elétrico equivalente com duas constantes de tempo para a liga Ti-6Al-4V com e sem recobrimento, em solução $\mathrm{NaCl} 3,5 \%$ p. a $25^{\circ} \mathrm{C}$.

\begin{tabular}{|c|c|c|c|c|c|c|c|}
\hline \multirow[b]{2}{*}{ Amostras } & \multicolumn{7}{|c|}{ Parâmetros } \\
\hline & $\begin{array}{l}\mathbf{C P E}_{\text {fpass }} \\
\left(\mathbf{F} . \mathrm{cm}^{-2}\right) \\
\end{array}$ & $\mathbf{n}_{\text {fpass }}$ & $\begin{array}{l}\mathbf{C P E}_{\text {fpor }} \\
\left(\mathrm{F} \mathrm{cm}^{-2}\right) \\
\end{array}$ & $\mathbf{n}_{\text {fpor }}$ & $\begin{array}{c}\mathbf{R}_{\mathrm{s}} \\
\left(\mathbf{\Omega . c m ^ { 2 }}\right) \\
\end{array}$ & $\begin{array}{c}\begin{array}{c}\mathbf{R}_{\text {fpor }} \\
\left.(\boldsymbol{\Omega . c m})^{2}\right)\end{array} \\
\end{array}$ & $\begin{array}{c}\begin{array}{c}\mathbf{R}_{\text {fpass }} \\
\left(\boldsymbol{\Omega} . \mathrm{cm}^{2}\right)\end{array} \\
\end{array}$ \\
\hline \multirow[t]{2}{*}{ Ti-6Al-4V } & $1,4 \times 10^{-6}$ & 0,97 & $2,6 \times 10^{-5}$ & 0,88 & 4,5 & 10,4 & $2,2 \times 10^{5}$ \\
\hline & $\begin{array}{c}\mathrm{CPE}_{\mathrm{rev}} \\
\left(\mathrm{F} . \mathrm{cm}^{-2}\right)\end{array}$ & $\mathbf{n}_{\mathrm{rev}}$ & $\begin{array}{c}\mathrm{CPE}_{\mathrm{dc}} \\
\left(\mathbf{F} . \mathrm{cm}^{-2}\right)\end{array}$ & $\mathbf{n}_{\mathrm{dc}}$ & $\begin{array}{c}\mathbf{R}_{\mathrm{s}} \\
\left(\Omega . \mathrm{cm}^{2}\right)\end{array}$ & $\begin{array}{c}\mathbf{R}_{\text {rev }} \\
\left(\mathbf{\Omega . c c ^ { 2 }}\right)\end{array}$ & $\mathbf{R}_{\mathrm{p}}\left(\mathbf{\Omega} . \mathrm{cm}^{2}\right)$ \\
\hline TiN & $3,4 \times 10^{-5}$ & 0,94 & $1,8 \times 10^{-5}$ & 0,80 & 6,1 & 76,4 & $1,0 \times 10^{7}$ \\
\hline TiAIN/TiAlCrN & $4,8 \times 10^{-5}$ & 0,85 & $2,5 \times 10^{-5}$ & 0,79 & 27,7 & 1285 & $3,1 \times 10^{7}$ \\
\hline
\end{tabular}

Dentre os parâmetros calculados em um modelo de circuito elétrico equivalente para impedância eletroquímica, $R_{p}$ e $R_{\text {fpass }}$ são os mais importantes. Pois, através deles, pode-se medir a resistência à corrosão dos diversos materiais. Portanto, quanto maior forem $R_{p}$ e $R_{\text {fpass }}$ (esses valores estão relacionados com o diâmetro do semicírculo do diagrama de Nyquist) maior a resistência à corrosão do material (DELGADOALVARADO, SUNDARAM, 2007).

No presente trabalho, a resistência à corrosão das amostras estudadas, baseada nos valores de $R_{p}$ em $\mathrm{HCl}$, apresentou-se da seguinte forma: liga sem recobrimento $<<$ recoberta por TiAlN/TiAlCrN $\approx$ recoberta por TiN. Estes resultados estão de acordo com os resultados obtidos nos testes de polarização potenciodinâmica, onde o valor de $\mathrm{i}_{\text {corr }}$ da liga Ti-6Al-4V sem recobrimento é muito maior do que os valores de $i_{\text {corr }}$ das condições revestidas por TiN e TiAlN/TiAlCrN. A análise de parâmetros como a capacitância 
também são indicadores de resistência à corrosão. De forma geral, altos valores de $\mathrm{R}_{\mathrm{p}}$ estão relacionados a valores menores de capacitância (CPE) (DELGADO-ALVARADO, SUNDARAM, 2007). Com base na Tabela 10, pode-se concluir que a liga revestida por TiN apresentou melhor comportamento à corrosão em $\mathrm{HCl}$, pois possui o maior valor de $\mathrm{R}_{\mathrm{p}}$ e os menores valores de capacitância.

A Tabela 12 apresenta os resultados de impedância obtidos por vários autores que trabalharam com diversas ligas metálicas em soluções ácidas e neutras.

Tabela 12 - Valores de resistência a transferência de carga $\left(\mathrm{R}_{\mathrm{p}}\right)$ para testes conduzidos com ligas metálicas em meios ácidos e neutros, tratadas ou não superficialmente.

\begin{tabular}{|c|c|c|c|}
\hline Material & $\begin{array}{l}\text { Condições de } \\
\text { corrosão* }\end{array}$ & $\begin{array}{c}\mathbf{R}_{\mathbf{p}} \\
\left(\Omega . \mathbf{c m}^{2}\right)\end{array}$ & Referências \\
\hline Ti-6Al-4V & $5 \% \mathrm{HCl}$ & $4,00 \times 10^{3}$ & ROSSI et al., 2003 \\
\hline Ti-6Al-4V & $\begin{array}{l}\text { fluido corpóreo } \\
\text { sintético }\end{array}$ & $1,4 \times 10^{6}$ & MANHABOSCO et al., 2011 \\
\hline Ti-6Al-4V-1Zr & Solução de Ringer & $5,2 \times 10^{5}$ & VASILESCU et al., 2011 \\
\hline Ti puro & $20 \% \mathrm{H}_{2} \mathrm{SO}_{4}$ & $1,00 \times 10^{3}$ & SOUZA, ROBIN, 2007 \\
\hline Ti grau $2(99 \%)$ & $\mathrm{HCl}+\mathrm{H}_{2} \mathrm{~S}$ & $4,1 \times 10^{5}$ & $\begin{array}{c}\text { MENDOZA-CANALES, } \\
\text { MARÍN-CRUZ, } 2008\end{array}$ \\
\hline $\begin{array}{l}\text { Ti-6Al-4V recoberto por } \\
\text { apatita }\end{array}$ & $\begin{array}{l}\text { fluido corpóreo } \\
\text { sintético }\end{array}$ & $1,7 \times 10^{7}$ & WANG et al., 2003 \\
\hline $\begin{array}{l}\text { Aço inox martensítico } \\
\text { recoberto por TiN }\end{array}$ & $0.5 \mathrm{M} \mathrm{H}_{2} \mathrm{SO}_{4}$ & $1,62 \times 10^{4}$ & WANG et al., 2007 \\
\hline $\begin{array}{c}\text { Ti grau } 2(99 \%) \text { recoberto } \\
\text { por TiN }\end{array}$ & saliva sintética & $2,0 \times 10^{7}$ & JOSKA et al., 2010 \\
\hline $\begin{array}{c}\text { Aço ferramenta recoberto } \\
\text { por TiN }\end{array}$ & $3.5 \% \mathrm{NaCl}$ & $1,20 \times 10^{4}$ & YOO et al., 2008 \\
\hline $\begin{array}{c}\text { Ti-6Al-4V recoberto por } \\
\text { TiN }\end{array}$ & Solução de Hank & $3,7 \times 10^{6}$ & WAN et al., 2004 \\
\hline $\begin{array}{c}\text { Aço } 0,37 \% \text { C recoberto por } \\
\text { TiAlN }\end{array}$ & $3.5 \% \mathrm{NaCl}$ & $4,41 \times 10^{3}$ & GRIPS et al., 2006 \\
\hline $\begin{array}{c}\text { Liga Ni-Cr-Mo recoberto } \\
\text { por TiAlN }\end{array}$ & Solução de Ringer & $6,8 \times 10^{4}$ & CHUNG et al., 2004 \\
\hline $\begin{array}{c}\text { Aço inox revestido por } \\
\text { TiAlN/SiN }\end{array}$ & $3.5 \% \mathrm{NaCl}$ & $2,2 \times 10^{4}$ & CHAN et al., 2013 \\
\hline
\end{tabular}

* as temperaturas foram informadas quando diferentes de $25^{\circ} \mathrm{C}$. 
Com base nos dados da Tabela 12, pode-se observar que o valor de $\mathrm{R}_{\mathrm{p}}$ para a liga Ti-6Al-4V sem revestimento em $\mathrm{HCl}$ encontrado no presente trabalho encontra-se dentro da faixa dos valores de $\mathrm{R}_{\mathrm{p}}$ reportados pelos autores Rossi (2003) e Souza e Robin (2007) (ROSSI et al., 2003; SOUZA, ROBIN, 2007). Com relação às amostras recobertas, observa-se que existe pouco ou nenhum estudo da impedância eletroquímica em solução $\mathrm{HCl}$ da liga Ti-6Al-4V recoberta por TiN e/ou TiAlN/TiAlCrN. Wang e colaboradores (2007) estudaram o comportamento à corrosão do aço inox martensítico recoberto por TiN em solução $\mathrm{H}_{2} \mathrm{SO}_{4}$ depositado por evaporação reativa por plasma. Os autores reportaram valores de $R_{p}=17,2 \Omega . \mathrm{cm}^{2}$ para a condição sem recobrimento e $R_{p}=1,62 \times 10^{4} \Omega . \mathrm{cm}^{2}$ para a condição recoberta (aumento na resistência à corrosão em cerca de 900 vezes). Os valores de $\mathrm{R}_{\mathrm{p}}$, encontrados no presente trabalho, para a condição com revestimento é cerca de 10 vezes maior do que o valor reportado por Wang e colaboradores (2007). A diferença nos valores de $\mathrm{R}_{\mathrm{p}}$ para as condições sem recobrimento e recoberta em $\mathrm{HCl}$ deste presente trabalho é cerca de 190 vezes. Observa-se que os resultados de $\mathrm{R}_{\mathrm{p}}$ reportados na literatura são diferentes dos resultados encontrados no presente trabalho para as condições recobertas em $\mathrm{HCl}$. E, que os valores de $\mathrm{R}_{\mathrm{p}}$ são resultantes de uma combinação de natureza do substrato, natureza do revestimento e método de deposição (AHN et al., 2007; GRIPS et al., 2006; ZHAO et al., 2011). Portanto, qualquer comparação de resultados torna-se difícil, pois são necessários mais estudos com condições semelhantes com a deste presente trabalho.

Os resultados em solução $\mathrm{NaCl}$ deste presente trabalho demonstraram que a resistência à corrosão da liga Ti-6Al-4V com e sem revestimento, baseada nos valores de $\mathrm{R}_{\mathrm{p}}$, variou da seguinte forma: liga sem recobrimento $<$ recoberta por TiAlN/TiAlCrN $\approx$ recoberta por TiN. Comparando-se os resultados obtidos nos testes de polarização com os resultados obtidos nos testes de impedância, observa-se uma diferença de comportamento à corrosão. A liga Ti-6Al-4V sem recobrimento em $\mathrm{NaCl}$ apresentou valor de $\mathrm{i}_{\text {corr }}$ semelhante aos valores de $i_{\text {corr }}$ das condições recobertas enquanto que, apresentou o menor valor de impedância em solução $\mathrm{NaCl}$ quando comparado com as amostras recobertas na mesma solução. Nestes casos acredita-se que os resultados de impedância são os mais confiáveis, pois a técnica de impedância só causa uma pequena perturbação do potencial de $10 \mathrm{mV}$ em torno do potencial de corrosão. Por outro lado, os testes de polarização começam em níveis de potencial $0,5 \mathrm{~V}$ mais negativos que o potencial de corrosão $\left(\mathrm{E}_{\text {corr }}\right) \mathrm{e}$ o potencial é levado para potenciais mais nobres (neste trabalho $+2,0 \mathrm{~V} / \mathrm{ECS}$ ). Esta grande variação de potencial negativo em relação ao potencial de corrosão pode causar 
perturbações na interface metal/solução, o que pode levar à medida errônea da densidade de corrente de corrosão, já que esta foi feita por extrapolação da parte catódica da curva de polarização. Os baixos valores de $i_{\text {corr }}$ nestas condições (ordem de $10^{-7} \mathrm{~A} / \mathrm{cm}^{2}$ ) podem também levar a erros de medidas significativas.

A Tabela 12 mostra que estudos feitos em meio corrosivo $\mathrm{NaCl}$ e/ou meios que contenham esse composto (como fluido corpóreo sintético e as soluções de Ringer e Hank) com ligas metálicas, revestidas ou não, são um pouco mais comuns. O trabalho de Vasilescu e colaboradores (2011) com uma liga de titânio reportou valores de $\mathrm{R}_{\mathrm{p}}$ na mesma ordem de grandeza dos valores de $\mathrm{R}_{\text {fpass }}$ encontrados neste presente trabalho $\left(\mathrm{R}_{\mathrm{p}} \approx 10^{5}\right.$ S.cm²) (VASILESCU et al., 2011) para a liga Ti-6Al-4V sem recobrimento. Observa-se que os valores de $\mathrm{R}_{\mathrm{p}}$ em solução $\mathrm{NaCl}$ apresentados na Tabela 12 para as condições recobertas variam em uma faixa de $4 \times 10^{3} \Omega \cdot \mathrm{cm}^{2}<\mathrm{R}_{\mathrm{p}}<2 \times 10^{7} \Omega \cdot \mathrm{cm}^{2}$. Isto indica, portanto, que a faixa de valores de $\mathrm{R}_{\mathrm{p}}$ reportados na literatura é grande e depende, não só do tipo de recobrimento, mas também da natureza do substrato. O trabalho de Wang e colaboradores (2003) apresenta a maior semelhança de condições de estudos com o presente trabalho, onde o substrato é o mesmo (Ti-6Al-4V) e a solução corrosiva é neutra. O autor reportou valores de $R_{p}=1,2 \times 10^{6} \Omega \cdot \mathrm{cm}^{2}$ para a condição sem revestimento e $R_{p}=1,7 \times 10^{7} \Omega . \mathrm{cm}^{2}$ para a condição recoberta por apatita (WANG et al., 2003). Os valores de $\mathrm{R}_{\mathrm{p}}$ encontrados neste presente trabalho para a liga Ti-6Al-4V recoberta por TiN e TiAlN/TiAlCrN estão de acordo com o trabalho de Wang e colaboradores (WANG et al., 2003).

No presente trabalho os valores de $\mathrm{R}_{\mathrm{p}}$ obtidos em solução $\mathrm{HCl}$ para todas as condições experimentais foram menores do que os valores de $R_{p}$ obtidos em solução de $\mathrm{NaCl}$. Em solução $\mathrm{HCl}$ os valores de $\mathrm{R}_{\mathrm{p}}$ para as condições recobertas por TiN e TiAlN/TiAlCrN encontram-se na ordem de $10^{5} \Omega . \mathrm{cm}^{2}$, enquanto que em solução $\mathrm{NaCl}$ estes valores estão na ordem de $10^{7} \Omega . \mathrm{cm}^{2}$. Este resultado não está totalmente de acordo com os resultados obtidos nos testes de polarização que apresentou valores de $\mathrm{i}_{\text {corr }}$ semelhantes entre os dois tipos de revestimento e soluções corrosivas. Tanto em solução $\mathrm{HCl}$ como em solução $\mathrm{NaCl}$, os valores de $\mathrm{i}_{\text {corr }}$ apresentaram-se na ordem de $10^{-7} \mathrm{~A} / \mathrm{cm}^{2}$.

De forma geral, todas as amostras testadas à corrosão comportaram-se de forma quase capacitiva nas duas soluções corrosivas, permanecendo em faixas amplas de frequências intermediárias com ângulo de fase máximo próximo a $-90^{\circ}\left(\sim-80^{\circ}\right)$, e com inclinação da reta do gráfico $\log |Z| x \log$ (freq.) próxima de -1. Em solução $\mathrm{HCl}$ a liga Ti6Al-4V sem revestimento apresentou uma faixa frequências intermediárias com ângulo de fase próximo a $-90^{\circ}$ de menor extensão (Figura 28b). Esta baixa extensão está relacionada 
com os valores de $R_{p}$ mais baixos quando comparados com os valores de $R_{p}$ obtidos em solução $\mathrm{NaCl}$.

No presente trabalho as análises do diagrama de Bode estão de acordo com outras análises feitas anteriormente. Kumar e colaboradores (2010), que caracterizaram microestrutural e eletroquimicamente a liga Ti-6Al-4V submetida à oxidação térmica e Wang et al. (2003), que fizeram um estudo sobre impedância eletroquímica na liga Ti-6Al$4 \mathrm{~V}$ recoberta com apatita obtiveram resultados bem parecidos nas curvas do diagrama de Bode. Os autores encontraram inclinação das retas do gráfico $\log |Z|$ x $\log$ (freq.) próxima a -1 e os ângulos de fase máximos entre $-70^{\circ}$ e $-85^{\circ}$ (KUMAR et al., 2010; WANG; WANG; ZHOU, 2003).

$\mathrm{O}$ valor de $n$ (que é obtido da inclinação da curva módulo de $\mathrm{Z}$ vs freqüência) para todas as condições experimentais ficou entre $0,85<\mathrm{n}_{\text {rev }}<0,97$ e estão na faixa dos reportados por GRIPS et al. (2006), LIU et al. (2001) e WAN et al. (2004) (GRIPS et al., 2006; LIU et al., 2001; WAN et al., 2004).

\subsection{2. ÁNALISE DO EFEITO DE TEMPERATURA}

Para um melhor entendimento dos efeitos do tratamento superficial por PVD e dos efeitos do aumento da temperatura das soluções fez-se uma comparação dos resultados da liga Ti-6Al-4V sem recobrimento, recoberta por TiN e por TiAlN/CrN obtidos nas temperaturas de 25,60 e $80^{\circ} \mathrm{C}$. Os resultados serão discutidos em termos de porcentagem de proteção superficial calculada com base nas densidades de corrente de corrosão. Essa medida é muito comum em trabalhos que tem como objetivo melhorar o desempenho de uma liga metálica através de uma modificação superficial. Os trabalhos reportados por Yoo et al. (2008), Yu et al. (2003), Bommersbach et al. (2005), Amaya-Vazquez et al. (2012) e Ananthakumar et al. (2012) utilizaram essa medida para quantificar a capacidade protetora de seus revestimentos quando comparados com o substrato sem nenhuma proteção superficial (AMAYA-VAZQUEZ et al., 2012.; ANANTHAKUMAR et al., 2012; BOMMERSBACH et al., 2005; YOO et al., 2008; YU et al., 2003).

A porcentagem de proteção superficial dos recobrimentos pode ser calculada pela Equação 9: 
$P_{i}(\%)=\left[1-\left(\frac{i_{\text {corr }}}{i_{\text {corr }}^{0}}\right)\right] \times 100$

onde $i_{c o r r}$ e $i_{c o r r}^{0}$ são a densidade de corrente de corrosão do filme e do substrato, respectivamente (YOO et al., 2008).

As Figuras 34 e 35 mostram as curvas de polarização a partir das quais os valores de $\mathrm{i}_{\text {corr }}$ foram obtidos, nas soluções de $\mathrm{HCl}$ e $\mathrm{NaCl}$ respectivamente.
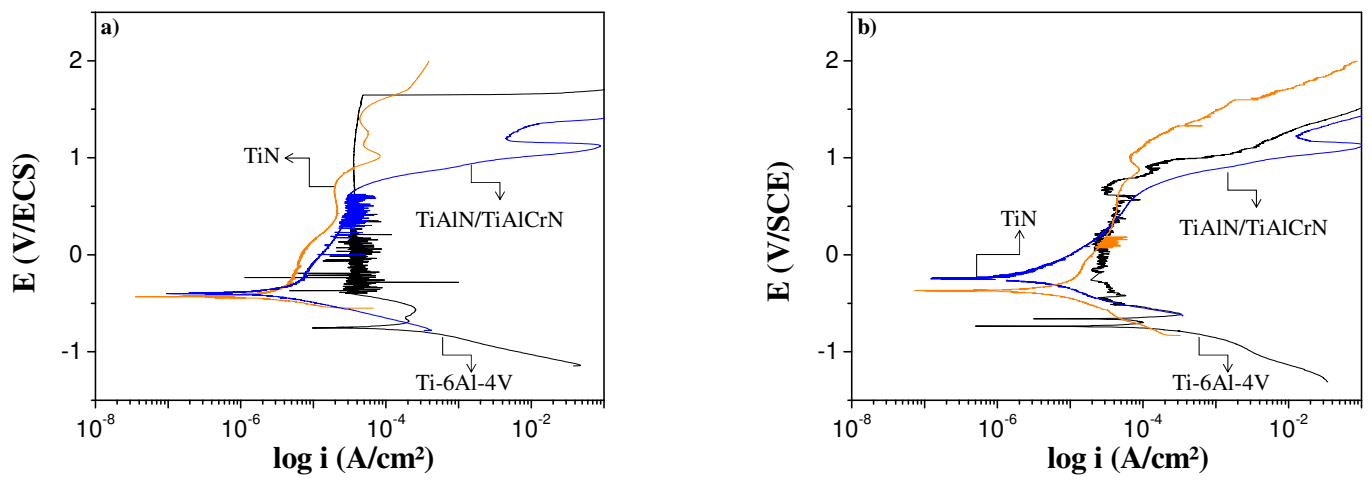

Figura 34. Curva de polarização potenciodinâmica da liga Ti-6Al-4V sem recobrimento e recoberta por TiN e TiAlN/TiAlCrN, em solução $\mathrm{HCl} 2 \mathrm{M}$ : a) $60{ }^{\circ} \mathrm{C}$, b) $80^{\circ} \mathrm{C}$.
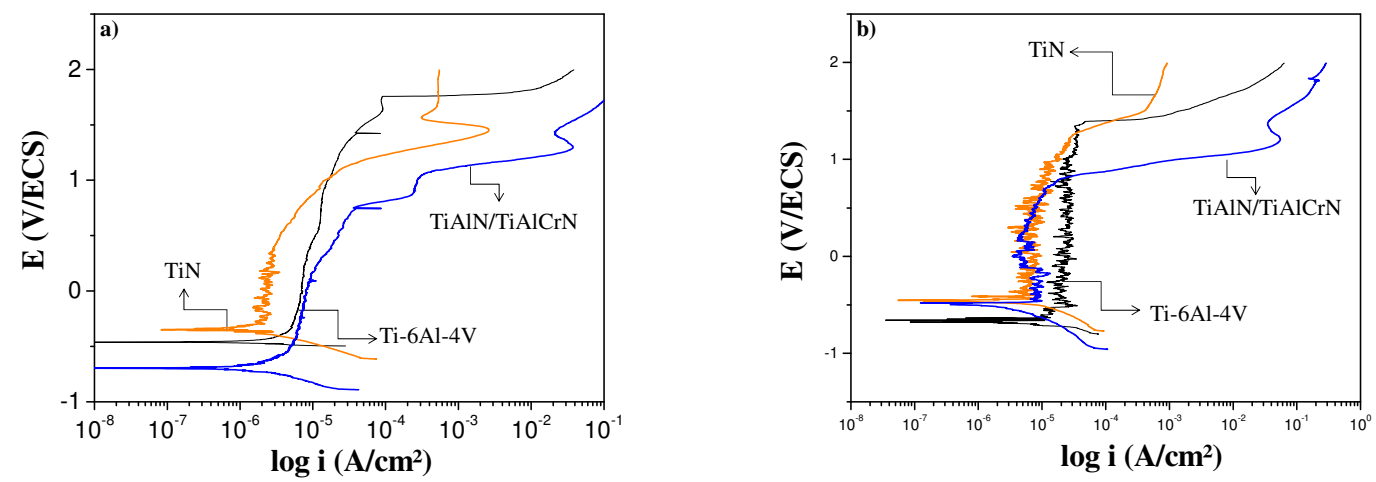

Figura 35. Curva de polarização potenciodinâmica da liga Ti-6Al-4V sem recobrimento e recoberta por TiN e TiAlN/TiAlCrN, em solução $\mathrm{NaCl} 3,5 \%$ p.: a) $60^{\circ} \mathrm{C}$, b) $80^{\circ} \mathrm{C}$.

As curvas de polarização potenciodinâmica a 60 e $80{ }^{\circ} \mathrm{C}$ mostram que a liga sem recobrimento e os revestimentos mantiveram os mesmos comportamentos sob corrosão: comportamento ativo com transição ativo-passiva da liga sem recobrimento em solução $\mathrm{HCl}$ (Figura 34a e 34b), e comportamento passivo da liga sem recobrimento em $\mathrm{NaCl}$ (Figura 35a e 35b); os revestimento comportaram-se passivamente em ambas as soluções corrosivas nas duas temperaturas (Figuras 34 e 35).

As Tabelas 13 e 14 listam os valores de $i_{\text {corr }}$ para a liga sem recobrimento e recoberta por TiN e TiAlN/TiAlCrN a 25, 60 e $80{ }^{\circ} \mathrm{C}$, para as soluções de $\mathrm{HCl}$ e $\mathrm{NaCl}$ respectivamente. 
Tabela 13. Valores de densidade de corrente de corrosão ( $\mathrm{i}_{\text {corr }}$ ) da liga Ti-6Al-4V sem recobrimento e recoberta por TiN e TiAlN/TiAlCrN em $\mathrm{HCl} 2 \mathrm{M}$ a 25,60 e $80^{\circ} \mathrm{C}$.

\begin{tabular}{cccc}
\hline $\mathrm{i}_{\text {corr }}\left(\mathrm{A} / \mathrm{cm}^{2}\right)$ & 25 & Temperatura $\left({ }^{\circ} \mathrm{C}\right)$ \\
\hline Ti-6Al-4V & $2,0 \times 10^{-5}$ & $1,5 \times 10^{-4}$ & 80 \\
TiN & $4,9 \times 10^{-7}$ & $2,4 \times 10^{-6}$ & $1,9 \times 10^{-4}$ \\
TiAlN/TiAlCrN & $7,2 \times 10^{-7}$ & $2,5 \times 10^{-6}$ & $3,2 \times 10^{-6}$ \\
\hline
\end{tabular}

Tabela 14. Valores de densidade de corrente de corrosão $\left(\mathrm{i}_{\text {corr }}\right.$ ) da liga Ti-6Al-4V sem recobrimento e recoberta por TiN e TiAlN/TiAlCrN em $\mathrm{NaCl} 3,5 \%$ p. a 25,60 e $80^{\circ} \mathrm{C}$.

\begin{tabular}{cccc}
\hline $\mathrm{i}_{\text {corr }}\left(\mathrm{A} / \mathrm{cm}^{2}\right)$ & \multicolumn{3}{c}{ Temperatura $\left({ }^{\circ} \mathrm{C}\right)$} \\
\hline Ti-6Al-4V & 25 & 60 & 80 \\
TiN & $3,7 \times 10^{-7}$ & $3,7 \times 10^{-6}$ & $1,0 \times 10^{-5}$ \\
TiAlN/TiAlCrN & $6,3 \times 10^{-7}$ & $2,0 \times 10^{-6}$ & $7,8 \times 10^{-6}$ \\
\hline
\end{tabular}

As Figuras 36 e 37 mostram a variação da densidade corrente de corrosão da liga Ti-6Al-4V sem recobrimento e recoberta com TiN e TiAlN/TiAlCrN em função da temperatura.

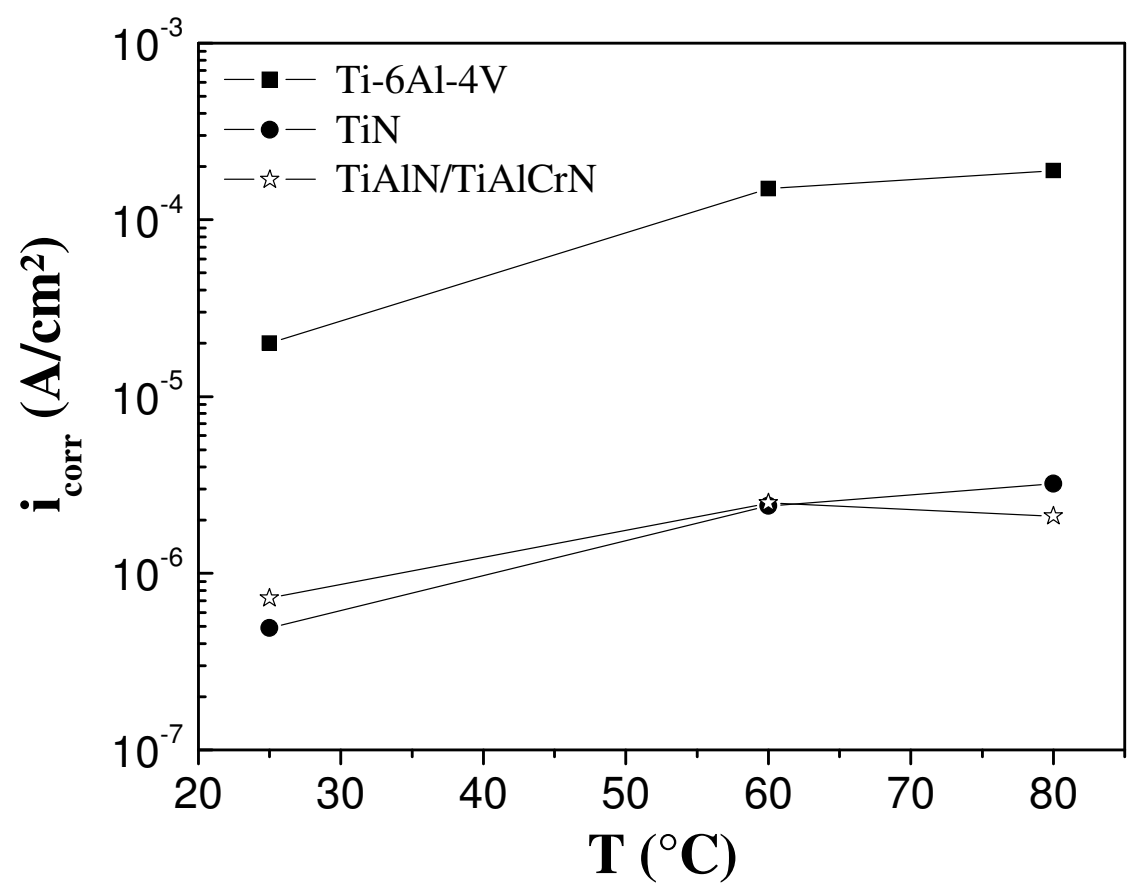

Figura 36. Influência da temperatura sobre a resistência à corrosão da liga Ti-6Al-4V sem recobrimento e recoberta por TiN e TiAlN/TiAlCrN em solução $\mathrm{HCl}$ 2M. 


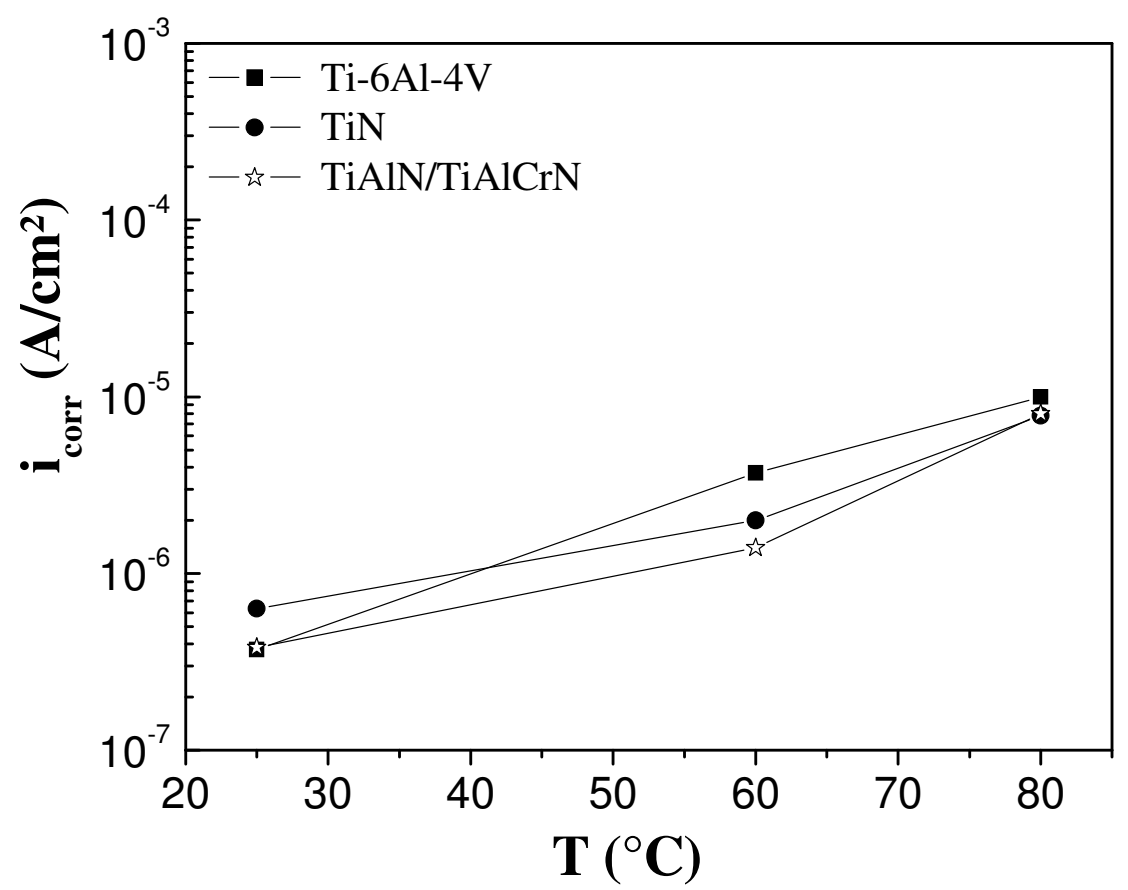

Figura 37. Influência da temperatura sobre a resistência à corrosão da liga Ti-6Al-4V sem recobrimento e recoberta por TiN e TiAlN/TiAlCrN em solução $\mathrm{NaCl} 3,5 \%$ p.

De modo geral, o aumento da temperatura aumentou a taxa de corrosão da amostra sem revestimento e revestida por TiN e TiAlN/TiAlCrN porque a temperatura influencia a energia térmica e a velocidade de dissolução dos materiais (HEAKAL et al., 2012).

A presença dos revestimentos melhorou a resistência à corrosão da liga em $\mathrm{HCl}$ em todas as temperaturas. Não foi observada nenhuma variação significante na resistência à corrosão com o aumento da temperatura de 60 para $80{ }^{\circ} \mathrm{C}$ (Figura 36).

Em NaCl, a análise dos valores das densidades de corrente de corrosão torna-se complicada, pois como discutido anteriormente, por serem valores muito baixos a medida é mais passível de erro. A Figura 37 nos mostra que a resistência da liga Ti-6Al-4V sem revestimento foi muito parecida com a resistência da liga revestida por TiN e TiAlN/TiAlCrN em todas as condições de temperatura. Observa-se também que o aumento da temperatura diminuiu a resistência à corrosão tanto da liga recoberta quanto da liga sem recobrimento.

A temperatura ambiente, a liga Ti-6Al-4V sem revestimento não sofre corrosão localizada em solução $\mathrm{NaCl}$ (Figura 19), pois a camada passiva de $\mathrm{TiO}_{2}$ é bastante compacta. Entretanto, a 60 e $80^{\circ} \mathrm{C}$ pode-se observar os efeitos da corrosão localizada da liga sem revestimento nos potenciais $\mathrm{E}_{60}{ }^{\circ} \mathrm{C}=1,7 \mathrm{~V} / \mathrm{ECS}$ e $\mathrm{E}_{80}{ }^{\circ} \mathrm{C}=1,3 \mathrm{~V} / \mathrm{ECS}$ causados pela presença de íons cloreto que, com o aumento da temperatura, ficaram mais ativos no 
processo corrosivo. Em solução $\mathrm{HCl}$, a liga Ti-6Al-4V sem recobrimento sofreu corrosão localizada nos seguintes potenciais $\mathrm{E}_{60}{ }^{\circ} \mathrm{C}=1,6 \mathrm{~V} / \mathrm{ECS}$ e $\mathrm{E}_{80}{ }^{\circ} \mathrm{C}=0,75 \mathrm{~V} / \mathrm{ECS}$.

Os valores de $\mathrm{P}_{\mathrm{i}}(\%)$ para a liga Ti-6Al-4V recoberta por TiN e TiAlN/TiAlCrN, a 25, 60, $80{ }^{\circ} \mathrm{C}$ estão apresentados nas Tabelas 15 e 16, para as soluções de $\mathrm{HCl}$ e $\mathrm{NaCl}$, respectivamente.

Tabela 15. Porcentagem de proteção superficial $\left(\mathrm{P}_{\mathrm{i}} \%\right)$ dos recobrimentos TiN e TiAlN/TiAlCrN em solução $\mathrm{HCl} 2 \mathrm{M}$.

\begin{tabular}{|c|c|c|c|}
\hline \multirow{2}{*}{$\mathrm{Pi}(\%)$} & \multicolumn{3}{|c|}{ Temperatura $\left({ }^{\circ} \mathrm{C}\right)$} \\
\hline & 25 & 60 & 80 \\
\hline TiN & 98 & 98 & 98 \\
\hline TiAlN/TiAlCrN & 96 & 98 & 99 \\
\hline
\end{tabular}

Tabela 16. Porcentagem de proteção superficial (Pi \%) dos recobrimentos TiN e TiAlN/TiAlCrN em solução NaCl 3,5 $\%$ p.

\begin{tabular}{cccc}
\hline Pi $(\%)$ & \multicolumn{2}{c}{ Temperatura $\left({ }^{\circ} \mathrm{C}\right)$} & 80 \\
\hline TiN & 25 & 60 & 22 \\
TiAlN/TiAlCrN & - & 46 & 20 \\
\hline
\end{tabular}

Com base na Tabela 15, pode-se afirmar que a liga revestida por TiN e por TiAlN/TiAlCrN apresentou valores de $\mathrm{P}_{\mathrm{i}}(\%)$ semelhantes em solução $\mathrm{HCl}$. Estes valores encontram-se dentro da faixa que varia entre 71 e $99 \%$ reportada por autores que trabalharam com revestimentos à base de nitretos e revestimentos multicamadas a $25{ }^{\circ} \mathrm{C}$ (ANANTHAKUMAR et al., 2012; LIU et al., 2013; YOO et al., 2008; YU et al., 2003).

A Tabela 16 foi apresentada neste trabalho, mas devido aos problemas de incoerência entre os testes de polarização e impedância eletroquímica, qualquer conclusão baseada nos valores de $\mathrm{i}_{\text {corr }}$ pode ser duvidosa.

As Figuras 38 e 39 mostram a variação dos valores de impedância $\left(\mathrm{R}_{\mathrm{tc}}\right)$ com a temperatura em $\mathrm{HCl}$ e $\mathrm{NaCl}$, respectivamente. 


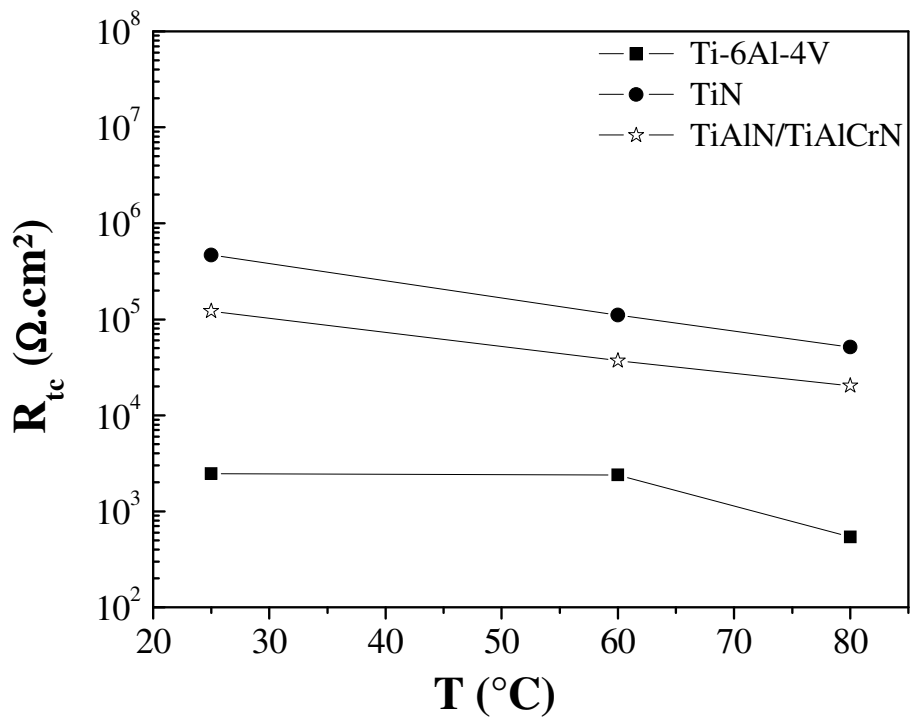

Figura 38. Variação da impedância $\left(\mathrm{R}_{\mathrm{p}}\right)$ com a temperatura para a liga Ti-6Al-4V sem recobrimento e recoberta por TiN e TiAlN/TiAlCrN em solução $\mathrm{HCl} 2 \mathrm{M}$.

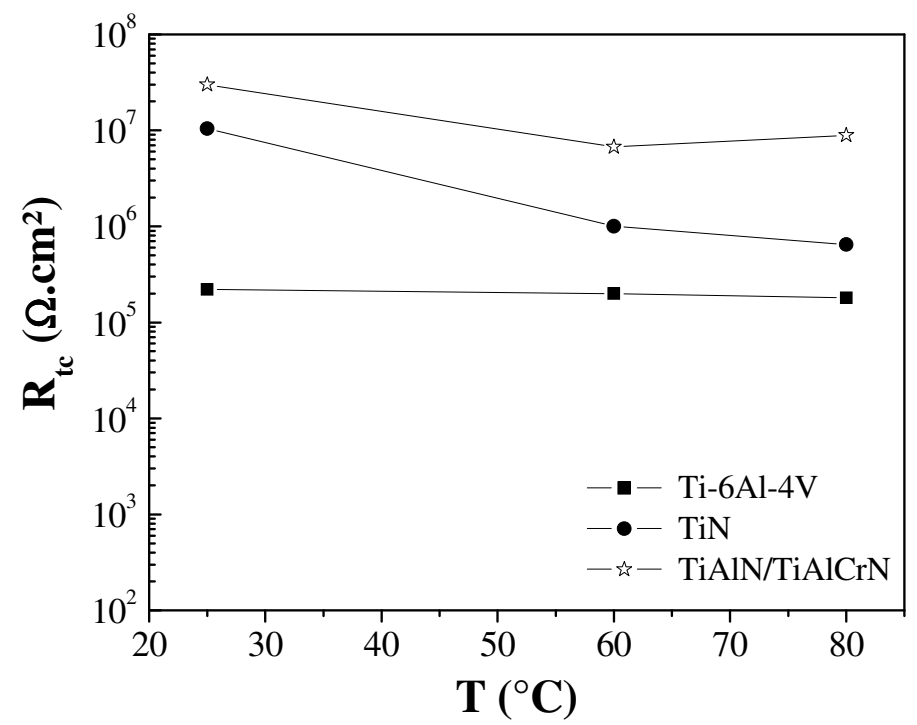

Figura 39. Variação da impedância $\left(\mathrm{R}_{\mathrm{p}}\right)$ com a temperatura para a liga Ti-6Al-4V sem recobrimento e recoberta por TiN e TiAlN/TiAlCrN em solução $\mathrm{NaCl}$ 3,5 \%p.

A influência da temperatura sobre os dados de impedância (Figuras 38 e 39) segue, de modo geral, as tendências de comportamento observadas na polarização (Figuras 36 e 37): o aumento da temperatura diminui a resistência à corrosão das amostras e a resistência à corrosão das amostras em $\mathrm{NaCl}$ é maior do que em $\mathrm{HCl}$.

Quando análises por polarização e impedância eletroquímica são feitas, espera-se que o comportamento observado nas duas análises seja o mesmo. Porém, o fato é que não existe nenhum estudo na literatura que faça ao mesmo tempo uma análise do comportamento de corrosão de uma amostra metálica com e sem revestimento em meios 
corrosivos diferentes e em temperaturas diferentes utilizando as duas ferramentas mostradas neste trabalho (polarização e impedância). E, por este motivo, tornam-se necessários mais estudos sobre este tema para tirarmos conclusões mais definitivas sobre as possíveis causas das diferenças de comportamento encontradas neste trabalho entre os testes de polarização e impedância eletroquímica em solução $\mathrm{NaCl}$.

Novamente, salientamos que as medidas de impedância são feitas causando pouca perturbação elétrica da interface metal/solução e por isso podem ser consideradas mais confiáveis. Entretanto, as analises por polarização potenciodinâmica dão respostas sobre a capacidade de passivação dos materiais, sobre os efeitos nocivos de um meio corrosivo específico e sobre a eficiência protetora dos revestimentos (GENTIL, 1996).

Finalmente, pode-se dizer que a liga revestida por TiN foi a que apresentou melhor comportamento em corrosão, pois aumentou a resistência à corrosão da liga Ti-6Al-4V nas duas soluções estudadas e manteve sua integridade estrutural e aderência à superfície durante polarização em $\mathrm{HCl}$ e $\mathrm{NaCl}$ de 25 a $80^{\circ} \mathrm{C}$.

\subsection{ENSAIOS DE OXIDAÇÃO ISOTÉRMICA}

A Figura 40 mostra as curvas cinéticas dos testes de oxidação isotérmica para a liga Ti-6Al-4V sem recobrimento e recoberta por TiN e TiAlN/TiAlCrN a $600{ }^{\circ} \mathrm{C}$. As medidas de diferenças de massa foram feitas em tempos variando de 20 a 180 horas. 


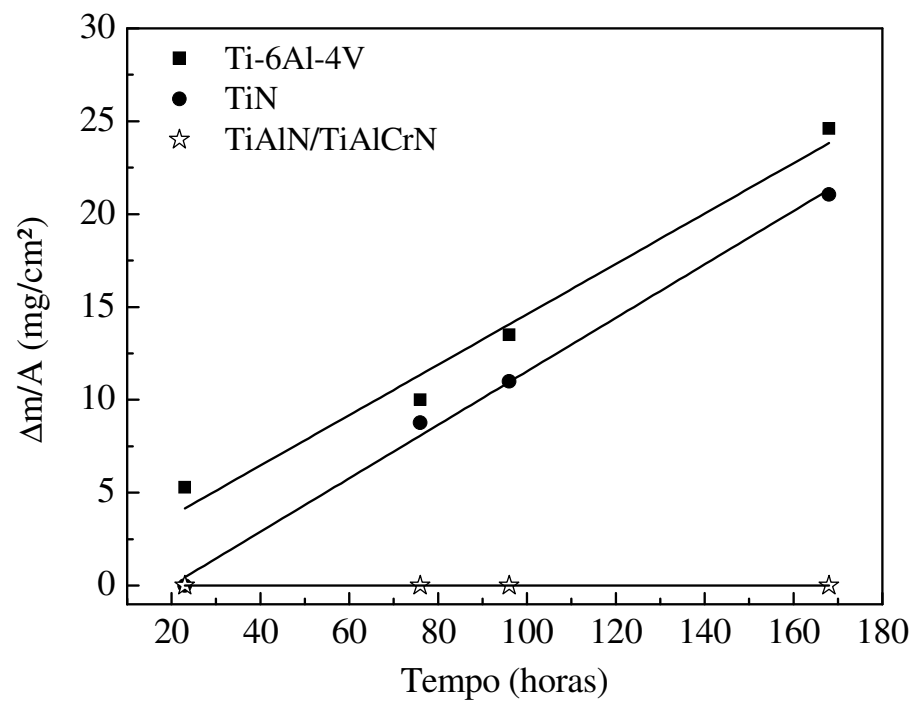

Figura 40. Cinética da oxidação isotérmica da liga Ti-6Al-4V sem recobrimento e recoberta por TiN e TiAlN/TiAlCrN, testada a $600{ }^{\circ} \mathrm{C}$ ao ar.

Por regressão linear dos dados experimentais obteve-se a Equação 10 para a liga Ti6Al-4V sem recobrimento e a Equação 11 para a liga recoberta por TiN. A amostra recoberta por TiAlN/TiAlCrN não sofreu oxidação (visível) a $600{ }^{\circ} \mathrm{C}$.

$\frac{\Delta m}{A}=0,13 t+1,04$

$\frac{\Delta m}{A}=0,14 t-2,85$

As análises da Figura 40 e das Equações 10 e 11 mostram que a lei cinética de oxidação isotérmica (crescimento dos óxidos na superfície com o tempo) foi linear para as condições sem recobrimento e recoberta por TiN. E que, apesar de ter formado uma quantidade menor de óxido (redução no ganho de massa), a liga recoberta por TiN apresentou praticamente a mesma taxa de oxidação da liga Ti-6Al-4V sem recobrimento a $600{ }^{\circ} \mathrm{C}$. Esta constatação pode ser feita ao se analisar os coeficientes angulares das Equações 10 e 11 que representam a constante de crescimento linear isotérmica dos materiais estudados $\left(\mathrm{k}_{\mathrm{ox}}\left[\mathrm{mg} / \mathrm{cm}^{2} . \mathrm{h}\right]\right)$ (REVIE; UHLIG, 2008). A liga recoberta por TiAlN/TiAlCrN não apresentou nenhuma evidência visível de oxidação a $600{ }^{\circ} \mathrm{C}$. É importante salientar que o número de testes de oxidação isotérmica feitos neste trabalho é pequeno para nos fornecer uma informação confiável sobre a lei segundo a qual os óxidos 
crescem durante a oxidação. Entretanto, os resultados são bons para fins de comparação de comportamento entre as amostras.

Os autores Revie e Uhlig em seu livro "Corrosion and Corrosion Control" afirmam que o titânio submetido à oxidação em temperaturas que variam entre 650 a 950 ${ }^{\circ} \mathrm{C}$ obedece a uma lei cinética linear, onde a camada óxida cresce a uma taxa constante com o tempo (REVIE; UHLIG, 2008). Contudo, não é este o comportamento que se verifica na prática, onde muitos estudos com titânio puro e com ligas base titânio demonstram que o crescimento da camada óxida sobre o titânio obedece, na maioria dos casos, uma lei parabólica. Segundo Gurrappa e Gogia (2001), o ganho de massa do material durante a exposição ao meio corrosivo é devido à formação da camada óxida externa e à formação da região $\alpha$ ou região de dissolução do oxigênio interna ou ainda solução sólida Ti-O. Os autores definiram os tamanhos da região de dissolução do oxigênio segundo as temperaturas: $12 \mu \mathrm{m}$ a $600{ }^{\circ} \mathrm{C}, 45 \mu \mathrm{m}$ a $700{ }^{\circ} \mathrm{C}$ e $140 \mu \mathrm{m}$ a $800{ }^{\circ} \mathrm{C}$ (GURRAPPA; GOGIA, 2001).

$\mathrm{Yu}$ e colaboradores (2007) estudaram o comportamento da liga Ti-6Al-4V submetida à oxidação isotérmica, a $600{ }^{\circ} \mathrm{C}$, por um período de 100 horas. Os autores observaram que o crescimento da camada óxida obedecia a uma lei parabólica nas primeiras 60 horas. A partir deste tempo, a camada óxida começou a se desprender do substrato, expondo-o ao meio oxidante e impossibilitando a medida das taxas de oxidação (YU et al., 2007b). Pérez (2005) estudou a resistência à oxidação do titânio puro e das ligas Ti-6Al-4V e Ti-7Nb a $700{ }^{\circ} \mathrm{C}$, por 100 horas. Segundo o autor, todos os materiais seguiram um comportamento cinético parabólico (ou quase parabólico) (PÉREZ, 2005). Guleryuz e Cimenoglu (2009) que estudaram a resistência à oxidação da liga Ti-6Al-4V, encontraram comportamento cinético parabólico para as temperaturas entre 600 e $650{ }^{\circ} \mathrm{C}$ e linear entre 750 e $800{ }^{\circ} \mathrm{C}$. Os autores observaram, a $700{ }^{\circ} \mathrm{C}$, um comportamento parabólico nas primeiras 36 horas, e para tempos mais prolongados de exposição à oxidação, o comportamento cinético foi linear. Concluíram adicionalmente que para exposições prolongadas à oxidação $(\mathrm{t}>300 \mathrm{~h})$ a $600-700{ }^{\circ} \mathrm{C}$ a cinética da oxidação é dominada por uma lei linear enquanto que para exposições curtas $(\mathrm{t}<100 \mathrm{~h})$ a cinética está associada a um comportamento parabólico (GYLERYUZ; CIMENOGLU, 2009). Leyens e colaboradores (1997) estudaram o comportamento em oxidação de uma liga de titânio near $\alpha$ revestida à base de $\mathrm{TiAl}$, a $750{ }^{\circ} \mathrm{C}$ por até 500 horas. Os autores observaram um comportamento que chamaram de paralinear, comandado principalmente pelo crescimento do óxido $\mathrm{TiO}_{2}$ (LEYENS; PETERS; KAYSSER, 1997). 
Contudo, encontram-se também "exceções" como os casos de Guleryuz e Cimenoglu (2009) e Leyens e colaboradores (1997) que encontraram comportamento linear entre 600 e $650{ }^{\circ} \mathrm{C}$ para a liga Ti-6Al-4V e paralinear a $750{ }^{\circ} \mathrm{C}$ para uma liga near $\alpha$, respectivamente (GYLERYUZ; CIMENOGLU, 2009; LEYENS; PETERS; KAYSSER, 1997). Portanto, entende-se que o comportamento linear observado a $600{ }^{\circ} \mathrm{C}$ é válido visto, que está de acordo com a afirmação de Revie e Uhlig (2008) ou que pode ser um comportamento particular da liga Ti-6Al-4V de morfologia Widmansttäten a $600{ }^{\circ} \mathrm{C}$ (REVIE; UHLIG, 2008).

Wu e colaboradores (2006) estudaram a influência da microestrutura na resistência à oxidação da liga Ti-46.6Al-1.4Mn-2Mo-0.3C-0.3Y, nas temperaturas de 800 e $900{ }^{\circ} \mathrm{C}$ por 350 horas. Os autores trabalharam com três tipos de microestrutura resultantes dos processos de extrusão (lamelar), fusão (parcialmente lamelar) e laminação a quente (duplex). A microestrutura que apresentou maior resistência a $800{ }^{\circ} \mathrm{C}$ foi a amostra extrudada devido a sua microestrutura lamelar refinada, a taxa de oxidação foi igual a 1,44 $\mathrm{mg} / \mathrm{cm}^{2} \mathrm{~h}$. No entanto, a $900{ }^{\circ} \mathrm{C}$, pouca influência da microestrutura foi observada entre os comportamentos das amostras extrudada e laminada a quente. A amostra fundida de microestrutura duplex, contudo, apresentou o melhor comportamento, devido à melhor adesão da camada óxida que não descolou com o tempo. As taxas de oxidação apresentadas a $900{ }^{\circ} \mathrm{C}$ foram $5,75 \mathrm{mg} / \mathrm{cm}^{2} \mathrm{~h}$ para a amostra fundida, $23,3 \mathrm{mg} / \mathrm{cm}^{2} \mathrm{~h}$ para a amostra extrudada e $19,6 \mathrm{mg} / \mathrm{cm}^{2} \mathrm{~h}$ para a amostra laminada a quente (WU et al., 2006). Desta forma, a dificuldade de se comparar taxas de oxidação encontra-se no fato de que o coeficiente de difusão do $\mathrm{O}$ em ligas de titânio depende da constituição da liga. Portanto a constituição das fases (proporção fase $\alpha / \beta$ ) afeta o comportamento das ligas de titânio em altas temperaturas e torna difícil a comparação entre dados experimentais dos diversos autores (GARBACZ; LEWANDOWSKA, 2003).

Não existem estudos sobre as taxas de oxidação de ligas de titânio recobertas por TiN ou TiAlN/TiAlCrN pela técnica de PVD a plasma. Contudo, pode-se encontrar na literatura trabalhos que testaram ligas metálicas protegidas por algum revestimento em oxidação isotérmica com o objetivo de melhorar o comportamento da liga metálica em altas temperaturas.

Perez (2005) estudou a influência da nitretação na oxidação de ligas de titânio a 700 ${ }^{\circ} \mathrm{C}$. Segundo o autor, a nitretação de ligas de titânio forma camadas compostas por TiN e $\mathrm{Ti}_{2} \mathrm{~N}$ capazes de prevenir a dissolução do oxigênio na microestrutura metálica evitando o ganho de massa por oxidação. Entretanto, este efeito é limitado aos primeiros estágios da 
oxidação, pois o substrato não consegue estabilizar a camada nitretada durante longos tempos de exposição (PEREZ, 2005). Choi e colaboradores (2005) depositaram compostos à base de $\mathrm{NiCrAl}$, NiCrAlY e TiAlO por vaporização a plasma (plasma spray) sobre a liga Ti-6Al-4V e testaram seu comportamento em oxidação a $800{ }^{\circ} \mathrm{C}$. Os autores reportaram que o processo de oxidação dos revestimentos segue a uma lei parabólica e que o melhor desempenho das amostras revestidas (taxa de oxidação menor) é devido à formação de óxidos complexos com maior estabilidade térmica que o $\mathrm{TiO}_{2}$ (CHOI; LIANG; GAO, 2005). Steyer et al. (2006) estudaram o processo de oxidação de um aço rápido recoberto por revestimentos à base de TiN e TiSiN depositados por evaporação a arco. Os testes foram conduzidos a $800{ }^{\circ} \mathrm{C}$ e os autores observaram que o processo de oxidação destes revestimentos seguiu uma lei parabólica. Os autores também colocaram em evidência que, apesar de ser um pouco mais resistente que o aço, o composto TiN é pouco resistente à oxidação em altas temperaturas (STEYER et al., 2006). Yu et al. (2007) mostraram que recobrimentos à base de NiSi reduzem a taxa de oxidação da liga quando testada a $650{ }^{\circ} \mathrm{C}$ e que a oxidação da liga recoberta não segue uma lei de crescimento parabólico (YU et al., 2007b). Fox-Rabinovich (2005) estudaram as propriedades tribológicas de revestimentos à base de TiAlCrN depositados sobre aços ferramenta e testaram sua estabilidade em oxidação a $900^{\circ} \mathrm{C}$ no ar. Os autores observaram que a presença de $\mathrm{Al}$ estabiliza o revestimento exposto por longos tempos em altas temperaturas (FOX-RABINOVICH et al., 2005). Tien e Duh (2006) compararam as modificações das microestruturas de revestimentos à base de CrN/AlN e TiN/AlN a $800{ }^{\circ} \mathrm{C}$. Segundos os autores, em altas temperaturas, TiN se oxida transformando-se em $\mathrm{TiO}_{2}$, esta transformação é acompanhada de uma expansão volumétrica que leva à formação de trincas no revestimento possibilitando a difusão do oxigênio no substrato metálico. Por outro lado, no revestimento à base de $\mathrm{CrN} / \mathrm{AlN}$, onde os nitretos se transformam em $\mathrm{Cr}_{2} \mathrm{O}_{3}$ e $\mathrm{Al}_{2} \mathrm{O}_{3}$, a expansão volumétrica é mínima. Os dois óxidos apresentam também a mesma estrutura cristalina, portanto podem se misturar como em uma solução sólida amorfa mantendo sua proteção contra a oxidação mais efetiva (TIEN; DUH, 2006).

As Figuras 41 a 43 apresentam os difratogramas de raios X da liga Ti-6Al-4V sem recobrimento e recoberta por TiN e TiAlN/TiAlCrN após oxidação isotérmica, respectivamente. Para cada condição experimental fez-se uma análise nas primeiras 23 horas e outra no final do teste de oxidação $(t=168$ h). 


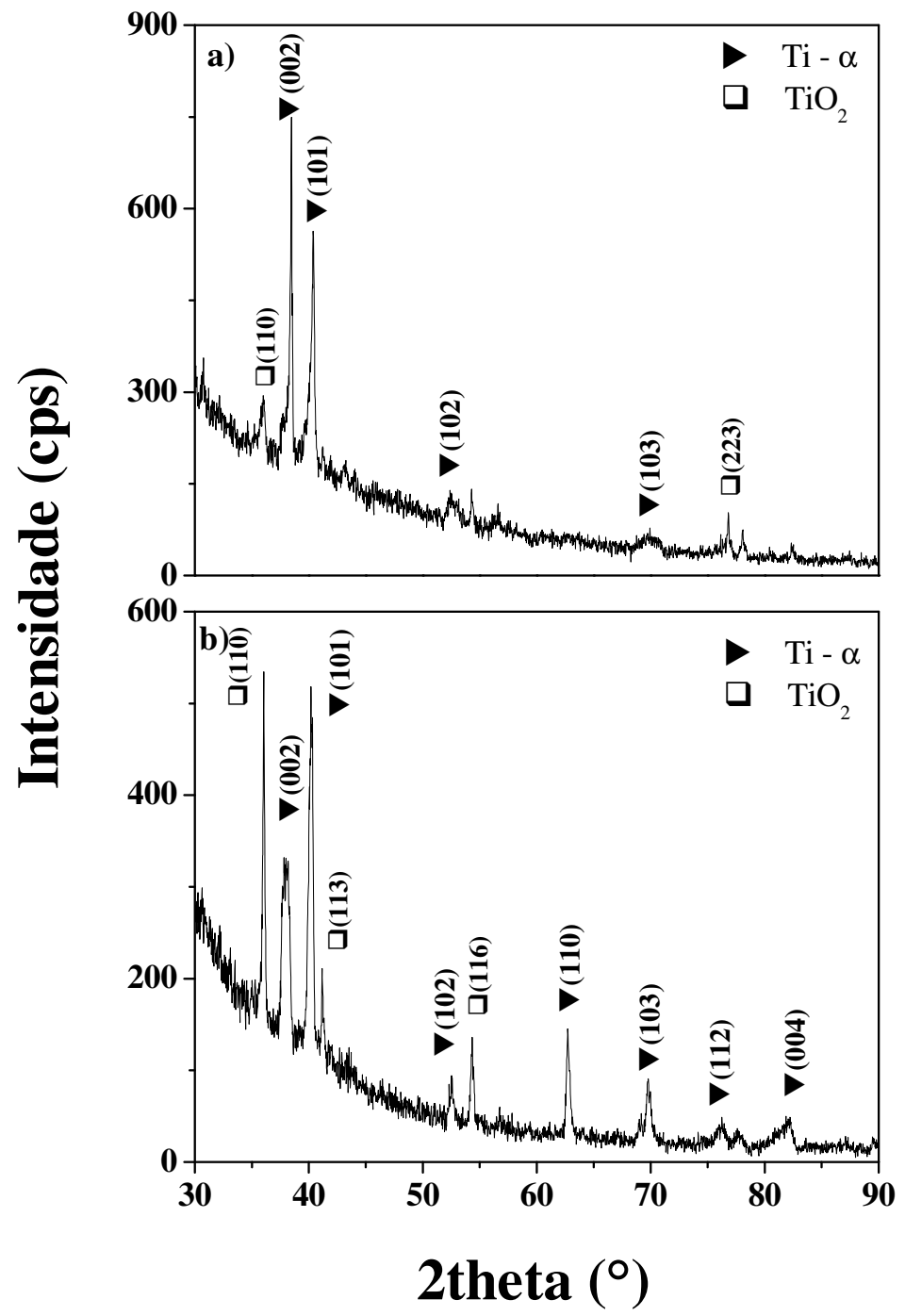

Figura 41. Difratogramas de raios $X(D R X)$ da liga Ti-6Al-4V sem recobrimento, oxidada a $600{ }^{\circ} \mathrm{C}:$ a) $t=23 \mathrm{~h}$, b) $\mathrm{t}=$ $168 \mathrm{~h}$.

Com base na Figura 41 observa-se que, quando exposta a uma temperatura de 600 ${ }^{\circ} \mathrm{C}$, a liga Ti-6Al-4V é oxidada, formando o óxido $\mathrm{TiO}_{2}$. Segundo Guleryuz e Cimenoglu (2009), altas temperaturas e longos tempos de exposição $\left(650{ }^{\circ} \mathrm{C}, 48 \mathrm{~h}\right)$ resultam na formação de um recobrimento composto dominantemente por $\mathrm{TiO}_{2}$ (GULERYUZ; CIMENOGLU, 2009). 


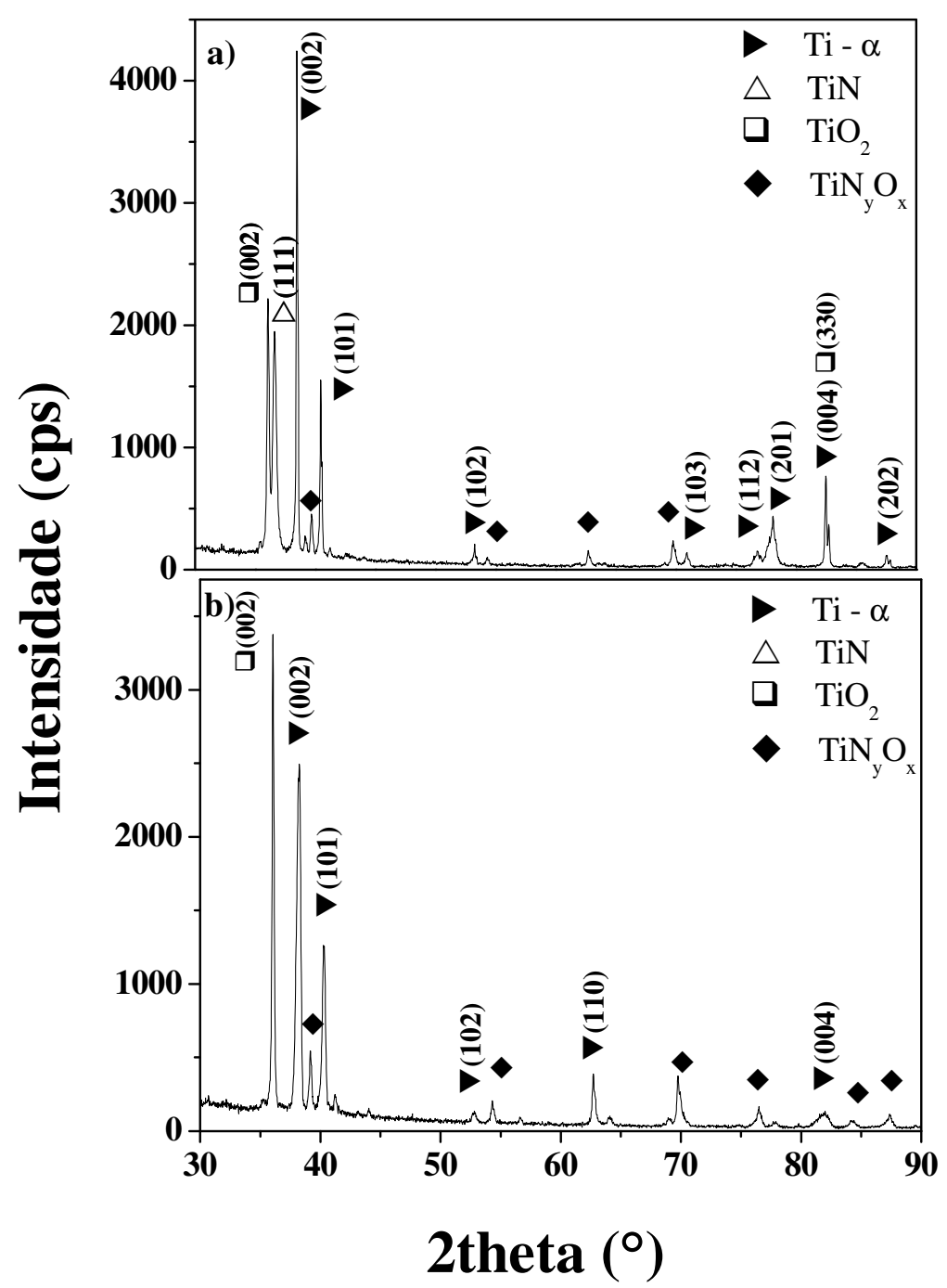

Figura 42. Difratogramas de raios $X(D R X)$ da liga Ti-6Al-4V recoberta por TiN, oxidada a $600{ }^{\circ} \mathrm{C}$ : a) $\left.t=23 \mathrm{~h}, \mathrm{~b}\right) \mathrm{t}=$ $168 \mathrm{~h}$.

Os difratogramas da amostra recoberta por TiN nos mostram a formação de $\mathrm{TiO}_{2}$ (que como já foi dito antes é resultado da oxidação do composto TiN) e de um oxinitreto de fórmula $\mathrm{TiN}_{\mathrm{y}} \mathrm{O}_{\mathrm{x}}$. Polyakova e Hübert (2001) investigaram a estabilidade térmica do nitreto TiN e reportaram que, antes da formação do $\mathrm{TiO}_{2}$, forma-se pelo menos um ou dois intermediários durante a oxidação, segundo o seguinte esquema:

TiN $\rightarrow \operatorname{TiN}_{y} \mathrm{O}_{x} \rightarrow \mathrm{TiO}_{2}$ (POLAYKOVA; HÜBERT, 2001). 

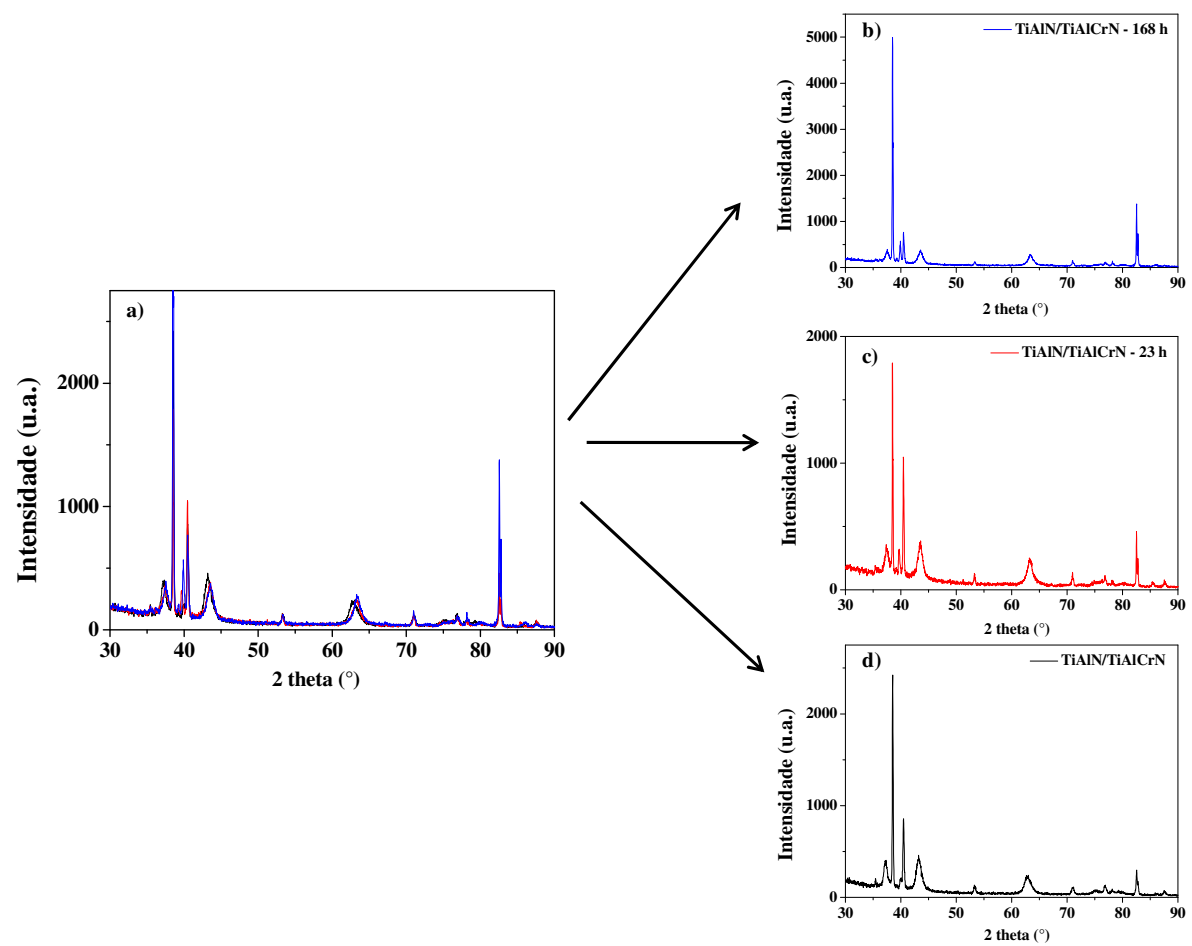

Figura 43. Difratogramas de raios $\mathrm{X}$ da liga Ti-6Al-4V recoberta por TiAlN/TiAlCrN, oxidada a $600{ }^{\circ} \mathrm{C}$ : a) sobreposição dos difratogramas, b) $t=23 \mathrm{~h}, \mathrm{c}$ ) $\mathrm{t}=168 \mathrm{~h}, \mathrm{~d}$ ) TiAlN/TiAlCrN antes do teste de oxidação isotérmica.

A Figura 43 mostra que, assim como as medidas de ganho de massa revelaram, a liga Ti-6Al-4V recoberta por TiAlN/TiAlCrN é resistente à oxidação a $600{ }^{\circ} \mathrm{C}$ para tempos de até 168 horas. A sobreposição dos difratogramas (Figura 43 a) apresenta picos idênticos com a mesma intensidade e mesma posição. Zhu et al. (2012) estudaram o comportamento em oxidação de revestimentos à base de TiAlN e TiAlSiN a 850, 900 e $1000{ }^{\circ} \mathrm{C}$. Segundo os autores, o bom desempenho desses revestimentos é devido à formação dos óxidos $\mathrm{Al}_{2} \mathrm{O}_{3}$ e $\mathrm{SiO}_{2}$ que atuam como barreiras contra a difusão do oxigênio (ZHU et al., 2012). Adicionalmente, a configuração de multicamadas de um revestimento retarda o processo de difusão do metal em direção à superfície (Ti) e do O em direção ao substrato (CHEN et al., 2011). Neste presente trabalho, a resistência à oxidação da liga Ti-6Al-4V recoberta por TiAlN/TiAlCrN foi atribuída à formação dos óxidos $\mathrm{Al}_{2} \mathrm{O}_{3}$ e/ou $\mathrm{Cr}_{2} \mathrm{O}_{3}$ e à microestrutura multicamadas do recobrimento TiAlN/TiAlCrN. Os óxidos formados sobre a superfície, provavelmente, formaram uma camada de ordem nanométrica e característica amorfa sobre a superfície e por isso não foram detectados na análise de DRX apresentada na Figura $43 b$ e $43 c$.

A fim de complementar o estudo de oxidação, fez-se análises via microscopia eletrônica de varredura. A Figura 44 mostra as imagens da seção transversal das amostras testadas a $600{ }^{\circ} \mathrm{C}$. 

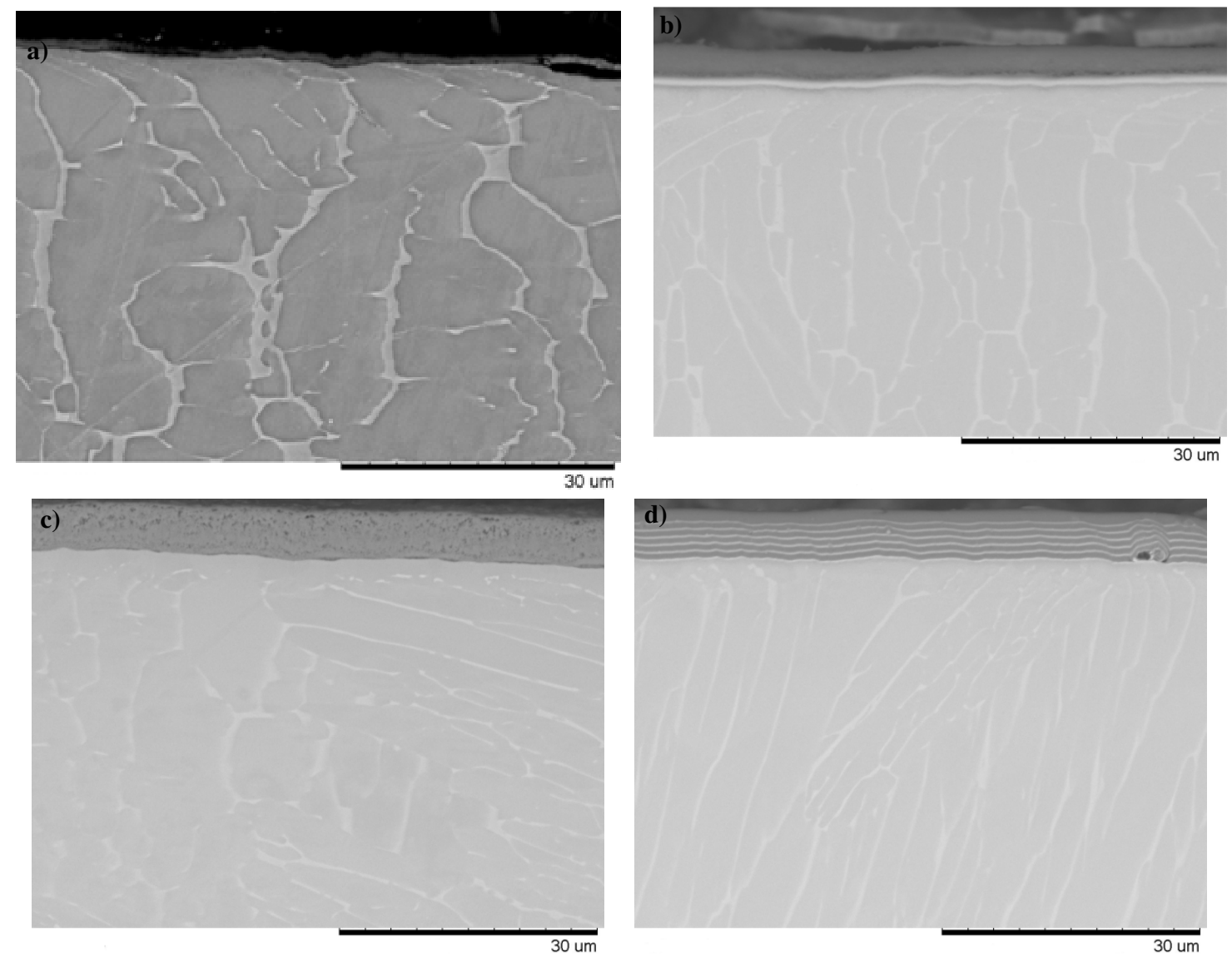

Figura 44. Micrografias das amostras oxidadas isotermicamente a $600{ }^{\circ} \mathrm{C}$ : a) Ti-6Al-4V sem recobrimento, $\mathrm{t}=168 \mathrm{~h}, \mathrm{~b}$ ) Ti-6Al-4V recoberta por $\mathrm{TiN}, \mathrm{t}=23 \mathrm{~h}, \mathrm{c}) \mathrm{Ti}-6 \mathrm{Al}-4 \mathrm{~V}$ recoberta por $\mathrm{TiN}, \mathrm{t}=168 \mathrm{~h}, \mathrm{~d}$ ) Ti-6Al-4V recoberta por TiAlN/TiAlCrN, $\mathrm{t}=168 \mathrm{~h}$.

Na Figura 44 (a) vê-se a formação de uma camada oxida de espessura igual a 1,3 $\mu \mathrm{m}$. Este valor está de acordo com a faixa encontrada por Kumar e colaboradores (2009) que oxidaram Ti puro a $650{ }^{\circ} \mathrm{C}$ por até 48 horas e obtiveram valores de espessura variando de 3,5 a 19 m (KUMAR et al., 2009). Nas Figuras 44 (b) e (c) observa-se a evolução da oxidação do TiN. Para $t=23 \mathrm{~h}$, apenas uma parte do recobrimento se modificou (oxidou) e o recobrimento demonstra ainda uma microestrutura bastante compacta; para $\mathrm{t}=168 \mathrm{~h}$, o revestimento oxidou-se completamente e apresenta aspecto poroso. As medidas de espessura dos óxidos formados a partir do revestimento TiN foram de 3,2 $\mu \mathrm{m}$ (camada cinza) em $t=23 \mathrm{~h}$ e $6,2 \mu \mathrm{m}$ em $\mathrm{t}=168 \mathrm{~h}$. A amostra recoberta por TiAlN/TiAlCrN manteve-se estável e com espessura de mesmo valor ao do inicial $(6 \mu \mathrm{m})$.

Sabe-se que, em camadas óxidas que apresentam crescimento controlado por difusão do elemento Ti em direção à interface óxido/meio ambiente, na medida em que estas camadas tornam-se mais espessas, mais difícil fica a difusão através delas (REVIE; UHLIG, 2008). Entretanto, a camada óxida que se forma, geralmente, apresenta mais de um composto em sua constituição ( $\mathrm{TiO}, \mathrm{TiO}_{2}, \mathrm{Al}_{2} \mathrm{O}_{3}, \mathrm{~V}_{2} \mathrm{O}_{5}$, entre outros) resultando em 
uma camada óxida heterogênea. Esta diferença composicional gera tensões internas, causando trincas e desprendimento da camada, expondo o substrato ao meio oxidante (GARBACZ; LEWANDOWSKA, 2003). Sendo assim, a camada óxida que se forma sobre as ligas de titânio não apresenta característica protetora em altas temperaturas. Este fato, portanto, contribui para acelerar o fenômeno de fluência pela redução da área útil de sustentação de força e, consequentemente, aumenta a taxa de deformação e reduz o tempo de vida.

\subsection{ENSAIOS DE FLUÊNCIA}

\subsubsection{LIGA TI-6AL-4V NA CONDIÇÃO SEM RECOBRIMENTO E NITRETADA POR PLASMA}

No ano de 2010, começou-se um trabalho de pesquisa com a liga Ti-6Al-4V tratada superficialmente e submetida a condições de fluência que gerou o trabalho de mestrado intitulado como "Estudo do fenômeno da fluência na liga Ti-6Al-4V submetida a tratamentos de nitretação e carbonetação por plasma" (OLIVEIRA, 2010). Os resultados foram promissores, particularmente com a liga Ti-6Al-4V que foi nitretada por plasma e, com base nestes resultados, continuou-se os estudos com a liga Ti-6Al-4V tratada superficialmente por nitretação a plasma e outras técnicas de recobrimento testada sob condições de fluência. O objetivo foi propor opções de melhorias no desempenho da liga Ti-6Al-4V quando solicitada mecanicamente em altas temperaturas. Portanto, esta seção destina-se a apresentar, resumidamente e para fins de comparação, os resultados obtidos na primeira parte deste trabalho para as condições sem recobrimento e nitretada por plasma.

Os testes de fluência foram conduzidos na liga Ti-6Al-4V sem proteção superficial (também denominada “condição como recebida - CR") e nitretada por plasma. O substrato possuía morfologia Widmanstätten (igual à apresentada na seção 4.1 deste trabalho) e a nitretação foi feita em duas etapas: uma de limpeza por $1 \mathrm{~h}$ a $500{ }^{\circ} \mathrm{C}$ em uma atmosfera de argônio e hidrogênio $\left(\mathrm{H}_{2}-75 \%\right.$ Ar), e uma de nitretação por $6 \mathrm{~h}$ a $725{ }^{\circ} \mathrm{C}$ em uma atmosfera de nitrogênio e hidrogênio $\left(\mathrm{H}_{2}-75 \% \mathrm{~N}_{2}\right)$ (OLIVEIRA, 2010). 
A camada nitretada foi caracterizada por microdureza, perfilometria e DRX. Onde se obteve uma camada de $4 \mu \mathrm{m}$ de espessura, composta por $\operatorname{TiN}$ e $\operatorname{Ti}_{2} \mathrm{~N}$, de dureza igual a 1539 HV (maior que a da condição CR) e de rugosidade média igual a 1,18 $\mu$ m (menor que a da CR) (OLIVEIRA, 2010).

Os ensaios de fluência foram conduzidos sob condições de carga constante na faixa de tensões de 222 a $300 \mathrm{MPa}$ a $600^{\circ} \mathrm{C}, 300 \mathrm{MPa}$ a $550{ }^{\circ} \mathrm{C}$ e de 300 a $450 \mathrm{MPa}$ a $500^{\circ} \mathrm{C}$. As curvas obtidas em ambas as temperaturas para todas as condições experimentais apresentaram os estágios primário, secundário e terciário muito bem definidos e um comportamento crescente da deformação $\varepsilon_{0}$ em função da tensão inicialmente aplicada a 500 e $600{ }^{\circ} \mathrm{C}$. No entanto, as ligas tratadas termoquimicamente apresentam os menores valores da deformação instantânea em função da maior rigidez elástica induzida pelos tratamentos a plasma. A taxa secundária aumentou com a tensão aplicada para todas as condições estudadas. A $500{ }^{\circ} \mathrm{C}$, a diferença percentual entre os valores da taxa estacionária das amostras CR e nitretada foram de 17 e $9 \%$ para as tensões de 350 e $450 \mathrm{MPa}$, respectivamente. Entretanto, a $600{ }^{\circ} \mathrm{C}$, a diferença percentual entre os valores da taxa estacionária das amostras CR e nitretada aumentou para 58\% nas tensões de 222 e 300 $\mathrm{MPa}$, revelando que o tratamento de nitretação por plasma foi bem mais efetivo em temperaturas mais elevadas. A $600{ }^{\circ} \mathrm{C}$ foram encontrados expoentes $n=4,83$ para a condição CR e $n=4,82$ para a liga nitretada (OLIVEIRA, 2010). Estes valores encontramse adequados para metais puros e ligas endurecidas por solução sólida (HAN; CHATUVERDI, 1987). A energia de ativação $Q$ para o regime secundário foi estimada para as amostras CR e nitretada para a tensão de $300 \mathrm{MPa}$. Os valores obtidos, $\mathrm{Q}=309$ $\mathrm{kJ} / \mathrm{mol}$ para a liga na condição $\mathrm{CR}, \mathrm{Q}=272 \mathrm{~kJ} / \mathrm{mol}$ para a nitretada encontram-se adequados à faixa apresentada por Tang (TANG, 2002) e por Gollapudi (GOLLAPUDI et al., 2008) para um conjunto de ligas à base de titânio. A análise conjunta dos valores da energia de ativação e dos expoentes de tensão a $600{ }^{\circ} \mathrm{C}$ indicaram que o mecanismo predominante nesta temperatura para estas duas condições microestruturais foi associado à escalagem de discordâncias (EVANS, 1979). O tempo de fratura diminuiu com o aumento da tensão para todas as condições de temperatura. As análises fractográficas mostraram que houve fratura transgranular por nucleação e coalescência de microcavidades com regiões de decoesão intergranular que pode estar associado ao tamanho médio de grão em torno de $946 \mu \mathrm{m}$ (OLIVEIRA, 2010). As Tabelas 17 e 18 mostram os valores dos principais parâmetros de fluência, onde $\varepsilon_{0}$ corresponde à deformação instantânea, $\dot{\varepsilon}_{s}$ à taxa 
de fluência secundária (ou estacionária), $\mathrm{t}_{\mathrm{f}}$ ao tempo de fratura e $\varepsilon_{f}$ à deformação correspondente à fratura. A Figura 45 mostra os aspectos fractográficos das amostras na condição CR e nitretada, respectivamente (OLIVEIRA, 2010).

Tabela 17. Parâmetros experimentais de fluência a $600{ }^{\circ} \mathrm{C}$ para a liga na condição CR.

\begin{tabular}{ccccc}
\hline \multirow{2}{*}{ Parâmetro } & \multicolumn{4}{c}{ Como Recebido } \\
& $222 \mathrm{MPa}^{*}$ & $250 \mathrm{MPa}$ & $278 \mathrm{MPa}$ & $300 \mathrm{MPa}^{*}$ \\
\hline$\varepsilon_{0}(\mathrm{~mm} / \mathrm{mm})$ & 0,00364 & 0,00411 & 0,00359 & 0,00713 \\
$\dot{\varepsilon}_{s}(1 / \mathrm{s})$ & $1,136 \times 10^{-5}$ & $2,015 \times 10^{-5}$ & $3,365 \times 10^{-5}$ & $4,866 \times 10^{-5}$ \\
$t_{f}\left(10^{3} \mathrm{~s}\right)$ & 7,884 & 2,984 & 1,235 & 0,684 \\
$\varepsilon_{f}(\mathrm{~mm} / \mathrm{mm})$ & 0,375 & 0,284 & 0,24 & 0,22 \\
\hline$*(\mathrm{OLIVEIRA,2010)}$ & & & &
\end{tabular}

*(OLIVEIRA, 2010)

Tabela 18. Parâmetros experimentais de fluência a $600{ }^{\circ} \mathrm{C}$ para a liga na condição nitretada por plasma (OLIVEIRA, 2010).

\begin{tabular}{ccccc}
\hline & & \multicolumn{3}{c}{ Nitretado } \\
Parâmetro & $222 \mathrm{MPa}$ & $250 \mathrm{MPa}$ & $278 \mathrm{MPa}$ & $300 \mathrm{MPa}$ \\
\hline$\varepsilon_{0}(\mathrm{~mm} / \mathrm{mm})$ & 0,00238 & 0,00280 & 0,00220 & 0,00562 \\
$\dot{\varepsilon}_{s}(1 / \mathrm{s})$ & $4,747 \times 10^{-6}$ & $9,366 \times 10^{-6}$ & $1,524 \times 10^{-5}$ & $2,015 \times 10^{-5}$ \\
$t_{f}\left(10^{3} \mathrm{~s}\right)$ & 23,688 & 10,152 & 4,467 & 3,528 \\
$\varepsilon_{f}(\mathrm{~mm} / \mathrm{mm})$ & 0,357 & 0,25 & 0,22 & 0,2095 \\
\hline
\end{tabular}
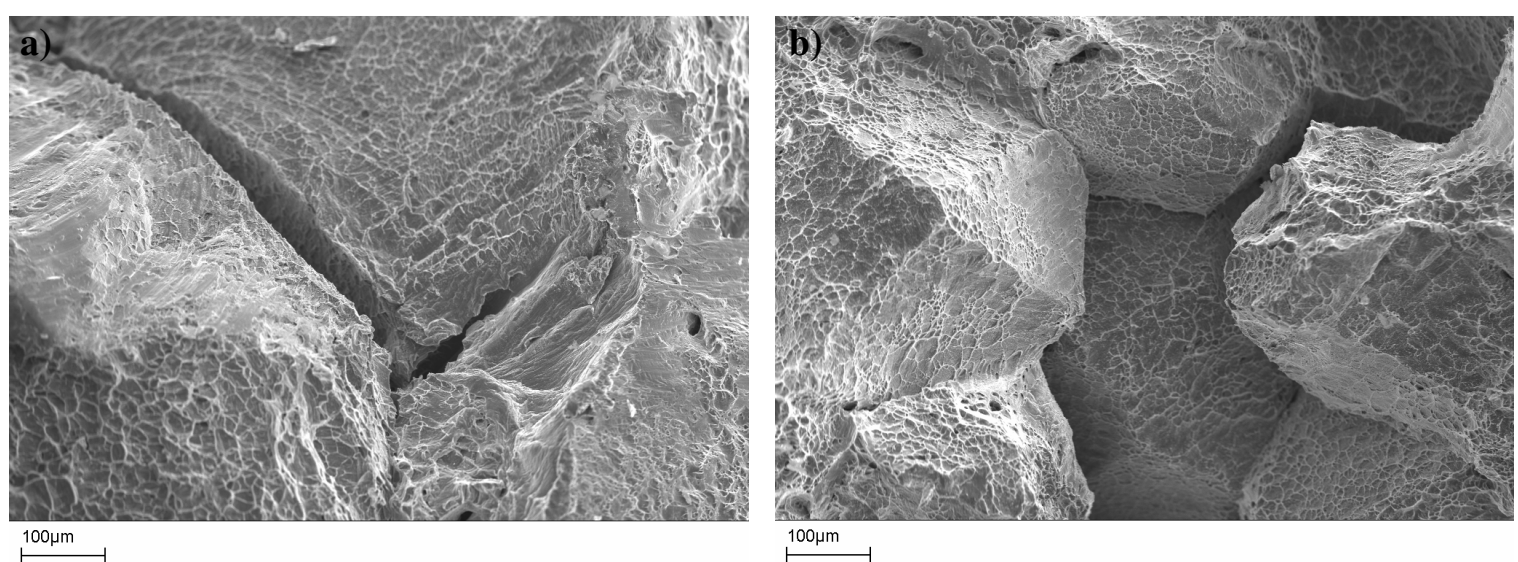

Figura 45. Aspecto geral da superfície de fratura a $600^{\circ} \mathrm{C}$ : a) Ti-6Al-4V sem recobrimento a $300 \mathrm{MPA}$, b) Ti-6Al-4V nitretado a plasma a $350 \mathrm{MPa}$ (OLIVEIRA,2010). 
4.5.2. LIGA TI-6AL-4V NA CONDIÇÃO RECOBERTA POR TIN E TiAlN/TiAlCrN

As Figuras 46 a 50 apresentam as curvas correspondentes à deformação $\varepsilon$ como função do tempo t, obtidas a $600{ }^{\circ} \mathrm{C}$, para o material nas condições como recebida (CR), nitretada por plasma, recoberta por TiN e por TiAlN/TiAlCrN, para vários níveis de tensão.

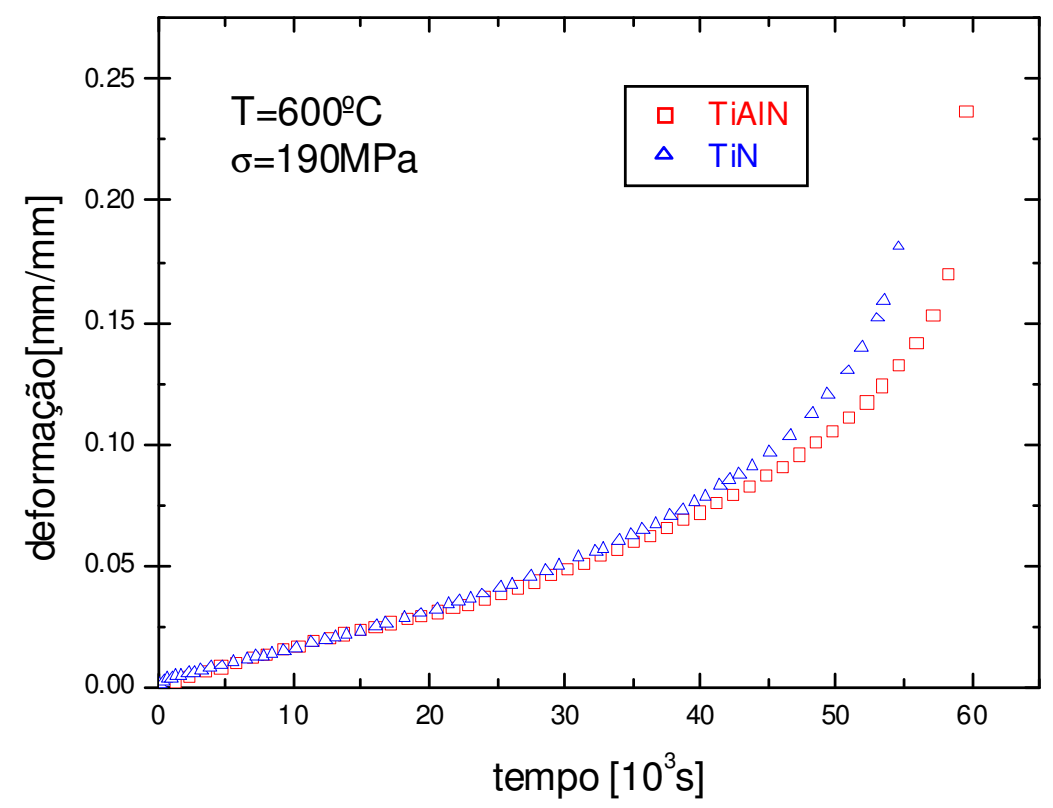

Figura 46. Curva deformação x tempo para a liga nas condições recoberta por TiN e TiAlN/TiAlCrN a $600{ }^{\circ} \mathrm{C}$ e 190 $\mathrm{MPa}$. 


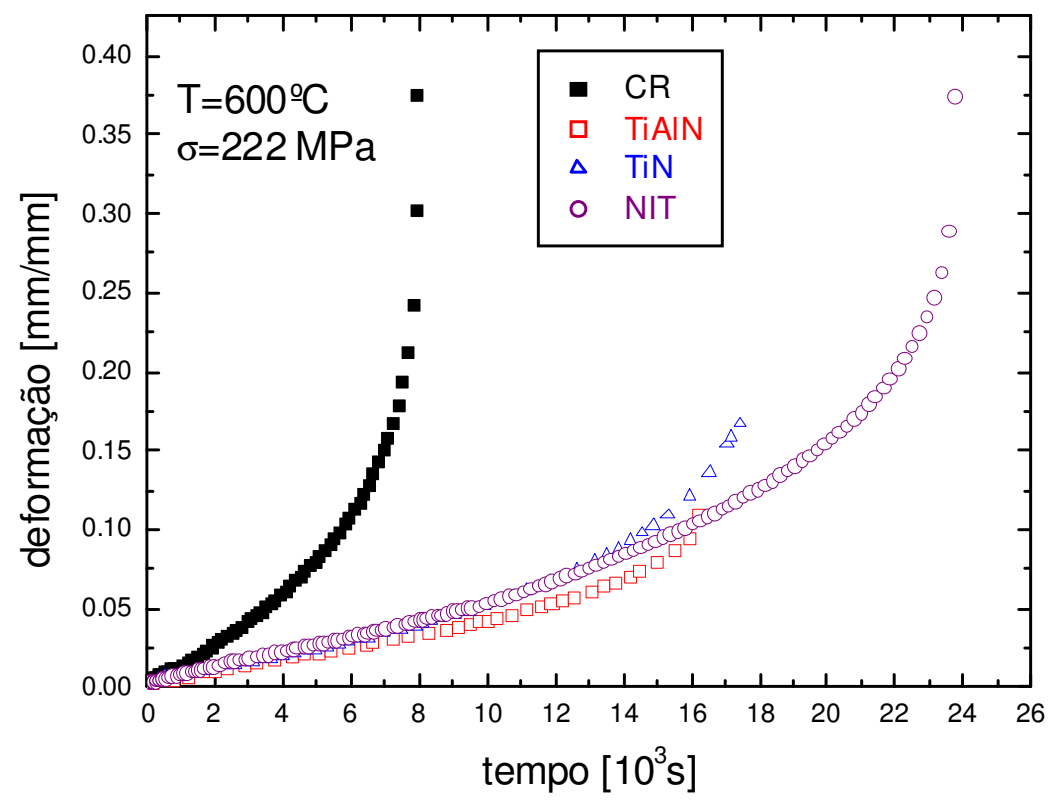

Figura 47. Curva deformação $\mathrm{x}$ tempo para a liga nas condições CR (OLIVEIRA, 2010), nitretada por plasma (OLIVEIRA, 2010) e recoberta por TiN e TiAlN/TiAlCrN a $600^{\circ} \mathrm{C}$ e $222 \mathrm{MPa}$.

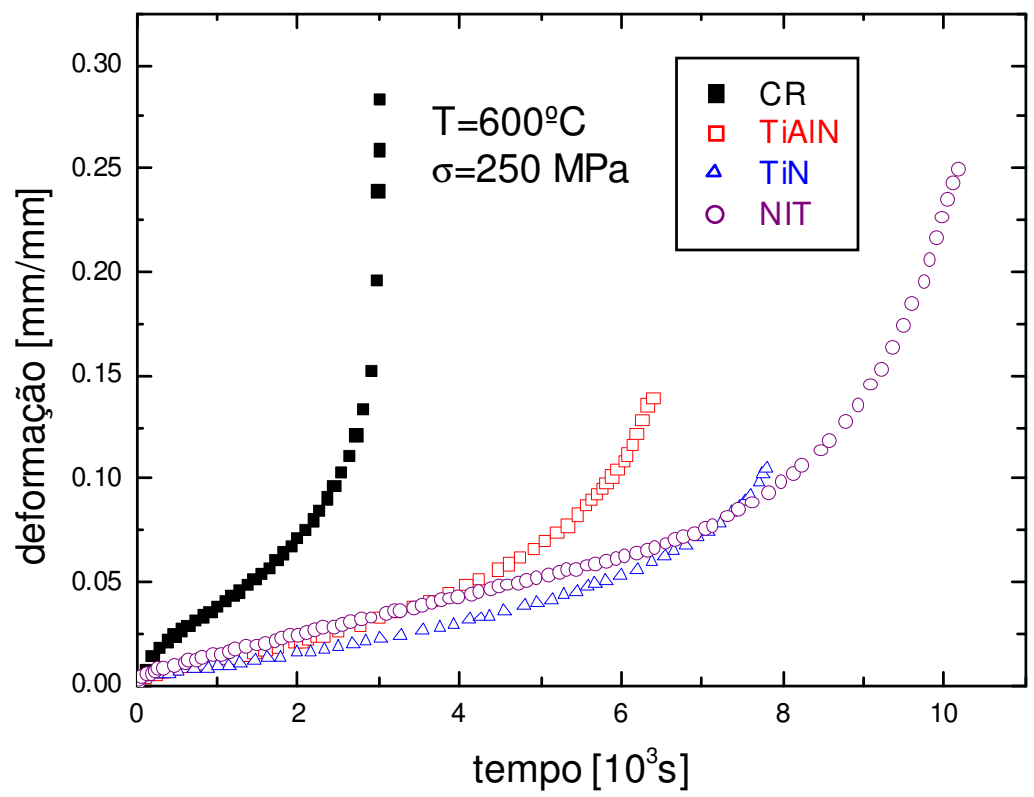

Figura 48. Curva deformação $x$ tempo para a liga nas condições CR, nitretada por plasma (OLIVEIRA, 2010) e recoberta por TiN e TiAlN/TiAlCrN a $600{ }^{\circ} \mathrm{C}$ e $250 \mathrm{MPa}$. 


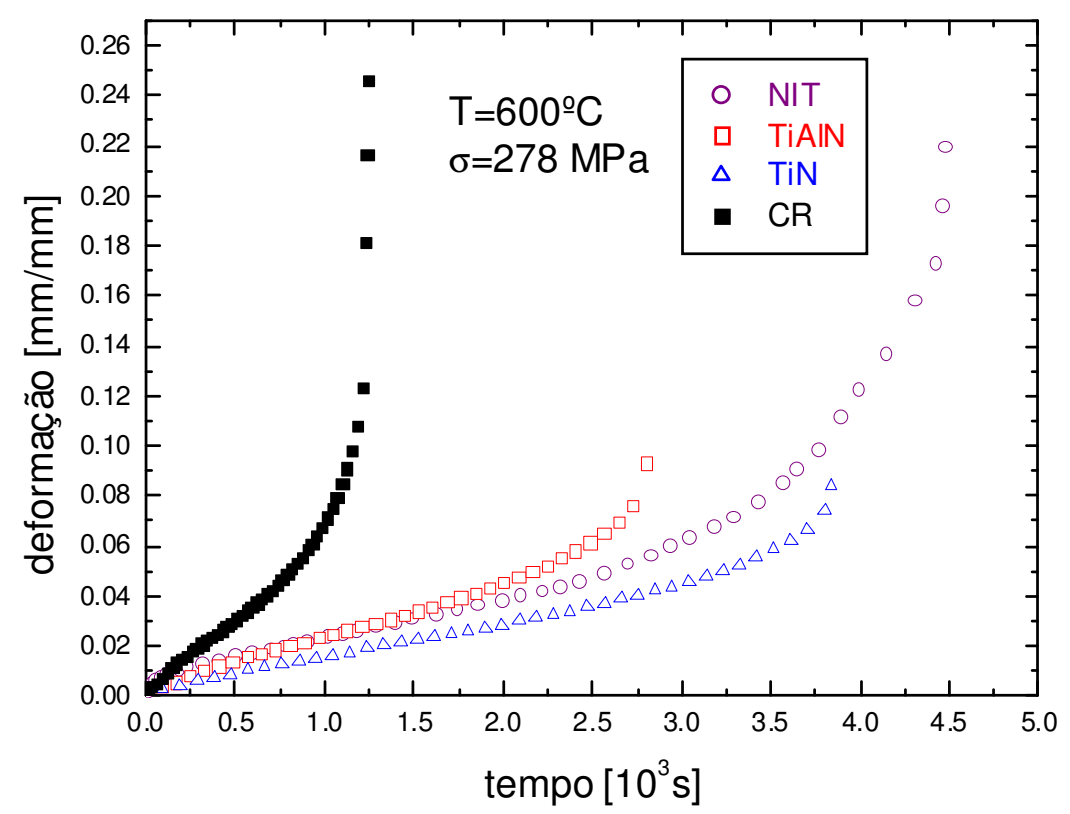

Figura 49. Curva deformação $x$ tempo para a liga nas condições CR, nitretada por plasma (OLIVEIRA, 2010) e recoberta por TiN e TiAlN/TiAlCrN a $600{ }^{\circ} \mathrm{C}$ e $278 \mathrm{MPa}$.

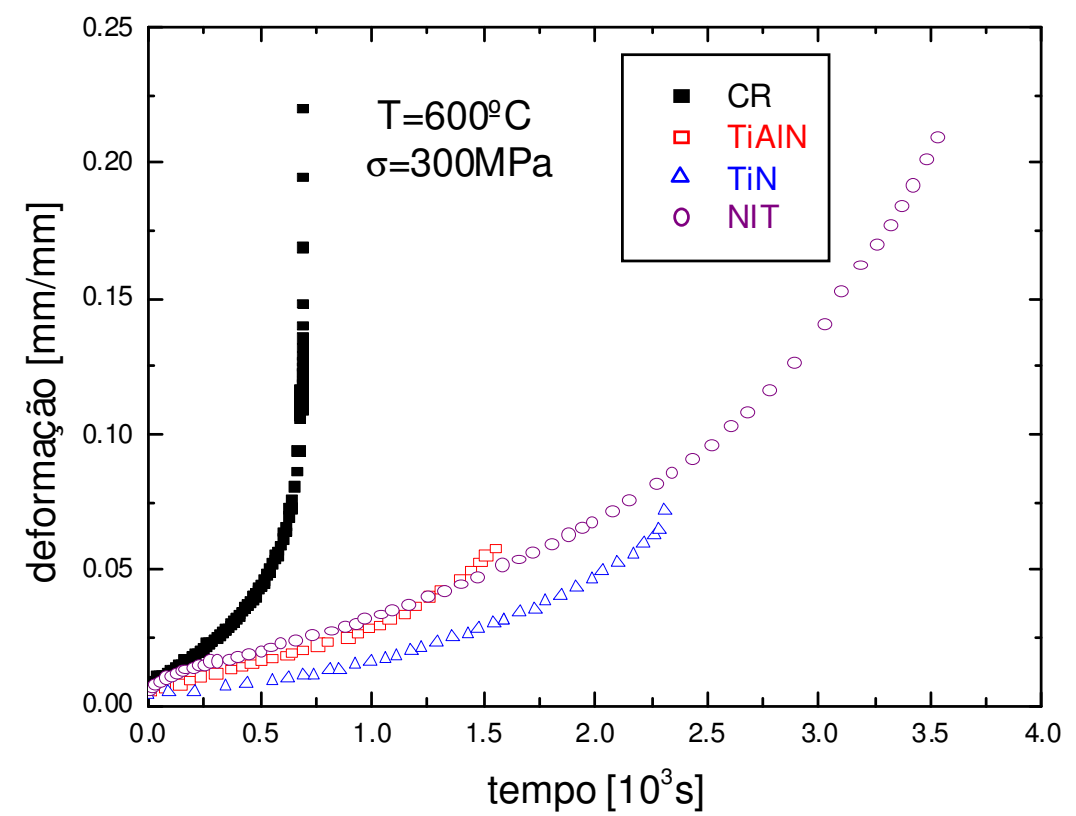

Figura 50. Curva deformação $x$ tempo para a liga nas condições CR (OLIVEIRA, 2010), nitretada por plasma (OLIVEIRA, 2010) e recoberta por TiN e TiAlN/TiAlCrN a $600{ }^{\circ} \mathrm{C}$ e $300 \mathrm{MPa}$.

As Tabelas 19 e 20 apresentam a relação dos principais parâmetros experimentais obtidos a $600{ }^{\circ} \mathrm{C}$ relativo às curvas $\varepsilon \times \mathrm{t}$ para a liga nas condições recoberta por $\mathrm{TiN} \mathrm{e}$ TiAlN/TiAlCrN. 
Tabela 19. Parâmetros experimentais de fluência a $600{ }^{\circ} \mathrm{C}$ para a liga na condição recoberta por TiN.

TiN

\begin{tabular}{|c|c|c|c|c|c|}
\hline Parâmetro & $190 \mathrm{MPa}$ & $222 \mathrm{MPa}$ & $250 \mathrm{MPa}$ & $278 \mathrm{MPa}$ & $300 \mathrm{MPa}$ \\
\hline $\mathcal{E}_{0}(\mathrm{~mm} / \mathrm{mm})$ & 0,0011 & 0,00341 & 0,00302 & 0,00206 & 0,00423 \\
\hline$\dot{\varepsilon}_{s}(1 / s)$ & $1,420 \times 10^{-6}$ & $3,866 \times 10^{-6}$ & $6,571 \times 10^{-6}$ & $9,744 \times 10^{-6}$ & $1,259 \times 10^{-5}$ \\
\hline$t_{f}\left(10^{3} \mathrm{~s}\right)$ & 54,631 & 17,461 & 7,801 & 3,839 & 2,308 \\
\hline$\varepsilon_{f}(\mathrm{~mm} / \mathrm{mm})$ & 0,181 & 0,16718 & 0,10536 & 0,0834 & 0,07172 \\
\hline \multirow{2}{*}{ Parâmetro } & \multicolumn{5}{|c|}{ TiAlN/TiAlCrN } \\
\hline & $190 \mathrm{MPa}$ & $222 \mathrm{MPa}$ & $250 \mathrm{MPa}$ & $278 \mathrm{MPa}$ & $300 \mathrm{MPa}$ \\
\hline $\mathcal{E}_{0}(\mathrm{~mm} / \mathrm{mm})$ & 0,0013 & 0,00241 & 0,00382 & 0,00309 & 0,00563 \\
\hline$\dot{\varepsilon}_{s}(1 / \mathrm{s})$ & $1,349 \times 10^{-6}$ & $3,373 \times 10^{-6}$ & $8,986 \times 10^{-6}$ & $1,485 \times 10^{-5}$ & $2,112 \times 10^{-5}$ \\
\hline$t_{f}\left(10^{3} \mathrm{~s}\right)$ & 59,475 & 16,207 & 6,401 & 2,796 & 1,549 \\
\hline $\mathcal{E}_{f}(\mathrm{~mm} / \mathrm{mm})$ & 0,2375 & 0,11038 & 0,14044 & 0,0933 & 0,05787 \\
\hline
\end{tabular}

\subsubsection{DISCUSSÃO DOS RESULTADOS DOS ENSAIOS DE FLUÊNCIA}

Vários são os trabalhos que procuraram melhorar o desempenho da liga Ti-6Al-4V em altas temperaturas. A vida em fluência de ligas de titânio pode ser muito grande (variando entre 20.000 a 120.000 h) e, por este motivo, os testes acelerados dão uma boa ideia do comportamento de uma liga metálica em fluência em um espaço curto de tempo (ABDALLAH et al., 2012). A faixa de temperatura e tensão dos trabalhos reportados na literatura varia de 450 a $700{ }^{\circ} \mathrm{C}$ e de 80 a $550 \mathrm{MPa}$ (dependendo da temperatura de trabalho e do limite de escoamento da liga metálica) (BOEHLERT, 2009; KRAL et al., 2013; LI et al., 2011; LI et al., 2013; PARK et al., 2006; REIS et al., 2013; XIAO et al., 2009).

As curvas obtidas para todas as condições experimentais apresentam os estágios primário, secundário e terciário muito bem definidos. De uma forma geral, com base nos 
dados das Tabelas 17, 18, 19 e 20, observa-se um comportamento crescente da deformação $\varepsilon_{0}$ em função da tensão inicialmente aplicada a $600{ }^{\circ} \mathrm{C}$. No entanto, as amostras tratadas superficialmente apresentam valores da deformação instantânea 1,5 vezes menor em função da maior rigidez elástica induzida pelos tratamentos.

A Figura 51 mostra a dependência da taxa estacionária nas condições CR, nitretada por plasma, recoberta por TiN e por TiAlN/TiAlCrN com a tensão aplicada.

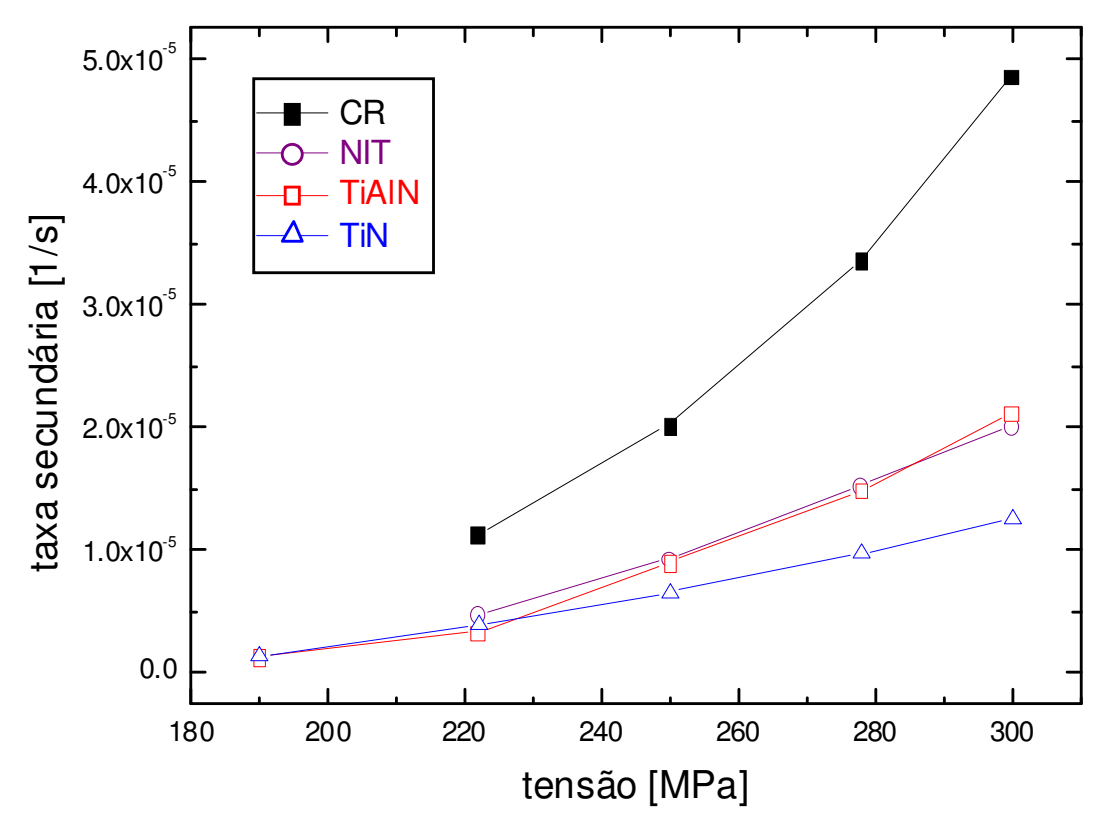

Figura 51. Dependência da taxa estacionária com a tensão a $600^{\circ} \mathrm{C}$ para a liga nas condições $\mathrm{CR}$, nitretada por plasma, recoberta por TiN e por TiAlN/TiAlCrN.

A análise das curvas permite concluir que a taxa secundária aumenta com a tensão aplicada para todas as condições estudadas. A diferença percentual entre os valores da taxa secundária na condição $\mathrm{CR}$ e nas condições tratadas superficialmente é de cerca de $56 \%$ menor na condição nitretada por plasma, 69 \% na condição recoberta por TiN e de $56 \%$ na condição recoberta por TiAlN/TiAlCrN. Observou-se que a diferença entre os valores da taxa secundária na condição $\mathrm{CR}$ e nas condições tratadas superficialmente (variação em porcentagem da taxa secundária) foi praticamente a mesma em todas as tensões aplicadas. Exceto para a condição recoberta por TiAlN/TiAlCrN quando comparada com a condição $\mathrm{CR}$, que mostrou diferença percentual entre os valores da taxa secundária 56\% menor entre as tensões de 250 a $300 \mathrm{MPa}$ e $70 \%$ menor para a tensão de $222 \mathrm{MPa}$.

Com base na Equação 8, a Figura 52 traz a relação ln (tensão) vs. In (taxa secundária) de todas as condições experimentais estudadas. 


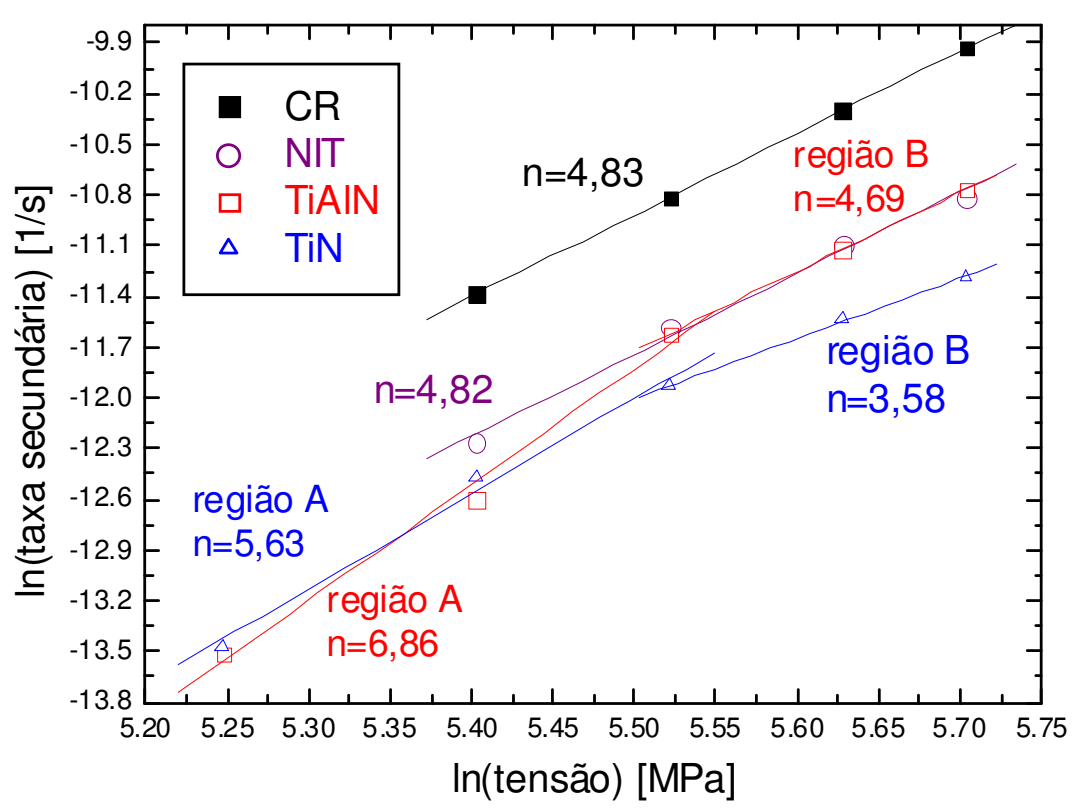

Figura 52. Ln (tensão) vs. ln (taxa secundária) a $600^{\circ} \mathrm{C}$ para a liga nas condições CR, nitretada por plasma, recoberta por TiN e por TiAlN/TiAlCrN.

Com o aumento da tensão, os valores da taxa de fluência aumentam, e estes mesmos valores são maiores para a liga sem recobrimento superficial, o que permite afirmar que as amostras tratadas superficialmente são mais resistentes em detrimento do material sem revestimento. Tal afirmação é válida já que a taxa secundária diminui pela ação da proteção superficial.

Com base na Figura 52 e na Equação 8, obteve-se uma estimativa dos parâmetros $B$ e do expoente de tensão $n$ para a liga sem recobrimento e tratada superficialmente, testadas em condições de fluência a $600{ }^{\circ} \mathrm{C}$. As Equações 12 a 17 são resultado desta estimativa.

$C R \rightarrow \dot{\varepsilon_{S}}=5,19 \times 10^{-17} \sigma^{4,83}$

Nitretado $\rightarrow \dot{\varepsilon_{S}}=2,46 \times 10^{-17} \sigma^{4,82}$

$T i N \rightarrow \dot{\varepsilon_{S}}=2,24 \times 10^{-19} \sigma^{5,63}$ (região A)

$T i N \rightarrow \dot{\varepsilon_{S}}=1,76 \times 10^{-14} \sigma^{3,58}$ (região B)

TiAlN $/$ TiAlCrN $\rightarrow \dot{\varepsilon}_{s}=3,03 \times 10^{-22} \sigma^{6,86}$ (região A) 
$\operatorname{TiAlN} / \operatorname{TiAlCrN} \rightarrow \dot{\varepsilon_{S}}=5,11 \times 10^{-17} \sigma^{4,69}$ (região B)

A $600^{\circ} \mathrm{C}$, os expoentes $n=4,83$ para a condição $\mathrm{CR}, n=4,82$ para a liga nitretada, $\mathrm{n}=5,63$ e 3,58 para a liga recoberta por TiN e $\mathrm{n}=6,86$ e 4,69 para a liga recoberta por TiAlN/TiAlCrN encontram-se adequados para metais puros e ligas endurecidas por solução sólida (HAN; CHATUVERDI, 1987).

Zhu e colaboradores (1998) estudaram a deformação por fluência da liga Ti-6Al-4V reforçado por whiskers de $\mathrm{TiC}$ nas temperaturas de 550 a $650{ }^{\circ} \mathrm{C}$. Os autores mostraram que a adição de partículas de TiC refina a microestrutura da liga metálica e melhora as propriedades mecânicas. Finalmente, reportaram $n=4,3$ que está de acordo com um mecanismo de deformação por fluência controlado por difusão na rede cristalina através de escalagem de discordâncias (ZHU et al., 1998). Park e colaboradores (2006) reportaram um estudo que melhorou as propriedades mecânicas da liga Ti-6Al-4V, em fluência, por meio de um recobrimento duplex ( $\mathrm{CrN}+$ carbonetação por plasma). Os autores obtiveram expoentes de tensão entre 8 e 9,5 e energia de ativação entre 220 a $260 \mathrm{~kJ} / \mathrm{mol}$ e relacionaram os altos valores de $\mathrm{n}$ com a presença da fase $\beta$ que não apresentou aumento na densidade de discordâncias depois do processo de fluência e, portanto, foi considerada estável e forte o suficiente para agir como barreira ao escorregamento de discordâncias (PARK et al., 2006). Singh e colaboradores (2014) investigaram a influência da adição de boro no comportamento em fluência da liga Ti-6Al-4V. Os autores observaram que o boro adicionado refina a microestrutura aumentando a área de interfaces $\alpha / \alpha, \alpha / \beta$ e $\alpha / \mathrm{TiB}$ (composto resultante da adição do boro) que agem como barreiras ao movimento de discordâncias. Os autores reportaram n variando entre 4,9 e 6,28 e energia de ativação variando entre 282 e $316 \mathrm{~kJ} / \mathrm{mol}$, indicando que o mecanismo de deformação em fluência foi controlado por escalagem de discordâncias (SINGH et al., 2014). Badea e colaboradores (2014) estudaram o comportamento em fluência da liga Ti-6Al-4V na faixa de temperatura de 450 a $600{ }^{\circ} \mathrm{C}$. Os autores reportaram n variando entre 4,3 a 6,1 e energia de ativação variando entre 251 a $326 \mathrm{~kJ} / \mathrm{mol}$ (BADEA et al., 2014). Pode-se concluir que, de forma geral, os valores de expoentes de tensão e energia de ativação bem como a definição de um mecanismo de deformação por fluência reportados neste trabalho estão de acordo com a literatura.

Em geral, observa-se que a mudança nos valores do expoente $n$ está relacionada com alterações nos mecanismos responsáveis pela deformação por fluência. As regiões indicadas por região A e região $\mathrm{B}$ nos testes com a liga Ti-6Al-4V revestida por TiN e 
TiAlN/TiAlCrN (Figura 52) apresentaram valores de $n$ variando de 3,58 a 5,3 e 4,69 a 6,86 , respectivamente. No entanto, encontram-se na mesma faixa de valores onde o mecanismo dominante é o movimento não conservativo de discordâncias (SHERBY; BURKE, 1968). Apesar da necessidade de se obter maiores informações através de outras análises para explicar o comportamento observado, neste presente trabalho, há indícios de que o aumento da ductilidade $\left(\varepsilon_{\mathrm{f}}\right)$ acompanhado pela redução do nível de cavitação nos contornos de grão contribuiu para esta mudança de comportamento.

A Figura 53 estabelece o comportamento do tempo de fratura em função da tensão aplicada.

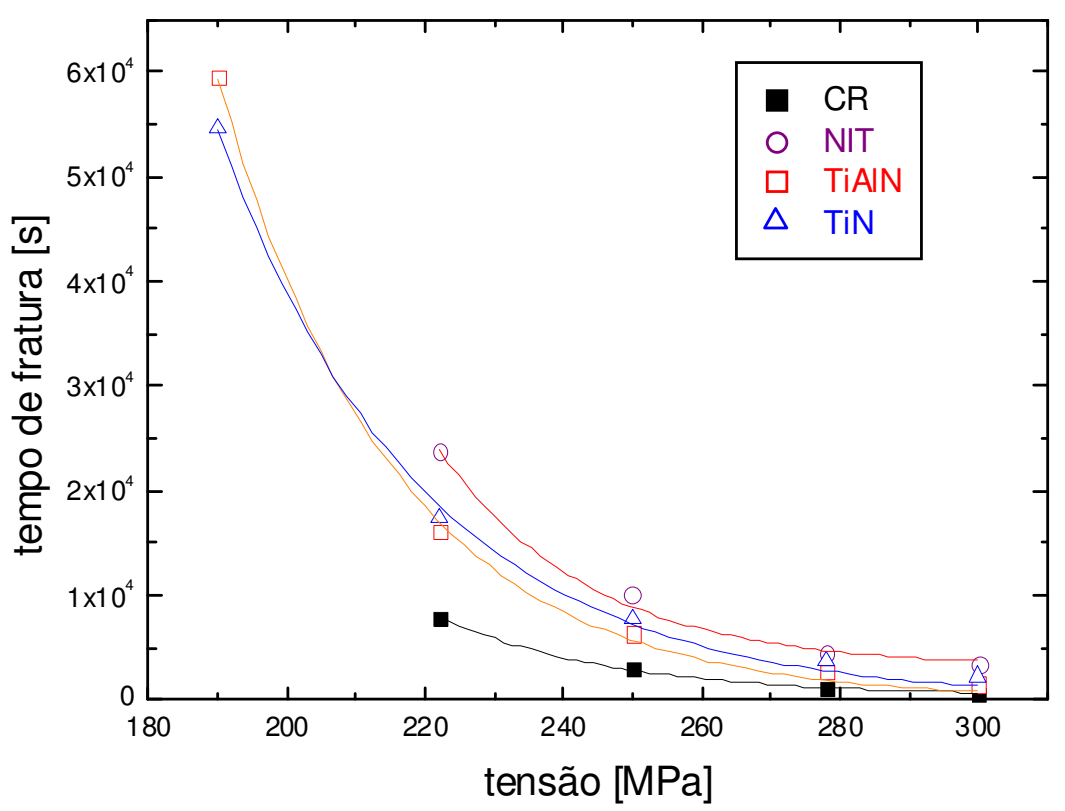

Figura 53. Dependência do tempo de fratura com a tensão a $600^{\circ} \mathrm{C}$ para a liga nas condições $\mathrm{CR}$, nitretada por plasma, recoberta por TiN e por TiAlN/TiAlCrN.

Este parâmetro diminui com o aumento da tensão para todas as condições estudadas. Na condição nitretada por plasma a vida aumenta de 3 a 5 vezes com base nos valores obtidos para as tensões de 222 e $300 \mathrm{MPa}$. Este melhor desempenho, observado pelos valores do tempo de fratura e pela taxa secundária, é resultado da formação da camada dura de $\mathrm{TiN}$ e $\mathrm{Ti}_{2} \mathrm{~N}$, do endurecimento por solução sólida devido à difusão do elemento nitrogênio na matriz e pela contribuição na redução nos valores de rugosidade superficial $(1,29 \mu \mathrm{m}$ da amostra $\mathrm{CR}$ para $1,18 \mu \mathrm{m}$ para a liga nitretada) induzidos pelo tratamento termoquímico (OLIVEIRA, 2010). Nas amostras recobertas por PVD observouse um aumento do tempo de fratura com relação à condição CR de 2,9 vezes para amostra 
recoberta de TiN e de 2,1 vezes para a amostra recoberta por TiAlN/TiAlCrN. No caso do tratamento por PVD o aumento observado na taxa secundária e no tempo de fratura é atribuído à presença de compostos cerâmicos duros e inertes resistentes à oxidação.

A Figura 54 estabelece o comportamento do tempo de fratura em função da tensão aplicada e demonstra a possibilidade de relacionar estes parâmetros por meio de uma lei de potência segundo a Equação 18 (EVANS; WILSHIRE, 1993):

$t_{f}=C \sigma^{-m}$

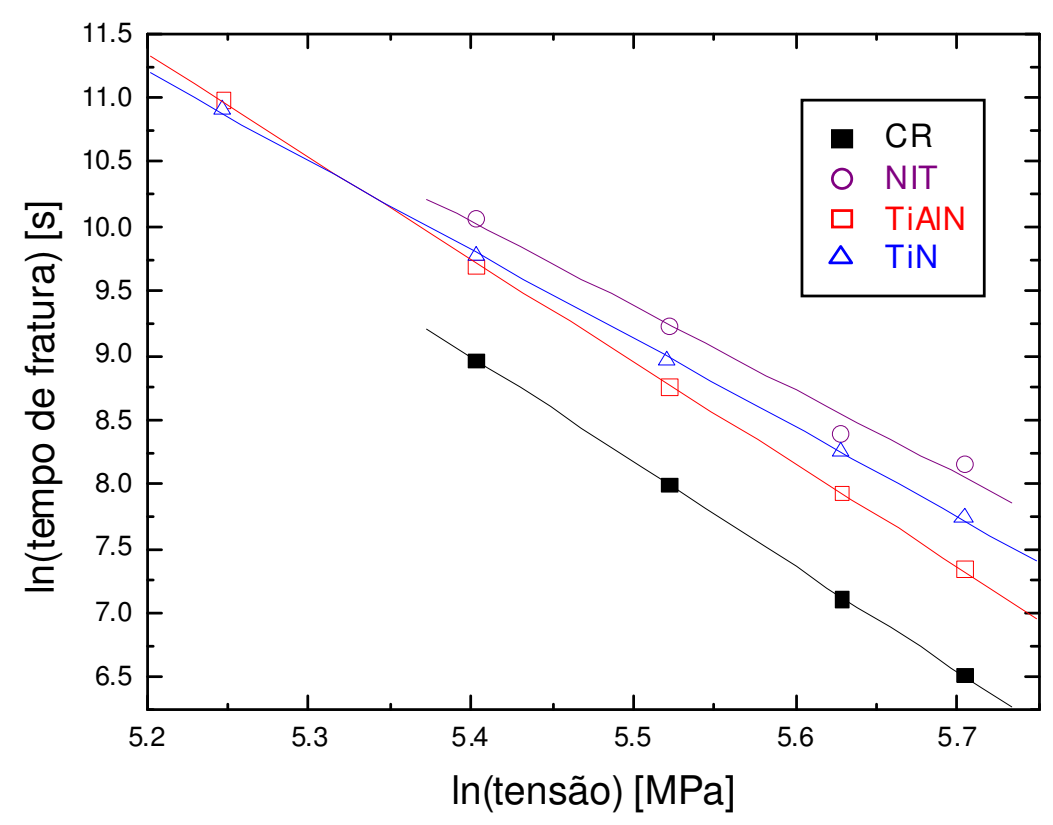

Figura 54. Ln (tensão) vs. In (tempo de fratura) a $600^{\circ} \mathrm{C}$ para a liga nas condições CR, nitretada por plasma, recoberta por TiN e por TiAlN/TiAlCrN.

Desta forma, as linearizações apresentadas (Figura 54) conduzem as relações de 15 a 18. Esta correlação entre o tempo de vida e a tensão aplicada pode ser usada para extrapolação de dados para uma dada temperatura (EVANS; WILSHIRE, 1993).

$C R \rightarrow t_{f}=1,02 \times 10^{23} \sigma^{-8,15}$

Nitretado $\rightarrow t_{f}=5,25 \times 10^{19} \sigma^{-6,55}$

$\operatorname{TiN} \rightarrow t_{f}=2,90 \times 10^{20} \sigma^{-6,91}$ 
$\operatorname{TiAlN} / \operatorname{TiAlCrN} \rightarrow t_{f}=8,28 \times 10^{22} \sigma^{-7,97}$

A Figura 55 apresenta a variação dos níveis de ductilidade, quantificados pela deformação final $\varepsilon_{f}$, com a tensão aplicada.

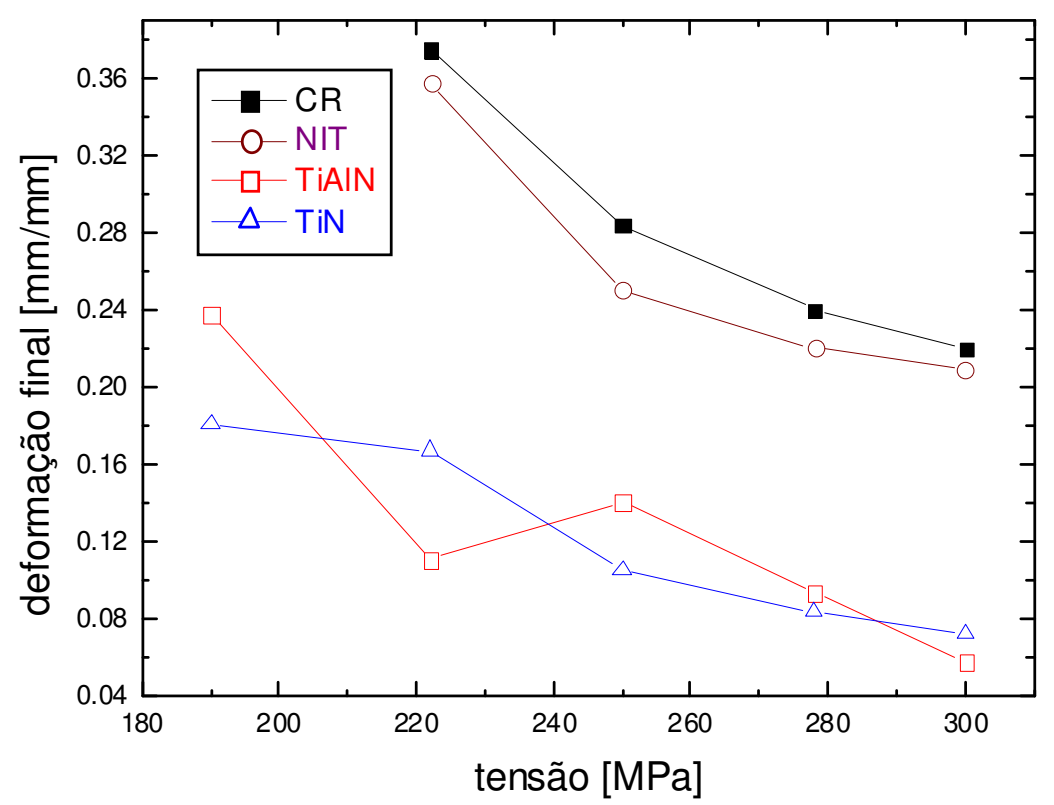

Figura 55. Dependência da deformação final com a tensão a $600^{\circ} \mathrm{C}$ para a liga nas condições $\mathrm{CR}$, nitretada por plasma, recoberta por TiN e por TiAlN/TiAlCrN.

Com base na Figura 55 pode-se observar que, de forma geral, a ductilidade das amostras diminui com o aumento da tensão aplicada. Este comportamento está relacionado com os efeitos da degradação superficial, resultantes da ação do meio sobre o material, induzindo a formação de trincas superficiais. As amostras recobertas por PVD mostraramse mais frágeis que as amostras $\mathrm{CR}$ e nitretadas. Uma análise mais apurada será apresentada no item 4.6 com base no estudo do parâmetro de tolerância ao dano W.

\subsubsection{COMPARAÇÃO DOS RESULTADOS DE FLUÊNCIA}

Com base nas Figuras 52 e 54 e nas Tabelas 17 a 20, observou-se que a amostra revestida por TiN depositado por PVD apresentou os menores valores de taxa secundária 
para tensões maiores que $222 \mathrm{MPa}$, contudo a amostra nitretada a plasma apresentou maiores valores de vida útil e níveis de ductilidade.

A diminuição da taxa secundária de fluência está relacionada com o efeito de barreira contra a o xidação que o material pode oferecer. A nitretação por plasma gerou uma camada de 4-5 $\mu$ m composta de $\mathrm{TiN}, \mathrm{Ti}_{2} \mathrm{~N}$ e zona de difusão de nitrogênio (que contribui para estabilização de fase $\alpha-\mathrm{Ti}$ ). A espessura da camada formada apenas pelos compostos cerâmicos inertes e duros foi cerca de $1 \mu \mathrm{m}$. No momento em que essa camada se rompe durante o processo de fluência o meio oxidante entra em contato com a zona de difusão. Apesar da presença do nitrogênio endurecer a liga, esta camada é basicamente fase $\alpha$ - Ti e não é resistente à oxidação a $600{ }^{\circ} \mathrm{C}$, como mostrado no item 4.4. Por outro lado, a amostra recoberta por PVD gerou uma camada cerâmica dura mais espessa capaz de proteger mais efetivamente a amostra metálica da deformação por fluência. No entanto, esta mesma camada cerâmica gerou um nível de fragilidade maior na amostra que foi traduzido em vida útil menor e menores níveis de ductilidade. Segundo Dobrzanski a Adamiak os mecanismos de falhas mecânicas de revestimentos à base de nitretos estão relacionados com o aparecimento de microtrincas e microcavidades no revestimento, geralmente próximo a algum ponto concentrador de tensão (como um risco) (DOBRZANSKI; ADAMIAK, 2003).

Ao comparar os dois revestimentos depositados por PVD, observa-se que a amostra revestida por TiAlN/TiAlCrN apresenta um comportamento melhor que a amostra revestida por TiN na medida em que a tensão diminui. Este fato pode ser explicado com base na aderência e na resistência à oxidação de cada um dos revestimentos. Durante os testes de corrosão observou-se que os revestimentos à base de TiAlN/TiAlCrN desprendiam-se da amostra metálica em todas as condições estudadas, indicando que a aderência deste recobrimento era menor do que a aderência do recobrimento à base de TiN. Contudo, durante os testes de oxidação constatou-se que a liga recoberta por TiAlN/TiAlCrN é muito resistente à oxidação a $600{ }^{\circ} \mathrm{C}$. Portanto, em níveis mais altos de tensão, onde a aderência do filme é mais importante, a amostra revestida por TiN apresentou-se mais resistente. Na medida em que a tensão diminui as resistências mecânicas dos recobrimentos passa a ser um parâmetro secundário e o parâmetro que comanda a resistência da liga em fluência é a resistência à oxidação. A maior resistência à oxidação do recobrimento TiAlN/TiAlCrN fez com que a amostra recoberta por TiAlN/TiAlCrN apresentasse menor taxa secundária e maior vida útil a $190 \mathrm{MPa}$. Essa diferença no comportamento entre os dois recobrimentos pode ser vista nas Figuras 52 e 54 
e nas Tabelas 19 e 20, onde a $350 \mathrm{MPa}$ a amostra recoberta por TiN é cerca de $67 \%$ mais resistente e sua vida útil 1,5 vezes maior e a $190 \mathrm{MPa}$ a amostra recoberta por TiAlN/TiAlCrN é cerca de $5 \%$ mais resistente e sua vida útil 1,1 vez maior.

Pode-se concluir, portanto, que os tratamentos superficiais melhoraram o comportamento da liga Ti-6Al-4V em fluência através da diminuição das taxas secundárias e do aumento do tempo de vida útil. Contudo, os recobrimentos depositados por PVD interferiram muito mais na ductilidade da liga.

\subsection{ANÁLISE FRACTOGRÁFICA E DE ESTRUTURA DE DISCORDÂNCIAS}

A complementação deste trabalho compreende o estudo dos principais aspectos fractográficos e de configuração de discordâncias de algumas amostras representativas das condições CR, nitretada, recoberta por TiN e TiAlN/TiAlCrN.

As Figuras 56 a 59 mostram as amostras recobertas por TiN e TiAlN/TiAlCrN testadas a 190 e $300 \mathrm{MPa}$, respectivamente.

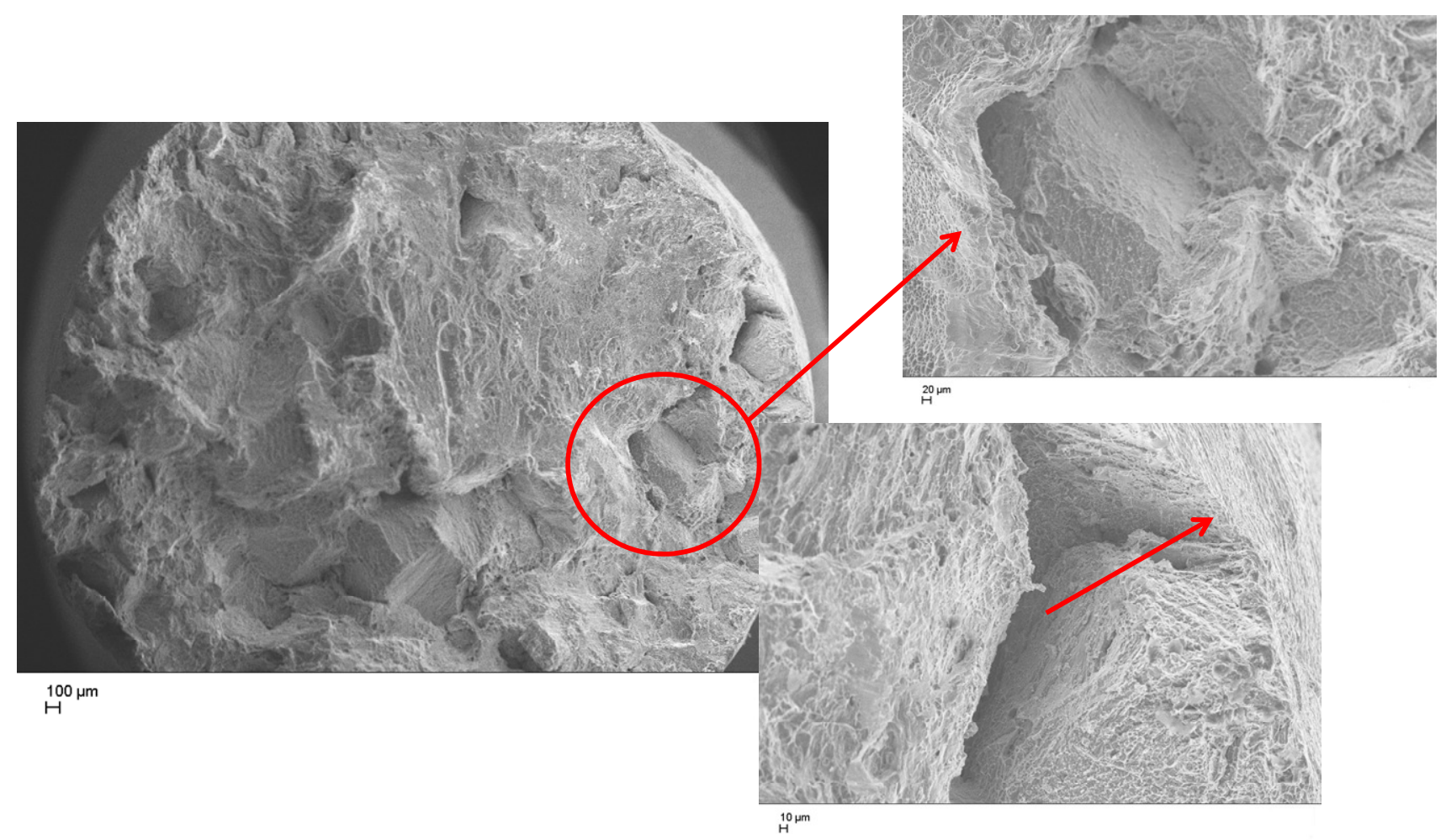

Figura 56. Aspecto geral da superfície de fratura a $600^{\circ} \mathrm{C}$ e $190 \mathrm{MPa}$ na condição recoberta por TiN. 


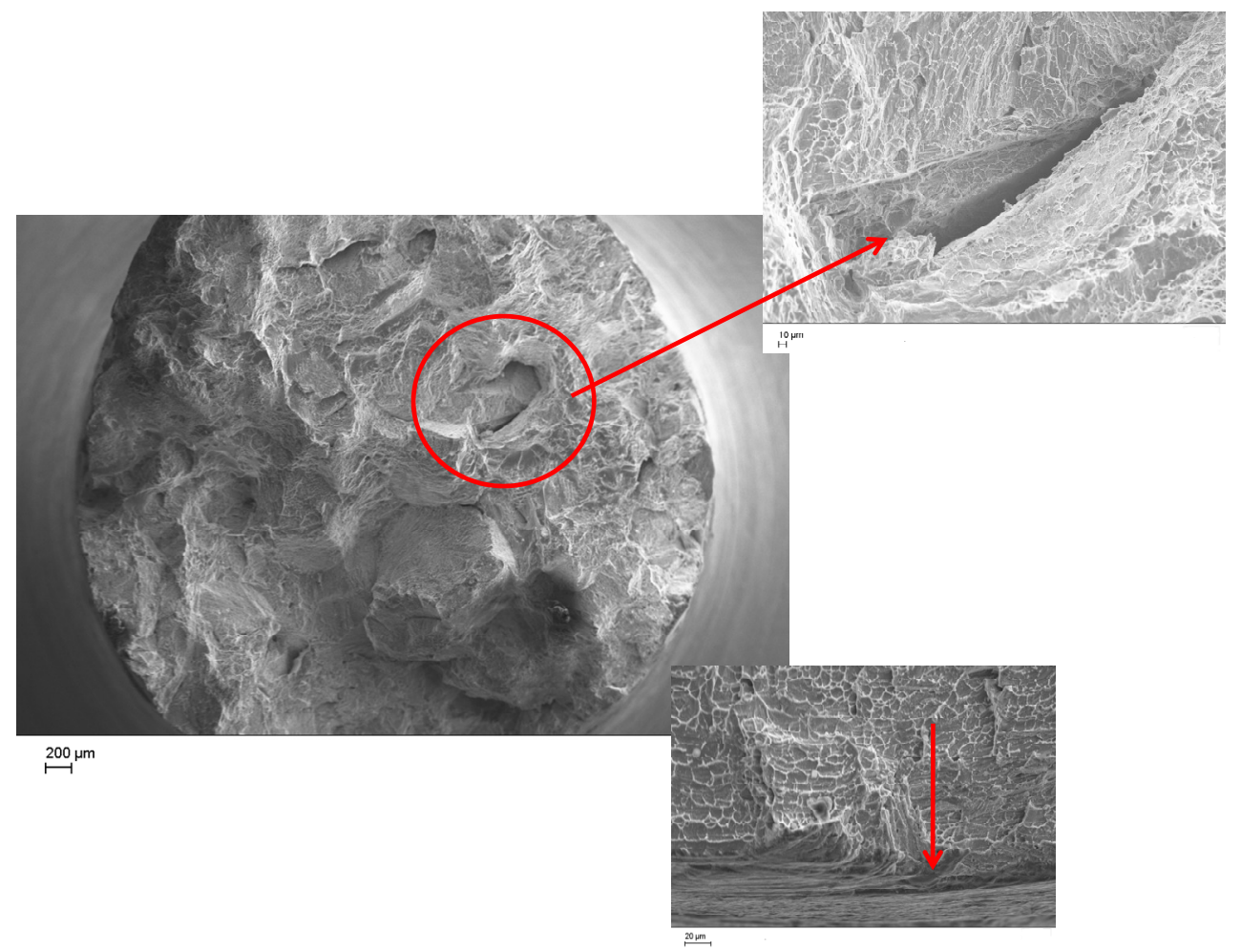

Figura 57. Aspecto geral da superfície de fratura a $600^{\circ} \mathrm{C}$ e $300 \mathrm{MPa}$ na condição recoberta por TiN.

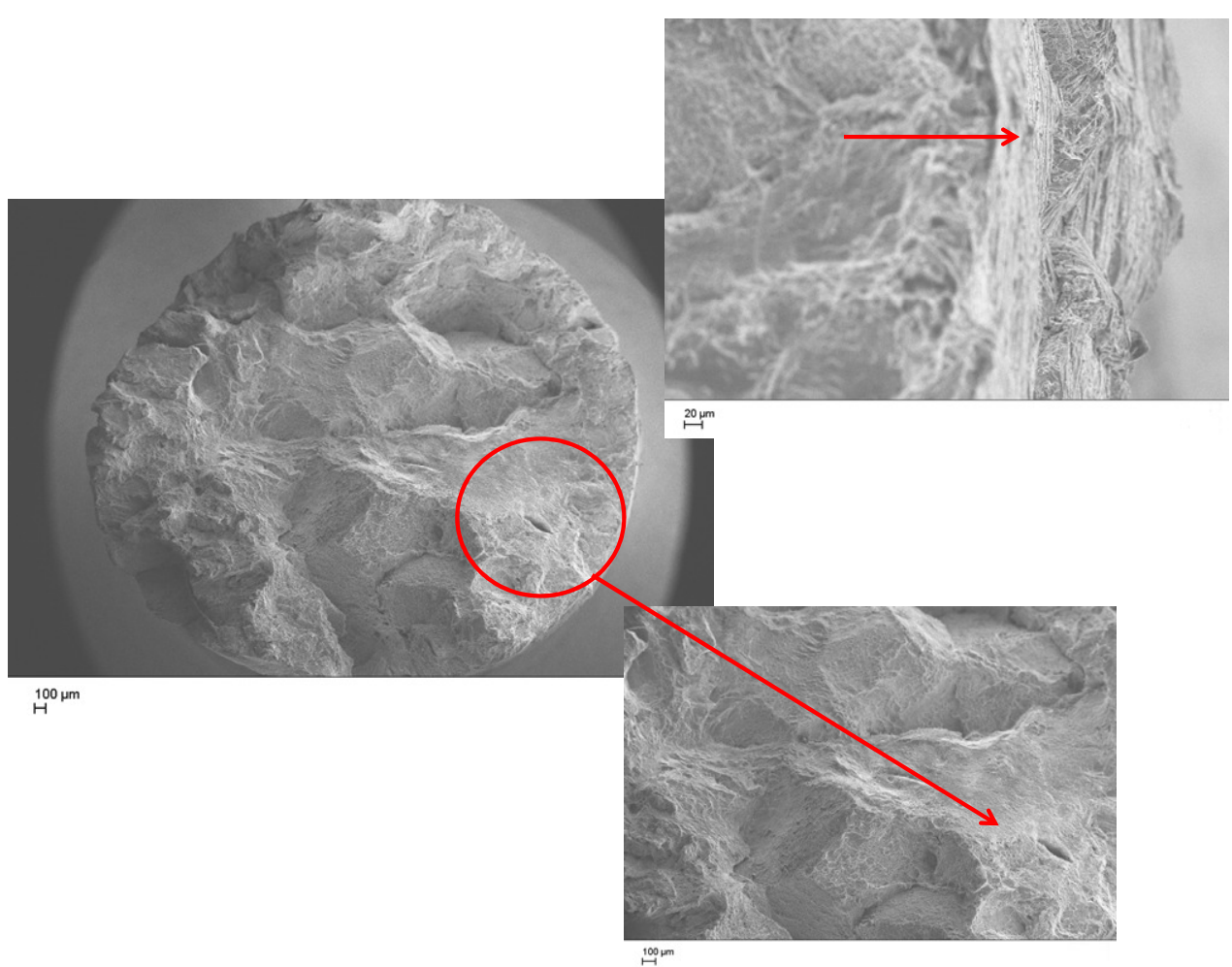

Figura 58. Aspecto geral da superfície de fratura a $600^{\circ} \mathrm{C}$ e $190 \mathrm{MPa}$ na condição recoberta por TiAlN/TiAlCrN. 


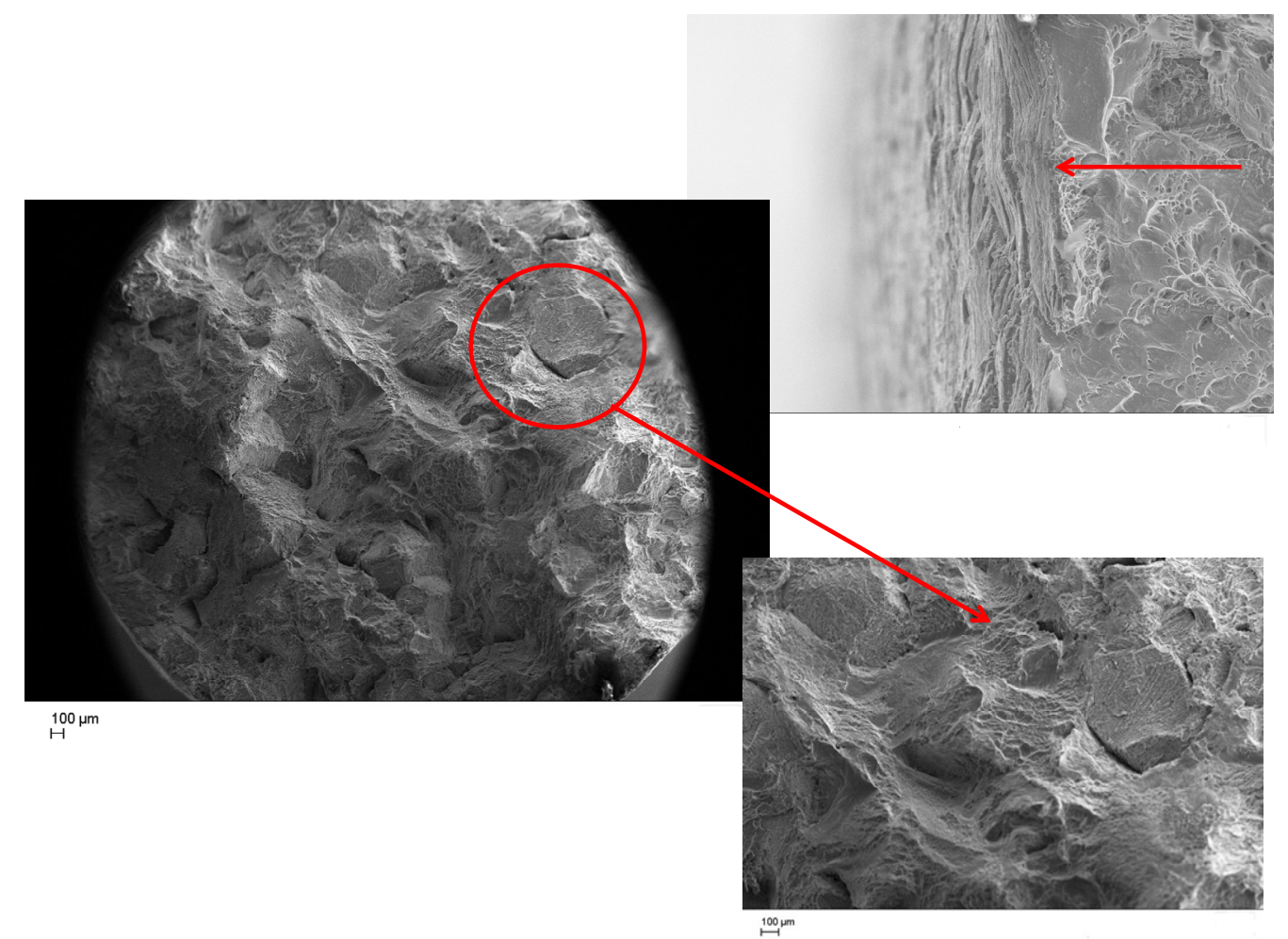

Figura 59. Aspecto geral da superfície de fratura a $600^{\circ} \mathrm{C}$ e $300 \mathrm{MPa}$ na condição recoberta por TiAlN/TiAlCrN.

A análise das Figuras 45 e 56 a 59 mostram que o modo de fratura é semelhante em todas as condições estudadas. Este modo de fratura é do tipo transgranular, por nucleação e coalescência de microcavidades (dimples), com regiões de decoesão intergranular independente do nível de deformação para cada uma das condições. A estrutura de alvéolos (dimples) está vinculada a atividades dos sistemas de deslizamento das estruturas cristalinas características do metal titânio. Para a fase $\alpha-\mathrm{Ti}$, que apresenta estrutura cristalina HC, os sistemas de escorregamento estão relacionados aos planos basal (0001), prismático $\{10 \overline{1} 0\}$ e piramidal $\{10 \overline{1} 1\}$, todos relacionados com a família de direções $\langle 11 \overline{2} 0\rangle$ (BALASUBRAMANIAN; ANAND, 2002). Para a fase $\beta-\mathrm{Ti}$, que apresenta estrutura cristalina CCC, os sistemas de escorregamento estão relacionados com os planos $\{110\},\{112\}$ e $\{123\}$, todos relacionados com a família de direções $\langle 111\rangle$ (DIETER, 1981). Este resultado está de acordo com os testes de fadiga feitos por Ghonem (GHONEM, 2010) conduzidos com a liga Timetal-1100 de microestrutura Widmanstätten, a $593{ }^{\circ} \mathrm{C}$; com os testes de fluência na liga Ti-6Al-4V feitos por Barboza (BARBOZA, 2001) a $600{ }^{\circ} \mathrm{C}$ e $278 \mathrm{MPa}$; e com testes de tração conduzidos por Gil et al. (2001) que estudaram o efeito do tamanho de grão e da taxa de resfriamento nas propriedades mecânicas da liga Ti-6Al-4V (GIL et al., 2001).

Os detalhes apresentados nas Figuras 56 a 59 mostram algum aspecto de decoesão intergranular das amostras resultando em fratura intergranular oriundas, provavelmente, do 
escorregamento dos contornos de grão e/ou difusão intergranular. O aspecto dos revestimentos após deformação também é mostrado nos detalhes das Figuras 57 a 59. As imagens confirmam as hipóteses discutidas sobre a aderência do recobrimento TiAlN/TiAlCrN nas diferentes tensões de ensaio. A $300 \mathrm{MPa}$, observa-se uma tendência maior de delaminação do recobrimento que a $190 \mathrm{MPa}$, onde o recobrimento se rompe (devido a sua fragilidade) sem descolar da amostra metálica.

As Figuras 60 e 61 correspondem às imagens obtidas por microscopia eletrônica de transmissão para as amostras sem tratamento superficial e nitretada, respectivamente, após os testes de fluência realizados a $600^{\circ} \mathrm{C}$ e $222 \mathrm{MPa}$. Na Figura 60 são observadas as lamelas $\beta(\mathrm{CCC})$ e a fase $\alpha(\mathrm{HC})$ contendo regiões alternadas de elevada concentração e baixa densidade de discordâncias oriundas do processo de recuperação dinâmica, resultando na formação de células.

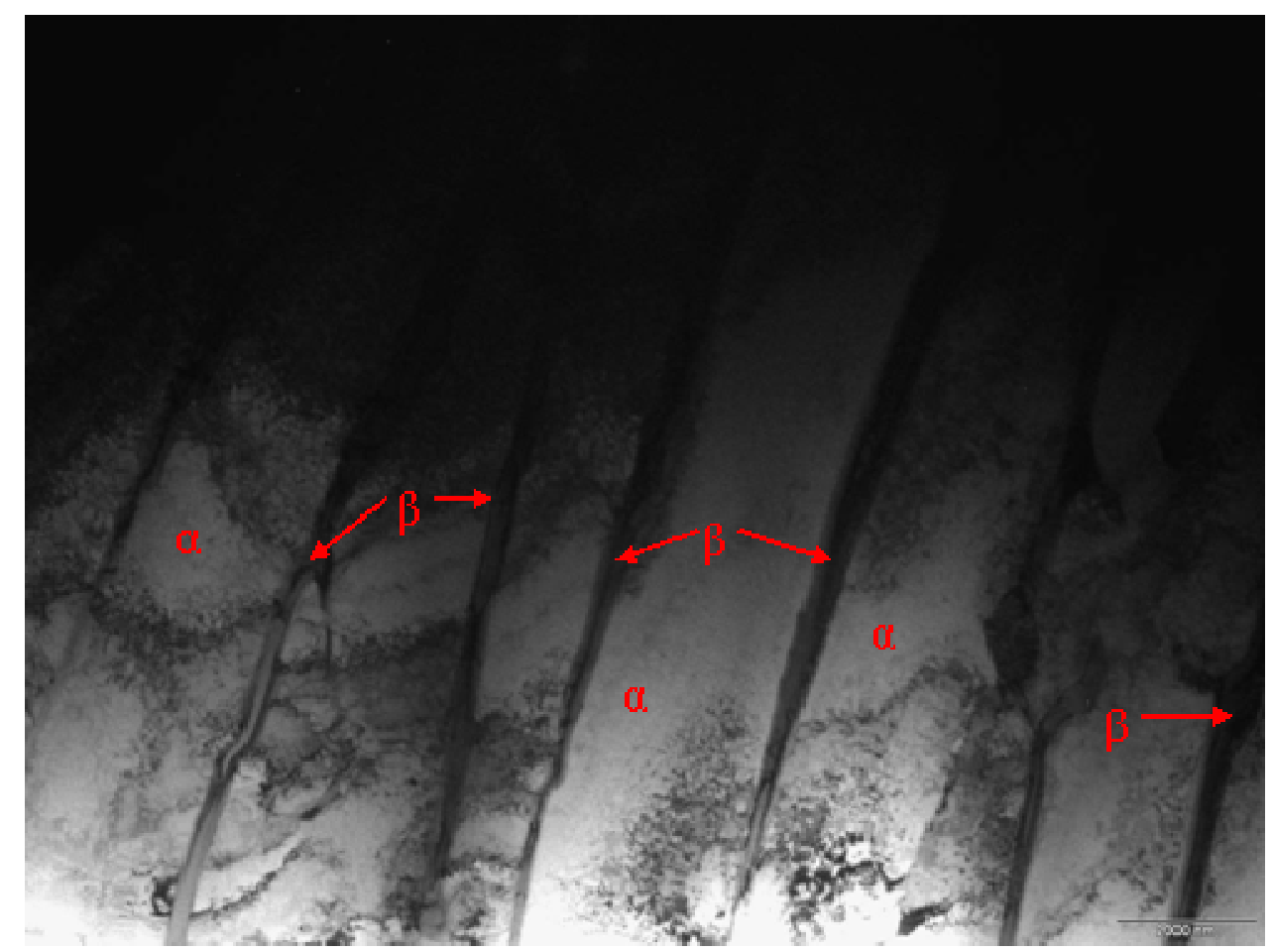

Figura 60. Imagem obtida por MET na liga Ti-6Al-4V na condição CR após fluência a $600^{\circ} \mathrm{C}$ e $222 \mathrm{MPa}$. 


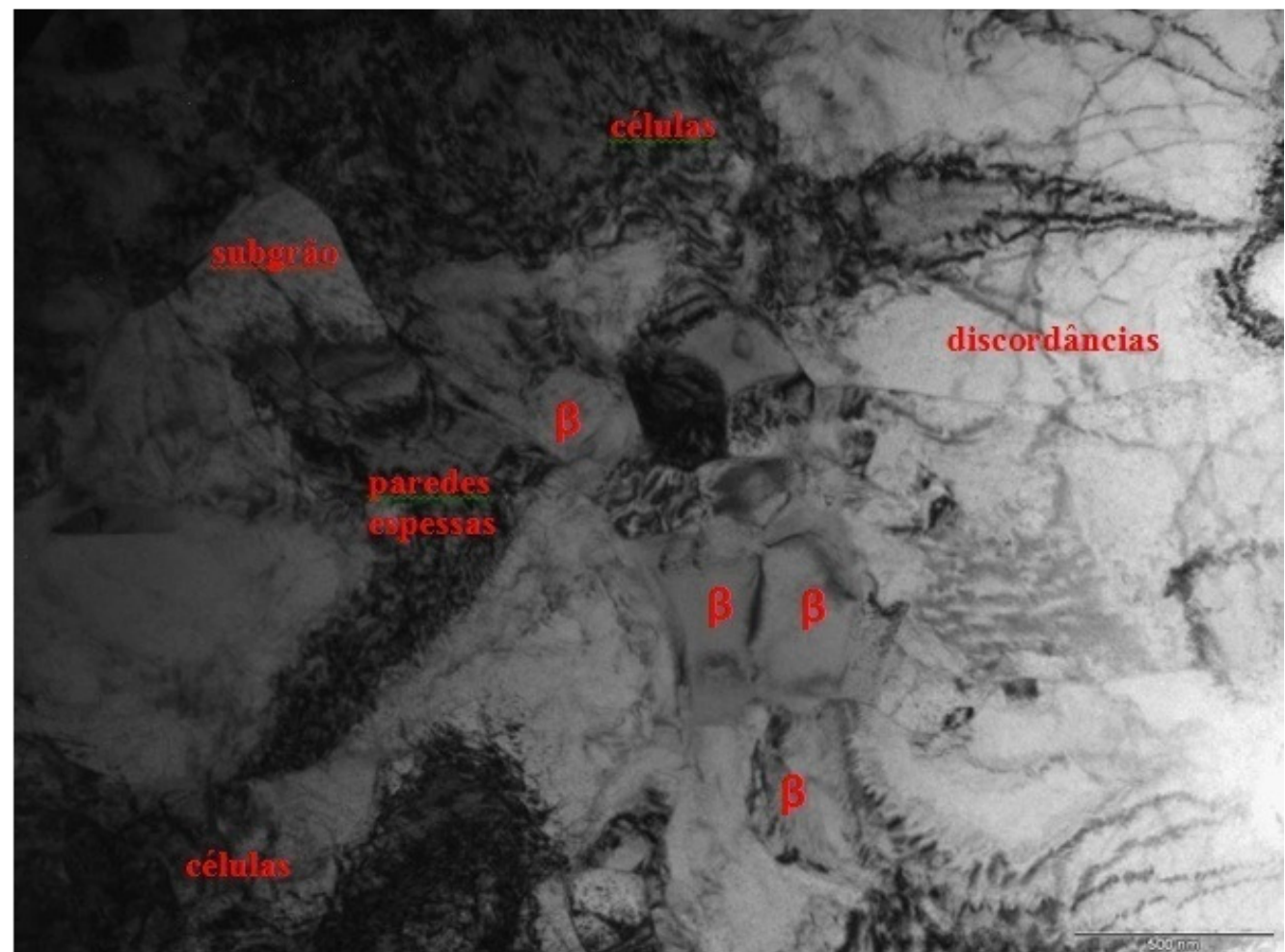

Figura 61. Imagem obtida por MET na liga nitretada por plasma após fluência a $600^{\circ} \mathrm{C}$ e $222 \mathrm{MPa}$.

No entanto, a configuração de discordâncias referente à liga nitretada, Figura 61, é constituída de uma estrutura de células com paredes espessas, regiões de emaranhados e a formação de subcontornos dando origem à formação de subgrãos. Em ambas as amostras a fase $\beta$ se apresenta com baixa densidade de defeitos, indicando que grande parte do processo de deformação da liga em questão envolve fluência predominantemente da fase $\alpha$, como previsto por Warren e colaboradores (WARREN et al., 1995). As regiões de emaranhados são oriundas de intensa movimentação, interação e multiplicação de discordâncias desenvolvidas durante a deformação por fluência. A presença de emaranhados e arranjos de células de discordâncias remanescentes após o processo de fratura está intimamente relacionada à interação de discordâncias por meio de deslizamentos múltiplos, ao longo dos estágios de fluência, como proposto por Vladiminov e Kusov (VLADIMINOV et al., 1976).

Os mecanismos básicos de recuperação estão vinculados à interação, aniquilação e à formação de configurações de menor energia. Estes mecanismos induzem, a partir do segundo estágio de fluência, maior atividade de discordâncias móveis e, como conseqüência, conduzem aos níveis de ductilidade encontrados nos testes a $600^{\circ} \mathrm{C}$.

Os subcontornos observados resultam do fenômeno da poligonização associado aos processos de aniquilação e escalagem de componentes em cunha, dando origem aos subgrãos. Com base na proposta de Weertmann (WEERTMANN, 1955), a presença de 
subgrãos confirma o mecanismo predominante associado à difusão e ao movimento não conservativo de discordâncias o qual, inicialmente, foi sugerido com base nos valores dos expoentes de tensão e da energia de ativação determinados para as condições de testes apresentadas na seção 4.5.1 (OLIVEIRA, 2010).

Com base nestas informações, as discussões posteriores podem colaborar com uma interpretação mais adequada dos resultados apresentados. A correlação entra a taxa estacionária e o tempo de fratura pode ser representada pela relação de Monkman-Grant (MG) apresentada pela Equação 19 (MONKMAN, 1956):

$\dot{\varepsilon}_{s}^{k} x t_{f}=C_{M G}$

onde $\mathrm{k}$ e $\mathrm{C}_{\mathrm{MG}}$ são constantes dependentes do material, da tensão aplicada e da temperatura. Em geral, a relação proposta relaciona a contribuição da fluência secundária à deformação total obtida nos testes de fluência e tem sido utilizada para previsão de vida com base em testes de curta duração. As avaliações dos autores para diferentes materiais indicaram que $\mathrm{k} \sim 1$ para uma grande variedade de materiais, demonstrando que o tempo de fratura é inversamente proporcional à taxa secundária (MONKMAN, 1956).

A Figura 62 apresenta a correlação entre a taxa estacionária e o tempo de fratura para as condições CR, nitretada e revestidas pelos filmes à base de TiN e TiAlN/TiAlCrN com base nos dados apresentados nas Tabelas 17 a 20. Após a linearização da Equação 19, a Tabela 21 indica que os valores de k encontram-se na faixa de 1,28 a 1,69 e $\mathrm{C}_{\mathrm{MG}}$ entre 0,0088 e 0,018 .

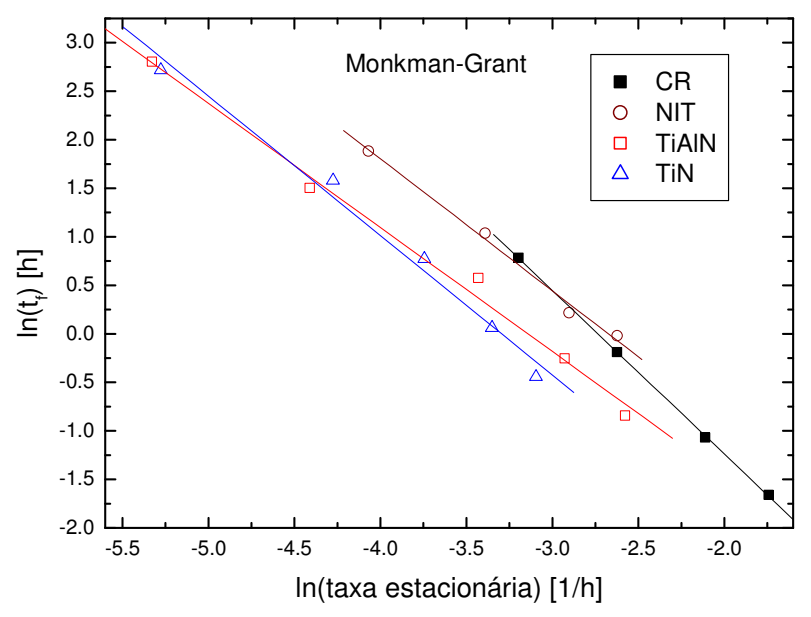

Figura 62. Relação entre as taxas de deformação e os tempos de ruptura a $600^{\circ} \mathrm{C}(\mathrm{MG})$. 
Os valores reportados por Barboza (BARBOZA, 2004) para a liga Ti-6Al-4V onde $\mathrm{k} \sim 1$ e $\mathrm{C}_{\mathrm{MG}}=0,086$, demonstram a influência da microestrutura nos parâmetros de Monkman-Grant. Neste caso, a configuração microestrutural denominada de equiaxial era composta por grãos $\alpha$ com tamanho médio de $10 \mu \mathrm{m}$ e fase $\beta$ presente ao longo de contornos de grão. Apesar da menor resistência à fluência quando comparada à estrutura de Widmanstätten, o valor de $\mathrm{C}_{\mathrm{MG}}$ indica maior contribuição da deformação secundária à deformação total para a microestrutura equiaxial.

Uma proposta alternativa foi elaborada por Dobes e Milicka (DOBES, 1976) e reconhecida como a equação de Monkman-Grant Modificada (MGM). Esta equação (Equação 20) é normalizada pela deformação correspondente à fratura e tem sido utilizada por vários autores para diferentes materiais com o objetivo de obter melhores ajustes dos dados experimentais.

$\frac{\dot{\varepsilon}_{s}^{p} \times t_{f}}{\varepsilon_{f}}=C_{M G M}$

A Figura 63 apresenta a relação entre a taxa estacionária e o tempo de fratura normalizada pela deformação $\varepsilon_{\mathrm{f}}$ para a liga Ti-6Al-4V nas condições $\mathrm{CR}$, nitretada e revestidas por filmes à base de TiAlN/TiAlCrN e TiN. A Tabela 21 apresenta os parâmetros p e $\mathrm{C}_{\mathrm{MGM}}$ obtidos pela linearização. Os ajustes dos dados experimentais foram mais adequados, com o parâmetro $p$ próximo da unidade. Os valores de $\mathrm{C}_{\mathrm{MGM}}$ entre 0,088 e 0,69 estão na mesma ordem de grandeza dos valores encontrados por Roy (ROY, 2013), Samuel (SAMUEL, 2013), Latha (LATHA, 2013) e Singh e colaboradores (SINGH et al., 2014) para aços e a liga Ti-6Al-4V com adição de diferentes teores de boro. 


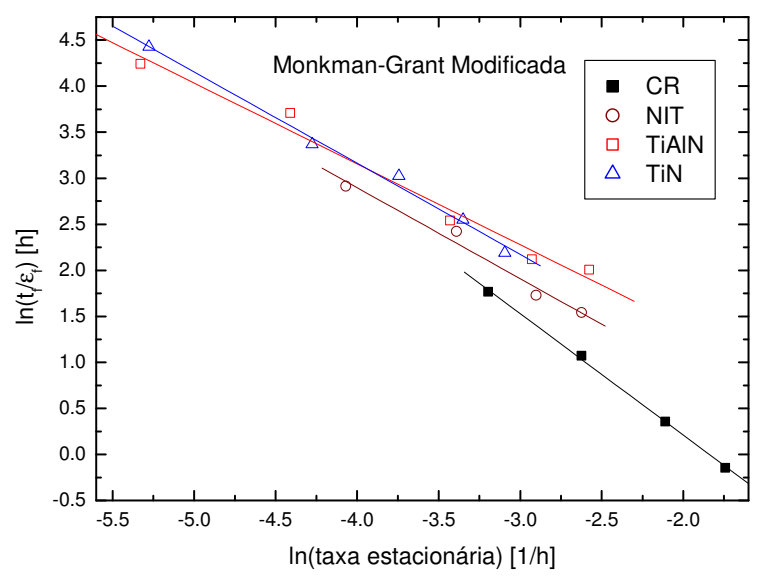

Figura 63. Relação entre as taxas de deformação e os tempos de ruptura a $600^{\circ} \mathrm{C}$ (MGM).

Tabela 21. Constantes de MG e MGM para a liga Ti-6Al-4V.

\begin{tabular}{ccccc}
\multirow{2}{*}{ Ti6Al4V } & \multicolumn{2}{c}{ Monkman-Grant } & \multicolumn{2}{c}{ Monkman-Grant Modificada } \\
& $\mathrm{k}$ & $\mathrm{C}_{\mathrm{MG}}$ & $\mathrm{p}$ & $\mathrm{C}_{\mathrm{MGM}}$ \\
\cline { 2 - 5 } Como Recebido & 1,69 & $9,93 \times 10^{-3}$ & 1,3 & $8,82 \times 10^{-2}$ \\
Nitretado & 1,36 & $2,63 \times 10^{-2}$ & $\approx 1$ & $3,47 \times 10^{-1}$ \\
TiAlN & 1,28 & $1,80 \times 10^{-2}$ & $\approx 1$ & $6,99 \times 10^{-1}$ \\
TiN & 1,44 & $8,75 \times 10^{-3}$ & $\approx 1$ & $4,48 \times 10^{-1}$ \\
\hline
\end{tabular}

Estes resultados permitem uma avaliação com base nos parâmetros de tolerância ao dano (W) definido pela Equação 21. (ROY et al., 2013).

$W=\frac{\varepsilon_{f}}{\dot{\varepsilon}_{s}^{p} x t_{f}}$

O parâmetro $\mathrm{W}$ é significativo na avaliação da susceptibilidade de um material à formação de trincas localizadas e à capacidade de acumular dano ao longo da deformação por fluência terciária. Em geral, diferentes mecanismos de dano podem contribuir para a degradação de um material sujeito à carga e temperatura constantes. A formação de microcavidades ao longo de contornos de grão oriundos de deslizamento de contornos ou de processos difusionais, estricção, coalescimento e/ou descolamento de partículas em materiais endurecidos por precipitação e a modificação na estrutura de discordâncias com a formação de estruturas de alvéolos, podem reduzir a resistência à fluência de ligas em temperaturas elevadas. Além disso, a interação com o oxigênio e a consequente formação de produtos de oxidação pode reduzir a área de sustentação da carga aplicada e atuar, de 
forma conjunta ou independente, com os mecanismos de dano levando, portanto, a possibilidade de uma falha catastrófica. (ROY et al., 2013).

Os valores de $\mathrm{W}$ encontram-se na faixa de 1 a 20 para ligas de aplicação em temperaturas elevadas. A faixa de $1<\mathrm{W}<2,5$ implica em um material susceptível à cavitação do tipo $w$ ou $r$ acompanhada de baixos valores de deformação $\varepsilon_{\mathrm{f}}$. Esta combinação de efeitos é aceita como indesejável e perigosa em função da eminência de uma falha repentina (ROY et al., 2013). Para o intervalo de $2,5<\mathrm{W}<5,0$, a fluência terciária ocorre, inicialmente, pela formação da estricção precedida por maiores valores de deformação plástica, em geral, acima de $20 \%$. No caso de elevados valores de $\mathrm{W}>5$, o fenômeno da estricção é acompanhado por instabilidades microestruturais em termos de redução na densidade de discordâncias, coalescimento de precipitados, subgrãos ou estrutura de células. Tais fenômenos podem contribuir com deformações plásticas acima de $20 \%$ e para o aumento do período de tempo referente ao regime terciário. Desta forma, a maior capacidade de deformação plástica pode conduzir a maior tolerância ao dano (SAMUEL, 2013; TERADA, 2013; ROY et al., 2013).

A Tabela 22 apresenta os valores de W obtidos para cada um dos materiais estudados.

Tabela 22. Parâmetros de tolerância ao dano (W).

\begin{tabular}{cccccc}
\hline \multirow{5}{*}{ Ti6Al4V } & \multicolumn{5}{c}{ W $(\mathrm{MPa})$} \\
\cline { 2 - 6 } & 190 & 222 & 250 & 278 & 300 \\
Como Recebido & - & 10,92 & 10,38 & 10,87 & 11,14 \\
Nitretado & - & 3,18 & 2,63 & 3,23 & 2,95 \\
TiAlN & 2,96 & 2,02 & 2,44 & 2,25 & 1,77 \\
TiN & 2,33 & 2,48 & 2,06 & 2,23 & 2,47 \\
\hline
\end{tabular}

Os valores de $\mathrm{W}>10$ para a condição $\mathrm{CR}$ indicam que a microestrutura sofreu degradação oriunda de processos de recuperação com grande atividade de discordâncias resultando em deformações plásticas $\left(\varepsilon_{\mathrm{f}}\right)$ acima de $20 \%$. A formação de estricção na faixa de $20 \%$ (300MPa) a 44\% (222MPa) conduziu a um modo de fratura predominantemente dúctil com uma região terciária bem desenvolvida. No entanto, a afinidade da liga em questão com o oxigênio, reduziu a área efetiva pela oxidação e posterior formação de trincas superficiais reduzindo o tempo de vida (OLIVEIRA, 2010).

Para o material nitretado, com $\mathrm{W}>2,5$, observou-se redução em área na faixa de $19,9 \%(300 \mathrm{MPa})$ a $30 \%(222 \mathrm{MPa})$. A maior vida detectada para esta condição foi 
conduzida por deformação correspondente à fratura acima de 20\% (Tabela 18). Neste caso, o efeito da oxidação foi minimizado pelo tratamento termoquímico, reduzindo os concentradores de tensões e retardando a falha, apesar das regiões com decoesão intergranular observadas nas análises fractográficas.

Os casos mais críticos foram detectados para os materiais revestidos por TiN e TiAlN/TiAlCrN com $\mathrm{W}<2,5$ na sua grande maioria. Neste caso, os intervalos determinados foram de 1,77 $<\mathrm{W}<2,96$ e 2,06 $<\mathrm{W}<2,48$ para TiAlN/TiAlCrN e TiN, respectivamente. Estes valores estão compatíveis com os estudos propostos por Singh e colaboradores (SINGH et al., 2014). Neste trabalho, os autores avaliaram os efeitos da adição de boro na liga Ti-6Al-4V com o parâmetro $\mathrm{W}$ na faixa de $1,55<\mathrm{W}<2,89$ e com valores de $\varepsilon_{\mathrm{f}}$ entre 5 e $20 \%$. As avaliações elaboradas para a liga Ti-45Al-2Mn-2Nb por Harrison (HARRISON, 2014) entre 625 e $750^{\circ} \mathrm{C}$, revelaram que uma grande parcela dos testes realizados resultou em tolerâncias entre 1 e 5 com poucos valores de $\mathrm{W}>5,0$.

Neste presente trabalho, o material com deposição de TiN apresentou maiores valores de tolerância ao dano do que as amostras recobertas por TiAlN/TiAlCrN nas tensões 222 e $300 \mathrm{MPa}$. Para os valores obtidos a $190 \mathrm{MPa}$ (em que W = 2,33 é menor do que o valor determinado para o revestimento TiAlN/TiAlCrN, $\mathrm{W}=2,96$ ) observou-se melhor resposta em fluência, com uma redução de $5 \%$ na taxa estacionária e um aumento de $8 \%$ no tempo de vida para o material revestido com TiAlN/TiAlCrN quando comparado aos valores da liga com TiN. Este efeito, observado a $190 \mathrm{MPa}$ com W > 2,5, sugere que a redução da taxa de oxidação pelo recobrimento à base de TiAlN/TiAlCrN contribuiu para minimizar o aparecimento de concentradores de tensão ao longo da camada, permitindo assim, uma deformação final acima de $20 \%$ e aumento da redução em área de $15,4 \%$ (300MPa) para 20,5\% (190MPa).

No entanto, apesar da contribuição dos filmes depositados para a redução dos valores das taxas estacionárias, o tempo de fratura foi menor, quando comparado ao material nitretado. Os baixos valores de $\mathrm{W}$ indicam a utilização dos revestimentos na liga Ti-6Al-4V foi determinante na redução da capacidade de deformação plástica em função da susceptibilidade ao fenômeno da cavitação. Com base nas Tabelas 19 e 20, os valores de $\varepsilon_{\mathrm{f}}$ estão na faixa de $0,06<\varepsilon_{\mathrm{f}}<0,24$ para o material recoberto por TiAlN/TiAlCrN e 0,07 $<\varepsilon_{\mathrm{f}}<0,18$ para o material recoberto por TiN. Estes valores correspondem a uma perda de ductilidade de 2 a 3 vezes com relação ao material nitretado. No que se refere à redução em área do material recoberto por TiN, este apresentou comportamento semelhante ao TiAlN/TiAlCrN na faixa de 14,8 (300 MPa) $<\varnothing<20,8 \%$ (190 MPa). Desta forma, ao 
atingir o regime terciário, as amostras revestidas por PVD não apresentaram capacidade de acumular dano, resultando numa fratura determinada pela formação de alvéolos e, principalmente, por cavitação intergranular, como observado nas análises efetuadas no item 4.6.

Neste contexto, Roy e colaboradores (ROY et al., 2013) estabeleceram que os diferentes mecanismos geradores de dano em conjunto com a ação do meio ambiente conduzem a um determinado modo de falha que, em geral, são avaliados de forma eficiente por análise microscópica. No entanto, em um ambiente industrial, esta técnica às vezes se torna impraticável. Do ponto de vista tecnológico e científico, o parâmetro $\mathrm{W}$ dá indícios da pré-disposição de um material à cavitação e tem sido utilizado para determinação de vida residual de componentes sujeitos ao fenômeno da fluência.

\subsection{INFLUÊNCIA DOS TRATAMENTOS SUPERFICIAIS NA} MICROESTRUTURA E PROPRIEDADES MECÂNICAS DA LIGA Ti-6Al-4V

Durante os estudos envolvendo a liga Ti-6Al-4V tratada superficialmente, levantouse a hipótese de que estes tratamentos superficiais poderiam modificar a microestrutura da liga Ti-6Al-4V pela formação de maior quantidade de fase $\alpha$ - Ti na microestrutura, pelo crescimento do grão, pela formação de uma camada mais dura denominada $\alpha$ case e pela nucleação de precipitados finos. Esta seção tem como objetivo discutir alguns destes aspectos.

Para analisar o aumento da quantidade de $\alpha$ - Ti e do crescimento do grão três corpos de prova cilíndricos foram tratados termicamente simulando os tempos e temperaturas de cada um dos tratamentos térmicos: para formação de microestrutura do tipo Widmanstätten, nitretação por plasma e PVD por plasma (descritos nas seções 3.3., 3.4. e 4.5.1.). As amostras foram analisadas com o auxílio do programa ImageJ (proporção de fases) e o tamanho de grão foi quantificado de acordo com o método da intercepção (CALLISTER, 2008). As análises de quantidade de fase foram feitas em 120 imagens de ampliações 50 e 100 vezes para cada condição estudada e as análises de tamanho de grão foram feitas em 20 imagens de ampliação 50 vezes para cada condição estudada. Todos os dados foram tratados estatisticamente e estão apresentados na Tabela 23. 
Tabela 23. Analise estatística da alteração da quantidade de fase (\%) e do tamanho de grão (mm) com os tratamentos térmicos.

\begin{tabular}{ccccccc}
\hline Tratamento térmico & \multicolumn{2}{c}{ Quantidade de fase $\beta-$ Ti $(\%)$} & \multicolumn{3}{c}{ Tamanho de grão $(\mathbf{m m})$} \\
\hline & média & erro & mediana & média & erro & mediana \\
\cline { 2 - 7 } Widmanstätten & 35,5 & 1,0 & 35,8 & 1,25 & 0,05 & 1,23 \\
Nitretação por plasma & 33,5 & 0,7 & 33,2 & 1,10 & 0,09 & 1,16 \\
PVD por plasma & 31,1 & 0,7 & 31,5 & 1,16 & 0,11 & 1,14 \\
\hline
\end{tabular}

Com base nos valores da Tabela 23 e levando-se em conta os erros percentuais calculados pode-se considerar que os tratamentos superficiais não modificam consideravelmente a quantidade relativa de fase $\alpha$ - Ti e o tamanho do grão na liga Ti-6Al4V. De fato, a morfologia do tipo Widmanstätten foi propositalmente escolhida por ser uma morfologia estável em altas temperaturas que varia com o tempo de recozimento em temperaturas acima de $980{ }^{\circ} \mathrm{C}$ e com a taxa de resfriamento (DONACHIE, 1988). Os tratamentos de nitretação por plasma e PVD não ultrapassaram $725^{\circ} \mathrm{C}$ e ambos resfriaram ao ar (mesma taxa de resfriamento).

A formação da camada conhecida como a case é muito comum no processo de oxidação e em tratamentos termoquímicos onde um elemento estabilizador de fase $\alpha-\mathrm{Ti}$ esteja envolvido (metais do grupo IIIA e IVA e os intersticiais C, $\mathrm{N}$ e O) (BALAZIC et al., 2007; DONACHIE, 1988). Segundo Pitt e Ramulu (2004) o ganho de massa de uma liga de titânio exposta a temperaturas em torno de $650{ }^{\circ} \mathrm{C}$ esta relacionado com a difusão do oxigênio na liga que forma uma zona de difusão conhecida como $\alpha$ case. Esta região é uma região de elevada dureza e pouca ductilidade (PITT; RAMULU, 2004). A Figura 64 mostra a seção transversal das amostras recobertas por PVD.
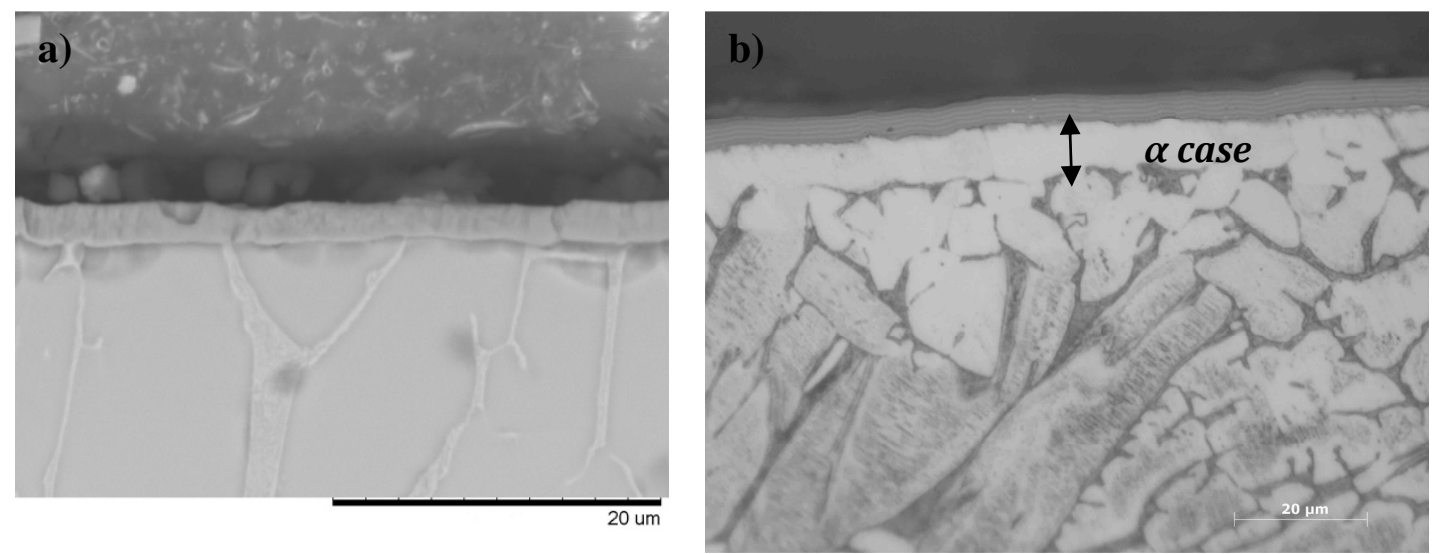

Figura 64. Seção transversal das amostras recobertas por PVD: a) TiN, b) TiAlN/TiAlCrN.

A medida da espessura de uma camada $\alpha$ case pode ser feita por análises de microdureza (em alguns casos nanodureza). As amostras recobertas por PVD não foram 
medidas em sua seção transversal por nanodureza (falta de equipamento) ou por microdureza (espessura do recobrimento muito pequena). Contudo, observando-se a seção transversal dos dois recobrimentos nota-se a que a fase $\beta$ - Ti está presente logo abaixo do recobrimento TiN (não houve estabilização da fase $\alpha$ - Ti) e que se formou uma camada de cerca de $9 \mu \mathrm{m}$ formada apenas por fase $\alpha-\mathrm{Ti} \operatorname{logo}$ abaixo do revestimento TiAlN/TiAlCrN. Esta camada de fase $\alpha$ foi formada, provavelmente, pelo nitrogênio ou alumínio presente na composição do revestimento TiAlN/TiAlCrN que estabilizam a fase $\alpha$ - Ti. A falta de informações mais específicas sobre o tratamento por PVD impede qualquer sugestão do motivo pelo qual se formou $\alpha$ case em apenas um tratamento. Para a amostra nitretada por plasma fez-se medidas de nanodureza e do módulo elástico na seção transversal da amostra e o seu perfil está representado na Figura 65.
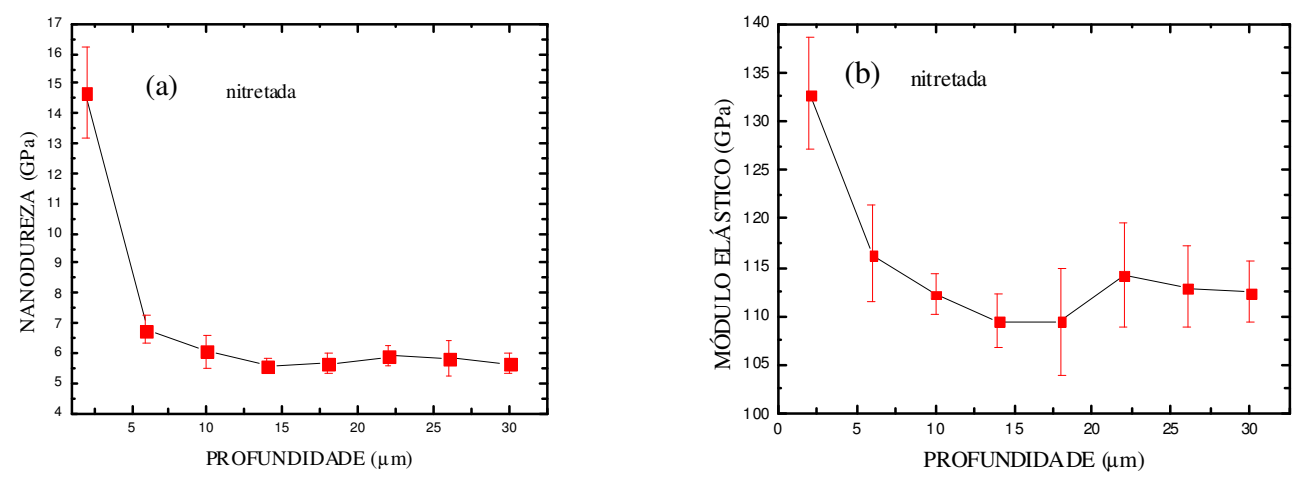

Figura 65. a) Perfil de nanodureza e b) Módulo Elástico (E) da amostra nitretada por plasma.

Com base na Figura 65a observa-se que os perfis de nanodureza indicam que os valores obtidos nas camadas para as condições nitretada $(14,71 \mathrm{GPa} \cong 1500 \mathrm{HV})$ corresponde à mesma ordem de grandeza dos valores de microdureza (1539 HV). A variação dos valores até a profundidade máxima de $37 \mu \mathrm{m}$ garante que além da camada composta por nitretos resultantes do tratamento superficial, há uma região endurecida por solução sólida denominada de camada de difusão. Pode-se concluir, portanto, que o nitrogênio atingiu cerca de $5 \mu \mathrm{m}$ de profundidade na amostra nitretada, resultando na formação do $\alpha$ case ou como a também conhecida zona de difusão $\alpha$ - Ti(N) (ZECHEVA et al., 2005). A Figura 65b mostra que o valor do módulo elástico E é maior na região dos nitretos e na zona de difusão $\alpha-\operatorname{Ti}(\mathrm{N})$ quando comparado com o valor de $\mathrm{E}$ do substrato (E $\approx 115 \mathrm{GPa}$ ). Zhang (2010) e Zhu (1998) estudaram os efeitos da microestrutura no comportamento em fluência de compósitos com matriz de titânio (TMCs - titanium matrix composites) e na liga Ti-6Al-4V reforçada com TiC. Segundo os autores o aumento da resistência em fluência dos materiais estudados está também ligado ao aumento do módulo 
elástico proporcionado pela presença de compostos cerâmicos duros (ZHANG et al., 2010; ZHU et al., 1998). Adicionalmente, Gollapudi e colaboradores (2008) reportaram outra forma de se relacionar taxa de deformação secundária $\left(\dot{\varepsilon}_{S}\right)$, tensão $(\sigma)$ e temperatura $(\mathrm{T})$ representada pela Equação 22 (GOLLAPUDI et al., 2008):

$\dot{\varepsilon}=A\left(\frac{\sigma}{E}\right)^{n} e^{-\frac{Q_{c}}{R T}}$

Pode-se observar na Equação 22 que a deformação secundária é também função do módulo elástico E, e quanto maior o valor do módulo elástico, menor será a taxa de deformação. Portanto, é correto dizer que o melhoramento do comportamento em fluência observado neste presente trabalho, principalmente para as condições nitretado por plasma e recoberto por TiAlN/TiAlCrN, é uma combinação de camada cerâmica dura, que possui alto módulo elástico, mais a camada de fase $\alpha-$ Ti conhecida como $\alpha$ case. Deve-se lembrar, porém, que a liga Ti-6Al-4V sofre com os efeitos da oxidação a $600{ }^{\circ} \mathrm{C}$ e que a simples estabilização de fase $\alpha-$ Ti na superfície nada adiantaria como alternativa (mais barata) de melhoramento das propriedades da liga Ti-6Al-4V em fluência.

Quando a liga Ti-6Al-4V é envelhecida entre 500 e $600{ }^{\circ} \mathrm{C}$, precipita-se em sua microestrutura uma fase conhecida como $\alpha_{2}$ de fórmula $\mathrm{Ti}_{3} \mathrm{Al}$ devido à presença do alumínio que altera os campos de fase $\alpha$ - Ti em um sistema Ti - Al, como mostra a Figura 66 (ASM HANDBOOK, 1992; LEE et al., 2005; LEE et al., 2008; ZHANG et al., 2005).

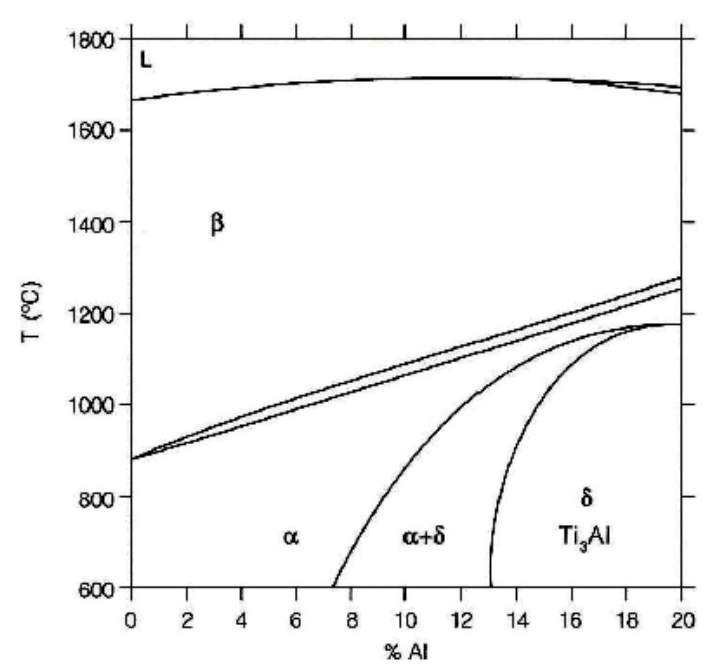

Figura 66. Diagrama de fases do sistema Ti-Al (ASM HANDBOOK, 1992).

Portanto, tratamentos que envolvam altas temperaturas por algum tempo podem resultar na precipitação deste composto de forma homogênea e dimensões nanometricas. A 
presença deste precipitado fino na microestrutura da liga Ti-6Al-4V resulta em um melhoramento das propriedades mecânicas bem como perda de ductilidade e tenacidade à fratura, pois este composto age como barreira ao movimento de discordâncias. Contudo, trabalhos reportados na literatura onde $\mathrm{Ti}_{3} \mathrm{Al}$ foi precipitado em uma matriz de titânio envolveram tempos de envelhecimentos bastante grandes variando entre 168 e 200 horas de tratamento e o composto formado pode ser identificado por técnicas de DRX (LEE et al., 2005; LEE et al., 2008; ZHANG et al., 2005). Os tempos de tratamento térmico informados neste trabalho atingiram no máximo 7 horas e as análises por DRX não indicaram a presença desta fase, levando a concluir que sua precipitação foi em pequena quantidade. As amostras na condição nitretada por plasma depois do processo de fluência e a amostra na condição CR antes do processo de fluência foram analisadas por microscopia eletrônica por transmissão, já que este precipitado não foi identificado por nenhuma das outras técnicas de caracterização feitas neste trabalho e estão apresentadas nas Figuras 67 e 68. As análises foram feitas por difração de área selecionada e por nanobeam (análises de partículas).
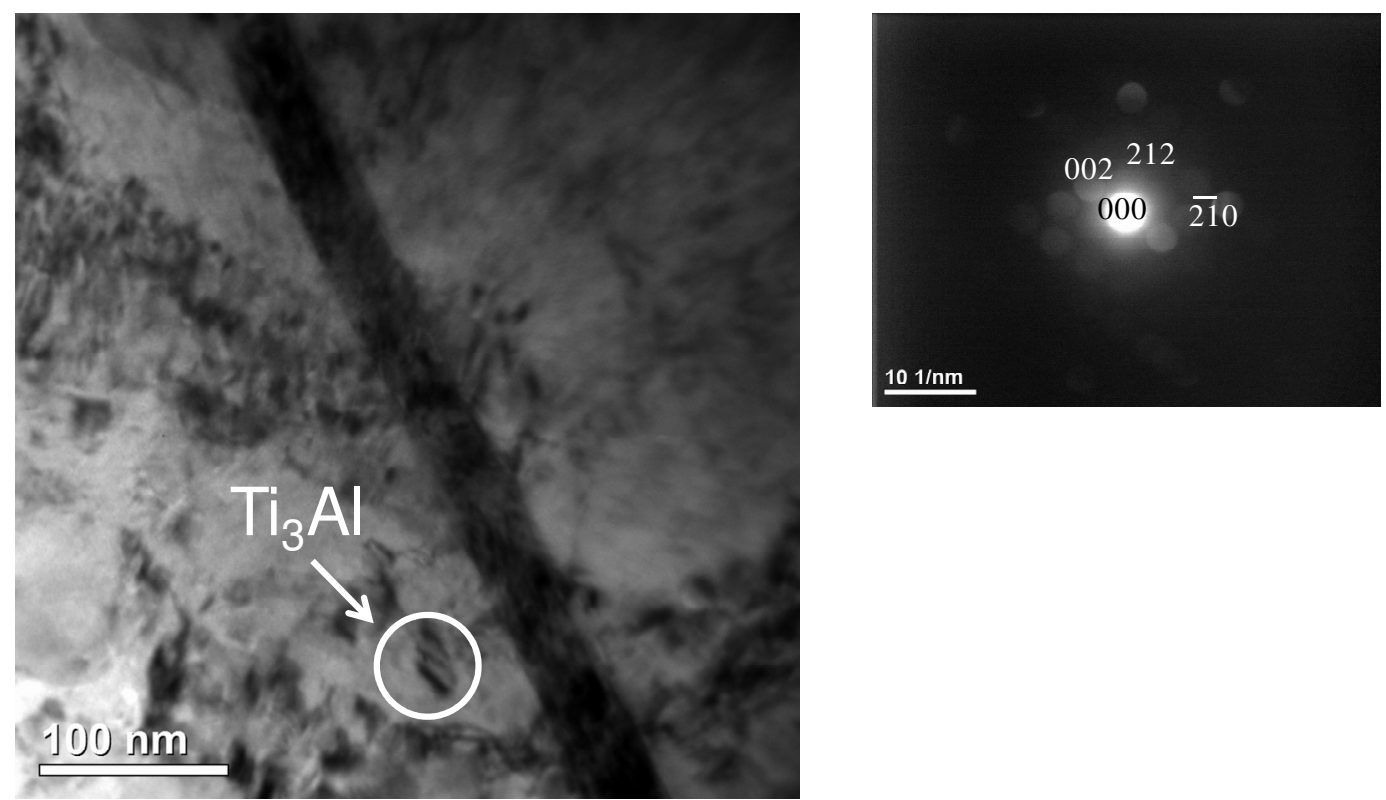

Figura 67. Microscopia Eletrônica por Transmissão (MET) da liga Ti-6Al-4V de morfologia Widmanstätten antes do processo de fluência. 

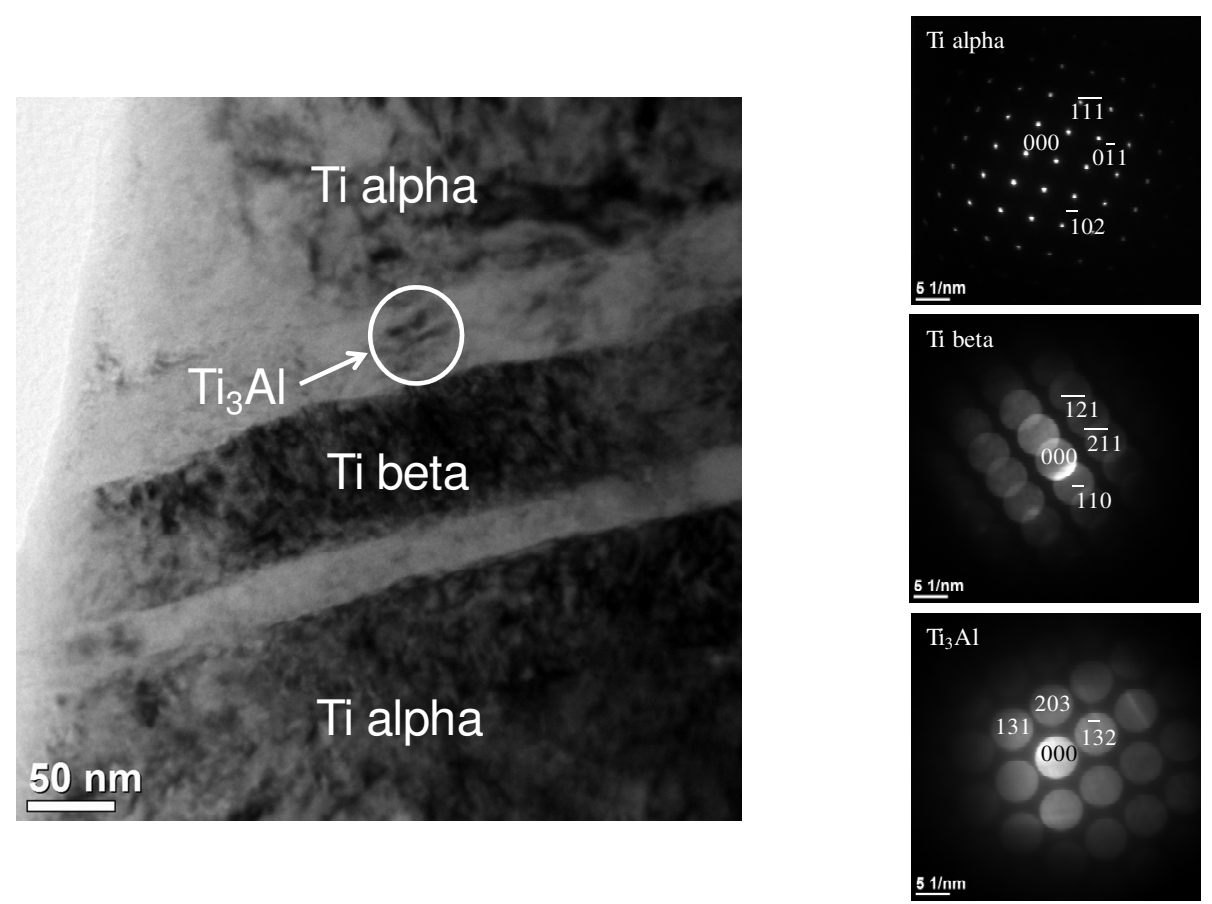

Figura 68. Microscopia Eletrônica por Transmissão (MET) da liga Ti-6Al-4V nitretada por plasma após o processo de fluência.

A indexação das fases foi feita medindo-se as distâncias entre um spot (pontos brancos) qualquer e o spot central, que são características e representam um plano cristalográfico específico de cada fase. As medidas de distâncias interplanares foram feitas com o auxílio do programa Digital Micrograh Gatan, mas pode também ser manualmente calculada através da Equação 23 (WILLIAM; CARTER, 2009):

$\lambda \times L=R \times d_{h k l}$

onde $\lambda$ é o comprimento de onda que é função da energia do feixe eletrônico (parâmetro do equipamento), L a distância entre o plano focal e a objetiva (parâmetro da câmera que captura as imagens em MET), R a distância entre o feixe central (spot) e o feixe difratado e d a distância interplanar. Cada $\mathrm{R}$ que é medido em uma difração está relacionado com uma distância interplanar específica, as medidas de $\mathrm{R}$ em conjunto com os valores dos parâmetros de rede de uma determinada fase resultam na indexação de um padrão de difração que é único para cada composto cristalino (WILLIAM; CARTER, 2009).

$\mathrm{Na}$ Figura 67 apenas a $\mathrm{Ti}_{3} \mathrm{Al}$ foi indexada, já na Figura 68 outras fases, como $\alpha-\mathrm{Ti}$ e $\beta$ - Ti, foram identificadas. As áreas mais escuras na Figura 68 são indícios de uma alta concentração de discordâncias, devido ao processo de deformação por fluência, e da 
formação de bandas de deformação, comuns em materiais de granulação grosseira onde o a deformação ocorre de forma heterogênea no grão cristalino.

As análises por MET (Figuras 67 e 68) mostraram que a partícula $\mathrm{Ti}_{3} \mathrm{Al}$ precipitada na microestrutura forma-se inclusive antes do tratamento térmico de nitretação. Este grupo sugere que este precipitado está presente no material recebido de fábrica que foi conformado à quente para a produção de barras cilíndricas de titânio. Portanto, a presença destes precipitados no composto nitretado por plasma não contribuiu com o melhoramento das propriedades de fluência visto que $\mathrm{Ti}_{3} \mathrm{Al}$ também está presente inclusive na amostra na condição CR. Finalmente, pode-se concluir que a influência dos tratamentos superficiais no desempenho em fluência da liga Ti-6Al-4V está correlacionado principalmente com o efeito protetor das camadas cerâmicas, mais duras e termicamente estáveis sobre a superfície. Qualquer outra modificação que estes tratamentos venham conferir à microestrutura da liga atua de forma secundária sobre as propriedades mecânicas desta liga. 


\section{CONCLUSÕES}

O estudo sobre o comportamento da liga Ti-6Al-4V tratada superficialmente em condições de corrosão, oxidação isotérmica e fluência levou as seguintes conclusões:

- O recobrimento à base de TiN apresentou espessura de 2,2 $\mu \mathrm{m}$ e composição igual a $\mathrm{Ti}_{0,7} \mathrm{~N}$;

- $\mathrm{O}$ recobrimento à base de TiAlN/TiAlCrN apresentou espessura em torno de $6 \mu \mathrm{m}$ e composição igual a $\left(\mathrm{Ti}_{0,38} \mathrm{Al}_{0,62}\right) \mathrm{N} /\left(\mathrm{Ti}_{0,31} \mathrm{Al}_{0,50} \mathrm{Cr}_{0,19}\right) \mathrm{N}$;

- A análise de DRX da liga Ti-6Al-4V recoberta por TiN e por TiAlN/TiAlCrN mostrou picos relacionados com a fase $\alpha-\mathrm{Ti}$ e com o composto TiN. O recobrimento TiAlN/TiAlCrN apresentou picos menos intensos e mais largos, quando comparado ao revestimento TiN, relacionados ao maior número de defeitos na rede cristalina devido à presença dos elementos $\mathrm{Cr}$ e $\mathrm{Al}$ que formaram solução sólida com TiN;

- As medidas do potencial em circuito aberto e polarização anódica mostraram que a liga Ti-6Al-4V apresenta comportamento ativo com transição ativo-passiva em solução $\mathrm{HCl}$ e comportamento passivo em solução $\mathrm{NaCl}$ a 25,60 e $80{ }^{\circ} \mathrm{C}$;

- As amostras recobertas por TiN e TiAlN/TiAlCrN apresentaram comportamento passivo nas duas soluções corrosivas e em todas as temperaturas estudadas. O revestimento à base de TiN manteve sua integridade microestrutural após o teste de corrosão nas duas soluções corrosivas e o revestimento à base de TiAlN/TiAlCrN desprendeu-se completamente da superfície após polarização potenciodinâmica em todas as condições experimentais;

- Segundo as análises de impedância, a resistência à corrosão das amostras estudadas em solução $\mathrm{HCl}$ a 25,60 e $80{ }^{\circ} \mathrm{C}$ pode ser representada da seguinte forma: liga sem recobrimento $<<$ recoberta por $\mathrm{TiAlN} / \mathrm{TiAlCrN} \approx$ recoberta por $\mathrm{TiN}$; e em solução $\mathrm{NaCl}$ a 25, 60 e $80{ }^{\circ} \mathrm{C}$ : liga sem recobrimento < recoberta por $\mathrm{TiN} \approx$ recoberta por TiAlN/TiAlCrN;

- Para a solução $\mathrm{NaCl}$, os resultados entre impedância e polarização foram discrepantes. Em polarização, a resistência à corrosão da liga com e sem revestimento foram praticamente a mesma, enquanto que em impedância eletroquímica as amostras revestidas mostraram comportamento superior; 
- A liga revestida por TiN foi a que apresentou melhor comportamento em corrosão, pois aumentou a resistência à corrosão da liga Ti-6Al-4V nas duas soluções estudadas e manteve sua integridade estrutural e aderência à superfície;

- As análises do comportamento em oxidação isotérmica mostraram um crescimento do óxido linear para todas as condições estudadas. Apesar de ter formado uma quantidade menor de óxido, a liga recoberta por TiN apresentou praticamente a mesma taxa de oxidação da liga Ti-6Al-4V sem recobrimento a $600{ }^{\circ} \mathrm{C}$;

- A liga recoberta por TiAlN/TiAlCrN não apresentou nenhuma evidência visível de oxidação a $600{ }^{\circ} \mathrm{C}$;

- A camada oxida formada sobre a liga sem recobrimento é basicamente $\mathrm{TiO}_{2}$, enquanto que a camada oxida formada sobre a liga recoberta por TiN é uma mistura de $\mathrm{TiO}_{2}$ e um oxinitreto intermediário $\operatorname{TiN}_{y} \mathrm{O}_{x}$;

- A amostra tratada termoquimicamente apresentou maior resistência à fluência do que a amostra não tratada a plasma. Verificaram-se no tratamento termoquímico valores de taxas de deformação secundária menores. O tratamento de nitretação a plasma foi bastante efetivo, pois combinou menor taxa de deformação secundária e maior tempo de fratura. Este comportamento é devido à maior dureza e menor rugosidade do material formado na superfície à base de nitretos ( $\mathrm{TiN}$ e $\mathrm{Ti}_{2} \mathrm{~N}$, espessura da camada igual a $4 \mu \mathrm{m}$ ) conferidos pelo tratamento termoquímico;

- A amostra revestida por TiN depositado por PVD apresentou os menores valores de taxa secundária para tensões maiores que $222 \mathrm{MPa}$, contudo a amostra nitretada a plasma apresentou maiores vida útil e níveis de ductilidade;

- Em níveis mais altos de tensão, onde a aderência do filme é mais importante, a amostra revestida por TiN apresentou-se mais resistente. Na medida em que a tensão diminuiu $(\sigma<$ $222 \mathrm{MPa}$ ) a amostra revestida por TiAlN/TiAlCrN foi mais resistente à deformação por fluência;

- As análises por MET permitiram concluir que a estrutura de discordâncias apresentou, basicamente, a formação de emaranhados, células de discordâncias e a formação de subgrãos. A presença de subgrãos confirmou que o mecanismo predominante na deformação por fluência foi o fenômeno da escalagem de discordâncias;

- Os expoentes de tensão variaram de 4,82 a 7,28. Com os cálculos de energia de ativação efetuados para as amostras nas condições sem tratamento superficial (272 kJ/mol) e nitretada (309 kJ/mol) e com as análises de estrutura de discordâncias feitas via MET, 
pode-se concluir, através da relação expoente de tensão e energia de ativação e das análises das micrografias, que os mecanismos de fluência estão associados à escalagem de discordâncias;

- O cálculo do parâmetro de tolerância ao dano (W) contribuiu para indicar que os revestimentos TiN e TiAlN/TiAlCrN reduzem deformação plástica e a tolerância ao dano contribuindo para a redução da vida útil;

- Análises da influência do tratamento térmico na microestrutura da liga Ti-6Al-4V mostraram que a faixa de temperatura e os tempos de tratamentos utilizados neste trabalho não modificaram a quantidade percentual da fase $\alpha$ - Ti e o tamanho do grão na liga Ti$6 \mathrm{Al}-4 \mathrm{~V}$

- A presença da camada de fase $\alpha$ - Ti estabilizada por algum elemento $\alpha$ - estabilizador conhecida como $\alpha$ case contribui com o melhoramento das propriedades mecânicas, mas não pode atuar como única alternativa de proteção superficial devido aos efeitos deletérios da oxidação;

- A precipitação da fase $\alpha_{2}$ não está relacionada somente com os tratamentos superficiais e sim com a conformação mecânica da liga Ti-6Al-4V. Portanto, os tratamentos superficiais utilizados neste trabalho são eficientes por seu efeito de proteção através da deposição de um elemento cerâmico mais estável na superfície e não por alguma transformação que estes possam causar na microestrutura do substrato. 


\section{TRABALHOS FUTUROS}

Os trabalhos que podem ser desenvolvidos a partir desta linha de pesquisa são:

- Testes de fluência com a liga Ti-6Al-4V recoberta por TiN e TiAlN/TiAlCrN depositados por PVD nas temperaturas de 500 e $550{ }^{\circ} \mathrm{C}$;

- Testes de fluência com a liga Ti-6Al-4V recoberta por compostos diferentes ou por técnicas de deposição diferentes;

- Análises por microscopia de transmissão das modificações microestruturais e composicionais da liga Ti-6Al-4V antes e depois de tratada superficialmente, e/ou antes e depois de deformada por fluência, e/ou antes e depois de processo de oxidação isotérmica;

- Testes de corrosão com a liga Ti-6Al-4V recoberta por compostos diferentes nos meios $\mathrm{HCl} 2 \mathrm{M} \mathrm{e} \mathrm{NaCl} 3,5 \%$;

- Testes de corrosão com a liga Ti-6Al-4V recoberta por TiN e TiAlN/TiAlCrN depositados por PVD em outros meios corrosivos;

- Análise da influência da microestrutura do revestimento de uma liga metálica em seu comportamento por corrosão: estudos de variação de espessura, composição, quantidade e espessura de intercamadas (multilayers), modo de deposição e de densidade de defeitos. 


\section{REFERÊNCIAS}

ABDALLAH, Z.; PERKINS, K.; WILLIAMS, S. Advances in the wilshire extrapolation technique - full creep curve representation for the aerospace alloy Titanium 834 . Materials Science and Engineering A,v. 550, p. 176-182, 2012.

AHMAD, Z. Principles of corrosion engineering and corrosion control. Oxford: Butterworth-heinemann, 2006, 656 p.

AHN, S.H.; HONG, J.H.; KIM, J.G.; HAN, J.G. Effect of microstructure on corrosion behavior of TiN hard coatings produced by a modified two-grid attachment magnetron sputtering process. Thin Solid Films, v. 515, p. 6878-6883, 2007.

AIHUA, L.; JIANXIN, D.; HAIBING, C.; YANGYANG, C.; JUN, Z. Friction and wear properties of TiN, TiAlN, AlTiN and CrAlN PVD nitride coatings. International Journal of Refractory Metals and Hard Materials, v. 31, p. 82-88, 2012.

ALVES, V. A.; REIS, R. Q.; SANTOS, I. C. B.; SOUZA, D. G.; GONÇALVES, T. F.; PEREIRA-DA-SILVA, M. A.; ROSSI, A.; SILVA, L. A. In situ impedance spectroscopy study of the electrochemical corrosion of Ti and Ti-6Al-4V in simulated body fluid at 25 ${ }^{\circ} \mathrm{C}$ and $37{ }^{\circ}$ C. Corrosion Science, v. 51, p. 2473-2482, 2009.

AMAYA-VAZQUEZ, M. R.; SÁNCHEZ-AMAYA, J. M.; BOUKHA, Z.; BOTANA, F. J. Microstructure, microhardness and corrosion resistance of remelted TiG2 and Ti6Al4V by a high power diode laser. Corrosion Science, v. 56, p. 36-48, 2012.

ANANTHAKUMAR, R.; SUBRAMANIAN, B.; KOBAYASHI, A.; JAYACHANDRAN, M. Electrochemical corrosion and materials properties of reactively sputtered TiN/TiAlN multilayer coatings. Ceramics International, v. 38, p. 477-485, 2012.

APERADOR, W.; DELGADO, A.; DUQUE, J. Corrosion resistance of the $[\mathrm{TiN} / \mathrm{CrN}]_{\mathrm{n}}$ coatings deposited on steel AISI 4140. International Journal of Eletrochemistry, v. 8 p. 10711-10719, 2013.

ARMSTRONG, R. D.; HARRISON, J. A.; THIRSK, H. R.; WHITFIELD, R. The anodic dissolution of titanium in sulfuric acid. Journal of Electrochemistry Society, v. 117, p. 1003-1006, 1970.

ASM handbook. Alloy Phase diagrams. Ohio: ASM International, 1992, v.3, seção 1, pág. 24.

ATAPOUR, M.; PILCHAK, A. L.; SHAMANIAN, M.; FATHI, M. H. Corrosion behavior of Ti-8Al-1Mo-1V alloy compared to Ti-6Al-4V. Materials and Design, v. 32, p. 16921696, 2011a.

ATAPOUR, M.; PILCHAK, A. L.; FRANKEL, G. S.; WILLIAMS, J. C. Corrosion behavior of $\beta$ titanium alloys for biomedical applications. Materials Science and Engineering C, v. 31, p. 885-891, 2011 b. 
AVELAR-BATISTA, J.C.; SPAIN, E.; HOUSDEN, J.; MATTHEWS, A.; FUENTES, G.G. Plasma nitriding of Ti6Al4V alloy and AISI M2 steel substrates using D.C. glow discharges under a triode configuration. Surface and Coatings Technology, v. 200, p. 1954-1961, 2005.

BALAMURUGAN, A.; BALOSSIER, G.; MICHEL, J.; FERREIRA, J. M. F. Electrochemical and structural evaluation of functionally graded bioglass-apatite composites electrophoretically deposited onto Ti6Al4V alloy. Electrochimica Acta, v. 54, p. 1192-1198, 2009.

BALASUBRAMANIAN, S.; ANAND, L. Plasticity of initially textured hexagonal polycrystals at high homologous temperatures: application to titanium. Acta Materialia, v. 50, n. 1, p. 133-148, 2002.

BALAZIC, M.; KOPAC, J.; JACKSON, M. J.; AHMED, W. Review: titanium and titanium alloy applications in medicine. International Journal of Nano and Biomaterials, v. 1, n. 1, p. 3-34, 2007.

BALLA, V. K.; BHAT, A.; BOSE, S.; BANDYOPADHYAY, A. Laser processed TiN reinforced Ti6Al4V composite coatings. Journal of the Mechanical Behavior of Biomedical Materials, v. 6, p. 9-20, 2012.

BARBOZA, M. J. R. Estudo e modelagem sob condições de fluência da liga Ti-6Al-4V. 2001. 196 f. Tese (Doutorado em Engenharia Aeronáutica e Mecânica) - Instituto Tecnológico da Aeronáutica, São José dos Campos, 2001.

BARBOZA, M. J. R.; MOURA NETO, C.; SILVA, C. M. M. Creep mechanisms and physical modeling for Ti-6Al-4V. Materials Science and Engineering A, v. 369, p. 201209, 2004.

BARBOZA, M.J.R.; PEREZ, E. A. C.; MEDEIROS, M. M.; REIS, D. A.P.; NONO, M. C. A.; PIORINO NETO, F.; SILVA, C. R. M. Creep behavior of Ti-6Al-4V and comparison with titanium matrix composites. Materials Science \& Engineering A, v. 428, p. 319-326, 2006.

BADEA, L.; SURAND, M.; RUAU, J.; VIGUIER, B. Creep behavior of Ti-6Al-4V from $450{ }^{\circ} \mathrm{C}$ to $600{ }^{\circ} \mathrm{C}$. UPB Scientific Bulletin B, v. 76, p. 185-196, 2014.

BARSHILIA, H. C.; DEEPTHI, B.; RAJAM, K. S.;BHATTI, K. P.; CHAUDHARY, S. Growth and characterization of TiAlN/CrAlN superlattices prepared by reactive direct current magnetron sputtering. Journal of Vaccum Science Technology A, v. 27,p. 29-36, 2009.

BLUM, W.; EINSENLOHR, P.; BREUTINGER, F. Understanding creep - a Review. Metallugical and Materials Transactions A, 33A, p. 291-303, 2002.

BOEHLERT, C. J.; CHEN, W. The elevated-temperature creep behavior of boron modified Ti-6Al-4V alloys. Materials Transactions, v. 50, n. 7, p. 1690-1703, 2009. 
BOEHLERT, C. J.; MIRACLE, D. B. Part II. The creep behavior of Ti-Al-Nb O + Bcc orthorhombic alloys. Metallurgical and Materials Transactions A, v. 30A, p. 23492367, 1999.

BOMMERSBACH, P.; ALEMANY-DUMONT, C.; MILLET, J. P.; NORMAND, B. Formation and behavior study of an environment-friendly corrosion inhibitor by electrochemical methods. Electrochimica Acta, v. 51, p. 1076-1084, 2005.

CAIRNEY, J.M.; HARRIS, S.G.; MUNROE, P.R.; DOYLE, E.D. Transmission electron microscopy of TiN and TiAlN thin films using specimens prepared by focused ion beam milling. Surface and Coatings Technology, v. 183, p. 239-246, 2004.

CALLISTER Jr., W. D. Ciência e engenharia de materiais: uma introdução. 7. ed. Rio de Janeiro: LTC, 2008. p. 174-176.

CESCHINI, L.; LANZONI, E; MARTINI, C.; PRANDSTRALLER, D.; SAMBOGNA, G. Comparison of dry sliding friction and wear of Ti-6Al-4V alloy treated by plasma electrolytic oxidation and PVD coating. Wear, v. 264, p. 86-95, 2008.

CHAN, Y.; CHEN, H.; CHAO, P.; DUH, J.; LEE, J. Microstructure control in TiAlN/SiN multilayers with appropriate thickness ratios for improvement of hardness and anticorrosion characteristics. Vacuum, v. 87, p. 195-199, 2013.

CHEN, L.; DU, Y.; XIONG, X.; CHANG, K. K.; WU, M. J. Improved properties of Ti-Al$\mathrm{N}$ coating by multilayer structure. International Journal of Refractory Metals and Hard Materials, v. 29, p. 681-685, 2011.

CHEN, W.; HUANG, J.; PENG, J. Characterisation of TiAlN PVD coatings on AZ31 magnesium alloy. Res. Chem. Intermed. DOI 10.1007/s11164-013-1270-5, 2013.

CHOI, B.; LIANG, J.; GAO, W. Correlation of microstrucutre and high temperature oxidation resistance of plasma sprayed $\mathrm{NiCrAl}, \mathrm{NiCrAlY}$ and $\mathrm{TiAlO}$ compoite coatings on Ti-6Al-4V. Metals and Materials International, v. 11, n. 6, p. 499-503, 205.

CHUNG, K. H.; LIU, G. T.; DUH, J. G.; WANG, J. H. Biocompatibility of titaniumaluminum nitride film coating on a dental alloy. Surface and Coatings Technology, v. 188-189, p. 745-749, 2004.

CHUNXIANG, C.; BAOMIN, H.; ZHAO, L.; SHUANGJIN, L. Titanium alloy, production technology, market prospects and industry development. Materials and Design, v. 32, p. 1684-1691, 2011.

COSTA, M. Y. P.; VENDITTI, M. R. L.; CIOFFI, M. O. H.; VOORWALD, H. G. C.; GUIMARÃES, V. A.; RUAS, R. Fatigue behavior of PVD coated Ti-6Al-4V alloy. International Journal of Fatigue, v. 33, p. 759-765, 2011.

CUNHA, L.; ANDRITSCHKY, M.; REBOUTA, L.; SILVA, R. Corrosion of TiN, (TiAl)N and $\mathrm{CrN}$ hard coatings produced by magnetron sputtering. Thin Solid Films, v. 317, p. 351-355, 1998. 
DELGADO-ALVARADO, C.; SUNDARAM, P. A. A study of the corrosion behavior of gamma titanium aluminide in $3.5 \% \mathrm{NaCl}$ solution and seawater. Corrosion Science, v. 49, p. 3732-3741, 2007.

DEVIA, D. M.; RESTREPPO-PARRA, E.; ARANGO, P. J. Comparative study of titanium carbide and nitride coatings grown by cathodic vacuum arc technique. Applied Surface Science, v. 258, p. 1164-1174, 2011.

DIETER, G. E. Metalurgia Mecânica. 2. ed. Rio de Janeiro: Guanabara Dois, 1981. p. 385-418.

DOBRZANSKI, L. A.; ADAMIAK, M. Structure and properties of the TiN and Ti(C,N) coatings deposited in the PVD process on high-speed steels. Journal of Materials Processing Technology, v. 133, p. 50-62, 2003.

DONACHIE Jr, M. J. Titanium: a technical guide. Ohio: ASM International, 1988. 469 p.

ELMER, J.W.; PALMER, T.A.; WONG J. In situ observations of phase transitions in Ti6Al-4V alloy welds using spatially resolved x-ray diffraction. Journal of Applied Physics, v. 93, n. 4, p. 1941-1947, 2003.

ES-SOUNI, M. Primary, secondary and anelastic creep of a high temperature near $\alpha$-Ti alloy Ti6242Si. Materials Characterization, v. 45, p. 153-164, 2000.

ES-SOUNI, M. Creep deformation behavior of three high-temperature near $\alpha$-Ti alloys: IMI 834, IMI 829, and IMI 685. Metallurgical and Materials Transactions A, v.32a, p. 285-293, 2001.

EVANS, W. J.; HARRISON, G. F. Validity of friction stress $\sigma_{0}$ measurements for hightemperature creep. Metal Science, v. 13, n. 6, p. 346-350, 1979.

EVANS, R. W.; WILSHIRE B. Introduction to creep. London: The Institute of Materials, 1993. $115 \mathrm{p}$.

FEKRY, A. M. The influence of chloride and sulphate ions on the corrosion behavior of Ti and Ti-6Al-4V alloy in oxalic acid. Electrochimica Acta, v. 54, p. 3480-3489, 2009.

FENG, C.; LI, M.; XIN, L.; ZHU, S.; WANG, F. Mechanical properties and oxidation behavior of graded $(\mathrm{Ti}, \mathrm{Al}) \mathrm{N}$ coating deposited by arc-ion plating. Oxidation of Metals, $\mathrm{v}$ 65,p. 307-327, 2006.

FILIP, R.; KUBIAK, K.; ZIAJA, W.; SIENIAWISKI, J. The effect of microstructure on the mechanical properties of two-phase titanium alloys. Journal of Materials Processing Technology, v. 133, p. 84-89, 2003.

FORTUNA, S. V.; SHARKEEV, Y. P.; PERRY, A. J.; MATOSSIAN, J. N.; SHULEPOV, I. A. Microstructural features of wear-resistant titanium nitride coatings deposited by different methods. Thin Solid Films, v. 377-378, p. 512-517, 2000. 
FOX-RABINOVICH, G. S.; YAMOMOTO, K.; VELDHUIS, S. C.; KOVALEV, A. I.; DOSBAEVA, G. K. Tribological adaptability of TiAlCrN PVD coatings under high performance dry machining conditions. Surface and coatings Technology, v. 200, p. 1804-1813, 2005.

FU, L. S. Creep crack growth in technical alloys at elevated temperature - a review. Engineering Fracture Mechanisms, v. 13, p. 307-330, 1980.

GAO, S.; DONG, C.; LUO, H.; XIAO, K.; PAN, X.; LI, X. Scanning electrochemical microscopy study on the electrochemical behavior of $\mathrm{CrN}$ film on 304 stainless steel by magnetron sputtering. Electrochimica Acta , v. 114, p. 233-241, 2013.

GARBACZ, H.; LEWANDOWSKA, M. Microstructural changes during oxidation of titanium alloys. Materials Chemistry and Physics, v. 81, p. 542-547, 2003.

GENTIL, V. Corrosão. 4 ed. Rio de Janeiro: LTC - Livros Técnicos e Científicos Editora S. A., 2003, 345 p.

GHONEM, H. Microstructure and fatigue crack growth mechanisms in high temperature titanium alloys. International Journal of Fatigue, v. 32, n. 9, 1448-1460, 2010.

GIL, F. J.; GINEBRA, M. P.; MANERO, J. M.; PLANELL, J. A. Formation of $\alpha-$ Widmanstätten structure: effects of grain size and cooling rate on the Widmanstätten morphologies and on the mechanical properties in Ti-6Al-4V alloy. Journal of Alloys and Compounds, v. 329, p. 142-152, 2001.

GOLLAPUDI, S.; CHARIT, I.; MURTY, K. L. Creep mechanisms in Ti-3Al-2,5V alloy tubing deformed under closed-end internal gas pressurization. Acta Materialia, v. 56, n. 10, p. 2406-2419, 2008.

GRIPS, V.K.W.; BARSHILIA, H.C.; SELVI, V.E.; KALAVATI, RAJAM, K.S. Electrochemical behavior of single layer $\mathrm{CrN}$, TiN, TiAlN coatings and nanolayered TiAlN/CrN multilayer coatings prepared by reactive direct current magnetron sputtering. Thin Solid Films, v. 514, p. 204-211, 2006.

GULERYUZ, H.; CIMENOGLU, H. Oxidation of Ti-6Al-4V alloy. Journal of alloys and compounds, v. 472, p. 241-246, 2009.

GURRAPPA, I.; GOGIA, A. K. High performance coatings for titanium alloys to protect against oxidation. Surface and coatings technology, v. 139, p. 216-221, 2001.

GURRAPPA, I. Protection of titanium alloy components against high temperature corrosion. Materials and Science Engineering A, v. 356, p. 372-380, 2003.

GULERYUZ, H.; CIMENOGLU, H. Oxidation of Ti-6Al-4V alloy. Journal of alloys and compounds, v. 472, p. 241-246, 2009.

HAN, Y.; CHATURVEDI, M. C. Steady State Creep Deformation of Superalloy Inconel 718. Materials Science and Engineering, v. 89, p. 25-33, 1987. 
HARRISON, W.; ABDALLA, Z.; WHITTAKER, M. A model for creep and creep damage in the $\gamma$-titanium aluminide Ti-45Al-2Mn-2Nb. Materials, v. 7, p. 2194-2209, 2014.

HAYES, R. W. Minimum strain rate and primary transient creep analysis of a fine structure orthorhombic titanium aluminide. Scripta Materialia, v. 34, p. 1005-1012, 1996.

HEAKAL, F.E.; TANTAWY, N.S.; SHEHATA, O.S. Influence of cerium (III) ions on corrosion and hydrogen evolution of carbon steel in acid solutions. International Journal of Hydrogen Energy, v. 37, p. 19219-19230, 2012.

HUANG, C.; DUH, J. Stress and oxidation behaviours of r.f.-sputtered (Ti,Al)N films. Surface and Coatings Technology, v. 81, p. 164-171, 1996.

HSU, C.; HUANG, K.; CHEN, Y.; HO, W. The effect of electroless Ni-P interlayer on corrosion behavior of TiN-coated austempered ductile iron. Thin Solid Films, v. 529, p. 34-38, 2013.

JCPDS - ICDD Joint Committee on Powder Diffraction Standards - International Center for Diffraction Data. Selected Powder Diffraction Data for Metals and Alloys. Swarthmore: JCPDS, 1988.

JOSKA, L.; FOJT, J.; HRADILOVA, M.; HNILICA, F.; CVRCEK, L. Corrosion behavior of TiN and $\mathrm{ZrN}$ in the environment containing fluoride ions. Biomedical Materials, v. 5, p. 1-8, 2010.

KAHLED, K.F. An electrochemical study for corrosion inhibition of iron by some organic phosphonium chloride derivates in acid media. Applied Surface Science, v. 230, p. 307318, 2004.

KASSNER, M. E.; HAYES, T. A. Creep cavitation in metals. International Journal of Plasticity, v. 19, p. 1715-1748, 2003.

KOVALEV, A.I.; WAINSTEIN, D.L.; RASHKOVSKIY, A.Y.; FOX-RABINOVICH, G.S.; YAMAMOTO, K.; VELDHUIS, S.; AGUIRRE, M.; BEAKE, B.D. Impact of Al and $\mathrm{Cr}$ alloying in TiN-based PVD coatings on cutting performance during machining of hard to cut materials. Vacuum, v. 84, p. 184-187, 2010.

KRAL, P.; DVORAK, J.; ZHEREBTSOV, S.; SALISHCHEV, G.; KVAPILOVA, M.; SKLENICKA, V. Effect of severe plastic deformation on creep behavior of a Ti-6Al-4V alloy. Journal of Materials Science, v. 48, p. 4789-4795, 2013.

KRISHNAN, V.; KRISHNAN, A.; REMYA, R.; RAVIKUMAR, K. K.; NAIR, S. A.; SHIBLI, S. M. A.; SUKUMARAN, K.; KUMAR, K. J. Development and evaluation of two PVD-coated $\beta$-titanium orthodontic archwires for fluoride-induced corrosion protection. Acta Biomaterialia, v. 7, p. 1913-1927, 2011.

KUMAR, S.; NARAYANAN, T. S. N.; RAMAN, S. G. S.; SESHADRI, S. K. Thermal oxidation of CP-Ti: Evaluation of characteristics and corrosion resistance as a function of treatment time. Materials Science and Engineering C, v. 29, n. 6, p. 1942-1949, 2009. 
KUMAR, S.; NARAYANAN, T. S. N.; RAMAN, S. G. S.; SESHADRI, S. K. Thermal oxidation of Ti-6Al-4V alloy: Microstructural and electrochemical characterization. Materials Chemistry and Physics, v. 119, p. 337-346, 2010.

LANGDON, T. G. Identifying creep mechanisms at low stresses. Materials Science and Engineering A, v. 283, p. 266-273, 2000.

LANGDON, T. G. Creep at low stresses: an evaluation of diffusion creep and Harper-Dorn creep as viable creep mechanisms. Metallurgical and Materials Transactions A, v. 33A, p. 249-259, 2002.

LAPIN, J. Creep behavior of a cast intermetallic Ti-45.2Al-2W-0.6Si-0.7B alloy. Scripta Materialia, v. 50, p. 261-265, 2004.

LAPIN, J. Creep behavior of a cast TiAl-based alloy for industrial applications. Intermetallics, v. 14, p. 115-122, 2006.

LATHA, S.; MATHEW M. D.; PARAMESWASRAN, P.; LATHA, K.; PANNEERSELVI, S.; MANNAN, S. L. Improvement in creep damage tolerance of 14Cr$15 \mathrm{Ni}$-Ti modified stainless steel by addition of minor elements. Procedia Engineering, v. 55, p. 58-63, 2013.

LEE, D.; LEE, S.; LEE, Y. Effect of precipitates on damping capacity and mechanical properties of Ti-6Al-4V alloy. Materials Science and Engineering A, v. 486, p. 19-26, 2008.

LEE, K.; SEO, S.; LEE, K. Oxidation behaviors of TiAl(La)N coatings deposited by ion plating. Scripta Materialia, v. 52, p. 445-448, 2005.

LEYENS, C.; PETERS, M.; KAYSSER, W. A. Intermetallic Ti-Al coatings for protection of titanium alloys: oxidation and mechanical behavior. Surface and Coatings Technology, v. 94-95, p. 34-40, 1997.

LEYENS, C.; PETERS, M. Titanium and titanium alloys: fundamentals and applications. Weinheim: WILEY-VCH, 2003. 499 p

LI, Y.; QU, L.; WANG, F. The electrochemical corrosion behavior of TiN and (Ti,Al)N coatings in acid and salt solution. Corrosion Science, v. 45, p. 1367-1381, 2003.

LI, X.; SUGUI, T.; XIANYU, B.; LIQING, C. Creep properties and effect factors of hot continuous rolled Ti-6Al-4V alloy. Materials Science and Engineering A, v.529, p.452458, 2011.

LI, X.; SUGUI, T.; XIANYU, B.; LIQING, C. Influence of heat treatment on microstructure and creep properties of hot continuous rolled Ti-6Al-4V alloy. Materials Science and Engineering A, v. 559, p. 401-406, 2013.

LIAN, Z.; GUOZHEN, L. Research and development of titanium in China. Materials and Science Engineering A, v. 243, p. 294-298, 1998. 
LIN, C.H.; DUH, J.G. Electrochemical impedance spectroscopy (EIS) study on corrosion performance of CrAlSiN coated steels in $3.5 \mathrm{wt} \% \mathrm{NaCl}$ solution. Surface and Coatings Technology, v. 204, p. 784-787, 2009.

LIU, C.; BI, Q.; MATTHEWS, A. Tribological and electrochemical performance of PVD TiN coatings on the femoral head of Ti-6Al-4V artificial hip joints. Surface and Coatings Technology,v. 163-164, p. 597-604, 2003.

LIU, C.; CHU, P.K.; LIN, G.; YANG, D. Effects of Ti/TiN multilayer on corrosion resistance of nickel-titanium orthodontic brackets in artificial saliva. Corrosion Science, v. 49, p. 3783-3796, 2007.

LIU, C.; LEYLAND, A.; BI, Q.; MATTHEWS, A. Corrosion resistance of multi-layered plasma-assisted physical vapour deposition $\mathrm{TiN}$ and $\mathrm{CrN}$ coatings. Surface and Coatings Technology, v. 141, p. 164-173, 2001.

LIU, C.; LEYLAND, A.; LYON, S.; MATTHEWS, A. Electrochemical impedance spectroscopy of PVD-TiN coatings on mild steel and AISI316 subtrates. Surface and Coatings Technology, v. 76-77, p. 615-622, 1995.

LIU X.; CHU, P.K.; CHUANXIAN, D. Surface modification of titanium, titanium alloys, and related materials for biomedical applications. Materials Science and Engineering R, v. 47, p. 49-121, 2004.

LIU, Z.; YAN, D.; DONG, Y.; YANG, Y.; CHU, Z.; ZHANG, Z. The effect of modified epoxy sealing on the electrochemical corrosion behavior of reactive plasma-sprayed TiN coatings. Corrosion Science, v. 75, p. 220-227, 2013.

LONG, M.; RACK, H. J. Titanium alloys in total joint replacement: a materials science perspective. Biomaterials, v. 19, p. 1621-1639, 1998.

LU, J. Corrosion of titanium in phosphoric acid at $250{ }^{\circ} \mathrm{C}$. Transactions of Nonferrous Metals Society of China, v. 19, p. 552-556, 2009.

MAN, B. Y.; GUZMAN, L.; MIOTELLO, A.; ADAMI, M. Microstructure, oxidation and $\mathrm{H}_{2}$-permeation resistance of TiAlN films deposited by DC magnetron sputtering technique. Surface and Coatings Technology, v. 180-181, p. 9-14, 2004.

MANHABOSCO, T. M.; TAMBORIM, S. M.; SANTOS, C. B.; MÜLlER, I. L. Tribological, electrochemical and tribo-electrochemical characterization of bare and nitride Ti6Al4V in simulated body fluid solution. Corrosion Science, v. 53, p. 1786-1793, 2011.

MARTIN, É.; AZZI, M.; SALISHCHEV, G. A.; SZPUNAR, J. Influence of microstructure and texture on the corrosion and tribocorrosion behavior of Ti-6Al-4V. Tribology International, v. 43, p. 918-924, 2010.

MATTHES, B.; BROSZEIT, E.; AROMAA, J.; RONKAINEN, H.; HANNULA, S.P.; LEYLAND, A.; MATTHEWS, A. Corrosion performance of some titanium-based hard coatings. Surface and Coatings Technology, v. 49, p. 489-495, 1991. 
McCAFFERTY, E. Validation of corrosion rates measured by the Tafel extrapolation method. Corrosion Science, v. 47, p. 3202-3215, 2005.

MENDOZA-CANALES, J.; MARÍN-CRUZ, J. EIS characterization of corrosion processes of titanium and alloy UNS N10276 in sour environments. Journal Solid State Eletrochemical, v. 12, p. 1637-1644, 2008.

MEYERS, M. A.; CHAWLA, K. K. Princípios de metalurgia mecânica. São Paulo: Edgard Blücher, 1982. p. 406-421.

MIAU DU, L. H.; LIU, X.; JIANG, L.; WANG, S.; LV, F.; LI, Z.; MI, J. Microstructure and thermal stability of $\mathrm{Ti}_{1-\mathrm{x}} \mathrm{Al}_{\mathrm{x}} \mathrm{N}$ coatings deposited by reactive magnetron co-sputtering. Physics Procedia, v.18, p. 222-226, 2011.

MO, J. L.; ZHU, M. H. Tribological oxidation behavior of PVD hard coatings. Tribology International, v. 42, p. 1758-1764, 2009.

MOISEL, M.; MELE, A. F. L.; MÜLLER, W. Biomaterial Interface Investigated by Electrochemical Impedance Spectroscopy. Advanced Engineering Materials, v. 10, n. 10, p. B33-B46, 2008.

MONKMAN, F. C.; GRANT, N. J. An empirical relationship between rupture life and minimum creep rate in creep-rupture tests. ASTM Proceedings, v. 56, p. 593-620, 1956.

NASTAC, L.; GUNGOR, M. N.; UCOK, I.; KLUG, K. L.; TACK, W. T. Advances in investment casting of Ti-6Al-4V alloy: a review. International Journal of Cast Metals Research, v. 19, n. 2, p. 73-93, 2006.

NORDIN, M.; HERRANEN, M.; HOGMARK, S. Influence of lamellae thickness on the corrosion behavior of multilayered PVD TiN/CrN coatings. Thin Solid Films, v. 348, p. 202-209, 1999.

OLIVEIRA, V. M. C. A. Estudo do fenômeno da fluência na liga Ti-6Al-4V submetida a tratamentos de nitretação e carbonetação por plasma. 2010. $124 \mathrm{f}$. Dissertação (Mestrado em Ciências no Programa de Pós-Graduação de Engenharia de Materiais) Escola de Engenharia de Lorena, Lorena, 2010.

ORLOVÁ, O.; CADEK, J. Dislocation structures and structural steady state in steady state creep. Materials Science and Engineering, v. 81, p. 371-377, 1986.

PARK, Y. G.; WEY, M. Y.; HONG, S. I.; IKENAGA, M. Creep and high temperature fatigue resistance of Ti-6Al-4V modified by duplex plasma carburization/ $\mathrm{CrN}$ coating. Solid State Phenomena, v. 118, p. 515-520, 2006.

PANJAN, M.; STURM, S.; PANJAN, P.; CEKADA, M. TEM investigation of TiAlN/CrN multilayer coatings prepared by magnetron sputtering. Surface and Coatings Technology, v. 202, p. 815-819, 2007.

PÉREZ, P. Influence of nitriding on the oxidation behavior of titanium alloys at $700{ }^{\circ} \mathrm{C}$. Science and Coating Technology, v. 191, p. 293-302, 2005. 
PITT, F.; RAMULU, M. Influence of Grain Size and Microstructure on Oxidation Rates in Titanium Alloy Ti-6Al-4V Under SuperplasticForming Conditions. Journal of Materials Engineering and Performance, v. 13, n. 6, p. 727-734, 2004.

PJESCIC, J.; MENTUS, S.; BLAGOJEVIC, N. Investigation of titanium corrosion in concentrated $\mathrm{NaOH}$ solutions. Material and Corrosion, v. 53, p. 44-50, 2002.

POURBAIX, M. Atlas of electrochemical equilibria in aqueous solution. $2^{\text {nd }}$ ed. Houston: NACE, 1974. p. 219.

POHRELYUK, I.M.; FEDIRKO, V.M.; TKACHUK, O.V.; PROSKURNYAK, R.V. Corrosion resistance of Ti-6Al-4V alloy with nitride coatings in Ringer's solution. Corrosion Science, v. 66, p. 392-398, 2013.

POLMEAR, I.J. Light alloys. $4^{\text {th }}$ ed. Oxford: Butterworth-Heinemann, 2005. p. 299-365.

POLYAKOVA, I. G.; HÜBERT, T. Thermal stability of TiN thin films investigated by DTG/DTA. Surface and Coatings Technology, v. 141, p. 55-61, 2001.

REED-HILL, R. E. Physical metallurgy principles. New York: Van Nostrand Reinhold Company, 1964. p. 571-611.

REIS, D. A. P. Efeito do recobrimento cerâmico e da atmosfera de ensaio na fluência de liga metálica refratária de titânio. 2005. 204 f. Tese (Doutorado em Ciência e Tecnologia de Materiais e Sensores) - Instituto Nacional de Pesquisas Espaciais, São José dos Campos, 2005.

REIS, A. G.; REIS, D. A. P.; MOURA NETO, C.; BARBOZA, M. J. R.; OÑORO, J. Creep behavior and surface characterization of laser surface nitride Ti-6Al-4V alloy. Materials Science and Engineering A, v. 577, p. 48-53, 2013.

REVIE, R. W.; UHLIG, H. H. Corrosion and corrosion control. $4^{\text {th }}$ ed. New Jersey: John Wiley \& Sons, 2008. 490 p.

ROBIN, A.; CARVALHO, O. A. S.; SCHNEIDER, S. G.; SCHNEIDER, S. orrosion behavior of Ti-xNb-13Zr alloys in inger's solution. Materials and Corrosion, v. 59, n. 12, p. 929-933, 2008.

ROSSI, S.; FEDRIZZI, L.; BACCI, T.; PRADELLI, G. Corrosion behavior of glow discharge nitride titanium alloys. Corrosion Science, v. 45, p. 511-529, 2003.

ROY, N.; BAGUI, S.; SAHU, J. K.; RAY, A. K. Creep characterization and damage assessment of long term service exposed P-22 grade of steel. Materials Science and Engineering A, v. 560, p. 802-810, 2013.

RUDENJA, S.; PAN, J.; ODNEVALL WALLINDER, I.; LEYGRAF, C.; KULU, P. Passivation and anodic oxidation of duplex TiN coating on stainless steel. Journal of the Electrochemical Society, v. 146, n. 11, p. 4082-4086, 1999. 
SAMUEL, I. E.; CHOUDHARY, B. K.; RAOPALAPARTI, D. P.; MATHEW, M. D. Creep deformation and rupture behaviour of P92 steel at 923K. Procedia Engineering, v. 55, p. 64-69, 2013.

SAVONOV, G. S.; UEDA, M.; OLIVEIRA, R. M.; OTANI, C. Electrochemical behavior of Ti6Al4V alloy implanted by nitrogen PIII. Surface and Coatings Technology, v. 206, p. 2017-2020, 2011.

SEARLES, T.; TILEY, J.; TANNER, A.; WILLIANS, R.; ROLLINS, B.; LEE, E.; KAR, S.; BANERJEE, R.; FRASER, H. L. Rapid characterization of titanium microstructural features for specific modelling of mechanical properties. Measurement Science and Technology, v.16, p. 60-69, 2005.

SERRO, A. P.; COMPLETO, C.; COLAÇO, R.; SANTOS, F.; LOBATO DA SILVA, C.; CABRAL, J. M. S.; ARAÚJO, H.; PIRES, E.; SARAMAGO, B. A comparative study of titanium nitrides TiN, TiNbN and TiCN, as coatings for biomedical applications. Surface and Coatings Technology, v. 203, p. 3701-3707, 2009.

SHERBY, O. D.; BURKE, P. M. Mechanical behavior of crystalline solids at elevated temperature. Progress in Materials Science, v. 13, p. 323-390, 1968.

SHETTY, A. R.; KARIMI, A.; CANTONI, M. Effect of deposition angle on the structure and properties of pulsed-DC magnetron sputtered TiAlN films. Thin Solid Films, v. 519, p. 4262-4270, 2011.

SHREIR, L. L.; JARMAN, R. A.; BURSTEIN, G. T. Corrosion. $3^{\text {rd }}$ ed. Oxford: Butterworth-Heinemann, 1994, vol. 1, 1432 p.

SILVA, S.L.R.; KERBER, L. O.; AMARAL, L.; SANTOS, C. A. X-ray diffraction measurements of plasma - nitrided Ti-6Al-4V. Surface \& Coatings Technology, v. 116119, p. 342-346, 1999.

SINGH, G.; SATYANARAYANA, D. V. V.; PEDERSON, R.; DATTA, R.; RAMAMURTY, U. Enhancement in creep resistance of Ti-6Al-4V alloy due to boron addition. Materials Science and Engineering A, v. 597, p. 194-203, 2014.

SOUTO, R. M.; ALANYALI, H. Electrochemical characteristics of steel coated with TiN and TiAlN coatings. Corrosion Science, v. 42, p. 2201-2211, 2000.

SOUZA, K. A.; ROBIN, A. Preparation and characterization of Ti-Ta alloys for application in corrosive media. Materials Letters, v. 57, p. 3010-3016, 2003.

SOUZA, K. A.; ROBIN, A. Influence of concentration and temperature on the corrosion behavior of titanium, titanium-20 and 40\% tantalum alloys and tantalum in sulfuric acid solutions. Materials Chemistry and Physics, v. 103, p. 351-360, 2007.

SOUZA, S. A. Ensaios mecânicos de materiais metálicos: fundamentos teóricos e práticos. 5 ed. São Paulo: Blucher, 1982. p. 201-219. 
SUBRAMANIAN, B.; ANANTHAKUMAR, R.; JAYACHANDRAN, M. Microstructural, mechanical, and electrochemical corrosion properties of sputtered titanium-aluminiumnitride films for bio-implants. Vacuum, v. 85, p. 601-609, 2010.

SUBRAMANIAN, B.; MURALEEDHARAN, C. V.; ANANTHAKUMAR, R.; JAYACHANDRAN, M. A comparative study of titanium nitride (TiN), titanium oxide nitride (TiON) and titanium aluminum nitride (TiAlN), as surface coatings for bio implants. Surface and coatings Technology, v. 205, p. 5014-5020, 2011.

STEYER, P.; PILlOUD, D.; PIERSON, J. F.; MILLET, J. -P.; CHARNAY, M.; STAUDER, B.; JACQUOT, P. Oxidation resistance improvement of arc-evaporated TiN hard coatings by silicon addition. Surface and coatings Technology, v. 201, p. 41584162, 2006.

TANG, F.; NAKAZAWA, S.; HAGIWARA, M. Transient creep of Ti-Al-Nb alloys. Materials Science and Engineering A, v. 325, p. 194-201, 2002.

TERADA, Y.; SATO, T. Relationship between minimum creep rate and rupture life for a die-cast Mg-Al-Mn alloy. Materials Transactions, v. 49, p. 439-442, 2008.

TIEN, S.; DUH, J. Comparison of microstructure and phase transformation for nanolayered CrN/AlN and TiN/AlN coatings at elevated temperatures in air environment. Thin Solid Films, v. 515, p. 1097-1101, 2006.

TRIBOLLET, B.; ORAZEM, M. E. Electrochemical impedance spectroscopy. New Jersey: John Wiley, 2008.

VALANIS, K. C.; LEE, C. F. Deformation kinetics of steady state creep in metals. International Journal of Solids Structures, v. 17, p. 589-604, 1981.

VASILESCU, C.; DROB, P.; VASILESCU, E.; IONITA, D.; PRODANA, M.; DROB, S. I. Characterisation and corrosion resistance of electrodeposited hydroxyapatite and bovine serum albumin/hydroxyapatite films on Ti-6Al-4V-1Zr alloy surface. Corrosion Science, v. 51, p. 992-999, 2011.

VLADIMIROV, V.I.; KUSOV, A.A. Theory of the growth of dislocation tangles during creep. Fizika Metallov I Metallovedenie, v. 42, p. 951-959, 1976.

VILLARS, P.; CALVERT, L. Pearson's handbook of crystallographic data for intermetallic phases. $2^{\text {nd }}$ ed., Materials Park: American Society for Metals, 1991.

WAN, G.J.; HUANG, N.; LENG, Y.X.; YANG, P.; CHEN, J.Y.; WANG, J.; SUN, H. TiN and Ti-O/TiN films fabricated by PIII-D for enhancement of corrosion and wear resistance of Ti-6Al-4V. Surface and Coatings Technology, v. 186, p. 136-140, 2004.

WANG, C. X.; WANG, M.; ZHOU, X. Nucleation and growth of apatite on chemically treated titanium alloy: an electrochemical impedance spectroscopy study. Biomaterials, $\mathrm{v}$. 24, p. 3069-3077, 2003. 
WANG, Y.; NORTHWOOD, O. An investigation of the electrochemical properties of PVD TiN-coated SS410 in simulated PEM fuel cell environments. International Journal of Hydrogen Energy, v. 32, p. 895-902, 2007.

WARREN, J.; HSIUNG, L.M.; WADLEY, H.N.G. High temperature deformation behavior of physical vapor deposited Ti-6Al-4V. Acta Metallurgica, v.43, p.2773-2787, 1995.

WEERTMAN, J. Theory of steady-state creep based on dislocation climb. Journal of Applied Physics, v. 26, n. 10, p. 1213-1217, 1955.

WEFERS, K.; MISRA, C. Oxides and hydroxides of aluminum, United States: Alcoa Laboratories, 1987. p. 64-75.

WILlIAMS, D. B.; CARTER, C. B. Transmission electron microscopy. New York: Springer, 2009. $760 \mathrm{p}$.

WILSHIRE, B.; BATTENBOURGH, A.J. Creep and creep fracture of polycrystalline copper. Materials Science and Engineering A, v. 447, p. 156-166, 2007.

WILSHIRE, B.; WHITTAKER, M. T. The role of grain boundaries in creep strain accumulation. Acta Materialia, v. 57, p. 4115-4124, 2009.

WU, Y.; HWANG, S. K.; HAGIHARA, K.; UMAKOSHI, Y. Isothermal oxidation behavior of two-phase TiAl-Mn-Mo-C-Y alloys fabricated by different processes. Intermetallics, v. 14, p. 9-23, 2006.

YAMADA, M. An overview on the development of titanium alloys for non-aerospace application in Japan. Materials and Science Engineering A, v. 213, p. 8-15, 1996.

YANG, D.; LIU, C.; LIU, X.; QI, M.; LIN, G. EIS diagnosis on the corrosion behavior of TiN coated NiTi surgical alloy. Current Applied Physics, v. 5, p. 417-421, 2005.

YILBAS, B. S.; SAHIN, A. Z.; AHMAD, Z.; ABDUL ALEEM, B. J. A study of the corrosion properties of TiN coated and nitride Ti-6Al-4V. Corrosion Science, v. 37, n. 10, p. 1627-1636, 1995.

YILDIZ, F.; YETIM, A. F.; ALSARAN, A.; ÇELIK, A. Plasma nitriding behavior of Ti6Al-4V orthopedic alloy. Surface and coatings technology, v. 202, p. 2471-2476, 2008.

YOO, Y.; LE, D.; KIM, J.; KIM, S.; VINH, P. Corrosion behavior of TiN, TiAlN, TiAlSiN thin films deposited on tool steel in the 3,5 wt\% NaCl solution. Thin Solid Films, v. 516, p. 3544-3548, 2008.

YOON, S.; LEE, K.; KANG, S.; KIM, K. Comparison for mechanical properties between TiN and TiAlN coating layer by AIP technique. Journal of Materials Processing Technology, v. 130-131, p. 260-265, 2002. 
YU, Y. J.; KIM, J. G.; CHO, S. H.; BOO, J. H. Plasma-polymerized toluene films for corrosion inhibition in microelectronic devices. Surface and Coatings Technology,v. 162, p. 161-166, 2003.

YU, C.; ZHU, S.; WEI, D.; WANG, F. Amorphous sol-gel $\mathrm{SiO}_{2}$ film for protection of Ti6Al-4V alloy against high temperature oxidation. Surface and Coatings Technology, v. 201, p. 5967-5972, 2007a.

YU, C.; ZHU, S.; WEI, D.; WANG, F. Oxidation and $\mathrm{H}_{2} \mathrm{O} / \mathrm{NaCl}$ - induced corrosion behavior of sputtered Ni-Si coatings on Ti6Al4V at $600-650{ }^{\circ} \mathrm{C}$. Surface and Coatings Technology, v, 201, p. 7530-7537, 2007b.

XIAO, L.; LU, W. J.; QIN, J. N.; CHEN, Y. F.; ZHANG, D.; WANG, M. M.; ZHU, F.; JI, B. Steady state creep of in situ TiB plus $\mathrm{La}_{2} \mathrm{O}_{3}$ reinforced high temperature titanium matrix composite. Materials Science and Engineering A, v. 499, p. 500-506, 2009.

ZHANG, S. Z.; XU, H. Z.; LI, G. P.; LIU, Y. Y.; YANG, R. Effect of carbon and aging treatment on precipitation of ordered $\alpha_{2}$ in Ti-5.6Al-4.8Sn-2Zr-1Mo-0.35Si-0.7Nd alloy. Materials Science and Engineering A, v. 408, p. 290-296, 2005.

ZHANG, Z.; QIN, J.; ZHANG, Z.; CHEN, Y.; LU, W.; ZHANG, D. Microstructure effect on mechanical properties of in situ synthesized titanium matrix composites reinforced with TiB and $\mathrm{La}_{2} \mathrm{O}_{3}$. Materials Letters, v. 64, p. 361-363, 2010.

ZHAO, J.; DING, H.; ZHAO, W.; TIAN, X.; HOU, H.; WANG, Y. Influence of hydrogenation on microstructures and microhardness of Ti6Al4V alloy. Transactions of Nonferrous Metals Society of China, v. 18, p. 506-511, 2008.

ZHAO, H.; WANG, X.; LIU, Q.; CHEN, L.; LIU, Z. Structure and wear resistnace of TiN and TiAlN coatings on AZ91 alloy deposited by multi-arc ion plating. Transactions of Nonferrous Metals Society of China, v. 20, p. 679-682, 2010.

ZHAO, X.; YAN, D.; LI, S.; CHENGUANG, L. The effect of heat treatment on the electrochemical corrosion behavior of reactive plasma-sprayed TiN coatings. Applied Surface Science, v. 257, p. 10078-10083, 2011.

ZHECHEVA, A.; SHA, W.; MALINOV, S.; LONG, A. Enhancing the microstructure and properties of titanium alloys through nitriding and other surface engineering methods. Surfaces and Coatings Technology, v. 200, p. 2192-2207, 2005.

ZHU, L.; HU, M.; NI, W.; LIU, Y. High temperature oxidation behavior of $\mathrm{Ti}_{0.5} \mathrm{Al}_{0.5} \mathrm{~N}$ coating and $\mathrm{Ti}_{0.5} \mathrm{Al}_{0.4} \mathrm{Si}_{0.1} \mathrm{~N}$ coating. Vacuum, v. 86, p. 1795-1799, 2012.

ZHU, S. J.; MUKHERJI, D.; CHEN, W.; LU, Y. X.; WANG, Z. G.; WAHI, R. P. Steady state creep behavior of $\mathrm{TiC}$ particulate reinforced $\mathrm{Ti}-6 \mathrm{Al}-4 \mathrm{~V}$ composite. Materials Science and Engineering A, v. 256, p. 301-307, 1998. 